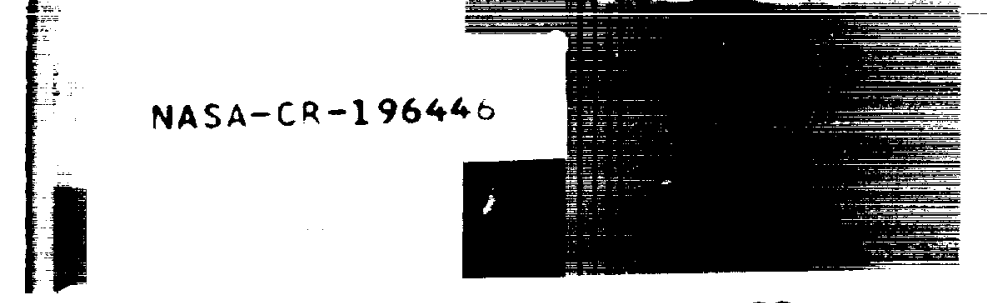

(NASA-CR-196446) SPACECRAFT

MAXIMUM ALLOWABLE CONCENTRATIONS

FOR SELECTED AIRBORNE CONTAMINANTS, VOLUME 1 (NAS-NRC) $226 \mathrm{p}$

Unclas

$63 / 10 \quad 0027221$

\title{
Spacecraft Maximum Allowable Concentrations for Selected Airborne Contaminants
}

\author{
Volume 1
}

COMMITTEE ON TOXICOIOGY

NATIONAL RESEARCH COUNCII
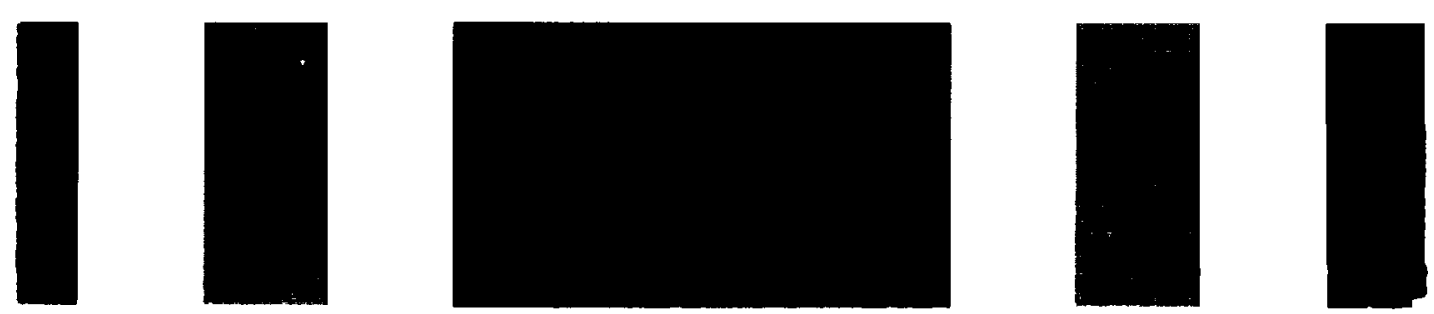



\section{Spacecraft Maximum Allowable Concentrations for Selected Airborne Contaminants}

\section{Volume 1}

Subcommittee on Spacecraft Maximum

Allowable Concentrations

Committee on Toxicology

Board on Environmental Studies and Toxicology

Commission on Life Sciences

National Research Council

\section{NATIONAL ACADEMY PRESS}

Washington, D.C., 1994 
NOTICE: The project that is the subject of this report was approved by the Governing Board of the National Research Council, whose members are drawn from the councils of the National Academy of Sciences, the National Academy of Engineering, and the Institute of Medicine. The members of the committee responsible for the report were chosen for their special competencies and with regard for appropriate balance.

This report has been reviewed by a group other than the authors according to procedures approved by a Report Review Committee consisting of members of the National Academy of Sciences, the National Academy of Engineering, and the Institute of Medicine.

The National Academy of Sciences is a private, non-profit, self-perpetuating society of distinguished scholars engaged in scientific and engineering research, dedicated to the furtherance of science and technology and to their use for the general welfare. Upon the authority of the charter granted to it by the Congress in 1863 , the Academy has a mandate that requires it to advise the federal government on scientific and technical matters. Dr. Bruce Alberts is president of the National Academy of Sciences.

The National Academy of Engineering was established in 1964, under the charter of the National Academy of Sciences, as a parallel organization of outstanding engineers. It is autonomous in its administration and in the selection of its members, sharing with the National Academy of Sciences the responsibility for advising the federal government. The National Academy of Engineering also sponsors engineering programs aimed at meeting national needs, encourages education and research, and recognizes the superior achievements of engineers. Dr. Robert $M$. White is president of the National Academy of Engineering.

The Instinte of Medicine was established in 1970 by the National Academy of Sciences to secure the services of eminent members of appropriate professions in the examination of policy matters pertaining to the health of the public. The Institute acts under the responsibility given to the National Academy of Sciences by its congressional charter to be an adviser to the federal government and, upon its own initiative, to identify issues of medical care, research, and education. Dr. Kenneth I. Shine is president of the Institute of Medicine.

The National Research Council was organized by the National Academy of Sciences in 1916 to associate the broad community of science and technology with the Academy's purposes of furthering knowledge and advising the federal government. Functioning in accordance with general policies determined by the Academy, the Council has become the principal operating agency of both the National Academy of Sciences and the National Academy of Engineering in providing services to the government, the public, and the scientific and engineering communities. The Council is administered jointly by both Academies and the Instiute of Medicine. Dr. Bruce Alberts and $\mathrm{Dr}$. Robert $\mathrm{M}$. White are chairman and vice chairman, respectively, of the National Research Council.

The project was supported by the National Aeronautics and Space Administration Grant No. NAGW-2239.

Copyright 1994 by the National Academy of Sciences. All rights reserved.

Printed in the United States of America 


\section{Subcommittee on Spacecraft Maximum Allowable Concentrations}

DONALD E. GaRDNER (Chair), ManTech Environmental Technology, Inc., Research Triangle Park, N.C.

JOSEPH BRADY, Johns Hopkins School of Medicine, Baltimore, Md.

RICHARD BULL, Washington State University, Pullman, Wash.

Gary P. Carlson, Purdue University, West Lafayette, Ind.

Charles E. Feigley, University of South Carolina, Columbia, S.C.

MARY E. GaUlden, University of Texas, Southwestern Medical School, Dallas, Tex.

WILlIAM E. HALPERIN, National Institute for Occupational Safety and Health, Cincinnati, Ohio

ROGENE F. HENDERSON, Lovelace Biomedical and Environmental Research Institute, Albuquerque, N.Mex.

MARSHALl JoHNSON, Thomas Jefferson Medical College, Philadelphia, $\mathrm{Pa}$.

RALPH L. KoDELL, National Center for Toxicological Research, Jefferson, Ark.

ROBERT SNYDER, Environmental and Occupational Health Sciences Institute, Piscataway, N.J.

BERNARD M. WAGNER, Wagner Associates, Millburn, N.J. G. Donald Whedon, Consultant, Clearwater Beach, Fla.

GAROLD S. YosT, University of Utah, Salt Lake City, Utah

Staff

KulbIR S. BAKSHI, Project Director and Program Director

RiCHARD D. Thomas, Program Director (until May 1994)

Ruth E. Crossgrove, Editor

Catherine M. KubIK, Senior Program Assistant

NIANi SutardJo, Project Assistant

Sponsor: National Aeronautics and Space Administration 

Rogene F. HeNDERSON (Chair), Lovelace Biomedical and Environmental Research Institute, Albuquerque, N.Mex. R. HAYS BeLL, Eastman Kodak Company, Rochester, N.Y. DEAN E. Carter, University of Arizona, Tucson, Ariz.

DEBORAH A. CORY-SlechtA, University of Rochester School of Medicine, Rochester, N.Y.

Charles E. Feigley, University of South Carolina, Columbia, S.C.

Donald E. GaRDNER, ManTech Environmental Technology, Inc., Research Triangle Park, N.C.

Davin W. GaYlor, U.S. Food and Drug Administration, Jefferson, Ark.

WALDERICo M. Generoso, Oak Ridge National Laboratory, Oak Ridge, Tenn

IAN A. Greaves, University of Minnesota, Minneapolis, Minn.

SidNey GreEN, U.S. Food and Drug Administration, Laurel, Md.

Carole A. KIMMel, U.S. Environmental Protection Agency, Washington, D.C.

LOREN D. KOLLER, Oregon State University, Corvallis, Oreg. ERNEST EUGENE MCCONNELL, Raleigh, N.C.

MiCHELE A. MEDINSKY, Chemical Industry Institute of Toxicology, Research Triangle Park, N.C.

ROBERT SNYDER, Rutgers University, Piscataway, N.J.

BaILUS WALKER, JR., University of Oklahoma, Oklahoma City, Okla.

HANSPETER R. WitschI, University of California, Davis, Calif.

GERALD N. WogaN, Massachusetts Institute of Technology, Cambridge, Mass.

GAROLD S. YoST, University of Utah, Salt Lake City, Utah

$\mathbf{v}$

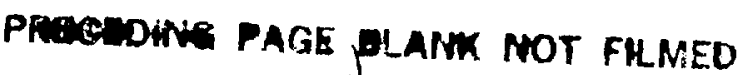

Privi: I 
Staff of Committee on Toxicology

KULBIR S. BaKSHI, Program Director

RichaRD D. ThOMAs, Program Director (until May 1994)

MARVIN A. SCHNEIDERMaN, Senior Staff Scientist

Ruth E. Crossgrove, Editor

Catherine M. Kubik, Senior Program Assistant

Ruth P. DanOFF, Project Assistant (until November 1993)

Niani SuTARDJo, Project Assistant 


\section{Board on Environmental Studies and Toxicology}

Paul G. RISSer (Chair), Miami University, Oxford, Ohio

FrEDERICK R. ANDERSON, Cadwalader, Wickersham \& Taft,

Washington, D.C.

MiChaEl J. BEAN, Environmental Defense Fund, Washington, D.C.

Eula Bingham, University of Cincinnati, Cincinnati, Ohio

EDWIN H. Clark, Clean Sites, Inc., Alexandria, Va.

Allan H. ConNeY, Rutgers University, Piscataway, N.J.

JOHN L. EMMERSON, Eli Lilly \& Company, Greenfield, Ind.

ROBERT C. FORNEY, Unionville, Pa.

RoberT A. Frosch, Harvard University, Cambridge, Mass.

KAI LEE, Williams College, Williamstown, Mass.

JANE LUBChENCO, Oregon State University, Corvallis, Ore.

GORDON ORIANS, University of Washington, Seattle, Wash.

Frank L. PARKER, Vanderbilt University, Nashville, Tenn., and

Clemson University, Anderson, S.Car.

Geoffrey Place, Hilton Head, S.Car.

DAVID P. RALL, Washington, D.C.

LESLIE A. REAL, Indiana University, Bloomington, Ind.

KRISTIN SHRADER-FRECHETTE, University of South Florida, Tampa, Fla.

Gerald VAN BELle, University of Washington, Seattle, Wash.

BAILUS WALKER, JR., Washington, D.C. 
Staff of Board on Environmental Studies and Toxicology

JAMES J. REISA, Director

DAVID J. PoliCanSKY, Associate Director and Program Director for Natural Resources and Applied Ecology

Gall Charnley, Acting Program Director for Human Toxicology and Risk Assessment (since May 1994)

RichaRD D. Thomas, Associate Director and Program Director for Human Toxicology and Risk Assessment (until May 1994)

LeE R. Paulson, Program Director for Information Systems and Statistics

RaYmond A. WASSel, Program Director for Environmental Sciences and Engineering 


\section{Commission on Life Sciences}

Thomas D. Pollakd (Chair), Johns Hopkins Medical School, Baltimore, Md.

BruCE N. AMES, University of California, Berkeley, Calif.

JoHN C. BaIlaR, III, McGill University, Montreal, Quebec

MICHAEL BISHOP, Hooper Research Foundation, University of California Medical Center, San Francisco, Calif.

JoHN E. BURRIS, Marine Biological Laboratory, Woods Hole, Mass.

Michael T. Clegg, University of California, Riverside, Calif.

GlenN A. Crosby, Washington State University, Pullman, Wash.

LEROY E. HOOD, University of Washington, Seattle, Wash.

MARIAN E. KoshLAND, University of California, Berkeley, Calif.

RICHARD E. LENSKI, Michigan State University, East Lansing, Mich.

EmIL A. Pfitzer, Hoffmann-La Roche Inc., Nutley, N.J.

Malcolm C. PIKE, University of Southern California School of Medicine, Los Angeles, Calif.

Henry C. PItot, III, University of Wisconsin, Madison, Wisc.

Paul G. RISSER, Miami University, Oxford, Ohio

Johnathan M. SaMet, University of New Mexico School of Medicine, Albuquerque, N.Mex.

HAROLD M. SCHMECK, JR., Armonk, N.Y.

Carla J. Shatz, University of California, Berkeley, Calif.

SUSAN S. TAYLOR, University of California at San Diego, La Jolla, Calif.

P. RoY Vagelos, Merck \& Company, Whitehouse Station, N. J.

JOHN L. VANDEBERG, Southwestern Foundation for Biomedical

Research, San Antonio, Tex.

TORSTEN N. WIESEL, Rockefeller University, New York, N.Y.

Paul GilmaN, Executive Director 



\section{Other Recent Reports of the Board on Environmental Studies and Toxicology}

Science and Judgment in Risk Assessment (1994)

Environmental Information for Outer Continental Shelf Oil and Gas Decisions (1994)

Measuring Lead Exposure in Infants, Children, and Other Sensitive Populations (1993)

Health Effects of Ingested Fluoride (1993)

Pesticides in the Diets of Infants and Children (1993)

Issues in Risk Assessment (1993)

Setting Priorities for Land Conservation (1993)

Protecting Visibility in National Parks and Wilderness Areas (1993)

Biologic Markers in Immunotoxicology (1992)

Dolphins and the Tuna Industry (1992)

Environmental Neurotoxicology (1992)

Hazardous Materials on the Public Lands (1992)

Science and the National Parks (1992)

Animals as Sentinels of Environmental Health Hazards (1991)

Assessment of the U.S. Outer Continental Shelf Environmental Studies Program, Volumes I-IV (1991-1993)

Human Exposure Assessment for Airborne Pollutants (1991)

Monitoring Human Tissues for Toxic Substances (1991)

Rethinking the Ozone Problem in Urban and Regional Air Pollution (1991)

Decline of the Sea Turtles (1990)

Tracking Toxic Substances at Industrial Facilities (1990)

Biologic Markers in Pulmonary Toxicology (1989)

Biologic Markers in Reproductive Toxicology (1989)

These reports may be ordered from the National Academy Press (800) 624-6242 or (202) 334-3313

xi

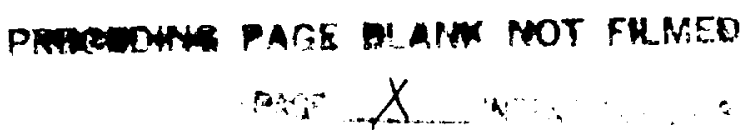





\section{Preface}

The National Aeronautics and Space Administration (NASA) is aware of the potential toxicological hazards to humans that might be associated with prolonged spacecraft missions. Despite major engineering advances in controlling the atmosphere within spacecraft, some contamination of the air appears inevitable. NASA has measured numerous airborne contaminants during space missions. As the missions increase in duration and complexity, ensuring the health and well-being of astronauts traveling and working in this unique environment becomes increasingly difficult.

As part of its efforts to promote safe conditions aboard spacecraft, NASA requested the National Research Council (NRC) to develop guidelines for establishing spacecraft maximum allowable concentrations (SMACs) for contaminants, and to review SMACs for various spacecraft contaminants to determine whether NASA's recommended exposure limits are consistent with the guidelines recommended by the subcommittee.

In response to NASA's request, the NRC organized the Subcommittee on Guidelines for Developing Spacecraft Maximum Allowable Concentrations for Space Station Contaminants within the Committee on Toxicology (COT). In the first phase of its work, the subcommittee developed the criteria and methods for preparing SMACs for spacecraft contaminants. The subcommittee's report, entitled Guidelines for Developing Spacecraft Maximum Allowable Concentrations for Space Station Contaminants, was published in 1992 . The executive summary of that report is reprinted as Appendix A of this volume.

In the second phase of the study, the Subcommittee on Spacecraft Maximum Allowable Concentrations reviewed reports prepared by

xiii

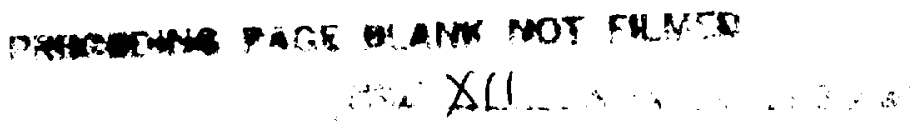


NASA scientists and contractors recommending SMACs for 35 spacecraft contaminants. The subcommittee sought to determine whether the SMAC reports were consistent with the 1992 guidelines. Appendix B of this volume contains the first 11 SMAC reports that have been reviewed for their application of the guidelines developed in the first phase of this activity and approved by the subcommittee.

The subcommittee gratefully acknowledges the valuable assistance provided by the following personnel from NASA and its contractors: Dr. John James, Dr. Martin Coleman, Dr. Lawrence Dietlein, Mr. Jay Perry, Mr. Kenneth Mitchell (all from NASA), Mr. James Hyde (Jet Propulsion Laboratory), Dr. King Lit Wong, Dr. Hector Garcia, Dr. Chiu Wing Lam (Krug International), and Mr. Donald Cameron (Boeing Company). The subcommittee is grateful to astronauts Drs. Shannon Lucid, Drew Gaffney, Mary Cleave, and Martin Fettman for sharing their experiences. The subcommittee also acknowledges the valuable assistance provided by the Johnson Space Center, Houston, Texas, the Marshall Space Flight Center, Huntsville, Alabama, the Kennedy Space Center, Cape Canaveral, Florida, and the Space Station Freedom Program Office, Reston, Virginia, for providing tours of their facilities.

No effort of this kind can be accomplished without the hard work and dedication of a talented staff. Wanda Smarr was the project assistant. Ruth Crossgrove edited the report. Drs. Richard Thomas, James Reisa, and Paul Gilman provided helpful insights. The subcommittee particularly acknowledges Dr. Kulbir Bakshi, project director for the subcommittee, whose hard work and expertise were most effective in bringing the report to completion.

Donald E. Gardner, Chair

Subcommittee on Spacecraft Maximum

Allowable Concentrations

Rogene F. Henderson, Chair

Committee on Toxicology 


$\begin{array}{lr}\text { SPACECRAFT MAXIMUM ALLOWABLE } & \\ \text { CONCENTRATIONS FOR SELECTED AIRBORNE } & 1 \\ \text { CONTAMINANTS } & 1 \\ \text { Introduction } & 3 \\ \text { Summary of Report on Guidelines for Developing SMACS } & 4 \\ \text { Review of SMAC Reports } & 5 \\ \text { References } & 7 \\ & \\ \text { APPENDIX A } & \\ \text { Executive Summary: Guidelines for Developing Spacecraft } & 9 \\ \text { Maximum Allowable Concentrations for Space Station } & \\ \text { Contaminants } & 17 \\ & 19 \\ \text { APPENDIX B } & 39 \\ \text { B1 Acetaldehyde } & 61 \\ \text { B2 Ammonia } & 91 \\ \text { B3 Carbon Monoxide } & 121 \\ \text { B4 Formaldehyde } & 139 \\ \text { B5 Freon 113 } & 143 \\ \text { B6 Hydrogen } & 149 \\ \text { B7 Methane } & 169 \\ \text { B8 Methanol } & 177 \\ \text { B9 Octamethyltrisiloxane } & 185 \\ \text { B10 Trimethylsilanol } & \\ \text { B11 Vinyl Chloride } & \end{array}$





\section{Spacecraft Maximum Allowable Concentrations for Selected Airborne Contaminants}

\section{INTRODUCTION}

The space station-a multinational effort-is expected to be launched in 1997 and, in its presently planned configuration, is expected to carry a crew of four to eight astronauts for up to 180 days. Because the space station will be a closed and complex environment, some contamination of its internal atmosphere is unavoidable. Several hundred chemical contaminants are likely to be found in the closed-loop atmosphere of the space station, most at very low concentrations. Important sources of atmospheric contaminants include off-gassing of cabin materials, operation of equipment, and metabolic waste products of crew members. Other potential sources of contamination are releases of toxic chemicals from experiments and manufacturing activities performed on board the space station and accidental spills and fires. The water recycling system has also been shown to produce chemical contaminants that can enter the cabin air. Therefore, the astronauts potentially can be chronically exposed to low levels of airborne contaminants and occasionally to high levels of contaminants in the event of a leak, spill, or fire.

The National Aeronautics and Space Administration (NASA) is seeking to ensure the health, safety, and functional abilities of astronauts and seeks to prevent the exposure of astronauts to toxic levels of spacecraft contaminants. Consequently, exposure limits need to be established for continuous exposure of astronauts to spacecraft contaminants for up to 180 days (for normal space-station operations) and for short-term (1-24 hr) emergency exposures of astronauts to high levels of chemical contaminants. 
Federal regulatory agencies such as the U.S. Occupational Safety and Health Administration (OSHA) and the U.S. Environmental Protection Agency (EPA) have not promulgated exposure limits for the unique environment of spacecraft, nor are their existing standards appropriate for this environment. In 1972, the National Research Council's Committee on Toxicology (COT) first recommended maximum levels for continuous and emergency exposures to spacecraft contaminants (NRC, 1972). However, that early report did not provide documentation of toxicity data or the rationale for the recommended exposure levels. Toxicity data for most of the compounds were not well developed at that time, and the risk-assessment methods were rudimentary. Over the past several years, COT has recommended emergency exposure guidance levels (EEGLs) and continuous exposure guidance levels (CEGLs) for several hundred chemical substances for the U.S. Department of Defense (NRC, 1984a,b,c,d; 1985a,b; 1986; 1987; 1988). However, EEGLs and CEGLs are not available for most spacecraft contaminants. Because of the experience of COT in recommending EEGLs and CEGLs, NASA requested that COT establish guidelines for developing spacecraft maximum allowable concentrations (SMACs) that could be used uniformly by scientists involved in preparing SMACs for airborne contaminants and review the SMACs for individual contaminants to ascertain whether they are consistent with the guidelines.

SMACs are intended to provide guidance on chemical exposures during normal operations of spacecraft as well as emergency situations. Short-term SMACs refer to concentrations of airborne substances (such as a gas, vapor, or aerosol) that will not compromise the performance of specific tasks by astronauts during emergency conditions or cause serious or permanent toxic effects. Such exposures might cause reversible effects, such as mild skin or eye irritation, but they are not expected to impair judgment or interfere with proper responses to emergencies. Long-term SMACs are intended to avoid adverse health effects (either immediate or delayed) and to prevent decremental change in crew performance under continuous exposure to chemicals in the closed environment of the space station for as long as $\mathbf{1 8 0}$ days.

In response to NASA's request to establish guidelines for developing SMACs and to review SMAC documents for selected spacecraft contaminants, COT organized the Subcommittee on Guidelines for Developing Spacecraft Maximum Allowable Concentrations for Space Station Con- 
taminants. The subcommittee comprised experts in toxicology, epidemiology, medicine, physiology, biochemistry, pathology, pharmacology, neurotoxicology, industrial hygiene, statistics, and risk assessment. In the first phase of the study, the subcommittee prepared Guidelines for Developing Spacecraft Maximum Allowable Concentrations for Space Station Contaminants (NRC, 1992). That report provided guidance for deriving SMACs from available toxicological and epidemiological data. It also provided guidance on what data to use, how to evaluate the data for appropriateness, how to perform risk assessment for carcinogenic and noncarcinogenic effects, and how to consider the effects of physiological changes induced by microgravity that might enhance the susceptibility of astronauts to certain spacecraft contaminants. The executive summary of that report is contained in Appendix A of this volume.

\section{SUMMARY OF REPORT ON GUIDELINES FOR DEVELOPING SMACS}

As described in Appendix A, the first step in establishing SMACs for a chemical is to collect and review all relevant information available on a compound. Various types of evidence are assessed in establishing SMAC values for a chemical contaminant. These include information from (1) chemical-physical characterizations, (2) structure-activity relationships, (3) in vitro toxicity studies, (4) animal toxicity studies, (5) human clinical studies, and (6) epidemiological studies. For chemical contaminants, dose-response data from human exposure are most applicable and are used when available in preference to data from animal studies and in vitro studies. Toxicity data from inhalation exposures are most useful because inhalation is the most likely route of exposure.

For most chemicals, actual human toxicity data are not available. Therefore, toxicity data from studies conducted in animals are extrapolated to estimate the potential toxicity in humans. This requires experienced scientific judgment. The toxicity data from animal species most representative of humans in terms of pharmacodynamic and pharmacokinetic properties are used for determining SMACs. If data are not available on which species best represents humans, the data from the most sensitive animal species are used to set SMACs. Safety or uncertainty factors are commonly used when animal data are extrapolated to a 
safe level for humans. The magnitude of uncertainty factors depends on the quality of the animal data used to determine the no-observed-adverseeffect level (NOAEL). Conversion from animals to humans is done on a body-weight or surface-area basis. When available, pharmacokinetic data on tissue doses are considered for use in species interconversion.

Based on the review of the toxicity data and the use of appropriate safety factors, SMACs for different periods are developed, and a rationale is provided for each recommendation. One- or 24-hr emergency SMACs are usually derived from acute exposure toxicity studies. Development of 1 - or 24-hr SMACs usually begins with providing a SMAC for the shortest exposure of $1 \mathrm{hr}$. Values for 24-hr SMACs might necessitate using Haber's law $(C \times T=k)$ when applicable. Detoxification or recovery and data available on $24-\mathrm{hr}$ exposures are taken into account in modifying Haber's law.

When data from chronic exposure studies are available, they are used to derive 7-, 30-, or 180-day SMACs, and safety factors are applied as needed. For substances that affect several organ systems or have multiple effects, all end points-including reproductive (in both sexes), developmental, carcinogenic, neurotoxic, respiratory, and other organ-related effects-are evaluated, the most important or most sensitive effects receiving the major attention. With carcinogenic chemicals, quantitative carcinogenic assessment is done, and the SMAC is set so that the estimated lifetime risk of a neoplasm is no more than 1 in 10,000 exposed persons. When a substance is known to cause an effect that will be aggravated by microgravity, additional safety factors are used.

\section{REVIEW OF SMAC REPORTS}

In the second phase of the study, the Subcommittee on Spacecraft Maximum Allowable Concentrations reviewed reports for 35 spacecraft contaminants to determine whether the recommended exposure limits were consistent with the 1992 guidelines (see Appendix A). One of the SMAC reports was prepared with the collaboration of members of this subcommittee to serve as an example for NASA scientists in preparing their reports on other substances. The remaining SMAC reports were prepared solely by NASA scientists or contractors.

These SMAC reports are intended for use by engineers in develop- 
ing design criteria for the space station. The SMAC reports will also be applicable to the space shuttle, because the recommended SMACs will cover the exposure times that are of interest to the space-shuttle program-1-hr and 24-hr SMACs for emergencies and 7-day and 30-day SMACs for continuous exposures.

The subcommittee's review of the SMAC reports prepared by NASA, NASA's contractors, and members of the subcommittee involved both oral and written presentations to the subcommittee by the authors of the reports. The subcommittee provided advice and recommendations for revisions. The authors of the SMAC reports presented their revised reports at subsequent meetings until approved by the subcommittee, which depended upon the appropriate application of the guidelines developed in the first phase of the study (NRC, 1992).

The subcommittee recognizes that many factors, such as the alterations in normal human physiological and biochemical processes associated with spaceflight, are not fully understood and could warrant revisions of proposed SMAC values as additional scientific data become available. Because of the enormity of the data presented in the SMAC reports, the subcommittee could not verify all the data. The subcommittee relied on NASA scientists for the accuracy and completeness of the toxicity data cited in the SMAC reports. Although individual data points were not verfied by the subcommittee, it agrees with the proposed SMAC values.

This report is the first volume in the series Spacecraft Maximum Allowable Concentrations for Selected Contaminants. It contains SMAC reports on 11 spacecraft contaminants; these reports, presented in Appendix B, are approved by the subcommittee as consistent with the 1992 NRC guidelines. SMAC reports for additional spacecraft contaminants will be presented in subsequent volumes.

\section{REFERENCES}

NRC (National Research Council). 1968. Atmospheric Contaminants in Spacecraft. Washington, D.C.: National Academy of Sciences.

NRC (National Research Council). 1972. Atmospheric Contaminants in Manned Spacecraft. Washington, D.C.: National Academy of Sciences. 
NRC (National Research Council). 1984a. Emergency and Continuous Exposure Limits for Selected Airborne Contaminants, Vol. 1. Washington, D.C.: National Academy Press.

NRC (National Research Council). 1984b. Emergency and Continuous Exposure Limits for Selected Airborne Contaminants, Vol. 2. Washington, D.C.: National Academy Press.

NRC (National Research Council). 1984c. Emergency and Continuous Exposure Limits for Selected Airborne Contaminants, Vol. 3. Washington, D.C.: National Academy Press.

NRC (National Research Council). 1984d. Toxicity Testing: Strategies to Determine Needs and Priorities. Washington, D.C.: National Academy Press.

NRC (National Research Council). 1985a. Emergency and Continuous Exposure Guidance Levels for Selected Airborne Contaminants, Vol. 4. Washington, D.C.: National Academy Press.

NRC (National Research Council). 1985b. Emergency and Continuous Exposure Guidance Levels for Selected Airborne Contaminants, Vol. 5. Washington, D.C.: National Academy Press.

NRC (National Research Council). 1986. Emergency and Continuous Exposure Guidance Levels for Selected Airborne Contaminants, Vol. 6. Washington, D.C.: National Academy Press.

NRC (National Research Council). 1987. Emergency and Continuous Exposure Guidance Levels for Selected Airborne Contaminants, Vol. 7. Washington, D.C.: National Academy Press.

NRC (National Research Council). 1988. Emergency and Continuous Exposure Guidance Levels for Selected Airborne Contaminants, Vol. 8. Washington, D.C.: National Academy Press.

NRC (National Research Council). 1992. Guidelines for Developing Spacecraft Maximum Allowable Concentrations for Space Station Contaminants, Washington, D.C.: National Academy Press. 
Appendix A

Executive Summary of Guidelines for Developing Spacecraft Maximum Allowable Concentrations for Space Station Contaminants 



\section{Executive Summary:}

\section{Spacecraft Maximum Allowable \\ Concentrations for Space Station \\ Contaminants}

The National Aeronautics and Space Administration (NASA) is preparing to launch a manned space station-Space Station Freedom-by the mid-1990's. Because Space Station Freedom will be a closed complex environment, some contamination of its atmosphere is inevitable. Several hundred chemicals are likely to be found in the closed atmosphere of the space station, most in very low concentrations. Important sources of atmospheric contaminants include metabolic waste products of crew members and off-gassing of cabin materials and equipment. Release of chemicals from experiments performed on board the space station is also a possible source of contamination, and the water reclamation system has the potential to introduce novel compounds into the air. NASA is concerned about the health, safety, and functional abilities of crews exposed to these contaminants.

This report, prepared by the Committee on Toxicology of the National Research Council's Board on Environmental Studies and Toxicology, is in response to a request from NASA for guidelines to develop spacecraft maximum allowable concentrations (SMACs) for space-station contaminants. SMACs are used to provide guidance on allowable chemical exposures during normal operations and emergency situations. Short-term SMACs refer to concentrations of airborne substances (such as gas, vapor, or aerosol) that will not compromise the performance of specific tasks during emergency conditions lasting up to $24 \mathrm{hr}$. Exposure to 1- or 24-hr SMACs will not cause serious or permanent effects but may cause

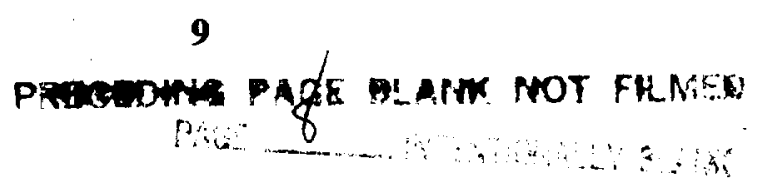


reversible effects that do not impair judgment or interfere with proper responses to emergencies such as fires or accidental releases.

Long-term SMACs are intended to avoid adverse health effects (either immediate or delayed) and to avoid degradation in crew performance with continuous exposure in a closed space-station environment for as long as 180 days. Chemical accumulation, detoxification, excretion, and repair of toxic insults are thus important in determining 180-day SMACs.

\section{ENVIRONMENTAL CONTROL AND LIFE-SUPPORT SYSTEM}

The environmental control and life-support system (ECLSS) of the space station is designed to control temperature, humidity, and composition of space-station air, including $\mathrm{CO}_{2}$ removal; recover water; dispose of waste; and detect and suppress fires. Fires are a great potential hazard and much attention has been given to suppressing them. A fire suppression system is available, but if all else fails, an escape vehicle can be used. A subsystem of the ECLSS, the atmosphere revitalization system, which includes a mass spectrometer called the major constituent analyzer, will analyze cabin air for $\mathrm{O}_{2}, \mathrm{~N}_{2}, \mathrm{H}_{2}, \mathrm{CO}, \mathrm{H}_{2} \mathrm{O}$, and $\mathrm{CH}_{4}$ in all areas of the habitation and laboratory modules. A design criterion for the atmosphere revitalization subsystem is the maintenance of space-station exposure levels below the 180-day SMACs under normal conditions.

\section{MODIFICATION OF CONTAMINANT TOXICITY BY ENVIRONMENTAL FACTORS}

The special conditions of the space environment must be taken into account in defining spacecraft contaminant exposure limits. Deposition of particles is clearly different and lung function and the toxic potential of inhaled particles may be different under microgravity conditions than under full gravity conditions, as on earth.

Astronauts will be physically, physiologically, and psychologically compromised for the following reasons: loss of muscle and bone mass, altered immune system, cardiovascular changes, decreased red-blood- 
cell mass, altered nutritional requirements, behavioral changes from stress, fluid shift in the body, altered hormonal status, and altered drug metabolism. These changes could be important factors in disease susceptibility.

The physiological changes noted in spaceflight to date demonstrate that the astronaut is in an altered homeostatic state and thus may be more susceptible to toxic chemicals. How this altered state modifies reactions to chemicals in the space-station environment is not fully known. The physiological changes induced in the space crew are important and their impact must be taken into account in developing SMAC values for various contaminants.

\section{SOURCES AND TYPES OF DATA FOR ESTABLISHMENT OF SMACS}

The subcommittee recommends the use of data derived from a number of sources in establishing SMAC values. These sources provide information on a variety of health effects including mortality, morbidity, clinical signs and symptoms, pulmonary effects, neurobehavioral effects, immunotoxicity, reproductive and developmental toxicity, pathology, mutagenicity, carcinogenicity, and biochemical and enzyme changes.

\section{Chemical-Physical Characteristics of Toxicants}

The chemical and physical characteristics of a substance provide valuable information on potential tissue dosimetry of the compound within the body and on its likely toxic effects. Preliminary estimates of the toxic potential of new chemicals also may be derived from known toxicities of structurally similar, well-investigated compounds. However, additional uncertainty (safety) factors must be applied to arrive at safe levels for those congeners that have no dose-response data from intact animals.

\section{In Vitro Toxicity Studies}

Useful information can be obtained from studies conducted to investi- 
gate adverse effects of chemicals on cellular or subcellular systems in vitro. Systems in which toxicity data have been collected include isolated organ systems, single-cell systems, and tissue cultures from multicellular organisms maintained under defined conditions or from functional units derived from whole cells. In vitro studies can be used to elucidate the toxic effects of chemicals and to study their mechanism of action.

\section{Animal Toxicity Studies}

The data necessary to evaluate the relationship between exposure to a toxic chemical and its effects on people are frequently not available from human experience; therefore, animal toxicity studies must be relied on to provide information on responses likely to occur in humans.

The usefulness of animal data depends in part on the route of exposure and species used. Although inhalation studies are most relevant in assessing the toxicity of atmospheric contaminants, data from skin absorption, ingestion, and parenteral studies are also useful. The relevance of animal data to humans may be limited by the absence of information on affected target organs and knowledge of metabolic pathways and pharmacokinetics in animals and humans.

\section{Clinical and Epidemiological Observations}

In establishing SMACs for chemicals, dose-response data from human exposure should be used whenever possible. Data from clinical inhalation exposures are most useful because inhalation is the most likely route of exposure. Human toxicity data also are available from epidemiological studies of long-term industrial exposures, from short-term high-level exposures following accidents, or from therapeutic uses of some pharmaceutical agents. Some of these data provide a basis for estimating a dose-response relationship.

Epidemiological studies have contributed to our knowledge of the health effects of many airborne chemical hazards. The limitations of epidemiology stem from its use of available data. The accuracy of data on health outcomes varies with the source of the information, and records documenting historical exposure levels are often sparse. For example, 
mortality information derived from death certificates is sometimes inaccurate, and exposure information collected from administrative purposes is limited. Despite these limitations, if the populations studied are large enough and have been exposed to high enough doses over a sufficient period to allow for the expression of disease, epidemiological studies usually provide valuable information on the effects of exposure in humans without resorting to cross-species extrapolation or to exposing humans in an experimental situation to possible injuries from chemical hazards.

\section{Pharmacokinetics and Metabolism}

Evaluation of the health effects of any chemical in a given environment is greatly facilitated by an understanding of its physiological disposition in the body. Many chemicals require some form of metabolic activation to exert their toxic effects. The formation of reactive metabolites may depend on the level of exposure and the pharmacokinetics of the chemical. Modern pharmacokinetic studies can provide physiologically based models describing disposition of chemicals within organs and tissues in the body. The space station is a closed system with limited capacity to clear the air of chemical vapors; the crew contributes to the removal of the chemicals from the air through sequestration and metabolism.

Toxic metabolites may be highly reactive chemically. These metabolites are biologically reactive intermediates that may covalently bind to nucleic acids or proteins that in turn, may alter DNA replication or transcription. In addition to formation of reactive metabolites, metabolic activity also may lead to formation of species of active oxygen that may damage nucleic acids or proteins or cause lipid peroxidation. The resulting health effects may range from direct, short-term target-organ toxicity to carcinogenesis.

\section{Biological Markers}

Biological markers are indicators of change within an organism that link exposure to a chemical to subsequent development of adverse health effects. Biological markers within an exposed individual can indicate the 
degree of exposure to a pollutant and may provide evidence of the initial structural, functional, or biochemical changes induced by the exposure and, ultimately, the biochemical or physiological changes associated with adverse health effects.

Biological markers can be divided into three classes:

1. Biological markers of exposure to pollutants may be thought of as "footprints" that the chemical leaves behind upon interaction with the body. Such markers contain the chemical itself or a metabolic fragment of the chemical and thus are usually chemical-specific.

2. Biological markers of the effects of exposure include the totality of subclinical and clinical signs of chemically induced disease states. The markers of greatest interest are those that are early predictors of serious effects or late-occurring effects. Such markers would be useful in determining what levels of pollutants in the space station can be tolerated without causing irreversible deleterious health effects.

3. Biological markers of increased susceptibility to the effects of exposure to pollutants could be used to predict which persons are most likely to be at excess risk as space-station crew members.

\section{RISK ASSESSMENT (DEVELOPMENT OF EXPOSURE CRITERIA)}

The assessment of toxicants that do not induce carcinogenic or mutagenic effects traditionally has been based on the concept that an adverse health effect will not occur below a certain level of exposure, even if exposure continues over a lifetime. Given this assumption, a reference dose intended to avoid toxic effects may be established by dividing the no-observed-adverse-effect level by an appropriate uncertainty factor or set of factors.

For carcinogenic effects, especially those known to be due to direct mutagenic events, no threshold dose may exist. However, when carcinogenesis is due to epigenetic or nongenotoxic mechanisms, a threshold dose may be considered. Attempts to estimate carcinogenic risks associated with levels of exposure have involved fitting mathematical models to experimental data and extrapolating from these models to predict risks at doses that are usually well below the experimental range. The multi- 
stage model of Armitage and Doll is used most frequently for low-dose extrapolation. According to multistage theory, a malignant cancer cell develops from a single stem cell as a result of a number of biological events (e.g., mutations) that must occur in a specific order. Recently, a two-stage model that explicitly provides for tissue growth and cell kinetics also has been used in carcinogenic risk assessment.

The multistage model, characterized by low-dose linearity, forms the basis for setting SMACs for carcinogens. Low-dose linearity is generally assumed for chemical carcinogens that act through direct interaction with genetic material.

\section{ISSUES IN MAKING RECOMMENDATIONS FOR THE ESTABLISHMENT OF SMACS}

A number of issues need to be considered in developing recommendations for establishing SMACs. These issues include (1) translating animal toxicity data to predict toxicities in humans; (2) determining 30- or 180day SMACs for carcinogens based on toxicological or epidemiological studies that often involve long-term or lifetime exposure; (3) considering limits set by the Occupational Safety and Health Administration, the American Conference of Governmental Industrial Hygienists, and the National Research Council in developing SMACs; (4) evaluating the toxicities of mixtures; and (5) modifying risk assessments based on the altered environment in the microgravity of space. 



\section{Appendix B}

Reports on Spacecraft Maximum

Allowable Concentrations (SMACs) for Selected Airborne Contaminants

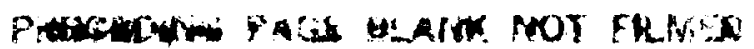

16 



\title{
B1 Acetaldehyde
}

King Lit Wong, Ph.D.

Johnson Space Center Toxicology Group

Biomedical Operations and Research Branch

Houston, Texas

\section{PHYSICAL AND CHEMICAL PROPERTIES}

Acetaldehyde is a colorless liquid with a fruity, pungent odor (Sax, 1984).

\author{
Synonyms: Ethanol, ethyl aldehyde, acetic \\ aldehyde \\ Formula: $\mathrm{CH}_{3} \mathrm{CHO}$ \\ CAS number: $75-07-0$ \\ Molecular weight: 44 \\ Boiling point: $20.8^{\circ} \mathrm{C}$ \\ Melting point: $\quad-123.5^{\circ} \mathrm{C}$ \\ Vapor pressure: $740 \mathrm{~mm} \mathrm{Hg}$ at $20^{\circ} \mathrm{C}$ \\ Conversion factors at $25^{\circ} \mathrm{C}, 1 \mathrm{~atm}: \quad 1 \mathrm{ppm}=1.80 \mathrm{mg} / \mathrm{m}^{3}$ \\ $1 \mathrm{mg} / \mathrm{m}^{3}=0.56 \mathrm{ppm}$
}

\section{OCCURRENCE AND USE}

Acetaldehyde is used as a solvent in the rubber, paper, and tanning industries. We are not aware of any use of acetaldehyde in the spacecraft, but acetaldehyde has been found in the cabin atmosphere during several space-shuttle nissions (NASA, 1988-90). The concentration detected usually ranged from 2 to $7 \mathrm{ppb}$. However, a sample in one space-shuttle mission was found to contain $140 \mathrm{ppb}$ of acetaldehyde.

19

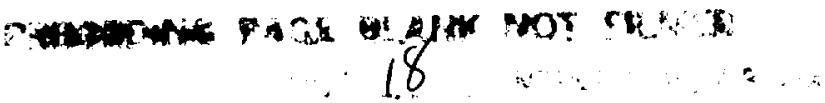


The human is a potential source of acetaldehyde in space shuttles. It has been estimated that acetaldehyde is produced at a rate of about $83 \mu \mathrm{g} / \mathrm{d}$ per human (Olcott, 1972). One production mechanism is the cleavage of L-threonine into glycine and acetaldehyde by threonine aldolase or serine hydroxy-methyltransferase (White et al., 1978; Diamondstone, 1982). It is also possible that acetaldehyde is absorbed during anaerobic metabolism of glucose by microorganisms in human intestines via decarboxylation of pyruvate by pyruvate decarboxylase (White et al., 1978; Harris, 1982). In human subjects fasted for $9 \mathrm{~h}$ previously, acetaldehyde was found in the expired air at an average rate of $17 \mu \mathrm{g} / \mathrm{h}$ (standard deviation $=25 \mu \mathrm{g} / \mathrm{h}$ ), with the data corrected for compounds present in the bottled, zero-grade air they breathed (Conkle et al., 1975).

\section{PHARMACOKINETICS AND METABOLISM}

When human volunteers inhaled acetaldehyde at $84-168 \mathrm{ppm}$ for about 1 $\mathrm{min}$, the respiratory tract retained $66-68 \%$ of acetaldehyde at a respiratory rate of $10 \mathrm{bpm}$ (Egle, 1970). The respiratory retention of acetaldehyde was somewhat concentration dependent because the retention dropped to $55 \%$ when the acetaldehyde concentration was raised to $336 \mathrm{ppm}$ (Egle, 1970). The respiratory rate also inversely affected acetaldehyde's respiratory retention. At an exposure concentration ranging from 84 to $336 \mathrm{ppm}$, the percent retention of acetaldehyde linearly decreased by 25 as the respiratory rate was increased from 5 to $40 \mathrm{bpm}$ (Egle, 1970). Unlike the respiratory rate, the tidal volume does not affect acetaldehyde's respiratory retention. Varying the tidal volume between 500 and $2000 \mathrm{~mL}$ did not change acetaldehyde's respiratory retention (Egle, 1970). Similar respiratory retention results were obtained in dogs (Egle, 1972).

Acetaldehyde is oxidized mainly in the liver to acetic acid by aldehyde dehydrogenase, aldehyde oxidase, and xanthine oxidase (White et al., 1978). In the liver, aldehyde dehydrogenase is found in the cytosol, mitochondria, and microsomes, but most of the hepatic aldehyde dehydrogenase activity exists in the mitochondria (Sipes and Gandolfi, 1986). Aldehyde dehydrogenase is present in many mammalian tissues (Sipes and Gandolfi, 1986), which probably include nasal mucosa because nasal 
mucosal homogenates of rats could oxidize acetaldehyde (CasanovaSchmitz et al., 1984).

After a 1-h inhalation exposure of rats to acetaldehyde at 24,500 to $491,000 \mathrm{ppm}$, acetaldehyde disappeared from blood monoexponentially with a half-life of $3.1 \mathrm{~min}$ (Hobara et al., 1985). During a 90-min, in vitro incubation of acetaldehyde with human blood, the acetaldehyde concentration showed an exponential biphasic decrease (Freundt, 1975). The half-lives of the first and second phases were 57 and $110 \mathrm{~min}$, respectively (Freundt, 1975).

\section{TOXICITY SUMMARY}

\section{Acute Toxicity}

\section{Mucosal Irritation}

The eye is the most sensitive organ to acetaldehyde's acute toxicity. In a study, 12 human subjects were exposed to acetaldehyde vapor for $15 \mathrm{~min}$ while being shown a movie "to divert their attention," most of the subjects developed eye irritation at $50 \mathrm{ppm}$, but it took more than $200 \mathrm{ppm}$ to cause nose or throat irritation in the majority of the subjects (Silverman et al., 1946).

Other than comparing the sensitivities of several organs to acetaldehyde's irritancy, the investigators in that study also obtained concentration-response data on acetaldehyde's irritancy on the eyes: $50 \mathrm{ppm}$ irritated the eyes of most of the subjects, and several subjects strenuously objected to the vapor at as low as $25 \mathrm{ppm}$ (Silverman et al., 1946). Even those who reported no eye irritation at $50 \mathrm{ppm}$ showed erythematous eyelids and bloodshot eyes when exposed to $200 \mathrm{ppm}$ of acetaldehyde (Silverman et al., 1946).

Based on a mouse model, acetaldehyde vapor is not as strong a sensory irritant as acrolein or formaldehyde (Steinhagen and Barrow, 1984). In this mouse model, a chemical's sensory irritancy slows down the breathing via a trigeminal nerve reflex (Alarie, 1973). Acetaldehyde at $2845 \mathrm{ppm}$ reduced the mouse's respiratory rate by $50 \%$ in $10 \mathrm{~min}$, but it took only 
$1.4 \mathrm{ppm}$ of acrolein or $5 \mathrm{ppm}$ of formaldehyde to slow the mouse breathing by $50 \%$ (Steinhagen and Barrow, 1984).

\section{Miscellaneous Mucosal Effects}

In addition to causing mucosal irritation, acetaldehyde vapor can produce ciliostasis at $560 \mathrm{ppm}$ within $30 \mathrm{~min}$ in rabbit tracheal explants (Dalhamn and Rosengren, 1971). Acetaldehyde apparently also caused DNA-protein crosslinks in rats' nasal mucosa (Lam et al., 1986). There was evidence that DNA-protein crosslinks could be formed in the nasal respiratory mucosa after a 6-h exposure and olfactory mucosa after five daily 6-h exposures of rats to acetaldehyde at $1000 \mathrm{ppm}$ (Lam et al., 1986).

\section{Lethality}

Acetaldehyde is lethal at sufficiently high exposure levels. Its 4-h $\mathbf{L C}_{50}$ in rats is $13,300 \mathrm{ppm}$ (Appelman et al., 1982). Exposure of mice to 5600 ppm for $2 \mathrm{~h}$ led to $40 \%$ mortality and elevated SGOT, SGPT, and serum $g$-glutamyltransferase activities in the survivors (Wakasugi and Yamada, 1988). There was, however, no evidence of acetaldehyde causing liver injury in other studies.

\section{Subchronic and Chronic Toxicity}

\section{Nasal Toxicity}

Consistent with acetaldehyde's acute toxicity, acetaldehyde causes primarily nasal injuries in subchronic and chronic exposures. In rats, exposures to acetaldehyde at $500 \mathrm{ppm}, 6 \mathrm{~h} / \mathrm{d}, 5 \mathrm{~d} / \mathrm{w}$ for $4 \mathrm{w}$ resulted in growth retardation, the degeneration of nasal olfactory epithelium and reduced phagocytic ability of pulmonary macrophages (Appelman et al., 1986). The no-sbserved-adverse-effect level (NOAEL) in that study in rats was $150 \mathrm{ppm}$. It is of interest that the NOAEL was $390 \mathrm{ppm}$ in hamsters in a 90-d study performed in the same laboratory with similar end points (Kruysse et al., 1975). It thus appears that the rat is more sensitive than 
the hamster to acetaldehyde's subchronic toxicity. As the duration of acetaldehyde's repetitive exposure was lengthened to $52 \mathrm{w}$, nasal injuries similar to that seen in the 4-w study were also observed (Woutersen and Feron, 1987). However, some of the rats that developed degeneration of the olfactory epithelium, after a 52-w, 6-h/d, 5-d/w exposure to acetaldehyde at $750 \mathrm{ppm}$, recovered from the nasal injury in 26 or $52 \mathrm{w}$ after the end of the exposure (Woutersen and Feron, 1987). This indicates that the nasal mucosa may regenerate after acetaldehyde exposure in rats.

\section{Pulmonary and Renal Toxicity}

In addition to injuring the nose, subchronic acetaldehyde exposures have been shown to affect the lung and kidney. A 5-w exposure of rats to acetaldehyde at $243 \mathrm{ppm}, 8 \mathrm{~h} / \mathrm{d}, 5 \mathrm{~d} / \mathrm{w}$ produced increases in functional residual capacity, residual volume, total lung capacity, and respiratory rate, but no change in forced expiratory mean flows (Saldiva et al., 1985). No changes in lung morphology, however, were detected in these rats (Saldiva et al., 1985) or in rats repetitively exposed to acetaldehyde at concentrations as high as 2200 ppm for 4 to 52 w (Appelman et al., 1982; Appelman et al., 1986; Woutersen and Feron, 1987). A 90-d exposure of hamsters to acetaldehyde at $1340 \mathrm{ppm}, 6 \mathrm{~h} / \mathrm{d}, 5 \mathrm{~d} / \mathrm{w}$ increased the kidney weight (Kruysse et al., 1975). A 4-w exposure of rats to acetaldehyde at $1000 \mathrm{ppm}$ has been shown to increase the urine output (Appelman et al., 1982). It was not known whether the increase in urine output was due to acetaldehyde's effect on the kidney.

\section{Carcinogenicity}

There was only one epidemiology study with acetaldehyde. It showed that the incidence of total cancer in acetaldehyde production workers was higher than that in the general population (Bittersohl, 1974). Out of 220 workers studied, nine cases of cancers were found: five cases of squamous cell carcinomas in the bronchial tress, two cases of squamous cell carcinomas in the mouth, one case of adenocarcinoma in the stomach, and one case of adenocarcinoma in the cecum. The rates of bronchial cancers and oral cancers were both higher than that in the whole German population. 
All nine men with cancers were smokers. Unfortunately, the study had several deficiencies, including a small number of subjects and the fact that the workers were exposed to a mixture of butyraldehyde, acetaldehyde, crotonaldehyde, $n$-butanol, and ethylhexanol, with butyraldehyde as the compound with the highest concentration. The measured concentration of acetaldehyde ( 1 to $7 \mathrm{mg} / \mathrm{m}^{3}$ ) was much lower than that of butyraldehyde ( 5 to $70 \mathrm{mg} / \mathrm{m}^{3}$ ). As a result, acetaldehyde's carcinogenicity could not be evaluated in this study.

A carcinogenicity bioassay was performed in rats by Woutersen et al. (1986). They exposed rats to acetaldehyde at $0,750,1500$, or $3000-1000$ ppm, $6 \mathrm{~h} / \mathrm{d}, 5 \mathrm{~d} / \mathrm{w}$ for up to $28 \mathrm{mo}$. The 3000-1000-ppm group was actually exposed at $3000 \mathrm{ppm}$ for $20 \mathrm{w}, 2000 \mathrm{ppm}$ for $14 \mathrm{w}, 1500 \mathrm{ppm}$ for $17 \mathrm{w}$, and $1000 \mathrm{ppm}$ for $69 \mathrm{w}$. Other than degeneration, hyperplasia, and metaplasia of the nasal mucosa, they found adenocarcinomas of the nasal olfactory epithelium and squamous cell carcinomas of the nasal respiratory epithelium in both the male and female rats. The combined incidences of nasal adenocarcinomas and squamous cell carcinoma in the male rats were 1 of 49,17 of 52,41 of 53 , and 36 of 49 in the $0-, 750-, 1500-$, and 30001000-ppm groups, respectively (Woutersen et al., 1986).

The International Agency for Research on Cancer (IARC) concluded that there is insufficient evidence of acetaldehyde's carcinogenicity in humans, but there is sufficient evidence that acetaldehyde is a carcinogen in animals (IARC, 1987). Based on the carcinogenic findings in the rat, the U.S. Environmental Protection Agency (EPA) classified acetaldehyde as a probable human carcinogen (EPA, 1990).

\section{Genotoxicity}

There are some indications that acetaldehyde might be genotoxic. As mentioned earlier, acetaldehyde exposure at $1000 \mathrm{ppm}, 6 \mathrm{~h} / \mathrm{d}$ for $5 \mathrm{~d}$ could produce DNA-protein crosslinks in the nasal mucosa in rats (Lam et al., 1986). The data on the reaction with DNA in nasal mucosa of rats supports the carcinogenicity findings in rats. Incubation of human leukocytes with 10-20 mM acetaldehyde for $4 \mathrm{~h}$ in vitro has been shown by Lambert et al. to produce DNA crosslinks, but not DNA strand breaks (Lambert et al., 1985).

Although acetaldehyde was negative in the Ames test (Mortelmans et al., 
1986), it was found to induce sex-linked recessive lethal mutations in Drosophila melanogaster (Woodruff et al., 1985) and sister chromatid exchange in human lymphocytes in vitro (Obe et al., 1979). Acetaldehyde was found to induce sister chromatid exchange in vitro without the addition of $S-9$ fraction, suggesting that metabolic activation was not required. Acetaldehyde also is known to produce chromosomal aberrations in mammalian cell culture (Bird et al., 1981). However, acetaldehyde failed to produce chromosomal aberrations in Drosophila (Woodruff et al., 1985).

\section{Reproductive and Developmental Toxicity}

No data were found on acetaldehyde's reproductive toxicity. However, acetaldehyde might affect the fetus. Acetaldehyde administered intraperitoneally at 50,75 , or $100 \mathrm{mg} / \mathrm{kg}$ to pregnant rats on days 10,11 , and 12 of gestation led to fetal resorptions and decreased ossification of sternebrae and vertebrae in all three dose groups on day 21 (Sreenathan and Padmanabhan, 1982). Fetal growth was also severely impaired because there were reductions in crown-rump length, tail length, body weight, and transumbilical distance at all doses. The investigators observed malformations, such as reduction in the number of sternebrae, but they did not report results of statistical analyses of those malformation data, making interpretation difficult. They also did not mention if any maternal toxicity was detected. No conclusive assessment of acetaldehyde's teratogenicity can be made.

\section{Synergistic Effects}

There is no evidence that inhaled acetaldehyde acts synergistically with other chemicals. Pretreatment of rats with inhaled formaldehyde is known to decrease the rat's sensitivity toward acetaldehyde's sensory irritation (Babiuk et al., 1985). Inhalation exposures of mice to acetaldehyde have been shown to cause a metabolic tolerance to ethanol (Latge et al., 1987). These findings should be considered in assessing the health risk of exposures to a mixture of these compounds. 


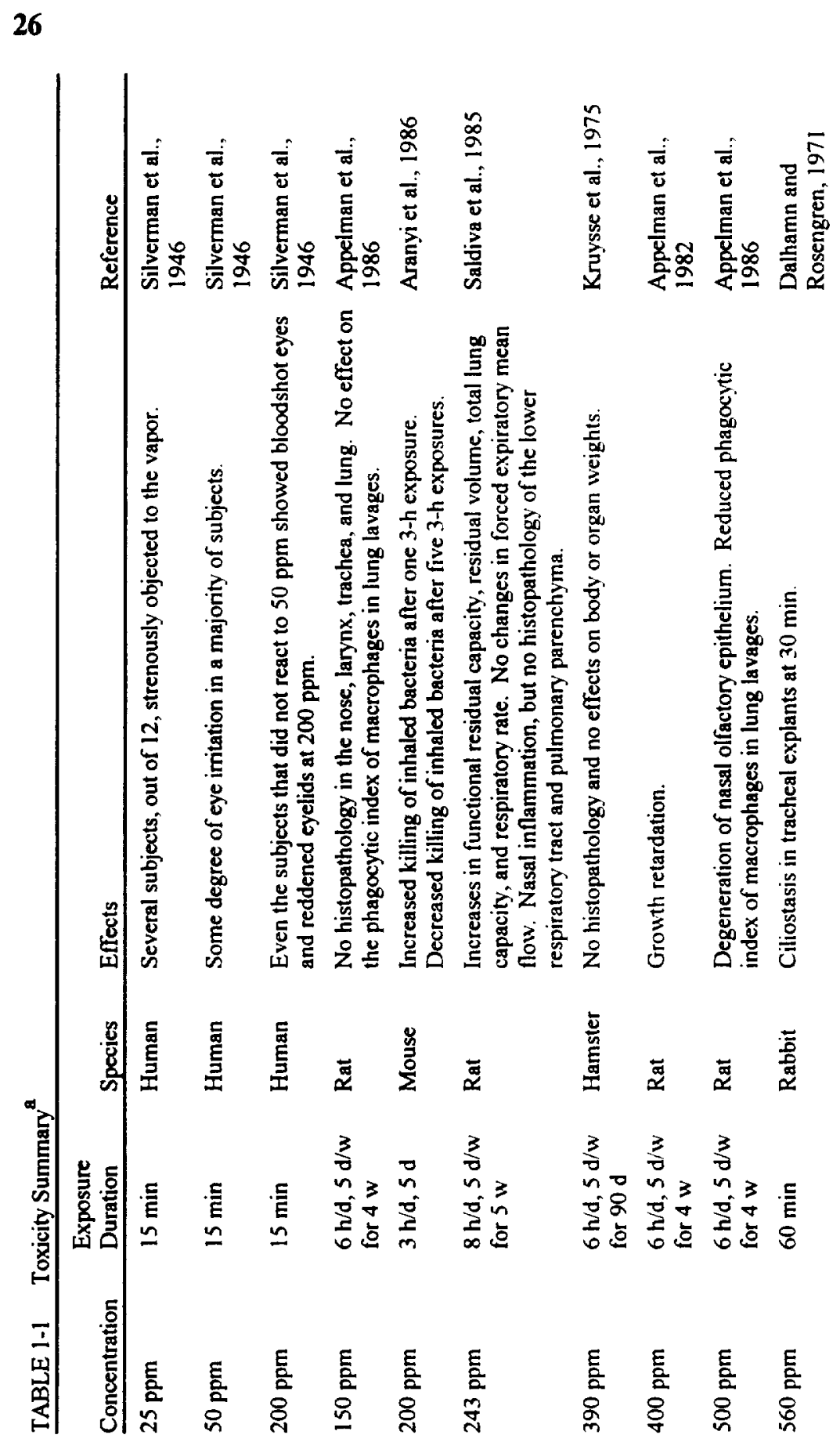



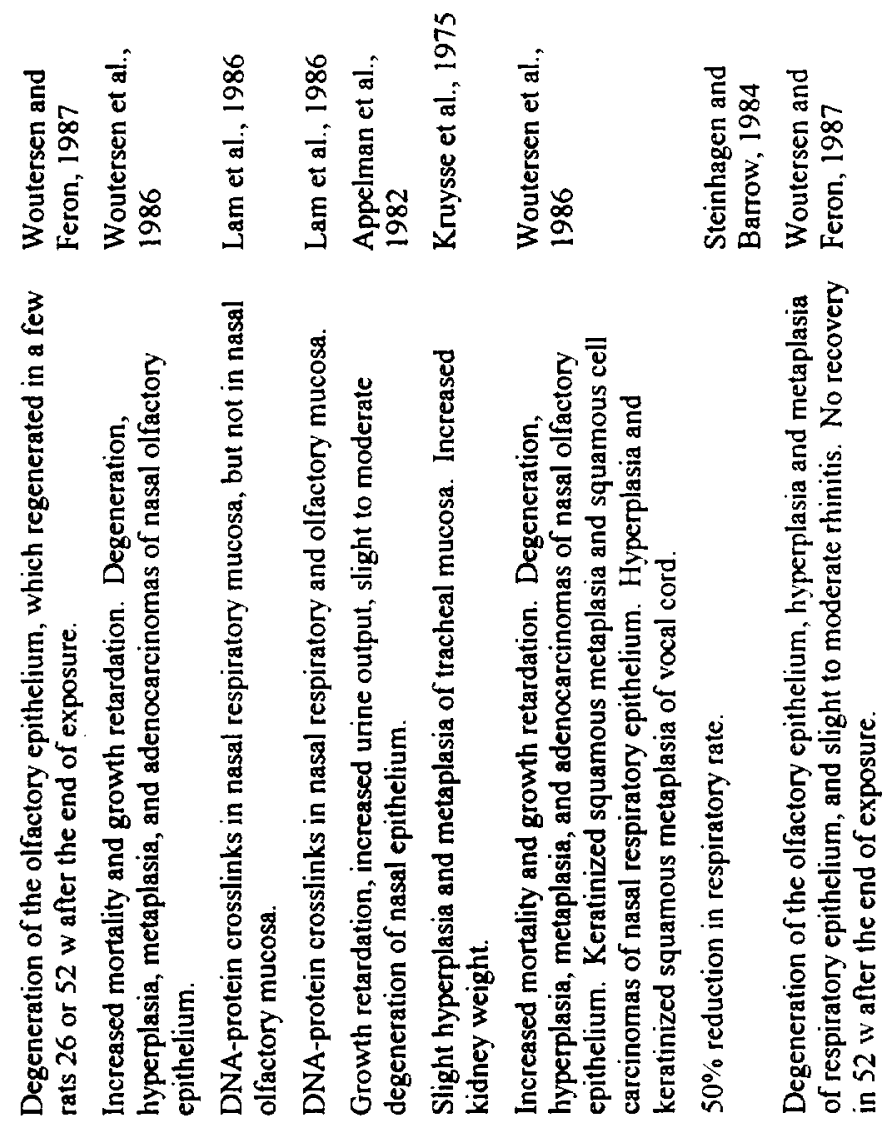

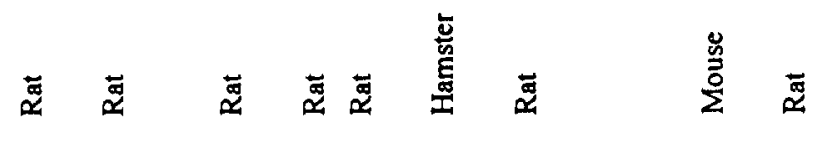

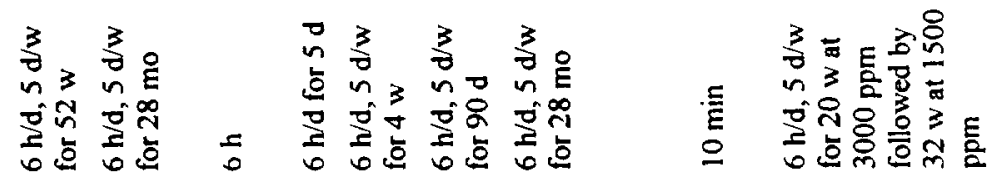

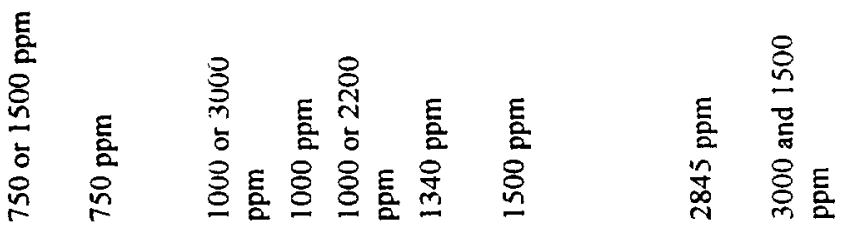




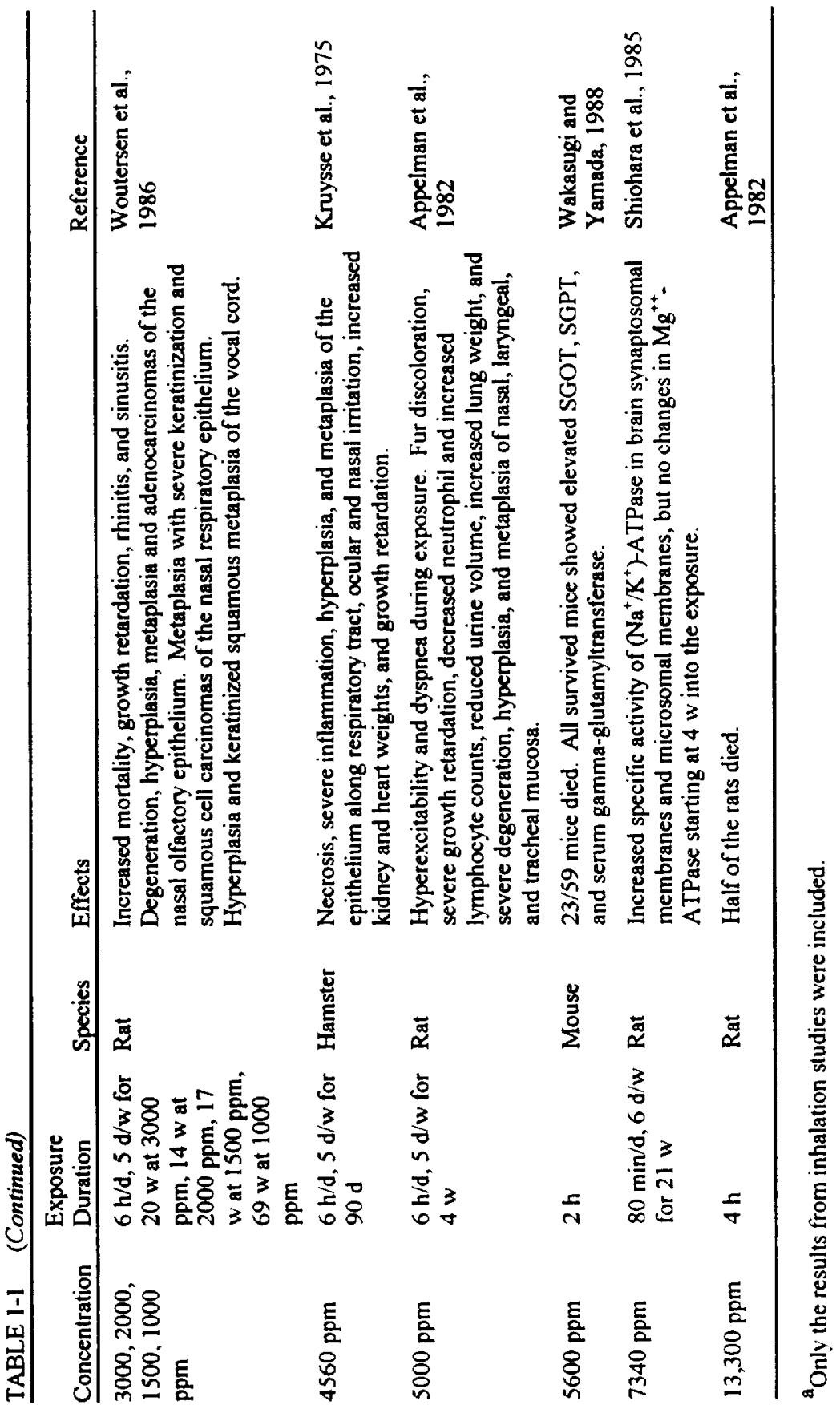


TABLE 1-2 Exposure Limits Set by Other Organizations

\begin{tabular}{ll} 
Organization & Concentration, ppm \\
\hline ACGIH's TLV & 100 (TWA) \\
ACGIH's STEL & 150 \\
OSHA's PEL & 200 (TWA) \\
NIOSH's IDLH & 10,000 \\
\hline
\end{tabular}

ACGIH = American Conference of Governmental Industrial Hygienists. OSHA = Occupational Safety and Health Administration. NIOSH = National Institute for Occupational Safety and Health. TLV $=$ threshold limit value. TWA $=$ time-weighted average. STEL $=$ short-term exposure limit. $\mathrm{PEL}=$ permissible exposure limit. $\mathrm{IDLH}=$ immediately dangerous to life and health.

TABLE 1-3 Spacecraft Maximum Allowable Concentrations

\begin{tabular}{llll}
\hline Duration $^{\mathrm{a}}$ & $\mathrm{ppm}$ & $\mathrm{mg} / \mathrm{m}^{3}$ & Target Toxicity \\
\hline $1 \mathrm{~h}$ & 10 & 18 & Mucosal irritation \\
$24 \mathrm{~h}$ & 6 & 11 & Mucosal irritation \\
$7 \mathrm{~d}^{\mathrm{b}}$ & 2 & 4 & Mucosal irritation \\
$30 \mathrm{~d}$ & 2 & 4 & Mucosal irritation \\
$180 \mathrm{~d}$ & 2 & 4 & Mucosal irritation \\
\hline
\end{tabular}

These SMACs are ceiling values.

${ }^{b}$ Former 7-d SMAC $=30$ ppm.

\section{RATIONALE}

To set acetaldehyde's SMACs, the acceptable concentrations according to carcinogenesis, for the various exposure durations, are compared with the corresponding concentrations based on noncarcinogenic end points. The noncarcinogenic end points produced by acetaldehyde include irritation sensation of the eyes, noncarcinogenic structural changes of nasal mucosa, lung function changes, and increased kidney weight (Silverman et al., 1946; Appelman et al., 1986; Kruysse et al., 1975; Saldiva et al., 1985). Among these noncarcinogenic end points, sensory irritation of the eyes is the most important because sensory irritation was detected in humans at as low as 25 ppm (Silverman et al., 1946), but much higher exposure concentrations were required for other end points. For instance, the NOAEL in a 4-w repetitive exposure of rats was $150 \mathrm{ppm}$ based on nasal histopathology 
(Appelman et al., 1986). The lowest-observed-effect level (LOEL) based on kidney weight changes was $1340 \mathrm{ppm}$ in a 4-w repetitive exposure of hamsters (Kruysse et al., 1975). Therefore, an exposure level low enough to prevent eye irritation will also prevent nasal histopathology and kidney weight changes.

It took $243 \mathrm{ppm}$ of acetaldehyde to cause lung function changes in a 5-w repetitive exposure of rats (Saldiva et al., 1985). In that study, the investigators used only one acetaldehyde exposure concentration. Without any concentration response data on the lung function, it is difficult to predict whether acetaldehyde, at a practically nonirritating level of $25 \mathrm{ppm}$, would affect the lung function of humans in a repetitive exposure. The lung function data of these investigators (Saldiva et al., 1985) were not relied on in estimating the acceptable level based on noncarcinogenic end points. The reason is that a 5-w repetitive exposure of rats to acetaldehyde at $243 \mathrm{ppm}$ increased the functional residual capacity, residual volume, and total lung capacity (Saldiva et al., 1985). This pattern of lung function changes is typical for pulmonary emphysema (McCarthy, 1981), but no emphysematous changes were detected in that study or in other subchronic studies of acetaldehyde (Appelman et al., 1982, 1986; Kruysse et al., 1975). Until these lung function effects of acetaldehyde are reproduced and more data on acetaldehyde's lung function effects are available, lung function changes will not be considered in estimating the acceptable acetaldehyde's exposure level for noncarcinogenic end points.

The process used to set SMACs involves individual consideration of significant toxic end points. For each toxic end point, an acceptable concentration $(\mathrm{AC})$ for the appropriate length of exposure is estimated. After ACs are estimated for all the toxic end points under consideration, the lowest AC for a given duration of exposure is then selected as the SMAC.

\section{Carcinogenicity}

According to EPA's estimates based on the linearized multistage model (EPA, 1990), a life-time, continuous exposure to acetaldehyde at 0.046 $\mathrm{mg} / \mathrm{m}^{3}$ or $0.025 \mathrm{ppm}$ would lead to an excess tumor risk of $1 \times 10^{-4}$ in humans. Using the approach of the NRC's Committee on Toxicology (NRC, 1990) and setting $\mathrm{k}=3, \mathrm{t}=25,550 \mathrm{~d}$ or $70 \mathrm{y}$, and $\mathrm{s}_{1}=10,950 \mathrm{~d}$ or $30 \mathrm{y}$, an adjustment factor of 26,082 is obtained to calculate a 
near-instantaneous exposure level that would yield the same excess tumor risk as a continuous life-time exposure.

24-h exposure level that would yield an excess tumor risk of $10^{-4}$

$$
\begin{aligned}
& =0.025 \mathrm{ppm} \times 26,082 \\
& =660 \mathrm{ppm} .
\end{aligned}
$$

For the 7-d, 30-d, and 180-d acceptable exposure levels based on carcinogenesis, adjustment factors are calculated with the approach of the NRC's Committee on Toxicology (NRC, 1990), setting $k=3, t=25,550$ $\mathrm{d}$, and $\mathrm{s}_{1}=10,950 \mathrm{~d}$. The adjustment factors are 3728,871 , and 146.7 for a continuous 7-d, 30-d, and 180-d exposure, respectively, that would yield the same excess tumor risk as a continuous life-time exposure.

7-d exposure level that would yield an excess tumor risk of $10^{-4}$

$=0.025 \mathrm{ppm} \times 3728$

$=94 \mathrm{ppm}$.

$30-\mathrm{d}$ exposure level that would yield an excess tumor risk of $10^{-4}$

$=0.025 \mathrm{ppm} \times 871$

$=22 \mathrm{ppm}$.

180-d exposure level that would yield an excess tumor risk of $10^{-4}$

$=0.025 \mathrm{ppm} \times 146.7$

$=4 \mathrm{ppm}$.

\section{Mucosal Irritation}

Silverman et al. (1946) conducted a study in which 12 human volunteers were exposed to various organic compounds, one at a time, including acetaldehyde, while the volunteers were shown motion pictures during the exposure to "divert their thoughts from the atmospheric contamination." A 15-min exposure to acetaldehyde at $50 \mathrm{ppm}$ resulted in some degree of eye irritation in a majority of the volunteers. Even though most of the subjects said that they were willing to work an 8-h day at $200 \mathrm{ppm}$ (Silverman et al., 1946), it does not mean that $200 \mathrm{ppm}$ is an acceptable concentration because the study of Silverman et al. was done in the mid-1940's, when workers were probably more willing to endure undesirable work conditions 
due to the economic hard times. The finding that a 15 -min exposure at 200 ppm produced bloodshot eyes and reddened eyelids in those subjects who did not respond to $50 \mathrm{ppm}$ (Silverman et al., 1946) also tends to support the conclusion that $200 \mathrm{ppm}$ could be quite irritating. Several of the 12 volunteers strenuously objected to even $25 \mathrm{ppm}$ of acetaldehyde, a concentration not irritating to the majority of the test subjects (Silverman et al., 1946). These data were prudently interpreted to mean that a 15-min acetaldehyde exposure at 200 and $50 \mathrm{ppm}$ would probably result in moderate and mild eye irritation, respectively; and some individuals, however, are more sensitive to acetaldehyde's sensory irritation than others, so that $25 \mathrm{ppm}$ is nonirritating except to supersusceptible individuals.

Since the 1-h SMAC is designed for contingencies, slight eye irritation is acceptable. Although a 15 -min acetaldehyde exposure at $25 \mathrm{ppm}$ is not irritating except to a minority of the individuals (Silverman et al., 1946), $25 \mathrm{ppm}$ is not acceptable as the 1-h SMAC because the irritation response to $25 \mathrm{ppm}$ could increase if the acetaldehyde exposure is extended to $1 \mathrm{~h}$. There is no time-response data on acetaldehyde's irritancy, but in humans the eye irritancy of acrolein, another irritating aldehyde, at $0.3 \mathrm{ppm}$ increased when the exposure was extended from 15 to $40 \mathrm{~min}$ and it stayed constant from 40 to $60 \mathrm{~min}$ (Webber-Tschopp et al., 1977). Therefore, the 15 -min acetaldehyde exposure level of $25 \mathrm{ppm}$ should be lowered in estimating a 60-min exposure level that would not be irritating except to a minority of individuals.

How much it should be lowered is determined from the acetaldehyde and acrolein data. The degree of eye irritation during an acrolein exposure increased by one grade, from slight to moderate, when the exposure was extended from 15 to $60 \mathrm{~min}$ (Weber-Tschopp et al., 1977). So to estimate a 60-min exposure concentration of acetaldehyde that is as irritating as a 15-min exposure concentration of acetaldehyde, the 15-min exposure concentration should be decreased by an amount that would drop the irritancy by one grade and this lower concentration is made the 60 -min exposure concentration. When the acetaldehyde concentration was reduced two-fold from $50 \mathrm{ppm}$ to $25 \mathrm{ppm}$ in a 15 -min acetaldehyde exposure, the degree of eye irritation was found to decrease by one grade, from mildly irritating in most of the 12 subjects to nonirritating in the majority of the subjects (Silverman et al., 1946). Therefore, a 60-min exposure concentration of acetaldehyde that is one half the 15 -min exposure concentration would probably be as irritating as the 15 -min exposure concentration. 
1-h acceptable exposure level that would be nonirritating to most people $=15$-min nonirritating exposure level $\times 1 /$ time factor $(\mathrm{TF})$

$=25 \mathrm{ppm} \times 1 / 2$

$=12.5 \mathrm{ppm}$.

It should be noted that, even though the 1-h AC based on irritation is derived from data generated from only 12 human subjects by Silverman et al. (1946), no correction is made for the small number of subjects. This is because some degree of mucosal irritation is acceptable for a 1-h contingency, so the 1-h AC for irritation need not be too conservative. By the same token, no correction is made for the small number of subjects in deriving the 24-h AC based on Silverman's data.

In setting the 24-h AC, a 24-h exposure concentration of acetaldehyde that is one half the 15-min exposure concentration is assumed to be as irritating as the 15-min concentration. Although there is no direct evidence that the irritancy of acetaldehyde's vapor at $24 \mathrm{~h}$ would be the same as that at $1 \mathrm{~h}$, data on the irritancy of acrolein and ammonia indicate that the irritancy of most sensory irritants reaches a plateau near $1 \mathrm{~h}$. The irritancy of 0.3-ppm acrolein in humans stayed constant from 40 to 60 min into an exposure (Weber-Tschopp et al., 1977). There were no significant differences in ammonia's irritancy at $50 \mathrm{ppm}$ in volunteers exposed for 0.5 , 1 , or $2 \mathrm{~h}$ (Verberk, 1977). As a result, it is safe to assume that the irritancy of acetaldehyde would not increase from $1 \mathrm{~h}$ to $24 \mathrm{~h}$. This assumption is consistent with the general belief that mucosal irritation is a surface phenomenon, affected mainly by the exposure concentration, not the exposure duration. So by applying the time adjustment factor of 2 on the 15 -min exposure concentration of $25 \mathrm{ppm}$, which was nonirritating to most of the subjects in $15 \mathrm{~min}$ (Silverman et al., 1946), the resulting concentration of $12.5 \mathrm{ppm}$ should also be nonirritating to most of the people in a 24-h exposure. But because a few of the 12 exposed subjects "strenuously objected" to a 15-min acetaldehyde exposure at $25 \mathrm{ppm}$ (Silverman et al., 1946), a number of sensitive individuals might also strenuously object to a 60-min exposure at $12.5 \mathrm{ppm}$. For this reason, the acceptable $24-\mathrm{h}$ exposure concentration based on eye irritation should be lower than $12.5 \mathrm{ppm}$.

There is another reason why it should be lower. Even though some probability of eye irritation is acceptable during a 24-h exposure to an irritant at its 24-h SMAC because 24-h SMACs are designed for contingency scenarios, the 24-h AC of an irritant is usually set slightly lower 
than its 1-h AC to reduce the degree of irritation that the astronauts have to endure in 24-h contingencies. So in setting the 24-h AC, an additional uncertainty factor (UF) is needed compared with the derivation of the $1-\mathrm{h}$ AC. Because it is known that a reduction of the 15-min exposure level of acetaldehyde by 2 , from $50 \mathrm{ppm}$ to $25 \mathrm{ppm}$, reduced acetaldehyde's irritancy from being slightly irritating to nonirritating in most of the subjects (Silverman et al., 1946), 2 is selected to be that UF.

$$
\begin{aligned}
& \text { 24-h acceptable exposure level based on eye irritation } \\
& \quad=15 \text {-min nonirritating level } \times 1 / \mathrm{TF} \times 1 / \mathrm{UF} \\
& \quad=25 \mathrm{ppm} \times 1 / 2 \times 1 / 2 \\
& =6 \mathrm{ppm} .
\end{aligned}
$$

As discussed above, it is safe to assume that acetaldehyde's irritancy would not increase from $1 \mathrm{~h}$ to $24 \mathrm{~h}$. Similarly, the irritancy would not be expected to increase as the acetaldehyde exposure is further lengthened to 7,30 , or $180 \mathrm{~d}$. Consequently, the same acceptable exposure level based on eye irritation may be used for 7,30 , or $180 \mathrm{~d}$. To prevent eye irritation in practically all astronauts in a 7-d, 30-d, or 180-d exposure, a correction factor of 10/(square root of $n$ ) is applied because there were only 12 human subjects in Silverman's data (Silverman et al., 1946). This correction factor for "small $n$ " would provide an added margin of safety.

7-, 30-, or 180-d acceptable exposure level that would prevent eye irritation

$=15$-min nonirritating level $\times 1 / \mathrm{TF} \times 1 / \mathrm{UF} \times 1 /$ small $n$ factor

$=25 \mathrm{ppm} \times 1 / 2 \times 1 / 2 \times($ square root of $n) / 10$

$=25 \mathrm{ppm} \times 1 / 2 \times 1 / 2 \times($ square root of 12$) / 10$

$=2 \mathrm{ppm}$.

\section{The Establishment of SMACs}

All the ACs derived for carcinogenesis are tabulated below. The ACs based on eye irritation are lower than that based on carcinogenesis, so the ACs of $10,6,2,2$, and $2 \mathrm{ppm}$ for mucosal irritation are chosen to be the 1-h, 24-h, 7-d, 30-d, and 180-d SMACs, respectively. 
TABLE 1-4 Acceptable Concentrations

\begin{tabular}{llllll} 
& \multicolumn{6}{l}{ Acceptable Concentration, ppm } \\
\cline { 2 - 6 } Toxic End Point & $1 \mathrm{~h}$ & $\mathbf{2 4} \mathrm{h}$ & $7 \mathrm{~d}$ & $\mathbf{3 0 \mathrm { d }}$ & $180 \mathrm{~d}$ \\
\hline Carcinogenesis & - & 660 & 94 & 22 & 4 \\
Mucosal Irritation & 12.5 & 6 & 2 & 2 & 2 \\
\hline SMAC & $\mathbf{1 0}$ & $\mathbf{6}$ & $\mathbf{2}$ & $\mathbf{2}$ & $\mathbf{2}$ \\
\hline
\end{tabular}

\section{REFERENCES}

Alarie, Y. 1973. Sensory irritation of the upper airways by airborne chemicals. Toxicol. Appl. Pharmacol. 24:279-297.

Appelman, L.M., R.N. Hooftman, and W.R.F. Notten. 1986. Effect of variable versus fixed exposure levels on the toxicity of acetaldehyde in rats. J. Appl. Toxicol. 6:331-336.

Appelman, L.M., R.A. Woutersen, and V.J. Feron. 1982. Inhalation toxicity of acetaldehyde in rats. I. Acute and subacute studies. Toxicology 23:293-307.

Aranyi, C, W.J. O'Shea, J.A. Graham, and F.J. Miller. 1986. The effects of inhalation of organic chemical air contaminants on murine lung host defenses. Fund. Appl. Toxicol. 6:713-720.

Babiuk, C., W.H. Steinhagen, and C.S. Barrow. 1985. Sensory irritation response to inhaled aldehydes after formaldehyde pretreatment. Toxicol. Appl. Pharmacol. 79:143-149.

Bird, R.P., H.H. Draper, and P.K. Basur. 1981. Effect of malonaldehyde and acetaldehyde on cultured mammalian cells: Production of micronuclei and chromosomal aberrations. Mutat. Res. 101:237-246.

Bittersohl, G. 1974. Epidemiologic investigations on cancer incidence in workers contacted by acetaldol and other aliphatic aldehydes. Arch. Geschwulstforsch. 43:172-176.

Casanova-Schmitz, M., R.M. David, and H.D. Heck. 1984. Oxidation of formaldehyde and acetaldehyde by $\mathrm{NAD}^{+}$-dependent dehydrogenases in rat nasal mucosal homogenates. Biochem. Pharmacol. 33: 1137-1142.

Conkle, J.P., B.J. Camp, and B.E. Welch. 1975. Trace composition of 
human respiratory gas. Arch. Environ. Health 30:290-295.

Dalhamn, T. and A. Rosengren. 1971. Effect of different aldehydes on tracheal mucosa. Arch. Otolaryng. 93:496-500.

Diamondstone, T.I. 1982. Amino acid metabolism II. P. 588 in Textbook of Biochemistry with Clinical Correlations. T.M. Devlin, ed. John Wiley \& Sons, New York, N.Y.

Egle, J.L., Jr. 1970. Retention of inhaled acetaldehyde in man. J. Pharmacol. Exp. Ther. 174:14-19.

Egle, J.L. 1972. Retention of inhaled acetaldehyde in the dog. Arch. Environ. Health 24:354-357.

EPA. 1990. Acetaldehyde. In Integrated Risk Information System. Office of Health and Environmental Assessment. U.S. Environmental Protection Agency, Washington, D.C.

Freundt, K.J. 1975. Behavior of the alcohol metabolite acetaldehyde in blood. Blutalkohol 12:389-392.

Harris, R.A. 1982. Carbohydrate metabolism I. P. 329 in Textbook of Biochemistry with Clinical Correlations. T.M. Devlin, ed. John Wiley \& Sons, New York, N.Y.

Hobara, N., A. Watanabe, M. Kobayashi, H. Nakatsukasa, H. Nagashima, T. Fukuda, and Y. Araki. 1985. Tissue distribution of acetaldehyde in rats following acetaldehyde inhalation and intragastric ethanol administration. Bull. Environ. Contam. Toxicol. 35:393-396.

IARC. 1987. Acetaldehyde. Pp. 77-78 in IARC Monographs on the Evaluation of Carcinogenic Risks to Humans. IARC Monogr. Suppl. 7.

Kruysse, A., V.J. Feron, and H.P. Til. 1975. Repeated exposure to acetaldehyde vapor. Studies in Syrian golden hamsters. Arch. Environ. Health 30:449-452.

Lam, C.W., M. Casanova, and H.D'A. Heck. 1986. Decreased extractability of DNA from proteins in the rat nasal mucosa after acetaldehyde exposure. Fund. Appl. Toxicol. 6:541-550.

Lambert, B., Y. Chen, S.M. He, and M. Sten. 1985. DNA cross-links in human leucocyte treated with vinyl acetate and acetaldehyde in vitro. Mutat. Res. 146:301-303.

Latge, C., Y. Lamboeuf, C. Roumec, and G. deSaint Blanquat. 1987. Effect of chronic acetaldehyde intoxication on ethanol tolerance and membrane fatty acid. Drug Alcohol Depend. 20:47-55.

McCarthy, D.S. 1981. Airflow obstruction. Pp. 19-33 in Pathophysi- 
ology of Respiration. M.H. Kryger, ed. John Wiley \& Sons, New York, N.Y.

Mortelmans, K., S. Haworth, T. Lawlor, W. Speck, B. Tainer, and E. Zeiger. 1986. Salmonella mutagenicity tests. II. Results from testing of 270 chemicals. Environ. Mutagen. 8:1-119.

NASA. 1988-90. Postflight reports for atmospheric analysis for STS-26, STS-27, STS-28, and STS-32. JSC Toxicology Group, NASA, Johnson Space Center, Houston, Tex.

NRC. 1990. Guidelines for Developing Spacecraft Maximum Allowable Concentration for Space Station Contaminants. National Academy Press, Washington, D.C.

Obe, G., A.T. Natarajan, M. Meyers, and A.D. Hertog. 1979. Induction of chromosomal aberrations in peripheral lymphocytes of human blood in vitro and of SCEs in bone-marrow cells of mice in vivo by ethanol and its metabolite acetaldehyde. Mutat. Res. 68:291-294.

Olcott, T.M. 1972. Development of a Sorbent Trace Contaminant Control System, Including Pre- and Postsorbers for a Catalytic Oxidizer. NASA CR-2027. Johnson Space Center, Houston, Tex.

Saldiva, P.H.N., M.P. do Rio Caldeira, E. Massad, D.F. Calheiros, L.M.N. Cardosa, G.M. Bohm, and C.D. Saldiva. 1985. Effects of formaldehyde and acetaldehyde inhalation on rat pulmonary mechanics. J. Appl. Toxicol. 5:288-292.

Sax, 1. 1984. P. 74 in Dangerous Properties of Industrial Materials. Van Nostrand Reinhold, New York, N.Y.

Shiohara, E., M. Tsukada, S. Chiba, H. Yamazaki, K. Nishiguchi, R. Miyamoto, and S. Nakanishi. 1985. Effect of chronic administration of acetaldehyde by inhalation on $\left(\mathrm{Na}^{+}+\mathrm{K}^{+}\right)$-activated adenosine triphophatase activity of rat brain membranes. Toxicology 34:277- 284 .

Silverman, L., H.F. Schulte, and M.W. First. 1946. Further studies of sensory response to certain industrial solvent vapors. J. Ind. Hyg. Toxicol. 28:262-266.

Sipes, I.G. and A.J. Gandolfi. 1986. Biotransformation of toxicants. P. 73 in Casarett and Doull's Toxicology. The Basic Science of Poisons. C.D. Klaassen, M.O. Amdur, and J. Doull, eds. Macmillan, New York, N.Y.

Sreenathan, R.N. and R. Padmanabhan. 1982. Teratogenic effects of acetaldehyde in the rat. Drug Alcohol Depend. 9:339-50. 
Steinhagen, W.H. and C.S. Barrow. 1984. Sensory irritation structure-activity study of inhaled aldehydes in B6C3F1 and Swiss-Webster mice. Toxicol. Appl. Pharmacol. 72:495-503.

Stowell, A.R., R. Greenway, and R.D. Batt. 1977. Acetaldehyde formation during deproteinization of human blood samples containing ethanol. Biochem. Med. 18:392-401.

Verberk, M.M. 1977. Effects of ammonia in volunteers. Int. Arch. Occup. Environ. Health 39:73-81.

Wakasugi, C. and M. Yamada. 1988. Inhalation toxicity of acetaldehyde. Kogai to Taisaku 24:57-60.

Weber-Tschopp, A., T. Fischer, R. Gierer, and E. Grandjean. 1977. [Experimentally induced irritating effects of acrolein on men.] Int. Arch. Occup. Environ. Health 40:117-130.

White, A., P. Handler, E.L. Smith, R.L. Hill, and I.R. Lehman. 1978. Principles of Biochemistry. Pp. 449, 476, and 737. McGraw-Hill, New York, N.Y.

Woodruff, R.C., J.M. Mason, R. Valencia, and S. Zimmering. 1985. Chemical mutagenesis testing in Drosophila. V. Results of 53 coded compounds tested for the National Toxicology Program. Environ. Mutagen. 7:677-702.

Woutersen, R.A., L.M. Appelman, A. Van Garderen-Hoetmer, and V.J. Feron. 1986. Inhalation toxicity of acetaldehyde in rats. III. Carcinogenicity study. Toxicology 41:213-231.

Woutersen, R.A. and V.J. Feron. 1987. Inhalation toxicity of acetaldehyde in rats. IV. Progression and regression of nasal lesions after discontinuation of exposure. Toxicology 47:295-305. 


\section{B2 Ammonia}

King Lit Wong, Ph.D.

Johnson Space Center Toxicology Group

Biomedical Operations and Research Branch

Houston, Texas

\section{PHYSICAL AND CHEMICAL PROPERTIES}

Ammonia is a colorless gas with a sharp, burning odor (ACGIH, 1986).

Formula: $\quad \mathrm{NH}_{3}$

CAS number: 7664-41-7

Molecular weight: 17.0

Boiling point: $\quad-33.5^{\circ} \mathrm{C}$

Melting point: $\quad-77,7^{\circ} \mathrm{C}$

Vapor pressure: $8.5 \mathrm{~atm}$ at $20^{\circ} \mathrm{C}$ for liquid $\mathrm{NH}_{3}$

Conversion factors at $25^{\circ} \mathrm{C}, 1 \mathrm{~atm}: 1 \mathrm{ppm}=0.69 \mathrm{mg} / \mathrm{m}^{3}$

$$
1 \mathrm{mg} / \mathrm{m}^{3}=1.44 \mathrm{ppm}
$$

\section{OCCURRENCE AND USE}

Ammonia can be used in coolant loops as a refrigerant. There is an internal biological source of ammonia from amino acid metabolism (White et al., 1978). It is difficult to predict the exposure levels in the spacecraft. On the shuttle, a large amount of ammonia is used in the coolant loop and it is triply contained. 


\section{PHARMACOKINETICS AND METABOLISM}

The principal internal source of ammonia is the oxidation of glutamate by glutamate dehydrogenase in tissues, in particular the liver (White et al., 1978). Minor internal sources include oxidative and nonoxidative deaminations of amino acids in the liver and kidney. Another source of ammonia is the bacterial degradation of urea in the large intestine (Diamondstone, 1982). Ammonia averages about $100 \mu \mathrm{g} / 100 \mathrm{~mL}$ in blood (Diamondstone, 1982). Once formed inside the body, ammonia is used in the syntheses of glutamine, asparagine, and carbamoyl phosphate, which is utilized in arginine synthesis (White et al., 1978).

The body eliminates ammonia in two major ways, both of which proceed indirectly via amino acid metabolism. One way is the hepatic metabolism of arginine into urea, which is excreted in the urine (White et al., 1978). The second major way is the renal metabolism of glutamine into free ammonia, which is excreted in the urine for maintaining the body's acid-base balance (Diamondstone, 1982). Ammonia could be excreted in the urine at $680 \mathrm{mg}$ or $40 \mathrm{mEq}$ per day in humans (Eastman, 1963). A minor elimination pathway is via exhalation. Ammonia vapor has been measured in the expired air from the mouth of rabbits ranging from 0.014 to $1.09 \mathrm{ppm}$ (Vollmuth and Schlesinger, 1984).

When exposed to ammonia gas, the human nose retains $83 \%$ of ammonia inhaled at a ventilation rate corresponding to light activity (Landahl and Herrmann, 1950). Being extremely water soluble, ammonia gas readily dissolves in the moisture present on the mucosa that comes in contact with it (Helmers et al., 1971; O'Kane, 1983).

\section{TOXICITY SUMMARY}

\section{Mechanisms of Tissue Injuries}

Ammonia's principal toxic effect is to irritate mucous membranes, causing burning sensation in the eyes, nose, and throat with little systemic toxicity, but sensory fatigue develops toward the irritation with continuous or repetitive exposure (Hatton et al., 1979). In accidental massive exposures, ammonia harms the tissue it comes in contact in two ways (Arwood et al., 1985). One is via the ammonium hydroxide formed when ammonia 
dissolves in the liquid lining the mucous membrane, causing liquefaction of tissues in a manner similar to that seen in alkali burns. The second mechanism of tissue injury is the release of heat in the solvation of ammonia in the liquid on the mucous membrane.

\section{Mucosal Irritation in Naive Subjects}

Ammonia's irritation response depends on whether the subject has adapted to it. Based on their experiences in manufacturing facilities for ammonia, nitrate, and urea in Italy, Vigliani and Zurlo (1956) reported that unadapted workers found 20-ppm ammonia irritating to the mucous membranes, but adapted workers did not complain of any irritating sensation upon long-term exposures to $20 \mathrm{ppm}$. However, there was a slight redness on the conjunctiva of the adapted workers after the 20-ppm exposures.

The irritation data on unadapted workers reported by other investigators are summarized here. MacEwen et al. (1970) studied the subjective irritation of a 10-min exposure of five or six unadapted human volunteers to 30 or $50 \mathrm{ppm}$ ammonia (MacEwen et al., 1970). Two of five subjects found $30 \mathrm{ppm}$ to be faintly irritating (the irritation was just perceptible, but not painful). In contrast, four of six subjects found $50 \mathrm{ppm}$ to be moderately irritating. Only one of six subjects felt that $50 \mathrm{ppm}$ was faintly irritating and this subject did not find $30 \mathrm{ppm}$ irritating (MacEwen et al., 1970). Irritation data of ammonia exposures at concentrations higher than $50 \mathrm{ppm}$, lasting longer than $10 \mathrm{~min}$, have been reported by Verberk (1977), who compared the irritation responses of eight students who did not know ammonia's toxicity with those of eight "experts" who were familiar with ammonia's toxicity. Since neither the students nor the "experts" were accustomed to ammonia's effects by personal contact before the study, the data of the two groups are combined and summarized in Table 2-1.

It can be concluded from the data of Vigliani and Zurlo (1956), MacEwen et al. (1970), and Verberk (1977) that ammonia vapor could produce irritation sensation on mucous membranes in unadapted human subjects at as low as $20 \mathrm{ppm}$. 


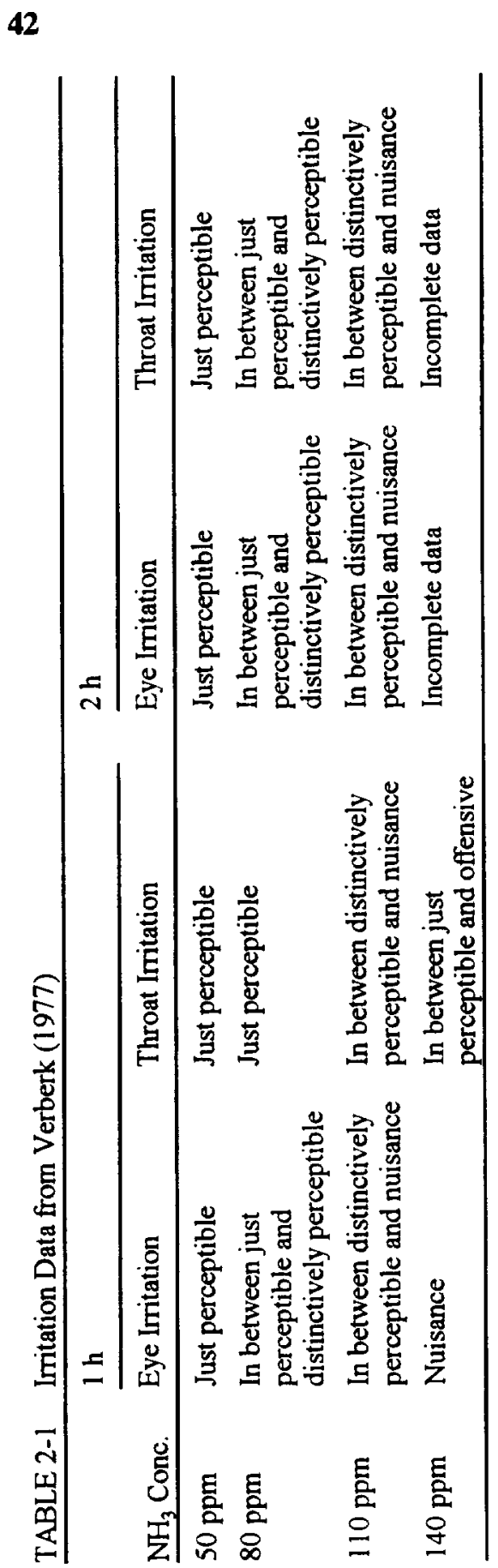




\section{Mucosal Irritation in Adapted Subjects}

Holness et al. (1989) reported that, in 58 soda ash workers, who have been continually exposed to ammonia on the job, an exposure to 9.2-ppm ammonia on the first and last workdays of their workweek did not produce any symptoms, effects on the sense of smell, or effects on lung functions, such as forced expiratory volume in $1 \mathrm{~s}$ and forced vital capacity (Douglas and Coe, 1987). Ferguson et al. (1977) showed that, in several subjects exposed to $25-100-\mathrm{ppm}$ ammonia daily for $2-6 \mathrm{~h}$ for $5 \mathrm{~d}$ in the previous week, only one of four subjects developed mild mucosal irritation (pinkish red mucosa upon examination by a physician) when exposed to $25-\mathrm{ppm}$ ammonia, $2 \mathrm{~h}$ a day for $5 \mathrm{~d}$. However, at a more severe exposure of 50pm ammonia, 4 or $6 \mathrm{~h} / \mathrm{d}$ for $5 \mathrm{~d}$, all six subjects developed mild mucosal irritation. Based on their experiences in manufacturing plants for ammonia, nitrate, and urea, Vigliani and Zurlo (1956) reported that workers, presumably adapted, could not breathe $100-\mathrm{ppm}$ ammonia for too long without developing irritation of the upper respiratory tract and the conjunctiva. In conclusion, in adapted human subjects, ammonia at $9 \mathrm{ppm}$ is not irritating, but whether $25 \mathrm{ppm}$ or $50 \mathrm{ppm}$ produces irritation symptoms is unknown. Nevertheless, based on an objective sign of irritation (mucosal erythema), $25 \mathrm{ppm}$ is barely irritating, and $50 \mathrm{ppm}$ is definitely irritating, albeit only mildly, in adapted subjects.

\section{Mucosal Irritation in Subjects Of Unknown Adaptation Status}

This section summarizes the irritation data on individuals with unknown adaptation status. Weatherby (1952) reported that five or six members of his laboratory staff, upon inhaling the exhaust from a chamber in which guinea pigs were exposed to $140-200$-ppm ammonia, gave their opinion that no person would voluntarily remain in such an atmosphere for any length of time because of the respiratory distress and disagreeable odor. Henderson and Haggard (1943) reported that it took at least 408-ppm ammonia to cause immediate throat irritation. Other reports indicate that ammonia could produce immediate eye injury at $700 \mathrm{ppm}$ and laryngospasm at $1700 \mathrm{ppm}$ (Helmers et al., 1971; Grant, 1974). Death is possible at 2500 ppm (Helmers et al., 1971). 


\section{Toxic Effects of Massive Exposures}

As the exposure concentration increases, ammonia affects not only the upper airways, it can also cause pulmonary or alveolar injuries (Hatton et al., 1979). All our knowledge of the toxic effects of ammonia at high concentrations in humans is generated from our experiences with accidental ammonia releases, in which there are no data on the exposure concentrations. However, via qualitative characterization of the exposure and response, the toxic effects of massive ammonia exposures can be separated into six groups.

Most accidental ammonia releases involved a rupture of refrigerant storage tanks, tank trucks, or railroad tank cars containing many gallons of anhydrous liquid ammonia (Price et al., 1983; Close et al., 1980; Montague and Macneil, 1980; Kass et al., 1972; Flury et al., 1983). In the first group of cases, the victims were situated close enough to the ruptured tank that they came in direct contact with anhydrous ammonia and also inhaled the ammonia vapor at presumably very high concentrations (Close et al., 1980). According to Close et al., victims in this group died shortly afterward with severe chemical burns over most of the body, full-thickness chemical burns of the entire tracheobronchial tree, and extensive pulmonary edema.

In the second group, the fatal course was more prolonged than in the first group (Arwood et al., 1985; Price et al., 1983). Immediately after the accident, the victims developed chemical burns over the face, eyes, oropharynx, back, and legs. Arwood et al. reported that some of them rapidly developed corneal opacities. Within a day, according to Price et al., some of them were coughing up large quantities of greenish mucus. Both studies reported severe respiratory distress, tachypnea, dyspnea, pulmonary edema, crackles or wheezing over the lung fields, and bilateral pulmonary infiltrates in chest $x$-ray. Hypoxemia began in the first or second day and remained until death. The hypoxemia showed a variable course of steady deterioration, oscillating between deterioration and improvement, or remaining constant with time. The victims died in $10 \mathrm{~d}$ to $12 \mathrm{w}$. The two victims who died in 10-16 d were oliguric a few days before death, and their autopsies showed lung congestion with purulent exudates in smaller bronchi, necrotizing bronchitis with ulceration and membrane formation, and severe intraalveolar fibroblastic proliferation (Arwood et al., 1985). For the victim who died $12 \mathrm{w}$ after the exposure, an autopsy revealed 
patchy ulceration and squamous metaplasia of bronchi, whose mucosa were partially replaced by granulation tissue, bronchiectasis, peribronchiolar fibrosis, patchy congestion and edema of the alveolar region (Price et al., 1983). Similarly, Kass et al. (1972) reported radiological studies showing bronchiectatic changes in two victums 2 y after a massive exposure to ammonia. Unlike the victims who died in 10-16 d in the study of Arwood et al. (985), Price et al. (1983) reported that the victim who died in $12 \mathrm{w}$ did not have fibrosis of the alveolar region. This victim also developed severe airflow obstruction, which got worse with time, in the last $8 \mathrm{w}$. Airflow obstruction was also detected by Kass et al. (1972) and Flury et al. (1983) in three victims 1-2 y after a massive exposure to ammonia.

The victims of the remaining three groups did not die from the ammonia exposure. The third group of victims were also exposed to anhydrous ammonia cutaneously and to ammonia vapor via inhalation, but they survived. They sustained chemical burns of the face and the mucous membranes of the upper airway (Close et al., 1980). There was also acute upper airway obstruction. Close et al. postulated that the upper airway obstruction might have protected the remainder of the tracheobronchial tree from the harmful effects of ammonia vapor. Although the acute airway obstruction was life-threatening, the victims probably did not die from that because they were rescued and hospitalized after less than $30 \mathrm{~min}$ of exposure, when emergency airways were created for them (Close et al., 1980). These victims developed inspiratory wheezing, rhonchi, and rales. They recovered in 1-2 mo and did not develop any pulmonary sequelae afterward.

The fourth group of victims were in the vicinity of the ruptured tank without coming in direct contact with the liquid ammonia, but they did inhale the gaseous ammonia for longer than $30 \mathrm{~min}$ (Close et al., 1980). Close et al. reported that they all had first-degree chemical burns of the eyes, face, and exposed skin, but they had no acute upper airway obstruction. Initially the victims appeared to have sustained very little internal injuries because, upon hospital admission, both the chest examination and $x$-ray were normal and only one of nine of the victims developed hypoxemia. Because the victims did not develop upper airway obstruction acutely, their lungs were not protected against ammonia at concentrations too low to cause acute lung damage but sufficient to lead to insidious lung damage. During the next 2 to $6 \mathrm{mo}$, obstructive pulmonary function gradually developed, followed by a slight improvement and then stabiliza- 
tion. The moderate obstructive pulmonary function with considerable bronchoalveolar perfusion deficits remained constant for the next 2 y (Close et al., 1980).

Both the fifth and sixth groups of victims were exposed to high concentrations of gaseous ammonia for several seconds to several minutes (Montague and Macneil, 1980). Montague and Macneil reported that in day 1 both groups had inflammation of conjunctiva and pharynx, pain in the pharynx and chest, cough, and dyspnea, but there were no chest $x$-ray abnormalities. The major difference between the fifth and sixth groups was their results in chest examinations. Based on this study, Montague and Macneil concluded that, in terms of predicting the clinical course of ammonia inhalation, chest $x$-ray is of little value, and chest examinations are much more important (Montague and Macneil, 1980). In chest examinations, the fifth group exhibited abnormalities, such as rales, rhonchi, or wheezing, while the sixth group had no abnormalities. The fifth group developed moderate hypoxemia, but the sixth group had only mild hypoxemia. In addition, the fifth group had tachypnea and tachycardia. The sixth group recovered on the second day after the exposure. In contrast, the fifth group developed airway obstruction and productive cough in the next several days. The fifth group finally recovered about $1 \mathrm{w}$ after the exposure (Montague and Macneil, 1980).

In summary, massive ammonia exposures usually cause chemical burns of the face, eyes, pharynx, or even the torso; some degree of mucosal injury of the tracheobronchial tree; productive cough; and hypoxemia. Airway obstruction is produced either acutely or as a sequelae. If the exposure is severe, there can be deep lung injuries, resulting in acute rales, rhonchi, or wheezing and bronchiectasis later.

\section{Animal Models of Ammonia's Respiratory Damage}

Niden (1968) demonstrated ultrastructural damage to the respiratory system of mice exposed to an extremely high concentration of ammonia, an exposure probably similar to that of the first group of human victims. He exposed mice to $28 \%$ ammonia, which killed the mice in 3 to $60 \mathrm{~min}$. $\mathrm{He}$ found an increase in the number of secretory granules in Clara cells and the ballooning of Clara cells. Mitochondrial and endoplasmic swelling in 
type II pneumocytes, extensive swelling of the alveolar epithelium with edema fluid, and intracapillary platelet thrombosis in the lung also occurred.

The biphasic nature of ammonia's damage to the respiratory system seen in the fourth group of human victims has been reproduced somewhat by Dodd and Gross (1980) in cats exposed to $1000 \mathrm{ppm}$ ammonia for $10 \mathrm{~min}$. In the first day after exposure, the cats exhibited necrotizing bronchitis primarily in the large bronchi, but the bronchioles were hardly damaged and the centriacinus was normal, indicating that the bronchoconstriction reflexes protected deep parts of the lung. Pulmonary function reflected the pathology in these cats. Increases in the work of breathing, airway resistance, and pulmonary tissue resistance agreed with pathological changes in the air conducting pathways, and a lack of change in the functional residual capacity agreed with the lack of central lung damage. On the seventh day after exposure, the mucosal lesions were healed, but pulmonary congestion, edema, and interstitial emphysema still existed. The increases in the work of breathing and airway resistance disappeared on the seventh day. However, both pulmonary resistance and pulmonary tissue resistance were increased. On the 21 st day after exposure, bronchitis, bronchiolitis, early bronchopneumonia, and scattered bulbous emphysema had developed, which the investigators felt represented sequelae of the initial chemical insult (Dodd and Gross, 1980). Even though there were no differences, compared with the values before exposure, in airway resistance, increases were seen in the functional residual capacity, work of breathing, pulmonary resistance, and pulmonary tissue resistance on the 21 st day (Dodd and Gross, 1980).

\section{Metabolic Acidosis}

Although mucosal irritation is its major toxicity, ammonia could cause a systemic effect. Manninen et al. (1988) exposed rats to ammonia at 25 or $300 \mathrm{ppm}, 6 \mathrm{~h} / \mathrm{d}$ for 5,10 , or $15 \mathrm{~d}$. They found metabolic acidosis after $5 \mathrm{~d}$ of exposure at both concentrations. However, the metabolic disturbance is not long lasting because it disappeared in later time points. After a 15-d exposure to 25 or $300 \mathrm{ppm}$, Manninen et al. failed to find any treatmentrelated histopathology in the lung, liver, and kidney. 


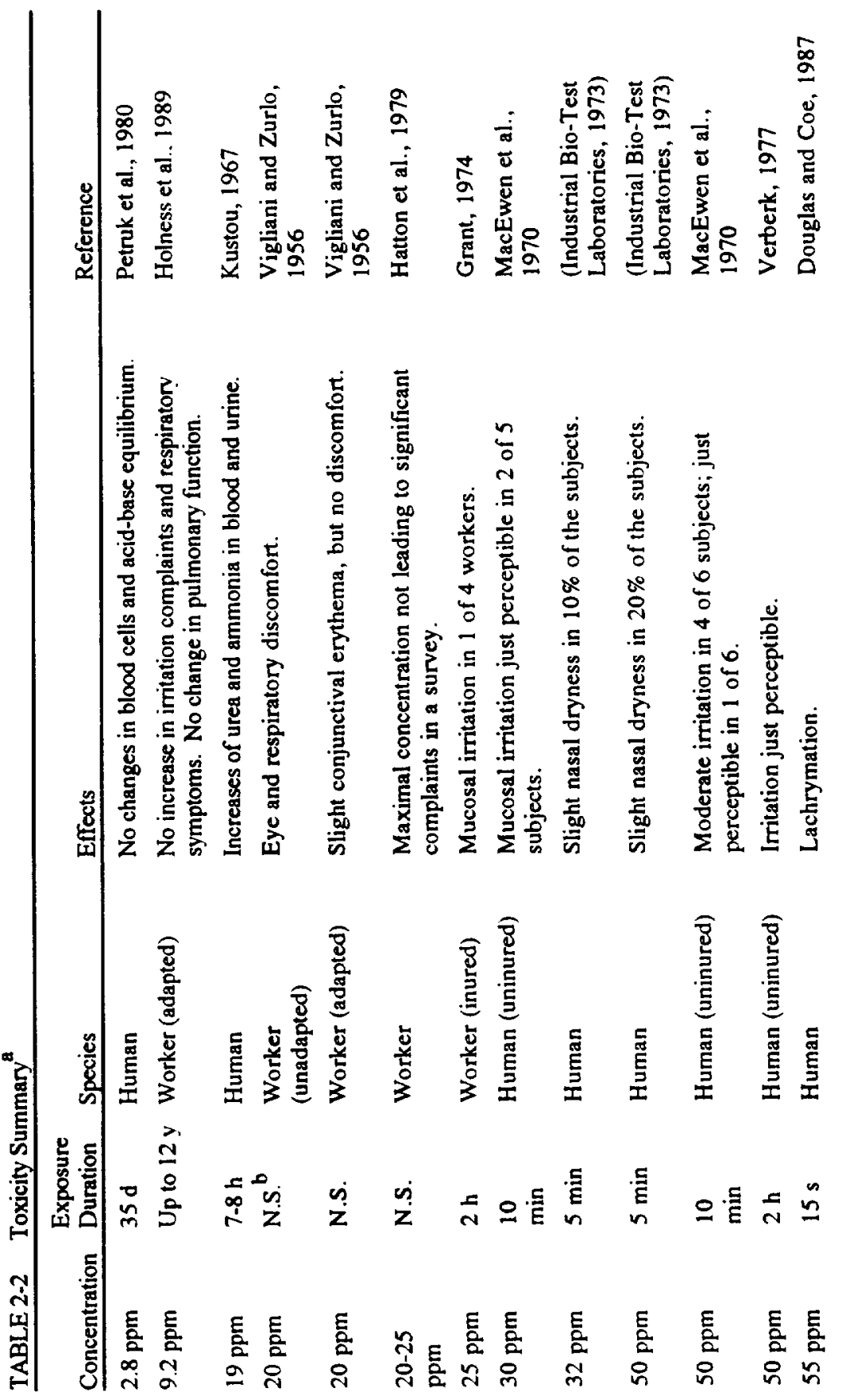




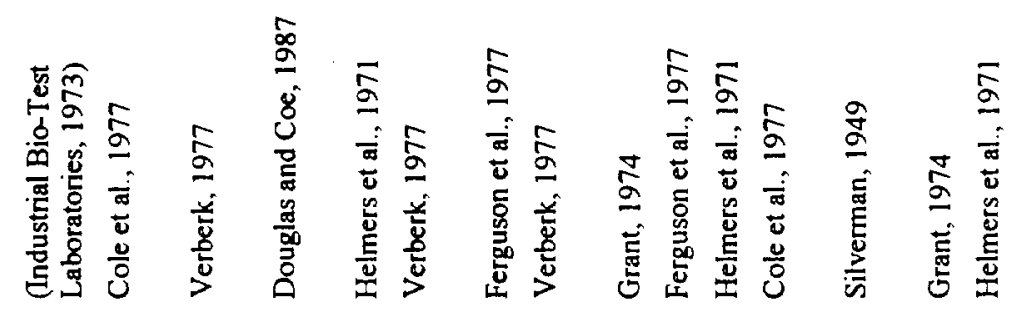
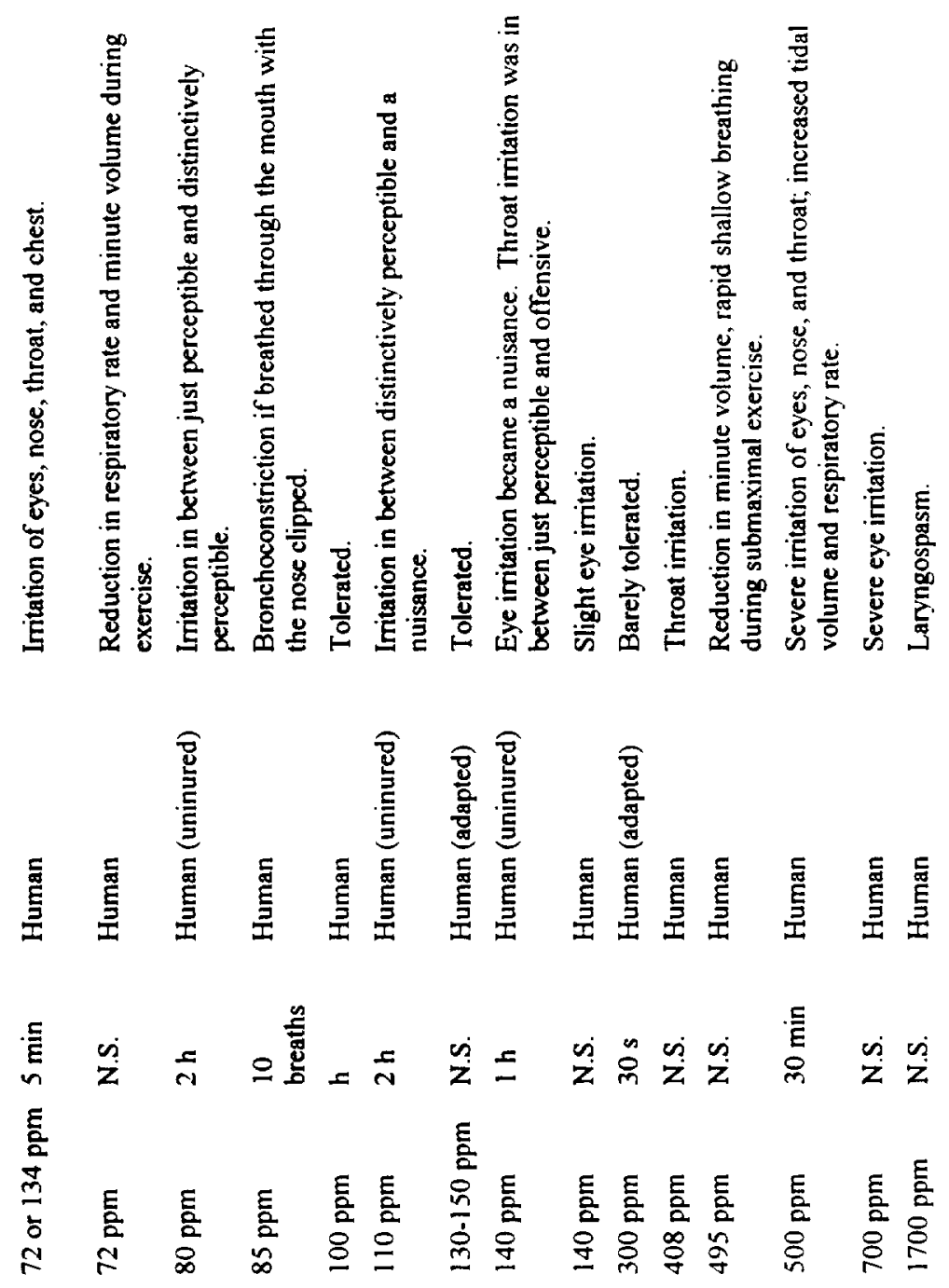


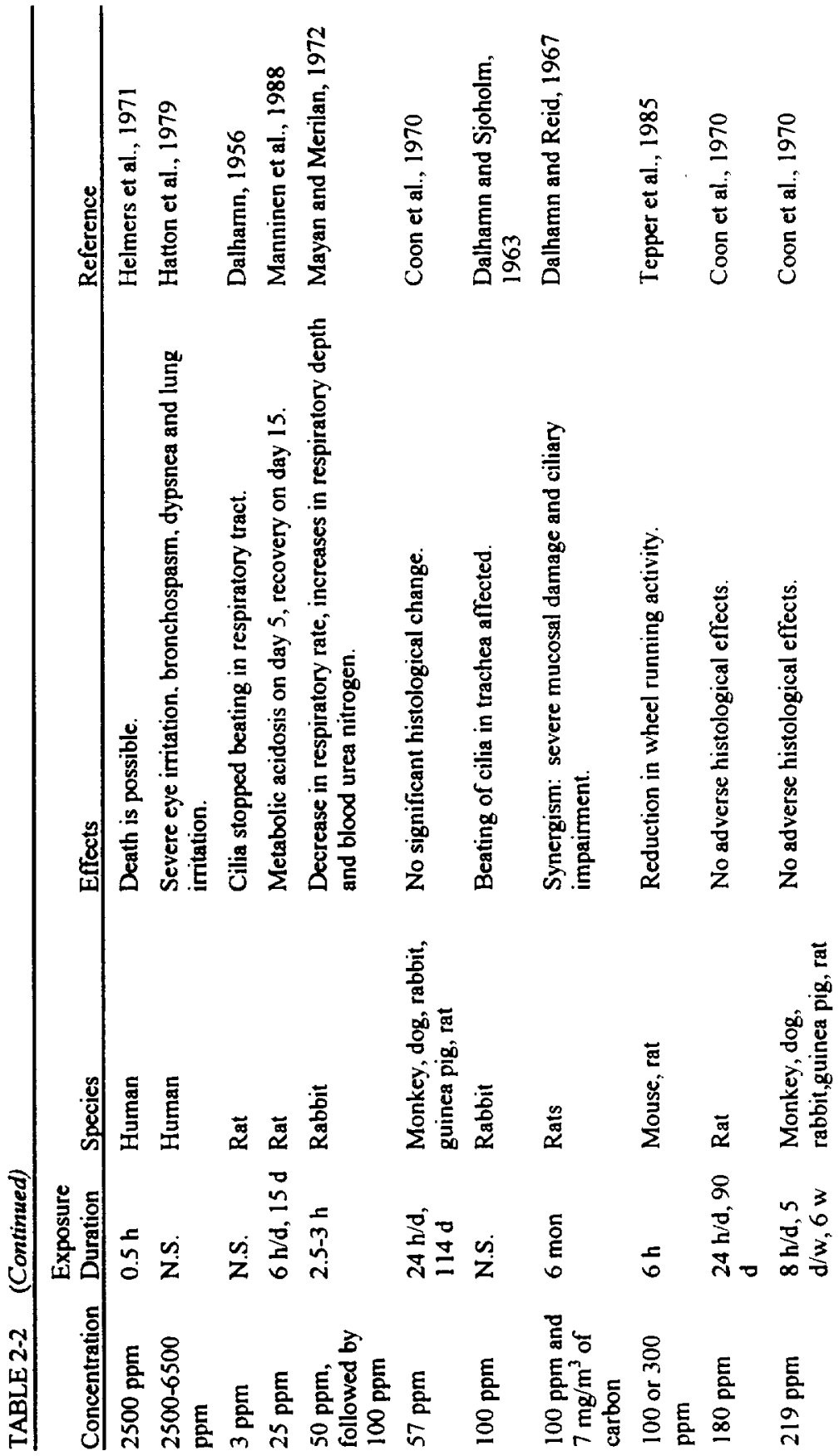




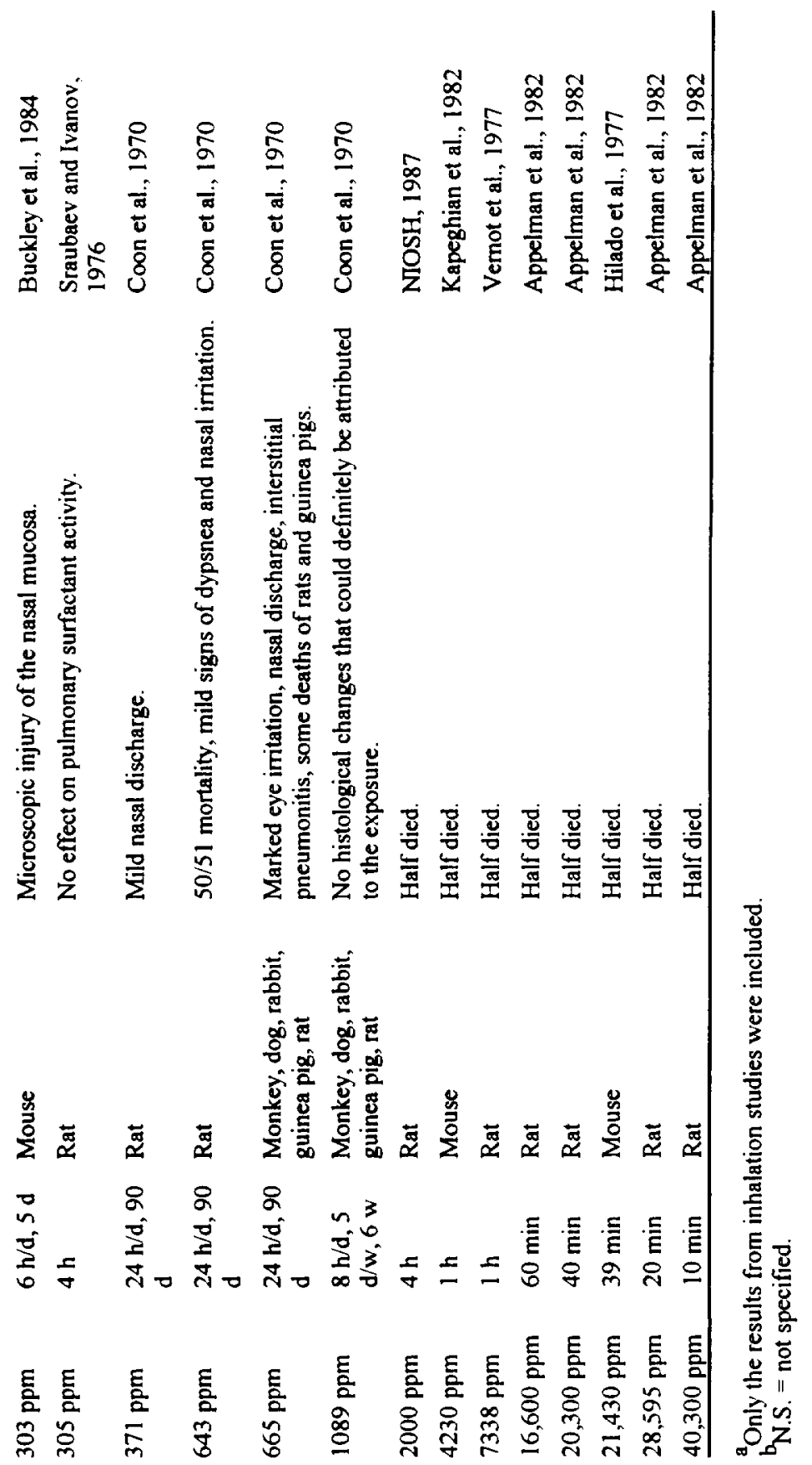


TABLE 2-3 Exposure Limits Set by Other Organizations

\begin{tabular}{ll}
\hline Organization & Concentration, ppm \\
\hline ACGIH's TLV & 25 (TWA) \\
OSHA's PEL & 50 (TWA) \\
NIOSH's REL & 50 (5-min ceiling) \\
NIOSH's IDLH & 50 \\
NRC's 1-h EEGL & 100 \\
NRC's 24-h EEGL & 100 \\
NRC's CEGL & 50 \\
\hline
\end{tabular}

TLV $=$ threshold limit value. TWA $=$ time-weighted average. $\quad$ PEL $=$ permissible exposure limit. $\mathrm{REL}=$ recommended exposure limit. $\mathrm{IDLH}=$ immediately dangerous to life and health. EEGL $=$ emergency exposure guidance level. $\mathrm{CEGL}=$ continuous exposure guidance level.

TABLE 2-4 Spacecraft Maximum Allowable Concentrations

\begin{tabular}{llll}
\hline Duration $^{\mathrm{a}}$ & $\mathrm{ppm}$ & $\mathrm{mg} / \mathrm{m}^{3}$ & Target Toxicity \\
\hline $1 \mathrm{~h}$ & 30 & 20 & Irritation \\
$24 \mathrm{~h}$ & 20 & 14 & Irritation \\
$7 \mathrm{~d}^{\mathrm{b}}$ & 10 & 7 & Irritation \\
$30 \mathrm{~d}$ & 10 & 7 & Irritation \\
$180 \mathrm{~d}$ & 10 & 7 & Irritation \\
\hline
\end{tabular}

These SMACs are ceiling values.

${ }^{b}$ The current $7-\mathrm{d}$ SMAC $=25 \mathrm{ppm}$.

\section{RATIONALE}

The SMACs for ammonia should be set based on mucosal irritation, which is the major toxic end point of ammonia inhalation at low-to-moderate concentrations. Vigliani and Zurlo (1956) noted that the adaptation status of workers played an important role in ammonia's irritation response. Based on their industrial experiences (they studied the health effects in workers and measured the ammonia concentrations in various industrial plants), Vigliani and Zurlo reported that 20-ppm ammonia could produce eye and nose discomfort in unadapted workers, but no complaints in adapted workers. Although $20 \mathrm{ppm}$ elicited no complaints from the 
adapted workers, there was conjunctival erythema (Vigliani and Zurlo, 1956). That means ammonia can cause mild inflammation in a person who has adapted to ammonia's irritation sensation. Therefore, the irritation sensation of adapted workers should not be used to set SMACs for ammonia because unadapted astronauts could be sensitive to levels tolerated by adapted workers. Consequently, in setting the SMACs, an emphasis is placed on irritation data on unadapted subjects.

\section{1-h SMAC and 24-h SMAC}

The 1-h and 24-h SMACs are intended for emergencies, so a potential of some discomfort is acceptable. However, the 1-h and 24-h SMACs should not be set at levels that produce more than slight mucosal irritation.

In eight uninured human volunteers studied by Verberk, 50-ppm ammonia was found to cause irritation that was, on the average, "just perceptible" in $2 \mathrm{~h}$ (Verberk, 1977). When the individual eye-irritation responses of the eight uninured volunteers exposed to 50-ppm ammonia for $2 \mathrm{~h}$ in Verberk's study were examined, it was discovered that the individual responses ranged from "no sensation," "just perceptible," "distinctively perceptible," to "nuisance." Although none of the eight uninured volunteers experienced "offensive" eye irritation in the 2-h exposure at $50 \mathrm{ppm}$, it is obvious that $50 \mathrm{ppm}$ could be irritating in some people.

Without citing any data, Ellenhorn and Barceloux (1988) stated that, upon an ammonia exposure, "eye and nasal irritation begins near $50 \mathrm{ppm}$."

According to Ellenhorn and Barceloux, ammonia concentrations below 50 ppm should be nonirritating. However, the lack of data support casts doubt on the accuracy of the statement of Ellenhorn and Barceloux. Indeed, there were investigators who contradicted their statement by reporting irritation at ammonia concentrations below $50 \mathrm{ppm}$. For instance, MacEwen et al. (1970) reported that 30-ppm ammonia caused just perceptible mucosal irritation in two of five uninured human subjects in $10 \mathrm{~min}$. Ferguson et al. (1977) cited an industrial hygiene report made by Mangold at the Puget Sound Naval Shipyard that workers engaged in diazo copying complained of discomfort and annoyance with $20 \mathrm{ppm}$ of ammonia. Vigliani and Zurlo (1956) also reported that 20-ppm ammonia could cause eye and respiratory discomfort in unadapted workers. These human data on ammonia's mucosal irritation are tabulated in Table 2-5. 
TABLE 2-5 Ammonia's Mucosal Irritation in Humans

\begin{tabular}{lllll}
\hline $\begin{array}{l}\text { Concen- } \\
\text { tration, ppm }\end{array}$ & Time & $\begin{array}{l}\text { Exposed } \\
\text { Subjects }\end{array}$ & Effect & Reference \\
\hline 20 & Occupational & $\begin{array}{l}\text { Unadapted } \\
\text { workers in manu- } \\
\text { facturing plants } \\
\text { for } \mathrm{NH}_{3}, \text { nitrate, } \\
\text { and urea } \\
\text { Workers in a } \\
\text { naval shipyard }\end{array}$ & $\begin{array}{l}\text { Eye and } \\
\text { respiratory } \\
\text { discomfort }\end{array}$ & $\begin{array}{l}\text { Vigliani and } \\
\text { Zurlo, 1956 }\end{array}$ \\
20 & $\begin{array}{l}\text { Discomfort } \\
\text { and } \\
\text { annoyance }\end{array}$ & $\begin{array}{l}\text { Ferguson et } \\
\text { al., 1977 }\end{array}$ \\
30 & Occupational & $\begin{array}{l}\text { Irritation just } \\
\text { perceptible }\end{array}$ & $\begin{array}{l}\text { MacEwen et } \\
\text { al., 1970 }\end{array}$ \\
\hline
\end{tabular}

Because 30-ppm ammonia caused only just perceptible irritation in 10 $\mathrm{min}$, it is not expected to produce more than mild irritation in $1 \mathrm{~h}$. The $1-\mathrm{h}$ SMAC is, therefore, set at $30 \mathrm{ppm}$. Although some irritation is acceptable for the 24-h SMAC, it should be set lower than the 1-h SMAC to reduce the degree of slight irritation astronauts have to endure in a 24-h contingency. Since $20-\mathrm{ppm}$ ammonia has been shown to produce only eye and nose discomfort in workers (Vigliani and Zurlo, 1956; Ferguson et al., 1977), the 24-h SMAC is set at $20 \mathrm{ppm}$.

It should be noted that, even though the 1-h SMAC was based on the response in only five subjects, no adjustment for a "small $n$ " is needed owing to the fact that a certain degree of mucosal irritation is acceptable in a 1-h or 24-h contingencies, so a smaller margin of safety is acceptable in the derivation of the 1-h and 24-h SMACs based on irritation.

\section{7-d SMAC}

There are no data on the effect of ammonia on humans after long-term continuous exposures. A continuous exposure to ammonia at $57 \mathrm{ppm}$ for $114 \mathrm{~d}$ or $180 \mathrm{ppm}$ for $90 \mathrm{~d}$ produced no adverse histological effects on monkeys, dogs, rats, and rabbits (Coon et al., 1970). However, the 7-d, 30-d, and 180-d SMACs are not set relying on these animal data because the data provide no information on irritation sensation of ammonia. 
The 7-d SMAC should be set at the maximum nonirritating level. Unfortunately, there are no data on that level. We know that $20 \mathrm{ppm}$ caused some discomfort in workers in Italy (Vigliani and Zurlo, 1956), so the 7-d SMAC should be lower than $20 \mathrm{ppm}$. Although $20 \mathrm{ppm}$ is the lowest-observed-adverse-effect level (LOAEL), the traditional factor of 10 to derive a no-observed-adverse-effect level (NOAEL) from a LOAEL will not be used because there are concentration-response data. In the study of Verberk, when the 1-h ammonia concentration was reduced $43 \%$ from 140 ppm to $80 \mathrm{ppm}$, the eye irritation went from "nuisance" to between "just perceptible" and "distinctly perceptible" (Verberk, 1977). In the same study, a $37 \%$ decrease in ammonia concentration from $80 \mathrm{ppm}$ to $50 \mathrm{ppm}$ caused the irritation sensation to drop from being between "just perceptible" and "distinctively noticeable" to "just noticeable." In another report, as the 10-min inhalation concentration is reduced by $40 \%$ from $50 \mathrm{ppm}$ to $30 \mathrm{ppm}$, the irritation decreases from "moderate" to "just perceptible" (MacEwen et al., 1970). Although the irritation effects were characterized subjectively and qualitatively in these studies, as long as we compare the effects within the same study group, the qualitative differences should give us an idea of the concentration response of ammonia. From these comparisons, it can be concluded that a $50 \%$ reduction of the 20 -ppm discomfort level (Vigliani and Zurlo, 1956) should yield a level that does not produce irritation or discomfort. Ten parts per million is selected as the 7-d NOAEL.

Because the 7-d NOAEL was derived from the experience of Vigliani and Zurlo with workers in various manufacturing plants with ammonia exposures in Italy (Vigliani and Zurlo, 1956), the NOAEL is based on a sufficiently large human population, requiring no "small $n$ " adjustment. Accordingly, the 7-d SMAC is set at the 7-d NOAEL of $10 \mathrm{ppm}$.

\section{0-d SMAC and 180-d SMAC}

Because of adaptation, a level that is nonirritating in $7 \mathrm{~d}$ should remain nonirritating up to $180 \mathrm{~d}$. Consequently, the 30-d and 180-d SMACs are also set at $10 \mathrm{ppm}$. Ten parts per million appears to be appropriate because workers exposed to ammonia at $9.2 \mathrm{ppm}$ for up to $12 \mathrm{y}$ did not complain of irritation any more than nonexposed workers did (Holness et 
al., 1989). Finally, because mucosal irritation is a surface response, the SMACs need not be adjusted for any microgravity-induced physiological changes.

\section{REFERENCES}

ACGIH. 1986. Threshold Limit Values and Biological Exposure Indices for 1986-87. American Conference of Governmental Industrial Hygienists, Cincinnati, Ohio.

Appelman, L.J., W.F. ten Berge, and P.G.J. Reuzel. 1982. Acute inhalation toxicity study of ammonia in rats with variable exposure periods. Am. Ind. Hyg. Assoc. J. 43:662-665.

Arwood, R., J. Hammond, and G. Gillon. 1985. Ammonia inhalation. Trauma 25:444-447.

Buckley, L.A., X.Z. Jiang, R.A. James, K.T. Morgan, and C.S. Barrow. 1984. Respiratory tract lesions induced by sensory irritants at the $R_{50}$ concentration. Toxicol. Appl. Pharmacol. 74:417- 429.

Close, L.G., F.I. Catlin, and A.M. Cohn. 1980. Acute and chronic effects of ammonia burns of the respiratory tract. Arch. Otolaryngol. 106:151-158.

Cole, T.J., J.E. Cotes, G.R. Johnson, H.D. Martin, J.W. Reed, and J.E. Saunders. 1977. Ventilation, cardiac frequency and pattern of breathing during exercise in men exposed to 0-chlorobenzylidene melononitrile (CS) and ammonia gas in low concentrations. Q.J. Exp. Physiol. Cogn. Med. Sci. 62:341-51.

Coon, R.A., R.A. Jones, L.J. Jenkins, Jr., and J. Siegel. 1970. Animal inhalation studies on ammonia, ethylene glycol, formaldehyde, dimethylamine, and ethanol. Toxicol. Appl. Pharmacol. 16:646-655.

Dalhamn, T. 1956. Mucous flow and ciliary activity in the trachea of healthy rats and rats exposed to respiratory irritant $\left(\mathrm{SO}_{2}, \mathrm{NH}_{3}, \mathrm{HCHO}\right)$. VIII. The reaction of the tracheal ciliary activity to single exposure to respiratory irritant gases and studies of the pH. Acta Physiol. Scand. Suppl. 123:93-97.

Dalhamn, T. and L. Reid. 1967. P. 299 in Inhaled Particles and Vapours II. C.N. Davies, ed. Pergamon, New York, N.Y.

Dalhamn, T. and J. Sjoholm. 1963. Studies on $\mathrm{SO}_{2}$ and $\mathrm{NH}_{3}-$ Effect on ciliary activity in the rabbit trachea of single in vitro exposure and 
resorption in rabbit nasal cavity. Acta Physiol. Scand. 58:287-91.

Diamondstone, T.I. 1982. Amino acid metabolism. I. P. 544 in Textbook of Biochemistry with Clinical Correlations. T.M. Devlin, ed. John Wiley \& Sons. New York, N.Y.

Dodd, K.T. and D.R. Gross. 1980. Ammonia inhalation toxicity in cats: A study of acute and chronic respiratory dysfunction. Arch. Environ. Health 35:6-14.

Douglas, R.B. and J.E. Coe. 1987. The relative sensitivity of the human eye and lung to irritant gases. Ann. Occup. Hyg. 31:265-267.

Eastman, R.D. 1963. P. 13 in Biochemical Values in Clinical Medicine. Wright, Bristol, U.K.

Ellenhorn, M.J. and D.G. Barceloux. 1988. Airborne toxins. P. 871 in Medical Toxicology. Diagnosis and Treatment of Human Poisoning. Elsevier, New York, N.Y.

Ferguson, W.S., W.C. Koch, L.B. Webster, and J.B. Gould. 1977. Human physiological response and adaptation to ammonia. J. Occup. Med. 19:319- 326.

Flury, K.E., D.E. Dines, J.R. Rodarte, and R. Rodgers. 1983. Airway obstruction due to inhalation of ammonia. Mayo Clin. Proc. 58:389393.

Grant, W.M. 1974. Pp. 121-128 in Toxicology of the Eye. Charies Thomas, Springfield, Ill.

Hatton, D.V., C.S. Leach, A.L. Beaudet, R.O. Dillman, and N. Di Ferrante. 1979. Collagen breakdown and ammonia inhalation. Arch. Environ. Health 34:83-87.

Helmers, S., F.H. Top, and L.W. Knapp. 1971. Ammonia injuries in agriculture. J. Iowa Med. Soc. 61:271-280.

Henderson, Y. and H.W. Haggard. 1943. Noxious Gases and the Principles of Respiration Influencing Their Action. Chemical Catalog, New York, N.Y.

Hilado, C.J., C.J. Casey, and A. Furst. 1977. Effect of ammonia on Swiss albino mice. J. Combust. Toxicol. 4:385-388.

Holness, D.L., J.T. Purdham, and J.R. Nethercott. 1989. Acute and chronic respiratory effects of occupational exposure to ammonia. Am. Ind. Hyg. Assoc. J. 50:646-650.

Industrial Bio-Test Laboratories. 1973. Irritation Threshold Evaluation Study with Animals. Report to International Institute of Ammonia Refrigeration. IBT 663-03161, March 1973. 
Kapeghian, J.C., H.H. Mincer, A.B. Jones, A.J. Verlangieri, and I.W. Waters. 1982. Acute inhalation toxicity of ammonia in mice. Bull. Environ. Contam. Toxicol. 29:371-378.

Kass, I., N. Zamel, C.A. Dobry, and M. Holzer. 1972. Bronchiectasis following ammonia burns of the respiratory tract. Chest 62:282-285.

Kustou, U.U. 1967. Means of Measuring the Maximum Allowable Concentrations of Toxic Products of Natural Human Metabolism. NASA Report, Oct. 1967.

Landahl, H.D. and R.G. Herrmann. 1950. Retention of vapors and gases in the human nose and lung. Arch. Ind. Hyg. Occup. Med. 1:36-45.

MacEwen, J.D., J. Theodore, and E.H. Vernot. 1970. Human exposure to EEL concentrations of monomethylhydrazine. Proc. 1st Ann. Conf. Environ. Toxicol., AMRL-TR-70-102, Paper 23, Sept. 1970. WrightPatterson Air Force Base, Dayton, Ohio.

Manninen, A., S. Anttila, and H. Savolainen. 1988. Rat metabolic adaptation to ammonia inhalation. Proc. Soc. Exp. Biol. Med. 187: 278-281.

Mayan, M.H. and C.P. Merilan. 1972. Effects ammonia inhalation on respiration rate of rabbits. J. Animal Sci. 34:448-452.

Montague, T.J. and A.R. Macneil. 1980. Mass ammonia inhalation. Chest 77:496-498.

NIOSH. 1987. Registry of the Toxic Effects of Chemical Substances. DHHS (NIOSH) Publ. No. 87-114. National Institute for Occupational Safety and Health, Cincinnati, Ohio.

Niden, A.H. 1968. Effects of Ammonia inhalation on the terminal airways. Pp. 41-44 in Proceedings of the 11th Aspen Emphysema Conference. Aspen, Colo.

O'Kane, G.J. 1983. Inhalation of ammonia vapour. Anaesthesia 38: 1208-1213.

Petruk, Y.A., I.D. Makulova, and I.M. Suvorov. 1980. Evaluation of the effect of prolonged and continuous exposure of a human subject to low $\left(2 \mathrm{mg} / \mathrm{m}^{3}\right)$ ammonia concentrations under conditions of an airtight chamber. Gig. Tr. Prof. Zabol. 12:63.

Price, S.K., J.E. Hughes, S.C. Morrison, and P.D. Potgieter. 1983. Fatal ammonia inhalation. A case report with autopsy findings. Sa. Mediese. Tydskrif. 64:952-955.

Silverman, L. 1949. Physiological response of man to ammonia at low concentrations. J. Ind. Hyg. Toxicol. 31:74-78. 
Sraubaev, E.N. and N.G. Ivanov. 1976. [Study of the activity of the pulmonary surfactant in determining the threshold of the irritating action of industrial poisons]. Gig. Tr. Prof. Zabol. 10:47-48.

Tepper, J.S., B. Weiss, and R.W. Wood. 1985. Alterations in behavior produced by inhaled ozone or ammonia. Fund. Appl. Toxicol. 5: 1110-1118.

TLV Committee. 1986. Documentation of TLV's and BEI's. American Conference of Governmental Industrial Hygienists, Cincinnati, Ohio.

Verberk, M.M. 1977. Effects of ammonia in volunteers. Int. Arch. Occup. Environ. Health 39:73-81.

Vernot, E.H., J.D. MacEwen, C.C. Haun, and E.R. Kinkead. 1977. Acute toxicity and skin corrosion data for some organic and inorganic compounds and aqueous solutions. Toxicol. Appl. Pharmacol. 42:417423.

Vigliani, E.C. and N. Zurlo. 1956. Ehfahrungen der clinica del lavoro mit einigen maximalen arbeitsplatzkonzentrationen (MAK) ven industrieniften. Arch. Gewerbepathol. Gewerbehyg. 13:528-534.

Vollmuth, T.A. and R.B. Schlesinger. 1984. Measurement of respiratory tract ammonia in the rabbit and implications to sulfuric acid inhalation studies. Fund. Appl. Toxicol. 4:455-464.

Weatherby, J.H. 1952. Chronic toxicity of ammonia fumes by inhalation. Proc. Soc. Exp. Biol. Med. 81:300-301.

White, A., P. Handler, E.L. Smith, R.L. Hill, and I.R. Lehman. 1978. Amino acid metabolism. II. Pp 695-700 in Principles of Biochemistry. McGraw-Hill, New York, N.Y. 



\section{B3 Carbon Monoxide}

King Lit Wong, Ph.D.

Johnson Space Center Toxicology Group

Biomedical Operations Research Branch

Houston, Texas

\section{PHYSICAL AND CHEMICAL PROPERTIES}

Carbon monoxide is a colorless and odorless gas (NRC, 1985).

$$
\begin{aligned}
\text { Formula: } & \text { CO } \\
\text { CAS number: } & 630-08-0 \\
\text { Molecular weight: } & 28.0 \\
\text { Boiling point: } & -192^{\circ} \mathrm{C} \\
\text { Melting point: } & -250^{\circ} \mathrm{C} \\
\text { Conversion factors at } 25^{\circ} \mathrm{C}, 1 \mathrm{~atm}: & 1 \mathrm{ppm}=1.14 \mathrm{mg} / \mathrm{m}^{3} \\
& 1 \mathrm{mg} / \mathrm{m}^{3}=0.87 \mathrm{ppm}
\end{aligned}
$$

\section{OCCURRENCE AND USE}

Carbon monoxide $(\mathrm{CO})$ is produced inside the body via hemoglobin metabolism at a rate of $0.4 \mathrm{~mL} / \mathrm{h}$ resulting in a carboxyhemoglobin (COHb) level of about $0.4 \%$ (Coburn et al., 1965). Other than an endogenous source, $\mathrm{CO}$ can also be produced in the thermodegradation of materials containing carbon in an atmosphere containing oxygen, so gas stoves and furnaces can be sources of $\mathrm{CO}$ indoors. A COHb level of 0.6$1.0 \%$ has been reported in nonsmokers in an indoor environment (Radford et al., 1981).

Automobile exhaust is a major source of $\mathrm{CO}$ in the environment. The urban atmospheric levels of $\mathrm{CO}$ vary with the traffic patterns (Rylander

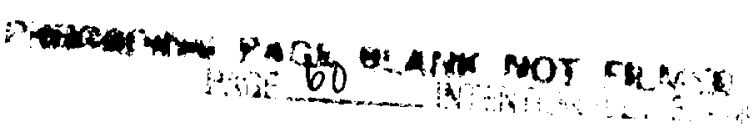


and Vesterlund, 1981). On expressways in major metropolitan areas, atmospheric CO levels commonly reach 25 ppm (Stewart, 1975). A second common source of $\mathrm{CO}$ is cigarette smoke. Most smokers who smoke a pack a day have a COHb level of 5-6\% (Stewart, 1975). There is no known use of $\mathrm{CO}$ in spacecraft, but $\mathrm{CO}$ has been predicted to be an offgas product in spacecraft (Leban and Wagner, 1989).

\section{PHARMACOKINETICS}

$\mathrm{CO}$ is absorbed rapidly in the lung at a rate of about $25.8 \mathrm{~mL} / \mathrm{min} \times$ $\mathrm{mm} \mathrm{Hg}$ (Jones et al., 1982). The minute volume, partial pressure of oxygen in the pulmonary capillary, and hemoglobin concentration are some of the major factors affecting CO absorption (EPA, 1985). More than $99 \%$ of $\mathrm{CO}$ in the body is eliminated unchanged via the lung and less than $1 \%$ is oxidized to carbon dioxide (Stewart, 1975). CO's elimination half-life is $4-5 \mathrm{~h}$ in resting subjects when breathing ambient air and $24 \mathrm{~min}$ when breathing hyperbaric oxygen.

\section{TOXICITY SUMMARY}

$\mathrm{CO}$ exerts its toxicity by binding reversibly to the heme group in hemoglobin-forming $\mathrm{COHb}$ (Laties and Merigan, 1979). Because the affinity of hemoglobin for $\mathrm{CO}$ is 200 times that for oxygen, less oxygen will be carried by hemoglobin to tissues during $\mathrm{CO}$ inhalation. The hypoxia is exacerbated by the inhibition of $\mathrm{CO}$ on the dissociation of oxygen from hemoglobin as the blood reaches the tissue (Laties and Merigan, 1979). As a result, the main toxicity targets for $\mathrm{CO}$ are the brain and heart, two organs with a critical need for oxygen.

$\mathrm{COHb}$ is cherry-red (Klaassen, 1990). Cherry-red skin has traditionally been regarded as one of the classical signs of $\mathrm{CO}$ poisoning, but some modern literature indicates that cherry-red skin might not be evident even in fatal CO intoxication (Findlay, 1988).

\section{Acute Toxicity}

This subsection summarizes the toxicity of $\mathrm{CO}$ after an exposure ranging 
from several minutes to $8 \mathrm{~h}$. CO's toxicity is generally believed to correlate with the $\mathrm{COHb}$ level (Stewart, 1975). Because an exposure to $\mathrm{CO}$ at a given concentration for a few hours will yield a COHb level similar to an exposure at a higher concentration for a shorter time (Peterson and Stewart, 1975), to simplify the picture, toxic effects are described based on the $\mathrm{COHb}$ level achieved.

A COHb level of $70 \%$ is lethal, and $50-60 \%$ leads to coma and convulsions. Headache, nausea, and vomiting are the most common symptoms of gross intoxication, and they are produced at $15-40 \% \mathrm{COHb}$ (DiMarco, 1988; Stewart et al., 1970). Myonecrosis has been reported to develop in a case of acute $\mathrm{CO}$ poisoning with a $\mathrm{COHb}$ level of $16 \%$ in the emergency room (Herman et al., 1988). CO, however, is known to produce toxicity at even lower levels.

In humans, $\mathrm{CO}$, at a $\mathrm{COHb}$ level of $7 \%$, gives a feeling of having to exert more during heavy exercise (Bunnell and Horvath, 1989) and, at $7.5 \% \mathrm{COHb}$, it causes a $23 \%$ reduction in the duration an individual can exercise maximally (Ekblom and Huot, 1972). At $3.4 \%$ or $4 \% \mathrm{COHb}$ (Horvath et al., 1975; Aronow and Cassidy, 1975), it reduces the maximal-exercise duration by only $5 \%$. A higher heart rate during exercise was detected at $7 \%$ or $5 \% \mathrm{COHb}$ (Bunnell and Horvath, 1989; Gliner et al., 1975 ), but $2.7 \%$ or $3.4 \% \mathrm{COHb}$ was found not to affect the heart rate during exercise (Horvath et al., 1975; Raven et al., 1974). CO decreases the maximal oxygen uptake during exercise at $20 \% \mathrm{COHb}$ (Vogel et al., 1972), whereas $5 \%$ or $2.7 \% \mathrm{COHb}$ has no such effect (Gliner et al., 1975; Raven et al., 1974).

$\mathrm{CO}$ inhalations could affect the heart. An acute $\mathrm{CO}$ exposure reduces the ventricular fibrillation threshold in dogs at $6.5 \% \mathrm{COHb}$ (Aronow et al., 1979a) and monkeys at 9.3\% COHb (DeBias et al., 1976). A COHb level of $6 \%$ increases the frequency of ventricular premature depolarization in patients with coronary artery diseases (Sheps et al., 1990).

There are contradictory reports on the neurological effects of low-level CO exposures in humans (Laties and Merigan, 1979). CO has been shown to impair vigilance in human subjects at a $\mathrm{COHb}$ level of 2,5 , or $6.6 \%$ (Beard and Grandstaff, 1975; Putz et al., 1979; Horvath, 1971), but no such impairment was detected at $2.3,4.8,7.1,7.5,8.2$, or $12.6 \% \mathrm{COHb}$ (Beard and Grandstaff, 1975; Christensen et al., 1977; Davies et al., 1981; Benignus et al., 1987; Benignus and Otto, 1977). Similarly, reaction time is known to be increased in humans by 5, 8.5, 10, or 12\% COHb (Putz et al., 1979; Ramsey, 1972, 1973; Ray and Rockwell, 1970), whereas no 
increase has been detected at 3.9, 7.5, 9, or $12 \% \mathrm{COHb}$ (Stewart et al., 1970; Beard and Grandstaff, 1975; Aronow et al., 1979b; Luria and McKay, 1979).

Studies have shown that CO impairs hand-eye coordination at 5 or $8.2 \%$ COHb (Putz et al., 1979; Benignus et al., 1987). On the other hand, 6.6 or $10.4 \%$ COHb had no effect on hand-eye coordination in some studies (Mikulka, 1970; O'Donnell et al., 1971). A COHb level of $4.5 \%$ has been shown to decrease the light-detection sensitivity in humans (Halperin et al., 1959), but $5,8.5,12$, or $17 \% \mathrm{COHb}$ did not affect the light detection sensitivity (Ramsey, 1972, 1973; Hudnell and Benignus, 1989). Finally, 6\% COHb was shown in one study not to affect the driving ability (McFarland, 1973), but 5.6,10, or $11 \% \mathrm{COHb}$ was found to impair the driving ability in others (Ray and Rockwell, 1970; Wright et al., 1973; McFarland, 1973).

There are many neurological functions not affected by low-level $\mathrm{CO}$ exposures in human subjects. $\mathrm{CO}$ has no effect on visual task performance at 3\% $\mathrm{COHb}$ (Putz et al., 1976), visual acuity at $17 \% \mathrm{COHb}$ (Hudnell and Benignus, 1989), night vision at $9 \% \mathrm{COHb}$ (Luria and McKay, 1979), time perception at 3.9-18\% COHb (Stewart et al., 1970; Aronow et al., 1979b; Mikulka, 1970, O'Donnell et al., 1971; Stewart et al., 1973), perceptual speed at 3.9\% COHb (Aronow et al., 1979b), depth perception at 5-12\% COHb (Ramsey, 1972; Ramsey, 1973), number facility at 3.9 or $7.5 \%$ $\mathrm{COHb}$ (Beard and Grandstaff, 1975; Aronow et al., 1979b), mental performance at 7-10\% COHb (Bender et al., 1972; Ettema and Zielhuis, 1975), short-term memory at $7.5 \% \mathrm{COHb}$ (Beard and Grandstaff, 1975), and manual dexterity at 5-12\% COHb (Stewart et al., 1970; Mihevic et al., 1983).

CO can produce latent effects on the nervous system. About $10 \%$ of the patients who have apparently recovered from a severe episode of acute $\mathrm{CO}$ poisoning might develop neurological sequelae in days or weeks (Smith and Brandon, 1973; Thom and Keim, 1989). In rats, the sciatic nerve conduction velocity is reduced $4 \mathrm{w}$ after an acute $\mathrm{CO}$ intoxication in which the $\mathrm{COHb}$ level of $19 \%$ was reached (Pankow et al., 1975).

$\mathrm{CO}$ is known to affect oxidative drug metabolism. It inhibits the cytochrome P-450 system in vitro (Estabrook et al., 1970). In rats, $60 \mathrm{ppm}$ of $\mathrm{CO}$ reduces the hepatic benzopyrene hydroxylase activity, and an exposure yielding $20 \% \mathrm{COHb}$ prolongs the hexobarbital sleeping time (Rondia, 1970; Montgomery and Rubin, 1971). $\mathrm{COHb}$ at $10-12 \%$ has been shown 
to inhibit the metabolism of hemoglobin-haptoglobin in dogs, which could be explained by CO's inhibitory effect on the cytochrome P-450 and its ability to decrease the hepatic blood flow (Coburn and Kane, 1968).

The acute toxic effects of $\mathrm{CO}$ are summarized in the following table.

TABLE 3-1 Acute Toxic Effects of $\mathrm{CO}$

\begin{tabular}{ll}
\hline Acute Toxic Effects & $\mathrm{COHb}, \%$ \\
\hline $5 \%$ reduction in exercise duration & $3.4-4.0$ \\
Reaction time increases and hand-eye impairment & 5 \\
Reduction in ventricular fibrillation threshold in dogs & 6.5 \\
Headache, nausea, and vomiting & $15-40$ \\
Decreases in maximal $\mathrm{O}_{2}$ uptake & 20 \\
Convulsions and coma & $50-60$ \\
Death & 70 \\
\hline
\end{tabular}

\section{Adaptation}

Adaptation to some of the acute effects of $\mathrm{CO}$ can develop after repeated $\mathrm{CO}$ exposures. A daily $6-\mathrm{h}$ exposure to $\mathrm{CO}$ at $230-400 \mathrm{ppm} \mathrm{CO}$ for $16 \mathrm{~d}$ reduced the severity of headache in humans (Killick, 1936, 1948). After the repeated $\mathrm{CO}$ exposures, the buildup rate of $\mathrm{COHb}$ during a subsequent acute $\mathrm{CO}$ exposure is lowered. The mechanism of this lower buildup rate of $\mathrm{COHb}$ is unknown because the repeated $\mathrm{CO}$ exposures did not change the hematocrit and blood volume in these human subjects.

A lower buildup rate of $\mathrm{COHb}$ was also seen in dogs after daily 6-h exposures to $\mathrm{CO}$ at $800-1000 \mathrm{ppm}$ for $133 \mathrm{~d}$ (Wilks et al., 1959). The lower buildup rate of $\mathrm{COHb}$ in this study was probably due to increased hematocrit and hemoglobin concentrations in the blood produced by the repeated $\mathrm{CO}$ exposures in these dogs. Even though the repeated $\mathrm{CO}$ exposure reduced the buildup rate of $\mathrm{COHb}$ during an acute $\mathrm{CO}$ challenge, the final $\mathrm{COHb}$ level achieved during the acute challenge was not affected by the repeated exposure.

There is also evidence of adaptation to the depression effects of $\mathrm{CO}$ on the central nervous system (CNS). An acute exposure to $\mathrm{CO}$ at $111 \mathrm{ppm}$ $(6.6-6.9 \% \mathrm{COHb})$ impaired the vigilance of nonsmokers, but not of smokers (O'Hanlon, 1975). CO exposure at $700 \mathrm{ppm}$ decreased the lever- 
pressing response of rats to get food pellets (Ator and Merigan, 1980). However, preconditioning with four daily $75-\mathrm{min}$ exposures to $700 \mathrm{ppm}$ of $\mathrm{CO}$ abolished this effect of $\mathrm{CO}$. A 7-d exposure to $\mathrm{CO}$ at $4000 \mathrm{ppm}$ for $10-15 \mathrm{~min} / \mathrm{d}$ increased the time it takes for $\mathrm{CO}$ at $4000 \mathrm{ppm}$ to cause coma by $50 \%$ in rats and mice (Gorbatow and Noro, 1948). A continuous exposure to $\mathrm{CO}$ at $300-2400 \mathrm{ppm}$ for $6 \mathrm{w}$ in mice has been shown to reduce the CNS depression effect of CO (Killick, 1937). In the last two studies, the adaptation could be due to increases in hematocrit and hemoglobin concentrations produced by the repeated or continuous $\mathrm{CO}$ exposure.

\section{Subchronic and Chronic Toxicity}

This subsection summarizes the toxicity produced by $\mathrm{CO}$ exposures lasting for $7 \mathrm{~d}$ or longer. In contrast to the abundance of studies on the acute neurological effects of $\mathrm{CO}$, there are no reports on its neurological effects after an exposure lasting $7 \mathrm{~d}$ or more. Stewart et al. (1970), however, reported that a $24-\mathrm{h}$ exposure to 50 -ppm $\mathrm{CO}$ (yielding $8 \% \mathrm{COHb}$ ) had no effect on response time, time perception, and manual dexterity in humans.

In a human study, a 7- or 8-d continuous exposure to $\mathrm{CO}$ at 15,50 , or $75 \mathrm{ppm}(2.4,7.1$, or $11 \% \mathrm{COHb})$ resulted in P-wave changes in the EKG (Davies and Smith, 1980). S-T-segment or T-wave changes were produced by $\mathrm{CO}$ at $75 \mathrm{ppm}$. $\mathrm{CO}$ at $75 \mathrm{ppm}$ also produced supraventricular extrasystole in one of nine subjects.

Whether $\mathrm{CO}$ exposures cause cardiovascular diseases is a question not yet resolved (Kuller and Radford, 1983). Increased mortality from arteriosclerotic heart disease was detected in New York City tunnel officers employed between 1952 and 1981 (Stern et al., 1988). The average CO concentration in the tunnels was $38 \mathrm{ppm}$ in 1981. Although this study provides epidemiological evidence that $\mathrm{CO}$ inhalation is associated with cardiac mortality, whether other automobile exhaust pollutants are responsible for the mortality is unclear (Walden and Gottlieb, 1990).

In animal studies, the $\mathrm{COHb}$ levels produced by a $\mathrm{CO}$ concentration varied with the species (Jones et al., 1971), so its toxicity in animals is discussed below mainly in terms of $\mathrm{COHb}$ levels rather than its concentrations. Subchronic or chronic $\mathrm{CO}$ exposures have been shown to increase the hemoglobin level and hematocrit in several animal species. These 
effects were detected in continuous exposures at $50 \mathrm{ppm}(7.3 \% \mathrm{COHb})$ for 6 mo in dogs (Musselman et al., 1959), $96 \mathrm{ppm}(7.5 \% \mathrm{COHb}$ ) for $90 \mathrm{~d}$ in rats (Jones et al., 1971), and $200 \mathrm{ppm}$ (16 to $20 \% \mathrm{COHb}$ ) for $90 \mathrm{~d}$ in rats and monkeys (Jones et al., 1971). These effects, however, were absent at generally lower $\mathrm{COHb}$ levels, for instance in continuous exposures at 20 ppm (3.4\% COHb) for $2 y$ in monkeys (Eckardt et al., 1972), 51 ppm (5\% $\mathrm{COHb}$ ) for $90 \mathrm{~d}$ in monkeys and rats (Jones et al., 1971), and $66 \mathrm{ppm}$ (7.4\% $\mathrm{COHb}$ ) for $2 \mathrm{y}$ in monkeys (Eckardt et al., 1972).

Long-term exposures to $\mathrm{CO}$ do not seem to have any morphological effects in laboratory animals. Continuous subchronic or chronic $\mathrm{CO}$ exposures failed to induce histopathology in dogs at $50 \mathrm{ppm}(7.3 \% \mathrm{COHb})$ for 6 mo (Musselman et al., 1959), in rats at $200 \mathrm{ppm}$ (16\% COHb) for 90 d (Jones et al., 1971), and in monkeys at $66 \mathrm{ppm}(7.4 \% \mathrm{COHb})$ for $2 \mathrm{y}$ (Eckardt et al., 1972), at $200 \mathrm{ppm}(20 \% \mathrm{COHb})$ for $90 \mathrm{~d}$ (Jones et al., 1971 ), or at $400 \mathrm{ppm}$ (32\% COHb) for $71 \mathrm{~d}$ followed by $500 \mathrm{ppm}(33 \%$ $\mathrm{COHb}$ ) for $97 \mathrm{~d}$ (Theodore et al., 1971).

Finally, continuous exposures to $\mathrm{CO}$ in gestation days 6-15 or 18 were not teratogenic in mice and rabbits at $250 \mathrm{ppm}(10-15 \% \mathrm{COHb})$ (Schwetz et al., 1979) and had no effect on fetal growth in mice at $65 \mathrm{ppm}$ (Singh and Scott, 1984). CO exposures at $125 \mathrm{ppm}$, however, retarded fetal growth in mice (Singh and Scott, 1984). In addition, a COHb level as low as $10 \%$ has been shown to decrease the birth weight and increase the newborn mortality in rabbits (Astrup et al., 1972).

\section{Synergistic Effects}

No evidence that $\mathrm{CO}$ acts synergistically with other chemicals was found. 


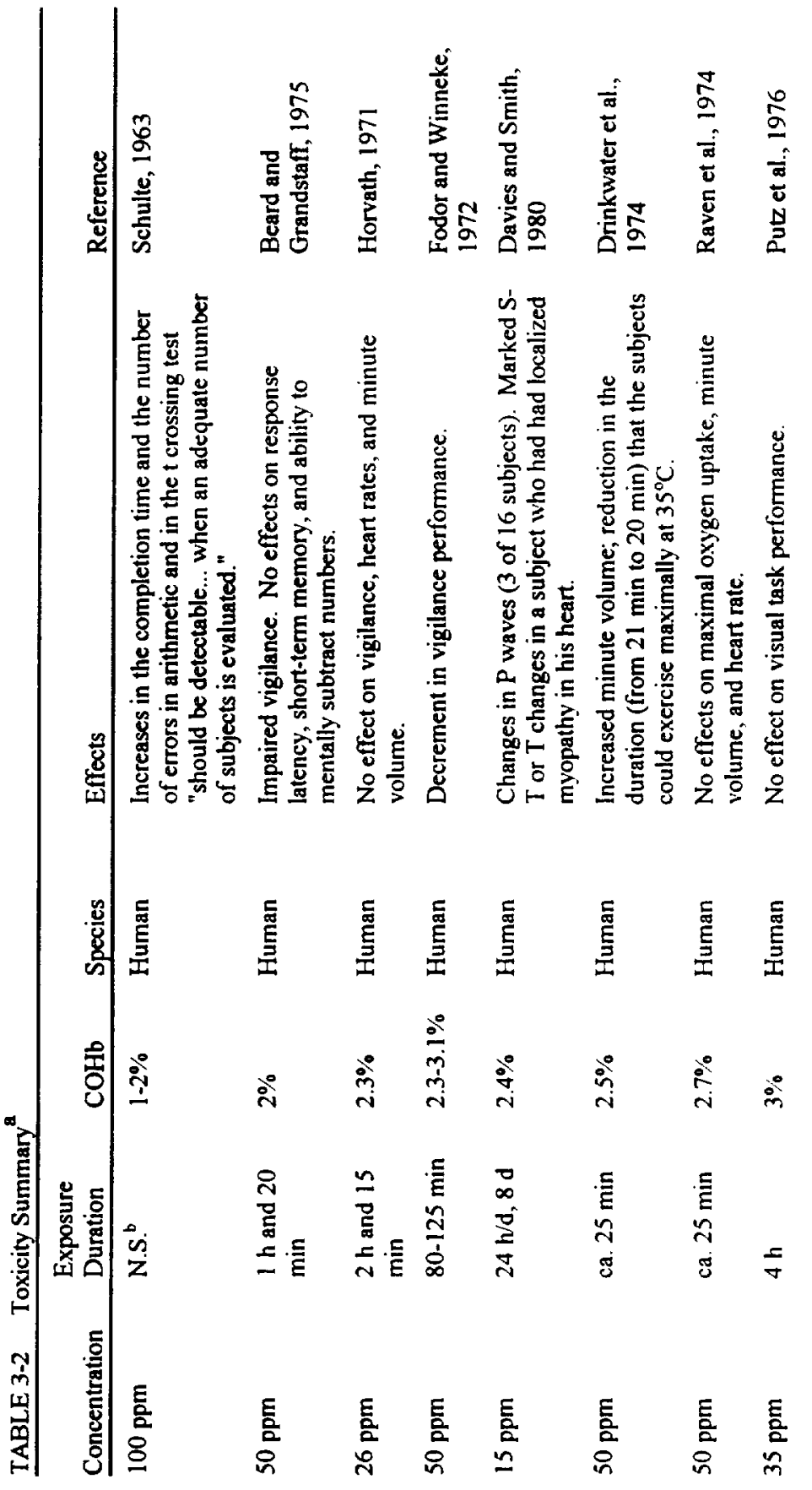



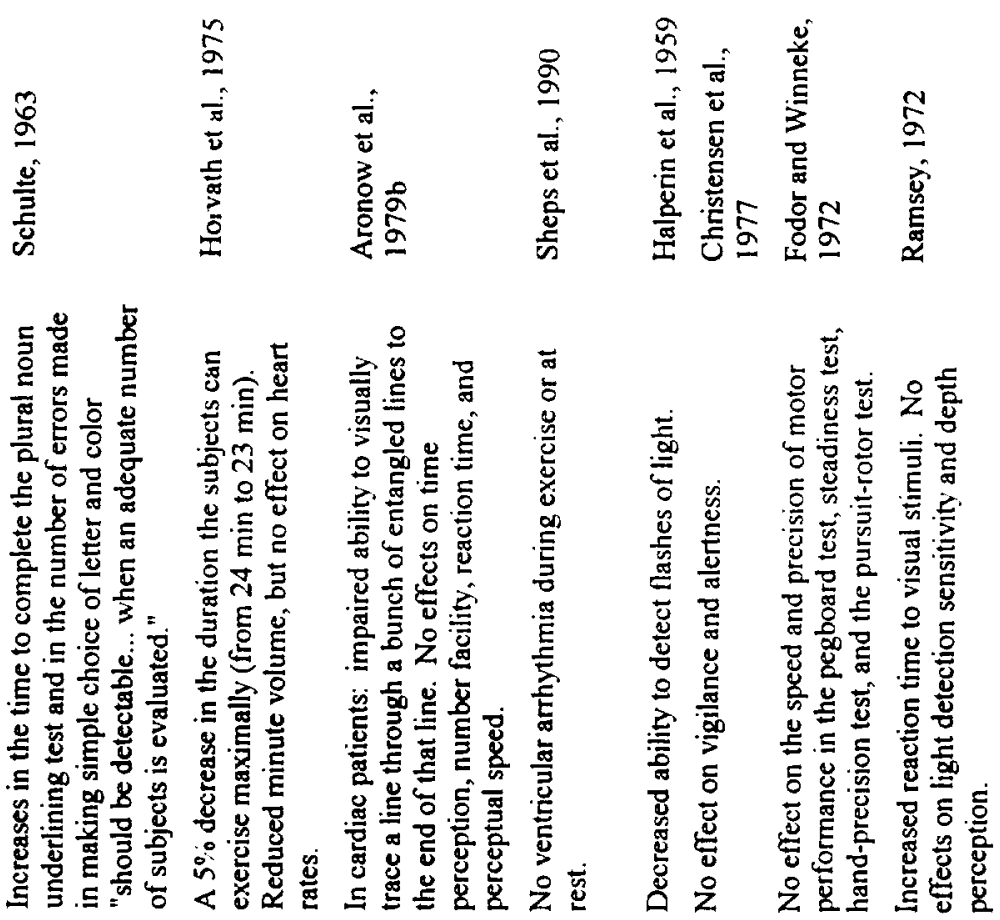
鵶

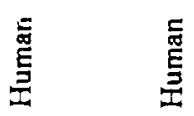

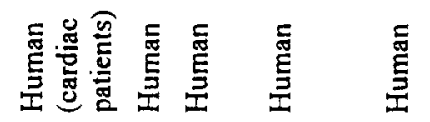

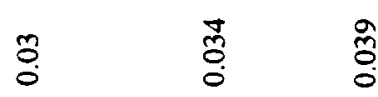
ว
sis

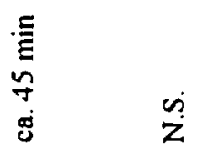

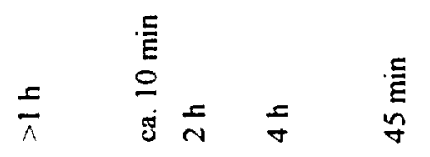
$\frac{E}{\underline{O}}$

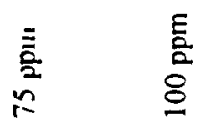

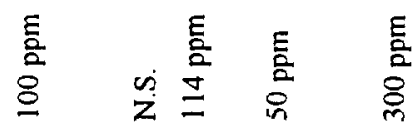




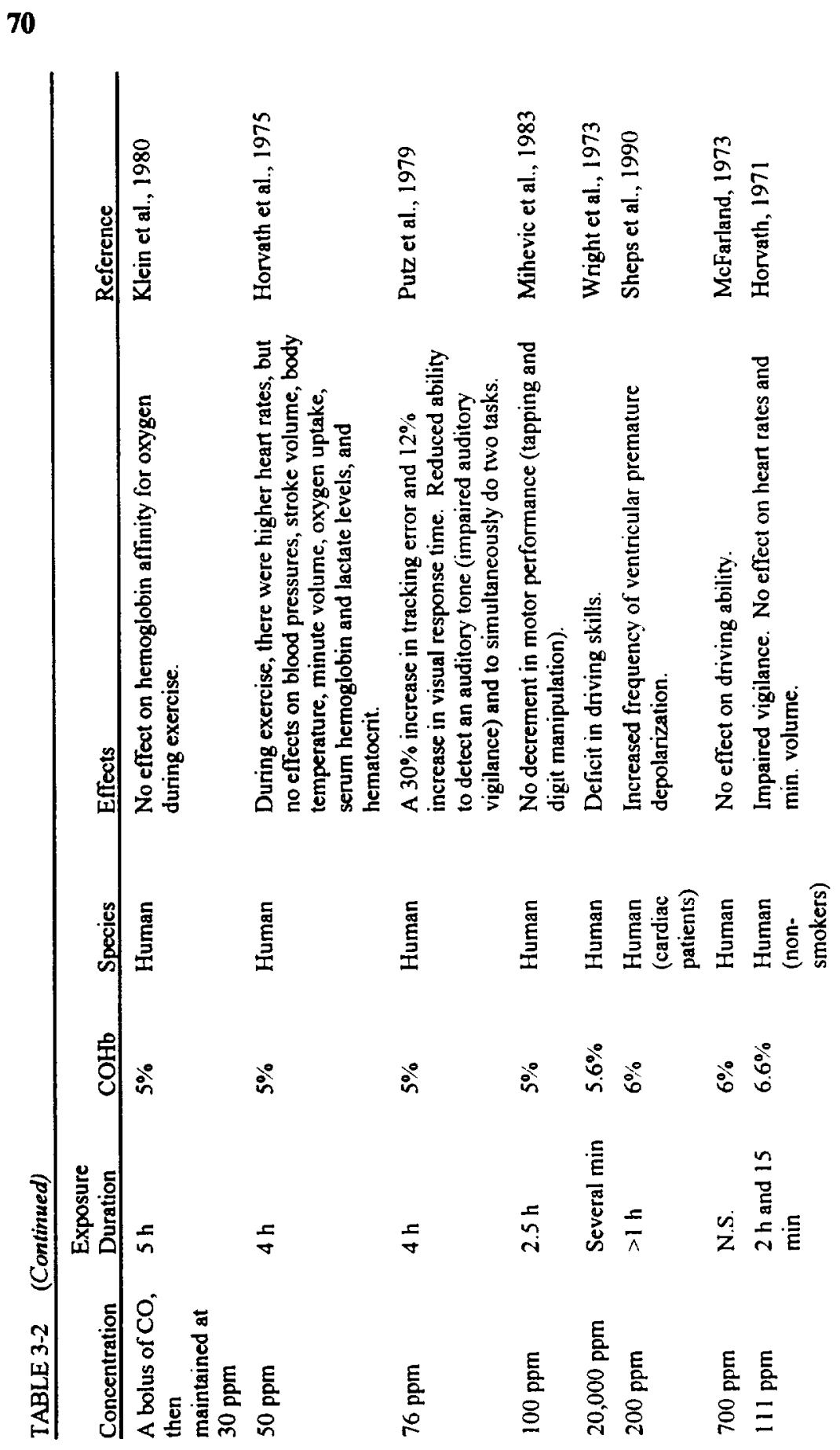




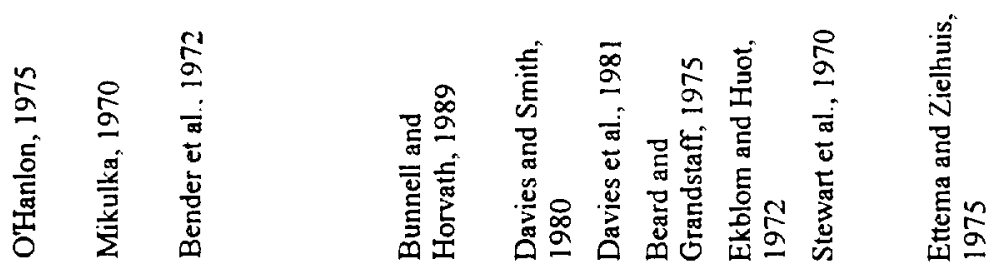

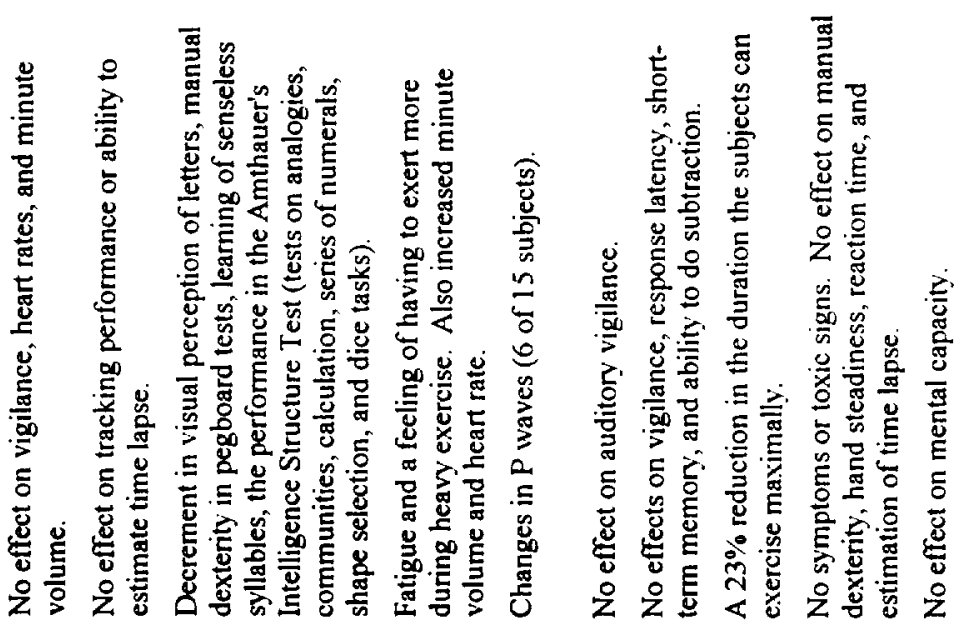

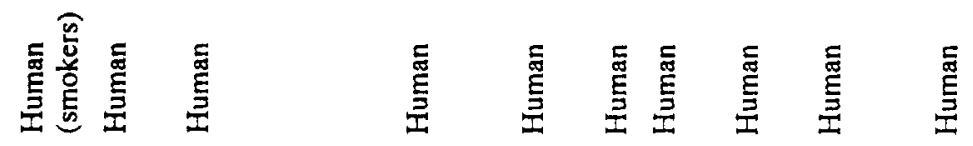

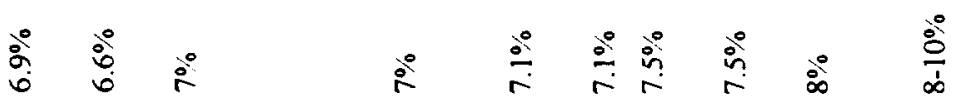

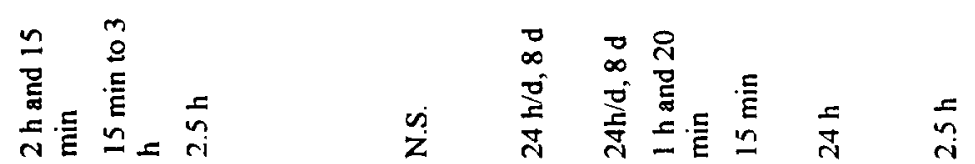

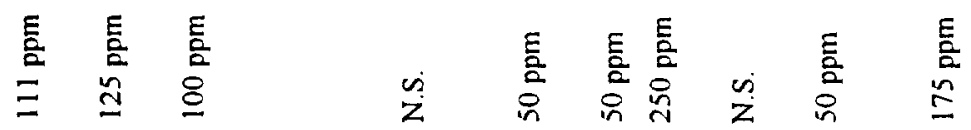




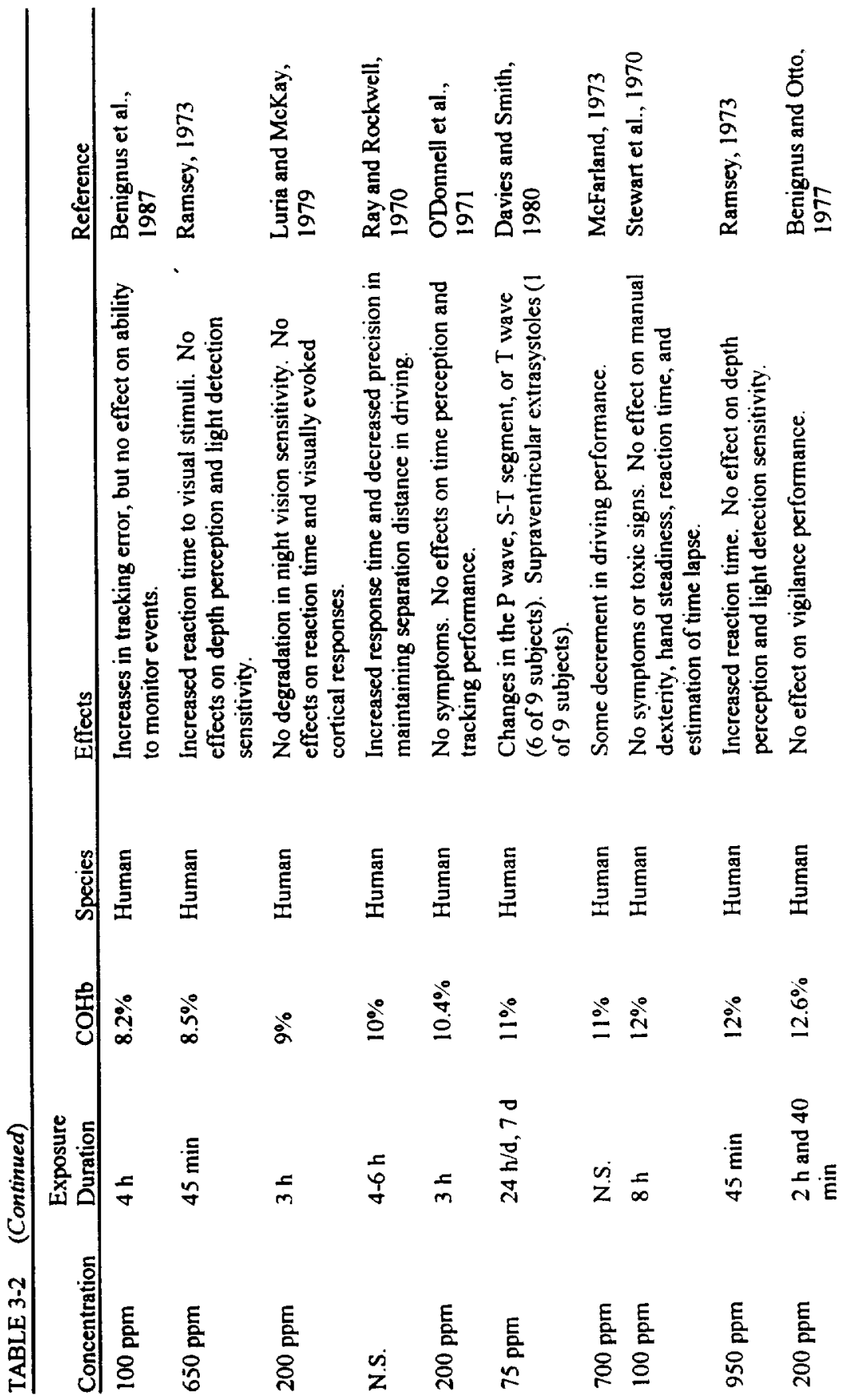




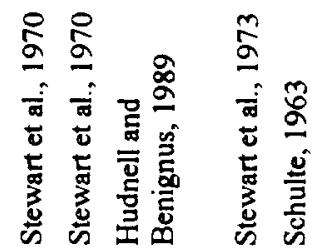

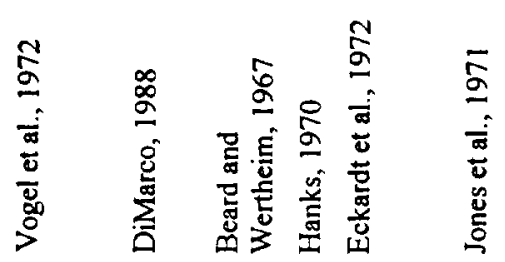
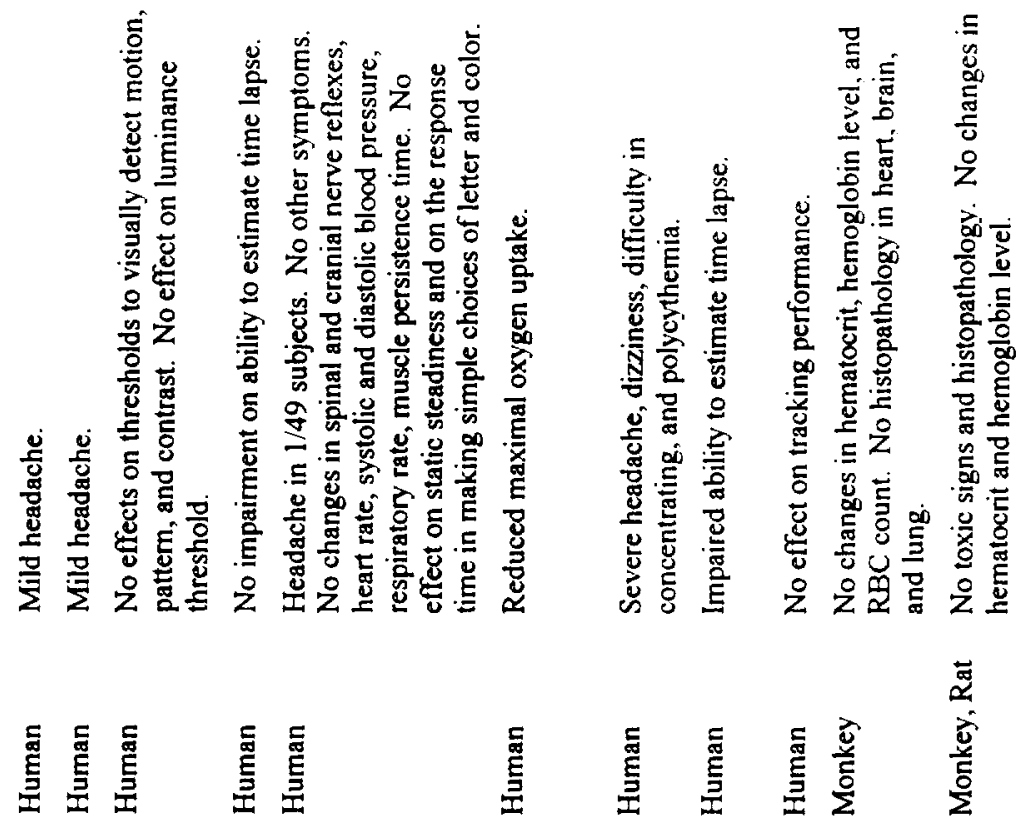

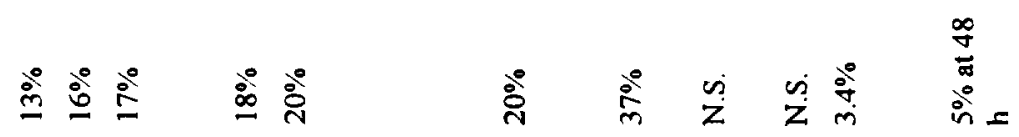

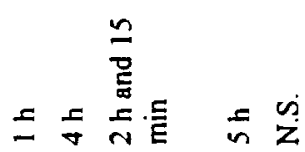

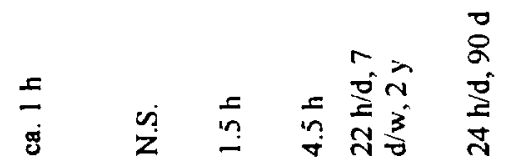

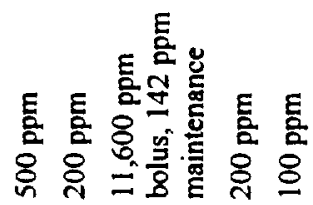

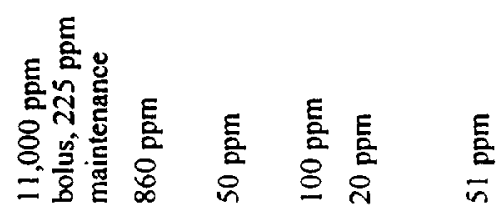




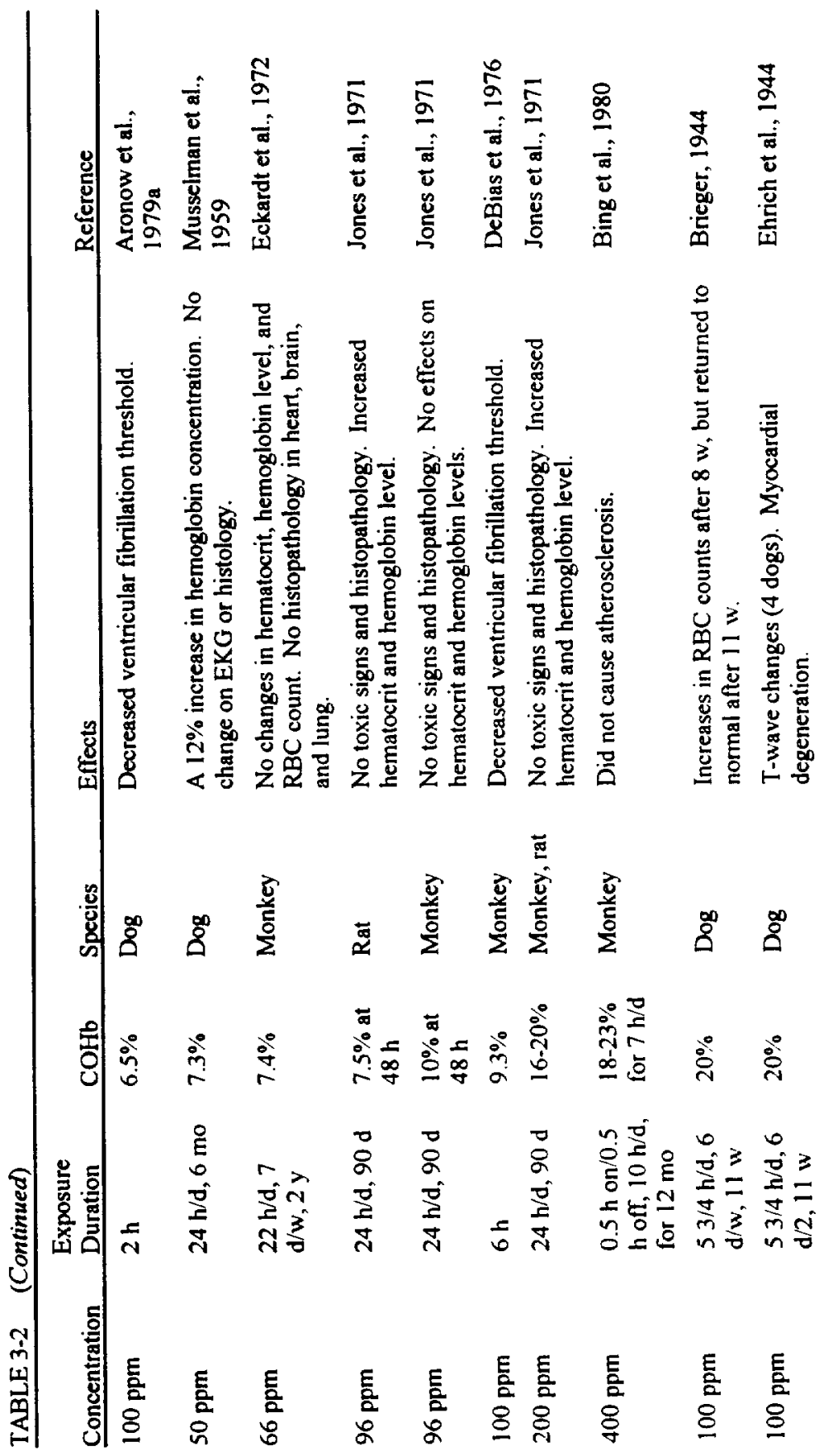




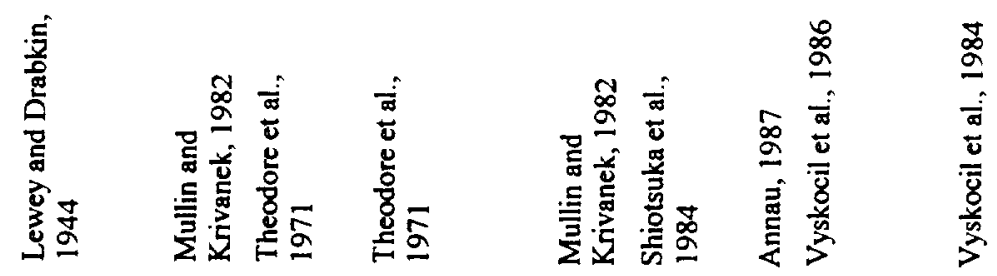

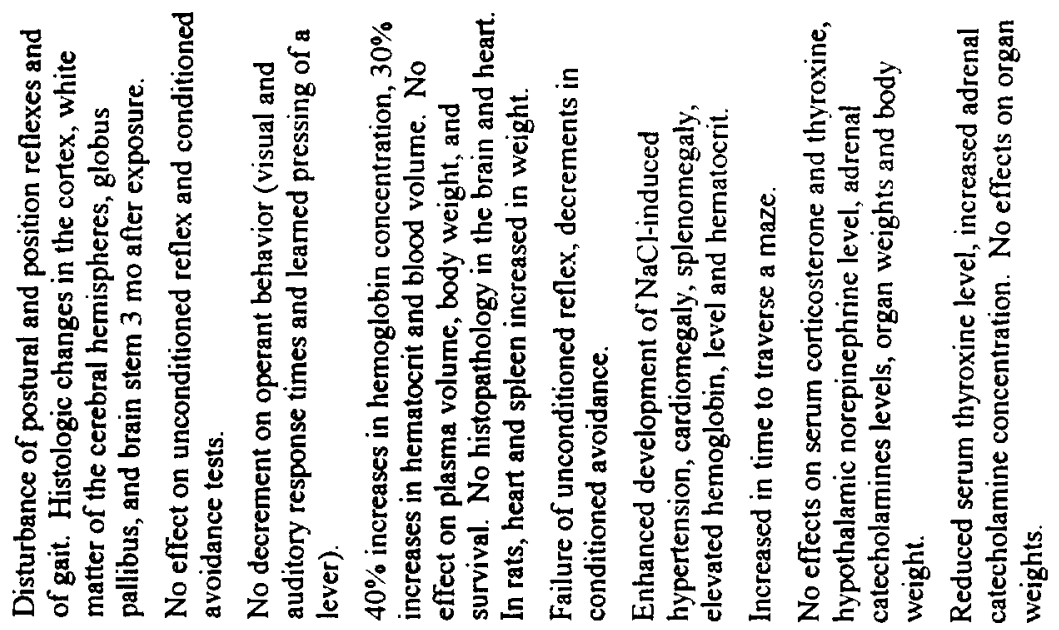

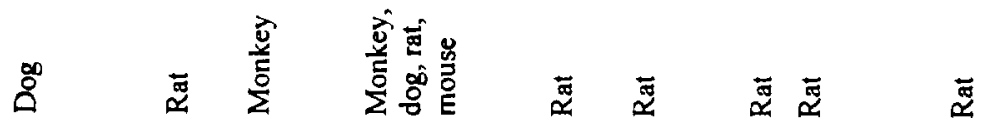

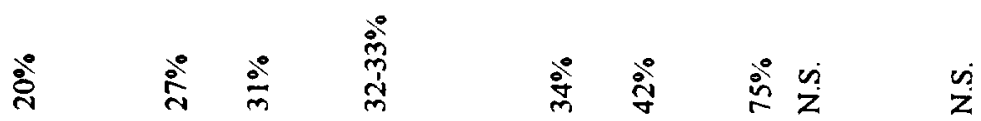

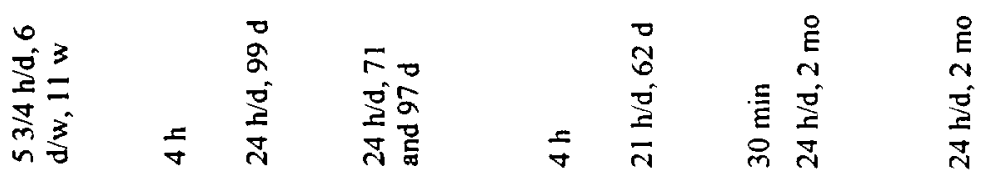

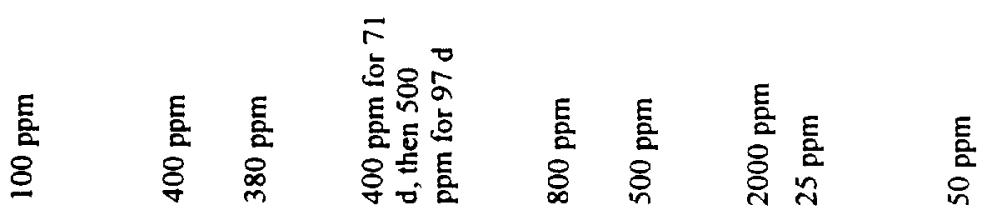




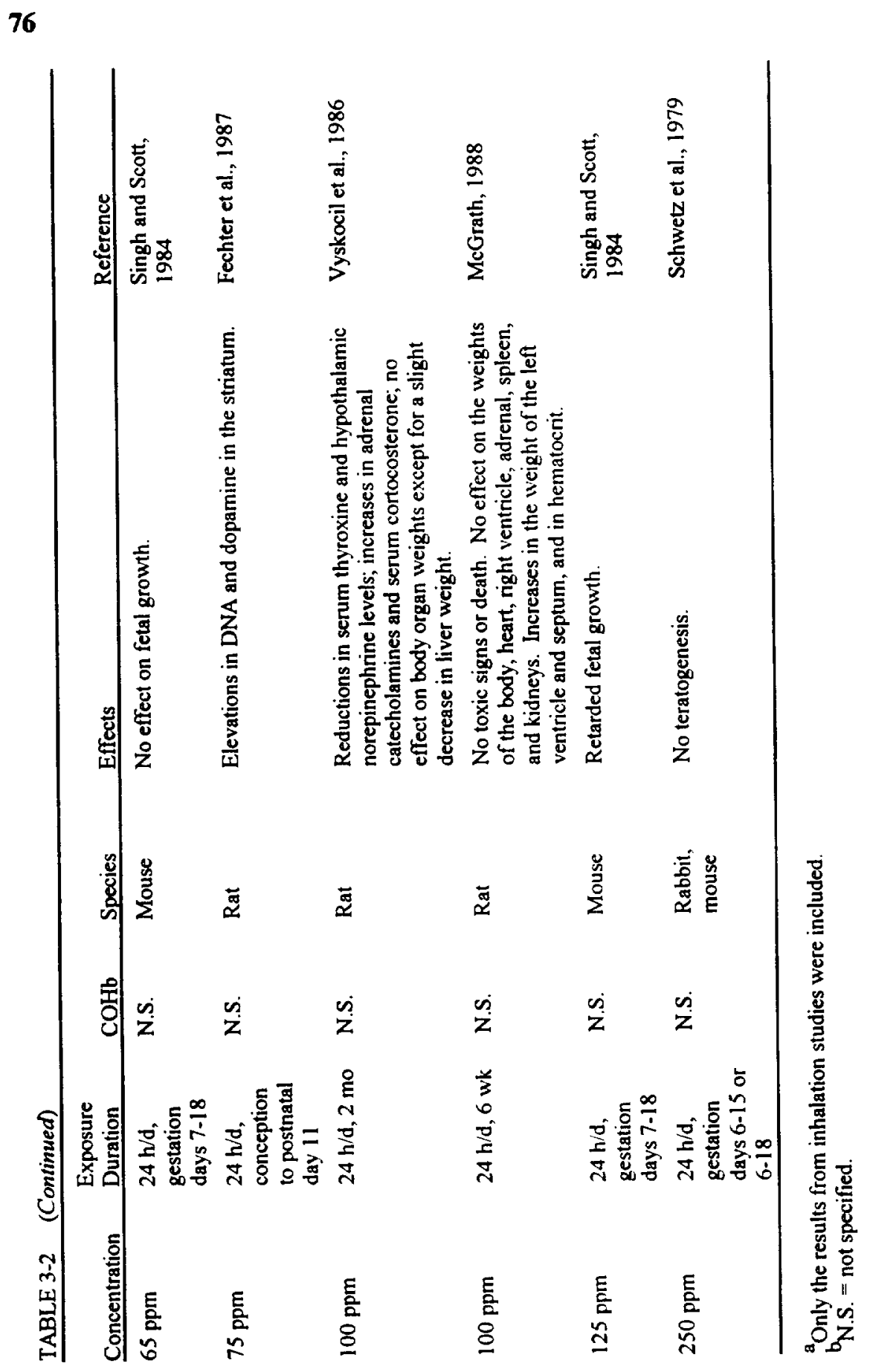


TABLE 3-3 Exposure Limits Set by Other Organizations

\begin{tabular}{ll}
\hline Organization & Concentration, ppm \\
\hline ACGIH's TLV & 50 \\
ACGIH's STEL & 400 \\
OSHA's PEL & 50 \\
NIOSH's REL & 35 (TWA) \\
& 200 (ceiling) \\
NIOSH's IDLH & 1500 \\
NRC's IDLH & 1500 \\
NRC's 10-min EEGL & 1500 \\
NRC's 30-min EEGL & 750 \\
NRC's 60-min EEGL & 400 \\
NRC's 24-h EEGL & 50 \\
NRC's 90-d EEGL & 20 \\
EPA's NAAQS & 35 for $1 \mathrm{~h}$ \\
& 9 for $8 \mathrm{~h}$ \\
FAA's standard & 50 \\
\hline
\end{tabular}

TLV $=$ threshold limit value. TWA $=$ time-weighted average. PEL $=$ permissible exposure limit. STEL $=$ short-term exposure limit. REL $=$ recommended exposure limit. IDLH $=$ immediately dangerous to life and health. EEGL = emergency exposure guidance level. NAAQS = national ambient air quality standard. FAA $=$ Federal Aviation Administration.

TABLE 3-4 Spacecraft Maximum Allowable Concentrations

\begin{tabular}{lllll} 
Duration & $\mathrm{ppm}$ & $\mathrm{mg} / \mathrm{m}^{3}$ & $\begin{array}{l}\text { Target } \\
\text { COHb, \% }\end{array}$ & Target Toxicity \\
\hline $1 \mathrm{~h}^{\mathrm{a}}$ & 55 & 63 & 3 & Heart, CNS \\
$24 \mathrm{~h}$ & 20 & 23 & 3 & Heart, CNS \\
$7 \mathrm{~d}^{\mathrm{b}}$ & 10 & 11 & 1.6 & Heart, CNS \\
$30 \mathrm{~d}$ & 10 & 11 & 1.6 & Heart, CNS \\
$180 \mathrm{~d}$ & 10 & 11 & 1.6 & Heart, CNS \\
\hline${ }^{\text {a }}$ Refer to "Rationale" section for a discussion of lowering the 1-h SMAC in the \\
unlikely event that the 1-h exposure immediately follows a 24-h exposure at the \\
24-h or 7-d SMAC. \\
Current 7-d SMAC = 25 ppm.
\end{tabular}




\section{RATIONALE}

The effects of acute $\mathrm{CO}$ exposures at low concentrations on mental functions are controversial (Stewart, 1975). The lowest effective level is $2 \% \mathrm{COHb}$, which was found to impair vigilance in normal subjects (Beard and Grandstaff, 1975). The practical significance of that finding is questionable because the same study showed that $7.5 \% \mathrm{COHb}$ did not impair vigilance.

A COHb level of 3.4 or $4 \%$ has been shown to reduce the duration subjects can exercise until exhaustion by $5 \%$ (Horvath et al., 1975; Aronow and Cassidy, 1975). The SMACs are not set to protect against this effect because a reduction of the duration an individual can exercise maximally, from 24 to 23 min (Horvath et al., 1975), will not significantly affect the ability of astronauts to achieve the mission objectives.

The next lowest effective level is $3.9 \% \mathrm{COHb}$, which was discovered to cause "impairment" of the ability of cardiac patients to visually trace a line through several tangled lines (Aronow et al., 1979b). This finding is disregarded because of an uncertainty of whether the effect detected was indeed an impairment. The score of that visual test represented the number of lines correctly traced (Aronow et al., 1979b), so the higher the score the better the ability to visually trace the lines. In that study, the $\mathrm{CO}$ exposure increased the score, compared with the pre-exposure baseline score, and the air exposure decreased the score. Therefore, $3.9 \% \mathrm{COHb}$ appeared not to impair that ability in cardiac patients.

The fourth lowest effective level is $4.5 \% \mathrm{COHb}$, which was found to reduce the ability to detect flashes of light (Halperin et al., 1959). That finding is not relied on to set the SMACs because no parallel control group was used in that study (Hudnell and Benignus, 1989).

\section{1-h SMAC}

The studies of Ramsey (1972) and Putz, et al. (1979) are relied on to set the 1-h SMAC. In these studies, $5 \% \mathrm{COHb}$ was found to increase the reaction time (about 30\%) and to impair hand-eye coordination (a $12 \%$ increase in tracking errors). Even though there are conflicting reports on the effects of $\mathrm{COHb}$ levels higher than $5 \%$ on reaction time and hand-eye 
coordination (Stewart et al., 1970; Beard and Grandstaff, 1975; Benignus et al., 1987; Ramsey, 1973; Ray and Rockwell 1970; Luria and McKay, 1979; Mikulka, 1970; O'Donnell et al., 1971), prudence dictates that we have to assume that $5 \% \mathrm{COHb}$ would slow down the reaction and impair the coordination of the crew. These impairments would clearly interfere with the crew's ability to deal with a contingency. To prevent the interference, the 1-h SMAC is aimed at a target $\mathrm{COHb}$ level of $3 \%$.

Three percent is chosen for three reasons. First, $5 \% \mathrm{COHb}$ appears to be the threshold of neurological detriments significant to mission's objectives. Second, EPA, NIOSH, and some scientists believed that $\mathrm{CO}$ causes no significant $\mathrm{CNS}$ toxicity below $5 \% \mathrm{COHb}$ (Rylander and Vesterlund, 1981; EPA, 1985; NIOSH, 1972). Third, a safety margin of $2 \% \mathrm{COHb}$ should be sufficient, considering that a $1-\mathrm{h}$ exposure at the 1-h NAAQS produces 3\% COHb during exercise (Rylander and Vesterlund, 1981) and $2 \% \mathrm{COHb}$ during moderate activity (EPA, 1985). Because the NAAQS is aimed at protecting the entire population, including potentially highly sensitive individuals, such as the old and the infirm, a SMAC that achieves a COHb level comparable to that achieved at the NAAQS should protect the astronauts also. This is because astronauts, being physically fit, are a hyposusceptible group compared with the general population.

The $\mathrm{CO}$ concentration required to yield $3 \% \mathrm{COHb}$ in $1 \mathrm{~h}$ was calculated using the Coburn-Forster-Kane equation (Peterson and Stewart, 1975). A minute volume of $20 \mathrm{~L} / \mathrm{min}$, corresponding to the minute volume of an adult at light activity (NRC, 1990), was used in calculating the CO concentration. A higher minute volume was not used, even though the crew is expected to exercise more than $1 \mathrm{~h} / \mathrm{d}$, because NASA will issue a flight rule that disallows exercise when the CO level in the spacecraft approaches the 1-h SMAC. In addition, a pre-exposure $\mathrm{COHb}$ level of $0.6 \%$ and the inflight hemoglobin concentration measured in Skylabs were used (Kimzey, 1977 ) in calculating the $\mathrm{CO}$ concentration. Under these conditions, $\mathrm{CO}$ at $55 \mathrm{ppm}$ will yield $3 \% \mathrm{COHb}$ in $1 \mathrm{~h}$; therefore, $55 \mathrm{ppm}$ becomes the $1-\mathrm{h}$ SMAC.

The 1-h SMAC will also protect against the cardiotoxicity of CO. Because an exposure to $\mathrm{CO}$ at $100 \mathrm{ppm}$ for over $1 \mathrm{~h}$ yielding $4 \% \mathrm{COHb}$ failed to increase the frequency of ventricular premature depolarization in cardiac patients (Sheps et al., 1990), 3\% COHb should not lead to EKG changes in a healthy crew. 


\section{4-h SMAC}

There is only one report on the neurological effects of $\mathrm{CO}$ exposures lasting over $8 \mathrm{~h}$ in humans. A $24-\mathrm{h}$ exposure to $50 \mathrm{ppm}$, yielding $8 \%$ $\mathrm{COHb}$, led to no effects on response time, manual dexterity, and time perception in human subjects (Stewart et al., 1970). Unfortunately, there are no data on the effect of a 24-h CO exposure on hand-eye coordination, so $5 \% \mathrm{COHb}$, which impairs hand-eye coordination in $4 \mathrm{~h}$ (Putz et al., 1979), is also assumed to impair hand-eye coordination in $24 \mathrm{~h}$. The same target COHb of $3 \%$ is, therefore, used to set the 24-h SMAC. With a minute volume of $20 \mathrm{~m}^{3} / \mathrm{d}$ used by NRC (1990) and the inflight hemoglobin level obtained in Skylabs (Kimzey, 1977), $20 \mathrm{ppm}$ is calculated to be the $\mathrm{CO}$ concentration required to yield a $\mathrm{COHb}$ of $3 \%$ in $24 \mathrm{~h}$ (Peterson and Stewart, 1975). The 24-h SMAC is, therefore, set at $20 \mathrm{ppm}$.

\section{7-d SMAC}

There is only one report on $\mathrm{CO}$ toxicity on humans for a continuous exposure lasting $7 \mathrm{~d}$ or more. In that study, an 8-d CO exposure at $15 \mathrm{ppm}$ $(2.4 \% \mathrm{COHb})$ or $50 \mathrm{ppm}(7.1 \% \mathrm{COHb})$ resulted in P-wave changes in 3 of 16 subjects or 6 of 15 subjects, respectively (Davies and Smith, 1980). The investigators concluded that the $\mathrm{P}$-wave changes reflects $\mathrm{CO}$ toxicity on atrial pacemaking or conducting tissue. At a higher concentration of 75 ppm ( $11 \% \mathrm{COHb})$, even more EKG changes, such as S-T-segment or Twave changes and supraventricular extrasystole, were detected (Davies and Smith, 1980). From these findings, it is decided that the 7-d SMAC will yield a COHb level less than $2.4 \%$. Because the EPA's NAAQS of $9 \mathrm{ppm}$ for $8 \mathrm{~h}$ will yield $1.6 \% \mathrm{COHb}$ in an exercising individual (Rylander and Vesterlund, 1981), $1.6 \%$ is selected to be the target $\mathrm{COHb}$ level for the 7-d SMAC. With the use of the Coburn-Forster-Kane equation (Peterson and Stewart, 1975), the minute volume of $20 \mathrm{~m}^{3} / \mathrm{d}$ recommended by NRC (1990), and the inflight hemoglobin concentration obtained in Skylabs (Kimzey, 1977), $10 \mathrm{ppm}$ is calculated to be the 7-d SMAC.

There are no data on the neurological effects of continuous $\mathrm{CO}$ exposures lasting $7 \mathrm{~d}$ or more. It is believed that a target $\mathrm{COHb}$ of $1.6 \%$ should be able to prevent any significant neurological effects on the crew for $7 \mathrm{~d}$. The reason is that $1.6 \%$ is not much higher than the $0.7-1.0 \%$ $\mathrm{COHb}$ detected in nonsmokers in their everyday lives (Radford et al., 
1981), but it is lower than the $2.8-3.2 \%$ (O'Hanlon, 1975) or $4-5 \%$ (Horvath et al., 1975) detected in smokers. It is also quite a bit lower than the threshold of $5 \% \mathrm{COHb}$ for significant neurological effects in acute $\mathrm{CO}$ exposures discussed above. In addition, $\mathrm{CO}$ at $111 \mathrm{ppm}$ (6.6-6.9\% $\mathrm{COHb}$ ) was shown to impair the vigilance ability of nonsmokers, but not smokers (O'Hanlon, 1975). That suggests that tolerance to CO's neurological toxicity may develop after repeated exposures. There are also data indicating that tolerance develops toward the effect of $\mathrm{CO}$ in causing headache in humans (Killick, 1936, 1948) and coma in mice (Gorbatow and Noro, 1948; Killick, 1937) after repeated exposures. Taken together, these studies point out that $1.6 \% \mathrm{COHb}$ should provide sufficient margin of safety toward potential $\mathrm{CO}$ 's neurological effects in subchronic exposures.

It has been pointed out earlier that, in general, astronauts are hyposusceptible to the toxic effects of $\mathrm{CO}$ compared with the general population because of their physical fitness. So using the $\mathrm{COHb}$ levels achievable in an exposure to the EPA's NAAQS usually will provide enough protection in setting the SMACs of CO. On the other hand, based on the cardiotoxicity of $\mathrm{CO}$, the astronauts could be considered a hypersusceptible population. The reason is that cardiac arrhythmias were occasionally detected inflight during the Skylab missions (Smith et al., 1977). Nevertheless, a $\mathrm{COHb}$ level of $1.6 \%$ should be sufficiently low to prevent cardiac toxicity of $\mathrm{CO}$ even in the "hypersusceptible" astronauts because $1.6 \%$ is only slightly higher than the $\mathrm{COHb}$ level in nonsmokers and is lower than the $\mathrm{COHb}$ level in smokers. It should be noted that coronary disease patients are also considered hypersusceptible to the cardiotoxic effect of CO. Sheps et al. (1990) showed that it takes a COHb of $6 \%$ to increase the frequency of ventricular premature depolarization in patients with coronary artery disease, whereas $4 \%$ fails to cause any increase. That indicates that a target $\mathrm{COHb}$ of $1.6 \%$ should prevent arrhythmia even in a hypersusceptible population, such as the astronauts. The Subcommittee on Guidelines for Developing SMACs of the NRC's Committee on Toxicology also agreed with this assessment.

\section{0-d SMAC and 180-d SMAC}

There are no data on CO's toxicity in humans after a continuous exposure lasting more than $8 \mathrm{~d}$. Although there are several subchronic or chronic studies in animals, very few of them used neurological or EKG 
effects as the end point (Jones et al., 1971; Musselman et al., 1959; Eckardt et al., 1972; Theodore et al., 1971). One study did show that a 6-mo continuous exposure to $\mathrm{CO}$ at $50 \mathrm{ppm}(7.3 \% \mathrm{COHb})$ produced no EKG changes in dogs (Musselman et al., 1959). This finding is not used to set the 30- and 180-d SMACs because EKG changes were produced in humans by a $7-\mathrm{d}$ continuous $\mathrm{CO}$ at a much lower $\mathrm{COHb}$ of $2.4 \%$ (Davies and Smith, 1980).

A 99-d continuous exposure to $\mathrm{CO}$ at $380 \mathrm{ppm}(31 \% \mathrm{COHb})$ did not cause any decrement in operant behavior in monkeys (Theodore et al., 1971). This study is also not relied on in setting the 30- and 180-d SMACs because significant neurological effects were detected in humans in acute CO exposure at a much lower COHb of $5 \%$ (Putz et al., 1979; Ramsey, 1972). We also know that rats are up to 10 -fold less sensitive than humans toward the acute behavioral effects of CO (Ehrich et al., 1944). It is likely that behavioral testing in monkeys also underestimates the no-behavioraleffect level for humans.

The target $\mathrm{COHb}$ level of $1.6 \%$ for $7-\mathrm{d}$ SMAC would also be appropriate for the 30 and 180-d SMACs because the same rationale for the 7-d SMAC should apply for a 30 - or $180-\mathrm{d}$ CO exposure. With $1.6 \%$ being lower than the COHb levels commonly detected in smokers and the possibility of tolerance, $1.6 \% \mathrm{COHb}$ should provide a sufficient margin of safety toward the neurological and cardiac effects of $\mathrm{CO}$ in a continuous 30- or 180-d exposure. Using the Coburn-Forster-Kane equation (Peterson and Stewart, 1975), both the 30- and 180-d SMACs are calculated to be 10 ppm. Exposures at these long-term SMACs also should not lead to any detrimental effect on tissue morphology because none was detected in monkeys with continuous $\mathrm{CO}$ exposures resulting in $3.4 \% \mathrm{COHb}$ for $2 \mathrm{y}$ or 32-33\% COHb for $168 \mathrm{~d}$ (Eckardt et al., 1972; Theodore et al., 1971).

Finally, the potential effect of microgravity-induced hematological changes on $\mathrm{CO}^{\prime}$ s toxicity can be accounted for by using the inflight hemoglobin concentration obtained in Skylabs to calculate the CO SMAC required to yield a given target $\mathrm{COHb}$ level. Therefore, no further adjustments of the SMACs are needed.

\section{1-h and 24-h SMACs Immediately Following CO Exposure}

The SMACs were calculated assuming a baseline $\mathrm{COHb}$ of $0.6 \%$. 
However, it was pointed out by the NRC's Subcommittee on Guidelines for Developing SMACs that NASA should also consider the impact on the 1-h and 24-h SMACs when the beginning $\mathrm{COHb}$ is not $0.6 \%$ (e.g., immediately after the $\mathrm{COHb}$ level has been raised by an exposure to $\mathrm{CO}$ at one of its SMACs). Because the $\mathrm{COHb}$ level reaches equilibrium $24 \mathrm{~h}$ into a $\mathrm{CO}$ exposure (Peterson and Stewart, 1975), we need only consider the impact on the 1-h and 24-h SMACs $24 \mathrm{~h}$ into a CO exposure at the 24-h or 7-d SMAC.

If a 1-h "spike" of 55-ppm CO occurs immediately after a 24-h CO exposure at the 24-h SMAC of $20 \mathrm{ppm}$, the 1-h spike will lead to a $\mathrm{COHb}$ of $4.7 \%$, which is too close to the $5 \%$ threshold of the CNS depression effects of $\mathrm{CO}$. Therefore, the 1-h SMAC should be reduced to $20 \mathrm{ppm}$ if a 1-h exposure follows a 24-h CO exposure at the 24-h SMAC. Following a 24-h CO exposure at the 24-h SMAC, a $1-\mathrm{h}$ CO exposure at $20 \mathrm{ppm}$ will result in a $\mathrm{COHb}$ level of $3 \%$, which is acceptable.

A 1-h spike of $55 \mathrm{ppm}$ following a 24-h exposure of $\mathrm{CO}$ at the 7-d SMAC of $10 \mathrm{ppm}$ will lead to a $\mathrm{COHb}$ level of $3.8 \%$. Consequently, the 1-h SMAC should be lowered to $40 \mathrm{ppm}$ in the special situation in which a 1-h spike follows a $\mathrm{CO}$ exposure at the 7-d SMAC for $24 \mathrm{~h}$ or longer. In that situation, $\mathrm{CO}$ at $40 \mathrm{ppm}$ will lead to an acceptable $\mathrm{COHb}$ level of $3.1 \%$.

A similar analysis was done for a spike at the 24-h SMAC. As shown before, a 24-h exposure at the 24-h SMAC of $20 \mathrm{ppm}$ will result in a $\mathrm{COHb}$ of only $3 \%$ starting from a $\mathrm{COHb}$ of $0.6 \%$. If the 24-h exposure at $20 \mathrm{ppm}$ follows a $24-\mathrm{h}$ exposure at the 7-d SMAC of $10 \mathrm{ppm}$ (a starting $\mathrm{COHb}$ of $1.6 \%$ ), the $24-\mathrm{h}$ exposure at $20 \mathrm{ppm}$ will only produce a $\mathrm{COHb}$ of only $3.2 \%$, which is acceptable. Therefore, $20 \mathrm{ppm}$ is low enough as the 24-h SMAC for all CO exposure scenarios.

\section{REFERENCES}

Annau, Z. 1987. Complex maze performance during carbon monoxide exposure in rats. Neurotoxicol. Teratol. 9:151-155.

Aronow, W.S. and J. Cassidy. 1975. Effect of carbon monoxide on maximal treadmill exercise. Ann. Intern. Med. 83:496-499.

Aronow, W.S., E.A. Stemmer, and S. Zweig. 1979a. Carbon monoxide and ventricular fibrillation threshold in normal dogs. Arch. Environ. Health $34: 184-186$. 
Aronow, W.S., R. Charter, and G. Seacat. 1979b. Effect of 4\% carboxyhemoglobin on human performance in cardiac patients. Prev. Med. 8:562-566.

Astrup, P., D. Trolle, H.M. Olsen, and K. Kjeldsen. 1972. Effect of moderate carbon-monoxide exposure on fetal development. Lancet 2:1220-1222.

Ator, N.A. and W.H. Merigan. 1980. Tolerance to the effects of carbon monoxide on operant behavior in rats: Repeated brief exposures. Neurobehav. Toxicol. 2:367-372.

Beard, R.R. and N.W. Grandstaff. 1975. Carbon monoxide and human functions. In Behavioral Toxicology. B. Weiss and V.G. Laties, eds. Plenum Press, New York.

Beard, R.R. and G.A. Wertheim. 1967. Behavioral impairment associated with small doses of carbon monoxide. Am. J. Public Health 57:2012-2022.

Bender, W., M. Göthert, and G. Malorny. 1972. Effect of low carbon monoxide concentrations on psychological function. Staub-Reinhalt. Luft 32:54-60.

Benignus, V.A., K.E. Muller, C.N. Barton, and J.D. Prah. 1987. Effect of low level carbon monoxide on compensatory tracking and event monitoring. Neurotoxicol. Teratol. 9:227-234.

Benignus, V.A. and D.A. Otto. 1977. Lack of effects of carbon monoxide on human vigilance. Percept. Motor Skills 45:1007-1014.

Bing, R.J., J.S.M. Sarma, R. Weishaar, A. Rackl, and G. Pawlik. 1980. Biochemical and histological effects of intermittent carbon monoxide exposure in cynomolgus monkeys (Macaca fascicularis) in relation to atherosclerosis. J. Clin. Pharmacol. 20:487- 499.

Brieger, H. 1944. Carbon monoxide polycythemia. J. Ind. Hyg. Toxicol. 26:321-327.

Bunnell, D.E. and S.M. Horvath. 1989. Interactive effects of heat, physical work, and $\mathrm{CO}$ exposure on metabolism and cognitive task performance. Aviat. Space Environ. Med. 60:428-432.

Christensen, C.L., J.A. Gliner, S.M. Horvath, and J.A. Wagner. 1977. Effects of three kinds of hypoxias on vigilance performance. Aviat. Space Environ. Med. 48:491-496.

Coburn, R.F., R.E. Forster, and P.B. Kane. 1965. Considerations of the physiological variables that determine the blood carboxyhemoglobin concentration in man. J. Clin. Invest. 44:1899-1910.

Coburn, R.F. and P.B. Kane. 1968. Maximal erythorcyte and hemoglo- 
bin catabolism. J. Clin. Invest. 47:1435-46.

Davies, D.M., E.J. Jolly, R.J. Pethybridge, and W.P. Colquhoun. 1981. The effects of continuous exposure to carbon monoxide on auditory vigilance in man. Int. Arch. Occup. Environ. Health 48:25-34.

Davies, D.M. and D.J. Smith. 1980. Electrocardiographic changes in healthy men during continuous low-level carbon monoxide exposure. Environ. Res. 21:197-206.

DeBias, D.A., C.M. Banerjee, N.C. Birkhead, C.H. Greene, D. Scott, and W.V. Harrer. 1976. Effects of carbon monoxide inhalation on ventricular fibrillation. Arch. Environ. Health 31:42-46.

DiMarco, A. 1988. Carbon monoxide poisoning presenting as polycythemia. N. Engl. J. Med. 319:874.

Drinkwater, B.L., P.B. Raven, S.M. Horvath, J.A. Gliner, R.O. Ruhling, N. W. Bolduan, and S. Taguchi. 1974. Air pollution, exercise, and heat stress. Arch. Environ. Health 28:177-181.

Eckardt, R.E., H.N. MacFarland, Y.C.E. Alarie, and W.M. Busey. 1972. The biologic effect from long-term exposure of primates to carbon monoxide. Arch. Environ. Health 25:381-387.

Ehrich, W.E., S. Bellet, and F.H. Lewey. 1944. Cardiac changes from CO poisoning. Am. J. Med. Sci. 208:511-523.

Ekblom, B. and R. Huot. 1972. Response to submaximal and maximal exercise at different levels of carboxyhemoglobin. Acta Physiol. Scand. 86:474-482.

EPA. 1985. Review of the National Ambient Air Quality Standards for carbon monoxide. Fed. Regist. 50:37484-37501.

Estabrook, R.W., M.R. Franklin, and A.G. Hildebrandt. 1970. Factors influencing the inhibitory effect of carbon monoxide on cytochrome P-450-catalyzed mixed function oxidation reactions. Ann. N.Y. Acad. Sci. 174:218-232.

Ettema, J.H. and R.L. Zielhuis. 1975. Effects of alcohol, carbon monoxide and trichloroethylene exposure on mental capacity. Int. Arch. Occup. Environ. Health 35:117-132.

Fechter, L.D., M.D. Karpa, B. Proctor, A.G. Lee, and J.E. Storm. 1987. Disruption of neostiatal development in rats following perinatal exposure to mild, but chronic carbon monoxide. Neurotoxicol. Teratol. 9:277.

Findlay, G.H. 1988. Carbon monoxide poisoning: Optics and histology of skin and blood. Br. J. Dermatol. 119:45-51.

Fodor, G.G. and G. Winneke. 1972. Effect of low CO concentrations on 
resistance to monotony and on psychomotor capacity. Staub-Reinhalt. Luft 32:46-54.

Gliner, J.A., P.B. Raven, S.M. Horvath, B.L. Drinkwater, and J.C. Sutton. 1975. Man's physiologic response to long-term work during thermal and pollutant stress. J. Appl. Physiol. 39:628-632.

Gorbatow, O. and L. Noro. 1948. Acclimatization in connection with acute carbon monoxide poisonings. Acta Physiol. Scand. 15:77-87.

Halperin, M.H., R.A. McFarland, J.I. Niven, and F.J.W. Roughton. 1959. The time course of the effects of carbon monoxide on visual thresholds. J. Physiol. 146:583-593.

Hanks, T.G. 1970. Human performance of a psychomotor test as a function of exposure to carbon monoxide. Ann. N.Y. Acad. Sci. 174:421-424.

Herman, G.D., A.B. Shapiro, and J. Leikin. 1988. Myonecrosis in carbon monoxide poisoning. Vet. Human Toxicol. 30:28-30.

Horvath, S.M. 1971. Carbon monoxide and human vigilance. A deleterious effect of present urban concentrations. Arch. Environ. Health 23:343-347.

Horvath, S.M., P.B. Raven, T.E. Dahms, and D.J. Gray. 1975. Maximal aerobic capacity at different levels of carboxyhemoglobin. J. Appl. Physiol. 38:300-303.

Hudnell, H.K. and V.A. Benignus. 1989. Carbon monoxide exposure and human visual detection thresholds. Neurotoxicol. Teratol. 11:369-371.

Jones, H.A., J.C. Clark, E.E. Davies, R.E. Forster, and J.M.Hughes. 1982. Rate of uptake of carbon monoxide at different inspired concentrations in humans. J. Appl. Physiol. 52:109-113.

Jones, R.A., J.A. Strickland, J.A. Stunkard, and J. Siegel. 1971. Effects on experimental animals of long-term inhalation exposure to carbon monoxide. Toxicol. Appl. Pharmacol. 19:46-53.

Killick, E.M. 1936. The acclimatization of the human subject to atmospheres containing low concentrations of carbon monoxide. J. Physiol. (London) 87:41-55.

Killick, E.M. 1937. The acclimatization of mice to atmospheres containing low concentrations of carbon monoxide. J. Physiol. 91:279-292.

Killick, E.M. 1948. The nature of the acclimatization occurring during repeated exposure of the human subject to atmospheres containing low concentrations of carbon monoxide. J. Physiol. 107:27-44.

Kimzey, S.L. 1977. Hematology and immunology studies. P. 249 in Biomedical Results from Skylab. R.S. Johnson and L.F. Dietlein, eds. 
National Aeronautics and Space Administration, Washington, D.C.

Kuller, L.H. and E.P. Radford. 1983. Epidemiological bases for the current ambient carbon monoxide standards. Environ. Health Perspect. 52:131-139.

Klaassen, C.D. 1990. Nonmetallic environmental pollutants. P. 1618 in Goodman and Gilman's The Pharmacological Basis of Therapeutics. A.G. Gilman et al., eds. Pergamon Press, New York.

Klein, J.P., H.V. Forster, R.D. Stewart, and A. Wu. 1980. Hemoglobin affinity for oxygen during short-term exhaustive exercise. J. Appl. Physiol. 48:236-237.

Laties, V.G. and W.J. Merigan. 1979. Behavioral effects of carbon monoxide on animals and man. Annu. Rev. Pharmacol. 19:357-392.

Leban, M.I. and P.A. Wagner. 1989. Space Station Freedom Gaseous Trace Contaminant Load Model Development. SAE Technical Paper Series 891513. Society of Automotive Engineers, Warrendale, Pa.

Lewey, F.H. and D.L. Drabkin. 1944. Experimental chronic carbon monoxide poisoning of dogs. Am. J. Med. Sci. 208:502-511.

Luria, S.M. and C.L. McKay. 1979. Effects of low levels of carbon monoxide on visions of smokers and nonsmokers. Arch. Environ. Health 34:38-44.

McFarland, R.A. 1973. Low level exposure to carbon monoxide and driving performance. Arch. Environ. Health 27:355-359.

McGrath, J.J. 1988. Body and organ weights of rats exposed to carbon monoxide at high altitude. J. Toxicol. Environ. Health 23:303-310.

Mihevic, P.M., J.A. Gliner, and S.M. Horvath. 1983. Carbon monoxide exposure and information processing during perceptual-motor performance. Int. Arch. Occup. Environ. Health 51:355-64.

Mikulka, P. 1970. The effect of carbon monoxide on human performance. Ann. N.Y. Acad. Sci. 174:409-420.

Montgomery, M.R. and R.J. Rubin. 1971. The effect of carbon monoxide inhalation on in vivo drug metabolism in the rat. J. Pharmacol. Exp. Ther. 179:465-473.

Mullin, L.S. and N.D. Krivanek. 1982. Comparison of unconditioned reflex and conditioned avoidance tests in rats exposed by inhalation to carbon monoxide, 1,1,1-trichloroethane, toluene or ethanol. Neurotoxicology 3:126-137.

Musselman, N.P., W.A. Groff, P.P. Yevich, F.T. Wilinski, M.H. Weeks, and F.W. Oberst. 1959. Continuous exposure of laboratory animals to low concentration of carbon monoxide. Aerosp. Med. 30:524-529. 
NIOSH. 1972. Criteria for a Recommended Standard: Occupational Exposure to Carbon Monoxide. NIOSH-TR-007-72. National Institute for Occupational Safety and Health, Cincinnati, Ohio.

NRC. 1985. Emergency and Continuous Exposure Guidance Levels for Selected Airborne Contaminants. Vol. 4., p. 17. National Academy Press, Washington, D.C.

NRC. 1990. Guidelines for Developing Spacecraft Maximum Allowable Concentrations for Space Station Contaminants. National Academy Press, Washington, D.C.

O' Donnell, R.D., R. Mikulka, P. Heinig, and J. Theodore. 1971. Low level carbon monoxide exposure and human psychomotor performance. Toxicol. Appl. Pharmacol. 18:593-602.

O'Hanlon, J.F. 1975. Preliminary studies of the effects of carbon monoxide on vigilance in man. Pp. 61-75 in Behavioral Toxicology. B. Weiss and G. Laties, eds. Plenum Press, New York.

Pankow, D., W. Glatzel, K. Tietze, and W. Ponsold. 1975. Motor nerve conduction velocity after carbon monoxide or m-dinitrobenzene poisoning following elimination of the poisons. Arch. Toxicol. 34:325-330.

Peterson, J.E. and R.D. Stewart. 1975. Predicting the carboxyhemoglobin 11 levels resulting from carbon monoxide exposures. J. Appl. Physiol. 39:633-11638.

Putz, V.R., B.L. Johnson, and J.V. Setzer. 1976. Effects of $\mathrm{CO}$ on Vigilance Performance: Effects of Low-Level Carbon Monoxide on Divided Attention, Pitch Discrimination, and the Auditory Evoked Potential. DHEW Publ. No. (NIOSH) 77-124. National Institute for Occupational Safety and Health, Cincinnati, Ohio.

Putz, V.R., B.L. Johnson, and J.V. Setzer. 1979. A comparative study of the effects of carbon monoxide and methylene chloride on human performance. J. Environ. Pathol. Toxicol. 2:97-112.

Radford, E., T. Drizd, and R. Murphy. 1981. Blood carbon monoxide levels in persons 3-74 years of age in the United States, 1976-80. Advance Data Report No. 76. U.S. Department of Health and Human Services, National Center for Health Statistics, Hyattsville, Md.

Ramsey, J.M. 1972. Carbon monoxide, tissue hypoxia, and sensory psychomotor response in hypoxaemic subjects. Clin. Sci. 42:619-625.

Ramsey, J.M. 1973. Effects of single exposures of carbon monoxide on sensory and psychomotor responses. Am. Ind. Hyg. Assoc. J. 34: 212-216.

Raven, P.B., B.L. Drinkwater, R.D. Ruhling, N. Bolduan, S. Taguchi, J.

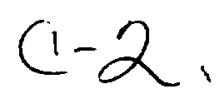


Gliner, and S.M. Horvath. 1974. Effect of carbon monoxide and peroxyacetyl nitrate on man's maximal aerobic capacity. J. Appl. Physiol. 36:288-293.

Ray, A.M. and T.H. Rockwell. 1970. An exploratory study of automobile driving performance under the influence of low levels of carboxyhemoglobin. Ann. N.Y. Acad. Sci. 174:396-408.

Rondia, D. 1970. [Inhibition of hepatic benzopyrene hydroxylase activity in vivo by the inhalation of carbon monoxide.] C.R. Acad. Sci. D 271:617-619.

Rylander, R. and J. Vesterlund. 1981. Carbon monoxide criteria. Scand. J. Work Environ. Health 7(Suppl. 1):1-39.

Schulte, J.H. 1963. Effects of mild carbon monoxide intoxication. Arch. Environ. Health 7:524-30.

Schwetz, B.A., F.A. Smith, B.K.J. Leong, and R.E. Staples. 1979. Teratogenic potential of inhaled carbon monoxide in mice and rabbits. Teratology 3:385-92.

Sheps, D.S., M.C. Herbst, A. L. Hinderliter, K.F. Adams, and L.G. Ekelund. 1990. Production of arrhythmias by elevated carboxyhemoglobin in patients with coronary artery disease. Ann. Intern. Med. 113:343-351.

Shiotsuka, R.N., R.T. Drew, and R.W. Wehner. 1984. Carbon monoxide enhances development of hypertension in Dahl rats. Toxicol. Appl. Pharmacol. 76:225-233.

Singh, J. and L.H. Scott. 1984. Threshold for carbon monoxide induced fetotoxicity. Teratology 30:253-257.

Smith, J.S. and S. Brandon. 1973. Morbidity from acute carbon monoxide poisoning at three-year follow-up. Br. Med. J. 1:318-321.

Smith, R.F., K. Stanton, D. Stoop, D. Brown, W. Janusq, and P. King. 1977. Vectorcardiographic changes during extended space flight (M093). Observations at rest and during exercise. Pp. 339-359 in Biomedical Results from Skylab. R.S. Johnson and L.F. Dietlein, eds. NASA, Washington, D.C.

Stern, F.B., W.E. Halperin, R.W. Hornung, V.L. Ringenburg, and C.S. McCammon. 1988. Heart disease mortality among bridge and tunnel officers exposed to carbon monoxide. Am. J. Epidemiol. 128:12761288.

Stewart, R.D. 1975. The effect of carbon monoxide on humans. Ann. Rev. Pharmacol. 15:409-423.

Stewart, R.D., P.E. Newton, M.J. Hosko, and J.E. Peterson. 1973. 
Effect of carbon monoxide on time perception. Arch. Environ. Health 27:155-160.

Stewart, R.D., J.E. Peterson, E.D. Baretta, R.T. Bachand, M.J. Hosko, and A.A. Herrmann. 1970. Experimental human exposure to carbon monoxide. Arch. Environ. Health 21:154-164.

Theodore, J., R.D. O'Donnell, and K.C. Back. 1971. Toxicological evaluation of carbon monoxide in humans and other mammalian species. J. Occup. Med. 13:242-255.

Thom, S.R. and L.W. Keim. 1989. Carbon monoxide poisoning. A review of epidemiology, pathophysiology, clinical findings, and treatment options, including hyperbaric oxygen therapy. J. Toxicol. Clin. Toxicol. 27:141-156.

Vogel, J.A., M.A. Gleser, R.C. Wheeler, and B.K. Whitten. 1972. Carbon monoxide and physical work capacity. Arch. Environ. Health 24:198-203.

Vyskocil, A., M. Tusl, and K. Zaydlar. 1984. The effect of chronic exposure to $0.005 \% \mathrm{CO}$ on hormone levels in brain and blood, and organ weights in rats. J. Hyg. Epidemiol. Microbiol. 28:377-382.

Vyskocil, A., M. Tusl, and K. Zaydlar. 1986. The effect of carbon monoxide on hormone levels and organ weights in rats. J. Appl. Toxicol. 6:443-446.

Walden, S.M. and S.O. Gottlieb. 1990. Urban angina, urban arrhythmias: carbon monoxide and the heart. Intern. Med. 113:337-338.

Wilks, S.S., J.F. Tomashefski, and R.T. Clark, Jr. 1959. Physiological effects of chronic exposure to carbon monoxide. J. App. Physiol. 14:305-310.

Wright, G., P. Randall, and R.J. Shephard. 1973. Carbon monoxide and driving skills. Arch. Environ. Health 27:349-354. 


\title{
B4 Formaldehyde
}

King Lit Wong, Ph.D.

Johnson Space Center Toxicology Group

Biomedical Operations and Research Branch

Houston, Texas

\section{PHYSICAL AND CHEMICAL PROPERTIES}

Formaldehyde is a colorless gas with a strong, pungent odor (TLV Committee, 1989; Sax, 1984).

\author{
Synonyms: Formic aldehyde; methyl \\ aldehyde; methanal \\ Formula: $\mathrm{HCHO}$ \\ CAS number: $\quad 50-00-0$ \\ Molecular weight: 30.0 \\ Boiling point: $\quad-19.5^{\circ} \mathrm{C}$ \\ Melting point: $\quad-92^{\circ} \mathrm{C}$ \\ Lower explosive limit: $\quad 7.0 \%$ \\ Upper explosive limit: $\quad 73.0 \%$ \\ Vapor pressure: $10 \mathrm{~mm} \mathrm{Hg}$ at $-88^{\circ} \mathrm{C}$ \\ Vapor density: 1.08 ( air's density $=1$ ) \\ Conversion factors at $25^{\circ} \mathrm{C}, 1 \mathrm{~atm}: 1 \mathrm{ppm}=1.23 \mathrm{mg} / \mathrm{m}^{3}$ \\ $1 \mathrm{mg} / \mathrm{m}^{3}=0.82 \mathrm{ppm}$
}

\section{OCCURRENCE AND USE}

Formaldehyde is not used in the operation of spacecraft, but it has occasionally been used as a fixative in biological payload experiments. 
There is insufficient information to estimate the potential exposure level of formaldehyde. However, Soviet cosmonauts gained sensitivity to formaldehyde during space missions (Peto, 1981). In addition, formaldehyde might be released into the space-shuttle cabin air as a result of thermodegradation of polymers, such as Delrin (James, 1991).

\section{PHARMACOKINETICS AND METABOLISM}

Inhaled formaldehyde does not appear to accumulate in blood. An inhalation exposure to $14.4 \mathrm{ppm}$ for $2 \mathrm{~h}$ in rats or $1.9 \mathrm{ppm}$ for $40 \mathrm{~min}$ in humans failed to increase the formaldehyde level in blood (Heck et al., 1985). Likewise, no significant increase in formaldehyde in blood was detected after a subchronic exposure $(6 \mathrm{~h} / \mathrm{d}, 5 \mathrm{~d} / \mathrm{w}$ for $4 \mathrm{w})$ at $6 \mathrm{ppm}$ in monkeys (Casanova et al., 1988). The blood data support the hypothesis that formaldehyde, being a highly water soluble compound, is retained primarily by the mucosa of the upper respiratory tract, so that very little enters the lung. After an intravenous injection in monkeys, formaldehyde is rapidly eliminated from the blood, with a half-life of about $1.5 \mathrm{~min}$ (McMartin et al., 1979).

In mammals, formaldehyde is metabolized mainly via oxidation by formaldehyde dehydrogenase into formate and some formaldehyde is incorporated into biological macromolecules via tetrahydrofolate-dependent one-carbon biosynthetic pathways (Huennekens and Osborne, 1959; Koivusalo et al., 1982). Formaldehyde dehydrogenase has been found in many tissues, including the human liver (Uotila and Koivusalo, 1974) and the rat nasal mucosa (Casanova-Schmitz et al., 1984).

\section{TOXICITY SUMMARY}

Acute formaldehyde exposure produces mainly mucosal irritation of the eye and upper respiratory tract in humans, and a long-term exposure leads to the production of nasal tumors in rodents. Formaldehyde also causes pulmonary function impairment and asthmatic reactions in sensitized individuals. 


\section{Acute Toxicity}

Most human studies have been done in the workplace so that the reported formaldehyde exposure concentrations typically spanned a wide range, making it difficult to determine the exact concentration-response relationship or the no-observed-adverse-effect level (NOAEL). One study showed that eye, nose, and throat irritation was detected in workers exposed to formaldehyde at an average peak level of $0.6 \mathrm{ppm}$ (Alexandersson and Hedenstierna, 1988). Another group of investigators reported that workers complained of mucosal discomfort at formaldehyde concentrations ranging from 0.04 to $0.4 \mathrm{ppm}$ (Holmstrom and Wilhelmsson, 1988). These data do not reveal formaldehyde's nonirritating level.

Exposure concentrations are better controlled in experimental studies. The few experimental human studies reported, unfortunately, used very high levels of formaldehyde. For instance, two studies presented evidence that formaldehyde exposure at $3 \mathrm{ppm}$, lasting more than an hour, caused mild to severe irritation of the eye and upper respiratory tract (Green et al., 1987; Sauder et al., 1986). Evidently, formaldehyde at $3 \mathrm{ppm}$ was so high that sufficient formaldehyde got past the nose to affect the lung, reducing the forced expiratory volume in $1 \mathrm{~s}\left(\mathrm{FEV}_{1}\right)$ or forced expiratory flow rate and forced vital capacity (FVC) in these test subjects. Another experimental study demonstrated that formaldehyde is irritating to the mucous membrane at $0.5,1$, or $2 \mathrm{ppm}$ (Kulle et al., 1987). These experimental studies show that formaldehyde is irritating at as low as $0.5 \mathrm{ppm}$.

Two studies of residents in mobile homes and a recent occupational study provide data on the concentration-response relationship of formaldehyde's irritation effects. Formaldehyde has been shown to make 1-2\% of 87 residents in the mobile homes in Minnesota complain of eye irritation at less than $0.1 \mathrm{ppm}$ (Ritchie and Lehnen, 1987). At a formaldehyde concentration of $0.1-0.3 \mathrm{ppm}, 22 \%$ of 181 residents complained of eye irritation and, when the concentration was above $0.3 \mathrm{ppm}$, about $90 \%$ of 336 residents complained of eye irritation. From the data gathered in a survey conducted with 61 mobile-home residents in Wisconsin, the predicted percentages of residents with eye irritation at different formaldehyde concentrations were as follows (Hanrahan et al., 1984).

Formaldehyde Concentration (ppm): $\begin{array}{llll}0.1 & 0.2 & 0.5 & 0.8\end{array}$ $\begin{array}{llllll}\text { Mean Responding Rate (\%): } & 4 & 18 & 65 & 82\end{array}$ 95\% Confidence Limits: $\quad 1,18 \quad 8,35 \quad 33,8644,96$ 
Similarly, the predicted percentages of formaldehyde-exposed workers afflicted with nose irritation obtained in a occupational study by Horvath et al. (1988) using 109 test subjects and 254 control subjects are shown below.

Formaldehyde Concentration (ppm): $\begin{array}{llll}0.1 & 0.2 & 0.5 & 0.8\end{array}$

Mean Responding Rate (\%): $\quad \begin{array}{lllll} & 2 & 4 & 21 & 32\end{array}$

95\% Confidence Limits: $\quad 1,4 \quad 2,8 \quad 16,28 \quad 22,44$

Therefore, these studies suggest that the irritation threshold is below 0.1 $\mathrm{ppm}$. In fact, the National Research Council concluded 10 years ago that formaldehyde causes irritation at as low as $0.1 \mathrm{ppm}$, and it is irritating in a higher fraction of people at $1.0 \mathrm{ppm}$ (NRC, 1980). It is, however, difficult to accurately estimate the threshold concentration for formaldehyde's mucosal irritation effect. A few percentage of individuals respond to formaldehyde at as low as $0.1 \mathrm{ppm}$. From the concentration-response data, it appears that in a population there would always be a small group of individuals who are sensitive to formaldehyde's irritation.

The Minnesota mobile-home study indicates that some individuals are more sensitive to formaldehyde than others (Ritchie and Lehnen, 1987), an observation also made by Horvath's group who detected wide individual variability in response to formaldehyde (Horvath et al., 1988). Similarly, Green et al. (1987) reported that, when 22 normal subjects were exposed to formaldehyde at $3 \mathrm{ppm}$ for $1 \mathrm{~h}$, some of the subjects rated the eye, nose, and throat irritation as nonexistent, and some rated them severe.

Unlike the irritation sensation, there are no human data on the structural effect of formaldehyde on the mucosa at concentrations that are not too irritating. A 6-h exposure to formaldehyde at $0.5 \mathrm{or} 2 \mathrm{ppm}$ is known to lead to the development of abnormal cilia in the nose of rats (MonteiroRiviere and Popp, 1986). However, a 6-h formaldehyde exposure at 2 $\mathrm{ppm}$ failed to affect the mucociliary function in the nose of rats (Morgan et al., 1986). It takes a 6-h exposure at $15 \mathrm{ppm}$ to impair the mucociliary function (Morgan et al., 1986).

As mentioned above, as the formaldehyde concentration gets sufficiently high, formaldehyde gas might reach the lung to affect lung function. Formaldehyde at $3 \mathrm{ppm}$ is known to reduce the FEV ${ }_{1}$ and FVC in humans (Green et al., 1987; Sauder et al., 1986). However, at 1 or $2 \mathrm{ppm}$, formaldehyde has no effect on lung function in volunteers (Kulle et al., 1987; Schachter et al., 1987; Day et al., 1984). There are species differences in 
the pulmonary effects of formaldehyde because formaldehyde has been shown to increase pulmonary resistance and decrease lung compliance at as low as $0.3 \mathrm{ppm}$ in guinea pigs (Alexandersson and Hedenstierna, 1988).

\section{Subchronic and Chronic Toxicity}

\section{Subchronic Data}

In the workplace, repetitive formaldehyde exposures are known to produce mucosal irritation and pulmonary function impairment similar to acute exposures. Nasal and eye discomfort, as well as chest discomfort, have been reported in individuals working for up to $10.4 \mathrm{y}$ in facilities with the formaldehyde concentration ranging from 0.04 to $0.4 \mathrm{ppm}$ (mean $=$ $0.22 \mathrm{ppm}$ ) (Holmstrom and Wilhelmsson, 1988). In another report, runny nose, runny eyes, squamous metaplasia, dysplasia, and goblet-cell hyperplasia of the nasal mucosal have been found in workers exposed to 0.08-0.9 ppm of formaldehyde for about 10.5 y (Edling et al., 1988). A slow progressive impairment in $\mathrm{FEV}_{75-25}$ was reported in workers exposed to $0.04-1.3 \mathrm{ppm}$ (mean $=0.4 \mathrm{ppm}$ ) of formaldehyde for greater than $5 \mathrm{y}$ (Alexandersson, 1988). It is of interest that the pulmonary function impairment went away during a 4-w vacation.

Unlike occupational studies, very few reports on experimental studies of the subchronic effects of formaldehyde in humans can be found. A repetitive exposure of human subjects to formaldehyde at $2 \mathrm{ppm}, 40 \mathrm{~min} / \mathrm{d}$ for 4 $\mathrm{d}$, produced an unusual odor and eye irritation, but no pulmonary function impairment (Schachter et al., 1987). A 7-mo exposure of medical students to formaldehyde at less than $1 \mathrm{ppm}$, time-weighted average (TWA), resulted in eye and upper respiratory irritation, but no bronchoconstriction, even in asthmatics (Uba et al., 1989).

Asthmatic reactions to formaldehyde have been demonstrated. Five of 28 nurses in a renal dialysis unit, where formalin was used to sterilize the dialysis machines, developed hypersensitivity to formaldehyde (Hendrick and Lane, 1977). Inhalation provocation challenge of these sensitized individuals to unknown concentrations of formaldehyde produced wheezing attacks with productive cough and reduction in peak expiratory flow rates beginning 2-3 $\mathrm{h}$ after the challenge and the symptoms and signs lasted for hours. There is also epidemiological evidence linking formaldehyde with asthma. A telephone survey in Massachusetts showed that indoor 
formaldehyde exposures, due to off-gassing from recently remodeled or constructed houses, newly upholstered furniture, foam insulation in walls, or mobile homes, were significantly associated with asthma, chronic bronchitis, or allergies in the youngest child in the household (Tuthill, 1984).

There are many reports on the subchronic effects of formaldehyde on laboratory animals and only a few of them will be discussed here. Generally, a 13-w formaldehyde exposure at $6 \mathrm{~h} / \mathrm{d}, 5 \mathrm{~d} / \mathrm{w}$ produces no histopathology, at the light microscopic level, at 1 or $2 \mathrm{ppm}$ in rats (Wilmer et al., 1989; Woutersen et al., 1987), but a similar exposure at $10 \mathrm{ppm}$ causes squamous metaplasia of the nasal mucosa (Woutersen et al., 1987; Feron et al., 1988). However, 2 ppm is not the NOAEL in subchronic discontinuous exposures, because, based on electron microscopic examinations, a 4-d formaldehyde exposure at $6 \mathrm{~h} / \mathrm{d}$ produced abnormal cilia at $0.5 \mathrm{ppm}$ in rats (Monteiro-Riviere and Popp, 1986). If the formaldehyde exposure concentration is sufficiently high, the rat does not recover from the morphological injuries of formaldehyde. Feron's group has shown that the squamous metaplasia produced by a 4-, 8-, or 13-w formaldehyde exposure at 20 ppm still remained after a 126-w nonexposure period (Feron et al., 1988).

In terms of histopathology in animals, the concentration of formaldehyde appears to be more important than the degree of cumulative exposure $(\mathrm{C} \times$ T) (Wilmer et al., 1989). Feron's group demonstrated that a 13-w formaldehyde exposure at $2 \mathrm{ppm}$ for $8 \mathrm{~h} / \mathrm{d}, 5 \mathrm{~d} / \mathrm{w}$ produced no histopathology in rats, but an exposure at $4 \mathrm{ppm}$ for $4 \mathrm{~h} / \mathrm{d}, 5 \mathrm{~d} / \mathrm{w}$ resulted in squamous metaplasia and basal cell hyperplasia of the nasal mucosa (Wilmer et al., 1989).

Most of the subchronic data on formaldehyde were based on discontinuous exposures. There has been only one report on formaldehyde's toxicity after a subchronic near-continuous exposure. A 26-w formaldehyde exposure, $22 \mathrm{~h} / \mathrm{d}, 7 \mathrm{~d} / \mathrm{w}$ at $0.2 \mathrm{ppm}$ resulted in increased nasal discharge, but no histopathology, in monkeys, rats, and hamsters (Rusch et al., 1983).

\section{Chronic Data}

Long-term formaldehyde exposures at $6 \mathrm{~h} / \mathrm{d}, 5 \mathrm{~d} / \mathrm{w}$ for 84 or $104 \mathrm{w}$ led to nasal squamous cell carcinoma in Fischer F-344 rats at about 14 ppm (Albert et al., 1982; Kerns et al., 1983). A 104-w exposure at 14.3 ppm 
also produced squamous cell carcinoma in $\mathrm{B}^{6} \mathrm{C} 3 \mathrm{~F}_{1}$ mice (Kerns et al., 1983). The study with the 104-w exposure showed that the rat was more sensitive than the mouse. The incidence in rats was 87 of 160 rats exposed versus 0 of 160 controls, and the incidence in mice was 2 of 88 exposed versus 0 of 89 controls (Kerns et al., 1983; EPA, 1990; Starr, 1990).

Even a subchronic exposure to formaldehyde could be carcinogenic in rats if the exposure concentration is sufficiently high. As mentioned above, a 13-w formaldehyde exposure at $10 \mathrm{ppm}$ produced non-neoplastic changes in the nasal mucosa of rats (Woutersen et al., 1987; Feron et al., 1988). However, a 13-w exposure at $20 \mathrm{ppm}$ is known to cause squamous cell carcinoma, carcinoma in situ, and polyploid adenomas in rats (Feron et al., 1988). It appears that the subchronic exposure has to be also sufficiently long to result in carcinogenesis because a 4- or 8-w exposure at $20 \mathrm{ppm}$ failed to produce nasal cancers in rats (Feron et al., 1988).

The difference between rat and mouse sensitivity to formaldehyde's carcinogenic effect appears to be related to the different responses to formaldehyde's sensory irritation in the two species. Formaldehyde gas depresses the respiration of rats and mice within a minute or two (Chang et al., 1981). The mouse is more sensitive than the rat because it takes only $5 \mathrm{ppm}$ to decrease the minute volume by $50 \%$ in the mouse, compared with $32 \mathrm{ppm}$ in the rat. The minute volume reduction is due to a corresponding decrease in respiratory rate. Other than being less sensitive to formaldehyde's respiratory-depression effect than the mouse, the rat also tends to recover from the respiratory-depression effect during a 10-min formaldehyde exposure, and the respiration of the mouse remains depressed during the $10 \mathrm{~min}$. The respiratory depression effect is the same in naive rats and mice or rats and mice pre-exposed to formaldehyde at $2-15 \mathrm{ppm}$ for $6 \mathrm{~h} / \mathrm{d}$ for $4 \mathrm{~d}$.

\section{Epidemiological Data}

Quite a number of epidemiology studies have been performed with formaldehyde and only some of the more recent ones will be discussed here. In general, the results are inconclusive, but there are indications that certain tumors might be related to formaldehyde exposure in humans. In a retrospective cohort study, conducted by Blair et al. (1986), of workers employed in formaldehyde-using or -producing facilities (exposure concentrations at 0.1 to greater than $2 \mathrm{ppm}$ ), there was a significant increase in 
mortality from nasopharyngeal cancer (Blair et al., 1986). There were also slight, but statistically insignificant, excesses of Hodgkin's disease and cancers of the lung, prostate gland, and oropharynx (Blair et al., 1986). Among these excesses, Hodgkin's disease was statistically correlated with the concentration of exposure, but not with the degree of cumulative exposure, i.e., $\mathrm{C} \times \mathrm{T}$. The excesses of cancers in the other sites were not statistically correlated with either C or C $\times$ T (Blair et al., 1986; Blair et al., 1987). However, a reanalysis of the data by two other investigators demonstrated a significantly higher risk for lung cancer, as well as for all cancers, in workers with higher levels of formaldehyde exposure than those with little or no exposure (Sterling and Weinkam, 1988). In a follow-up study, mortality from lung cancer actually exhibited a slightly negative correlation with formaldehyde exposure in workers exposed to formaldehyde alone (Blair et al., 1990). The mortality from lung cancer, however, was associated with exposure to wood dust, urea, melamine, and phenol rather than with exposure to formaldehyde in workers co-exposed to these substances and formaldehyde, suggesting that exposure to these substances may play a more important role than formaldehyde in causing hung cancer mortality.

In another retrospective cohort mortality study conducted by Stayner et al. (1988), where garment workers were potentially exposed to formaldehyde at $0.15 \mathrm{ppm}$ or higher, there were significant excesses in mortality from cancers of the connective tissue and buccal cavity. The excesses in mortality from leukemia and other lymphopoietic neoplasms were not statistically significant. However, the mortality from buccal cavity cancers, leukemia, and other lymphopoietic neoplasms increased with duration of formaldehyde exposure or latency. The investigators' conclusion was that formaldehyde exposure was possibly related to the development of buccal cancers, leukemias, and other lymphopoietic neoplasms in humans.

Unlike the study by Blair et al. (1987), the study by Stayner et al. (1988) did not show any excess in nasal cancer, probably due to the limited statistical power of the study. Another case-control study with 544 woodworkers exposed to formaldehyde also failed to show a significant increase in the odds ratio for cancer in the upper respiratory tract (Partanen et al., 1990). However, two case-control studies showed that employment in jobs with known formaldehyde exposures was associated with increased risks of nasal and sinus cancers (Hayes et al., 1986; Vaughn et al., 1986a,b). 
A similarity of the two epidemiology studies (Blair et al., 1986; Stayner et al., 1988) is that they both demonstrated a potential link of formaldehyde exposure and lymphopoietic neoplasms, which has also been shown in embalmers and pathologists (Levine et al., 1984; Harrington and Shannon, 1975). Interestingly, lymphopoietic neoplasms were not found in the animal bioassays (Albert et al., 1982; Kerns et al., 1983).

The U.S. Environmental Protection Agency has classified formaldehyde as a probable human carcinogen on the basis of limited evidence in humans and sufficient evidence in animals (EPA, 1990). The International Agency for Research on Cancer considers the evidence for formaldehyde carcinogenicity in humans limited and sufficient for carcinogenicity in animals (IARC, 1987). Formaldehyde has been classified by the American Conference of Governmental Industrial Hygienists as a suspected human carcinogen (TLV Committee, 1989).

\section{Genetic Toxicity}

Formaldehyde causes forward mutation in Salmonella typhimurium, strain TM677, and it also initiates cell transformation of $\mathrm{C} 3 \mathrm{H} / 10 \mathrm{~T} 1 / 2$ cells, a cell line of mouse embryo fibroblasts (Boreiko et al., 1982). Data from in vitro genotoxicity assays performed with formaldehyde should be interpreted with care for two reasons. First, formaldehyde's volatility is so great that $90 \%$ of the formaldehyde in a $250-\mathrm{ppm}$ solution is lost to the head space in closed vials after incubation at room temperature for $1 \mathrm{~h}$ (Proctor et al., 1986). Second, formaldehyde is extremely reactive in culture medium with fetal calf serum, and many interaction products were formed in the medium after a $1-\mathrm{h}$ incubation at $38^{\circ} \mathrm{C}$ (Proctor et al., 1986). These data suggest that only a small portion of formaldehyde remains to act on the genome in in vitro assays. Nevertheless, formaldehyde has been demonstrated to react with the genome in vitro.

\section{Developmental Toxicity}

Formaldehyde is not teratogenic in the rat (Saillenfait, 1989). Inhalation exposure of pregnant rats, on days 6-20 of gestation, to 20 - or 40-ppm formaldehyde reduced fetal body weight, but it caused no malformations (Saillenfait, 1989). 


\section{Synergistic Effects}

Some evidence indicate that formaldehyde might act synergistically with inert particles in causing certain, but not all, of its toxic end points. Due to the fact that carbon particles have been known to exacerbate the mucosal irritation of ammonia (Dalhamn and Reid, 1967), an irritant gas like formaldehyde, it is of interest to determine if inert particles will also potentiate formaldehyde's irritancy. In a Swedish study, in which the exposure levels were not measured, the respiratory symptoms and lung function in workers exposed to formaldehyde alone or formaldehyde with wood dust were compared (Holmstrom and Wilhelmsson, 1988). The formaldehyde-only group developed nasal and eye discomfort sooner than the formaldehyde-wood-dust group; these symptoms started $4.3 \mathrm{y}$ after the start of employment in the formaldehyde-only group versus $9.9 \mathrm{y}$ in the other group. Both groups suffered significant reduction in olfactory function and forced vital capacity, but no change in forced expiratory volume in $1 \mathrm{~s}$ as a fraction of the forced vital capacity (Holmstrom and Wilhelmsson, 1988). The amount of reduction in olfactory function and forced vital capacity were similar between the formaldehyde-only and formaldehydewood-dust groups (Holmstrom and Wilhelmsson, 1988).

In contrast, there appears to be synergism between formaldehyde and wood dust in causing nasal cancers. In a Danish epidemiology study, a nonstatistically significant higher risk ratio of carcinomas of the nasal cavity and sinuses was found with occupational formaldehyde exposure, but the risk ratio became statistically significant if there had been exposure to both formaldehyde and wood dust (Olsen et al., 1984). 


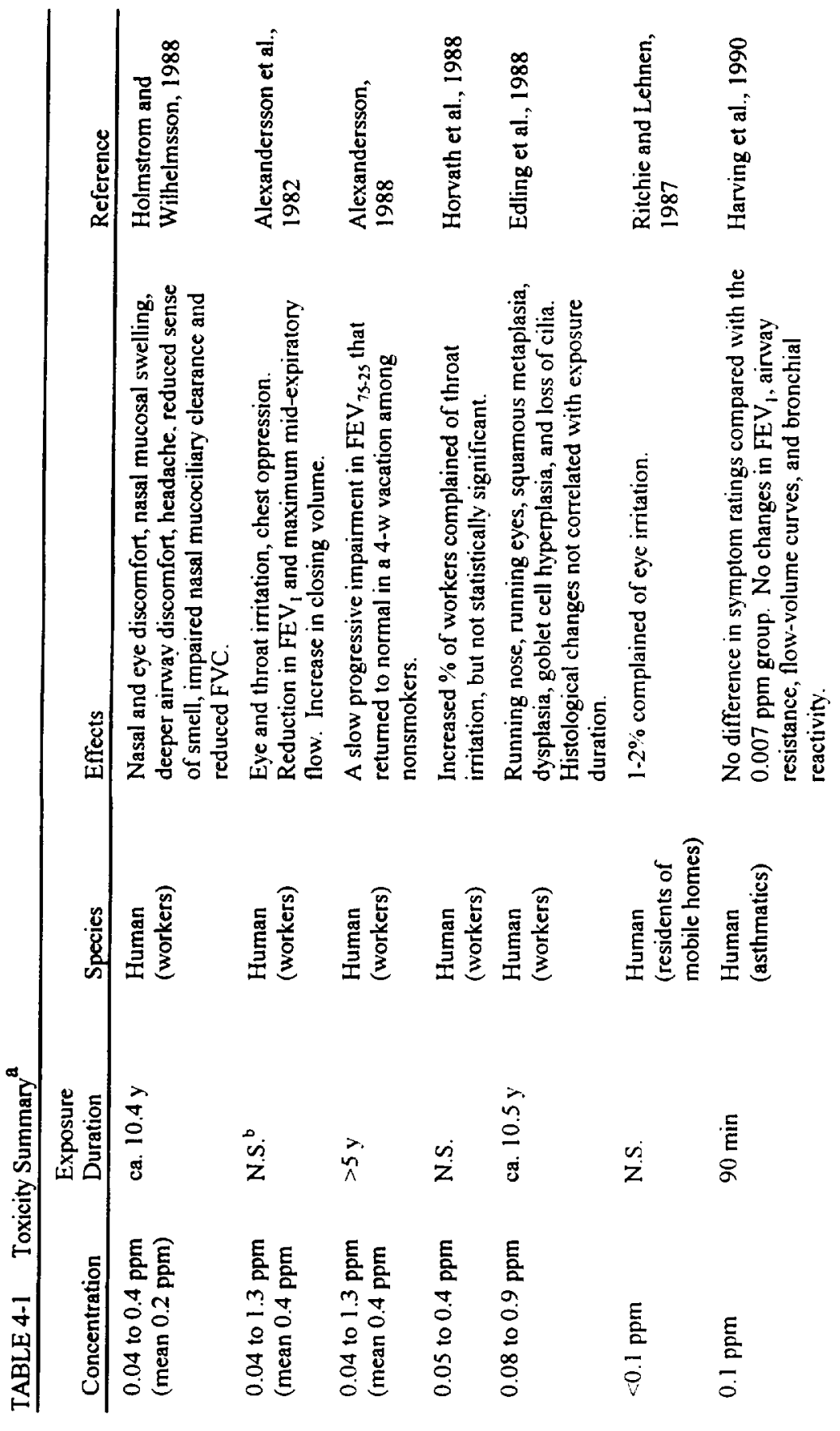




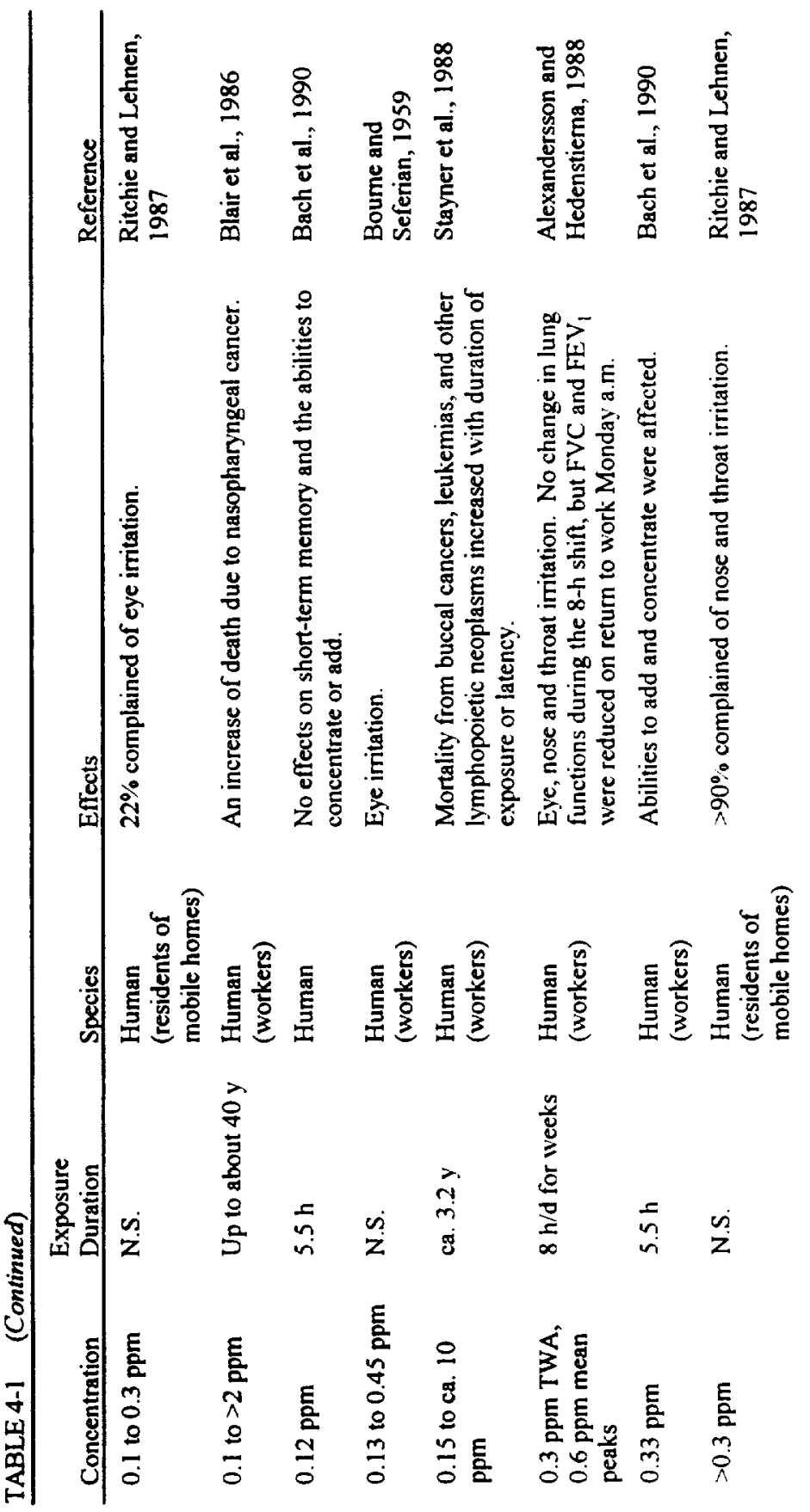




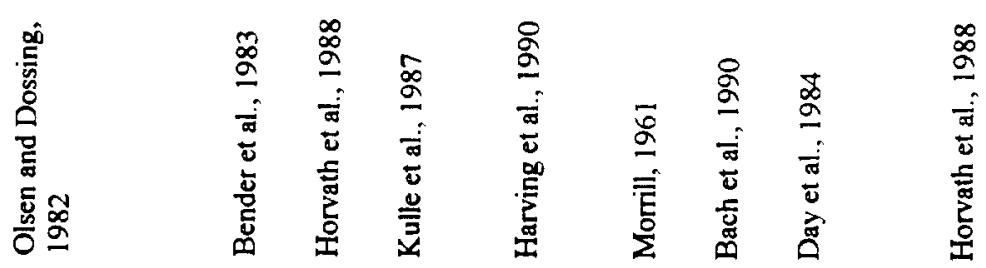

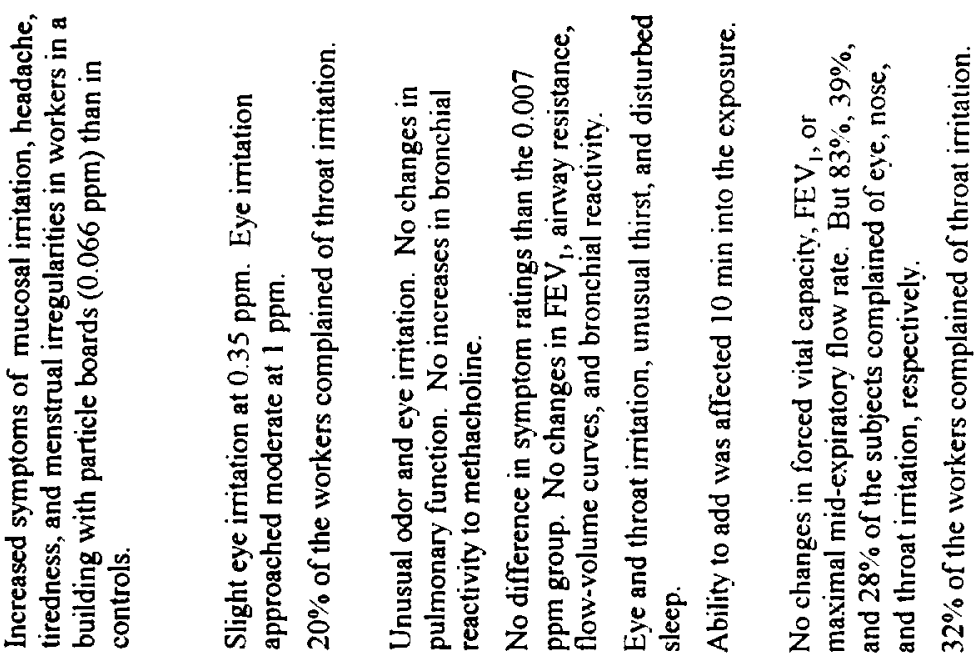

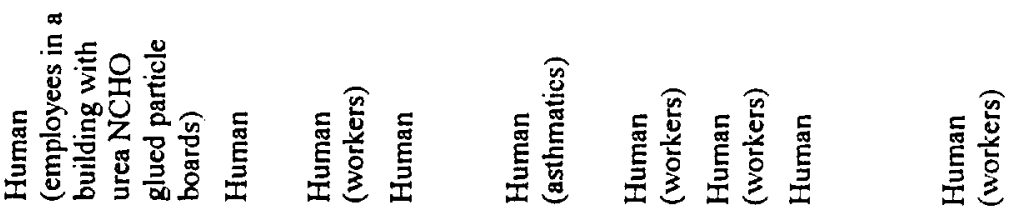

\begin{tabular}{|c|c|c|c|c|c|c|c|c|}
\hline$\stackrel{\oplus}{Z}$ & $\begin{array}{l}\text { 号 } \\
\text { Ẽ }\end{array}$ & $\stackrel{\dot{c}}{z}$ & $\dot{\tilde{z}}$ & $\begin{array}{l}\stackrel{E}{E} \\
\stackrel{8}{\Omega}\end{array}$ & $\stackrel{\dot{D}}{Z}$ & $\begin{array}{l}= \\
i n \\
i n\end{array}$ & $\begin{array}{l}\text { 들 } \\
8\end{array}$ & $\dot{c}$ \\
\hline $\begin{array}{l}\text { E. } \\
\text { 员 } \\
n \\
m \\
0\end{array}$ & 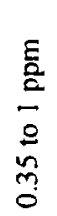 & 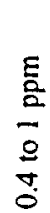 & 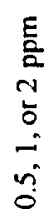 & $\frac{E}{2}$ & $\begin{array}{l}\frac{1}{2} \\
\frac{a}{2} \\
\frac{0}{0} \\
0 \\
0\end{array}$ & 틈 & $\begin{array}{l}E \\
\frac{E}{2} \\
\frac{y}{2} \\
\vdots\end{array}$ & 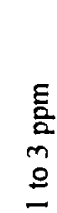 \\
\hline
\end{tabular}




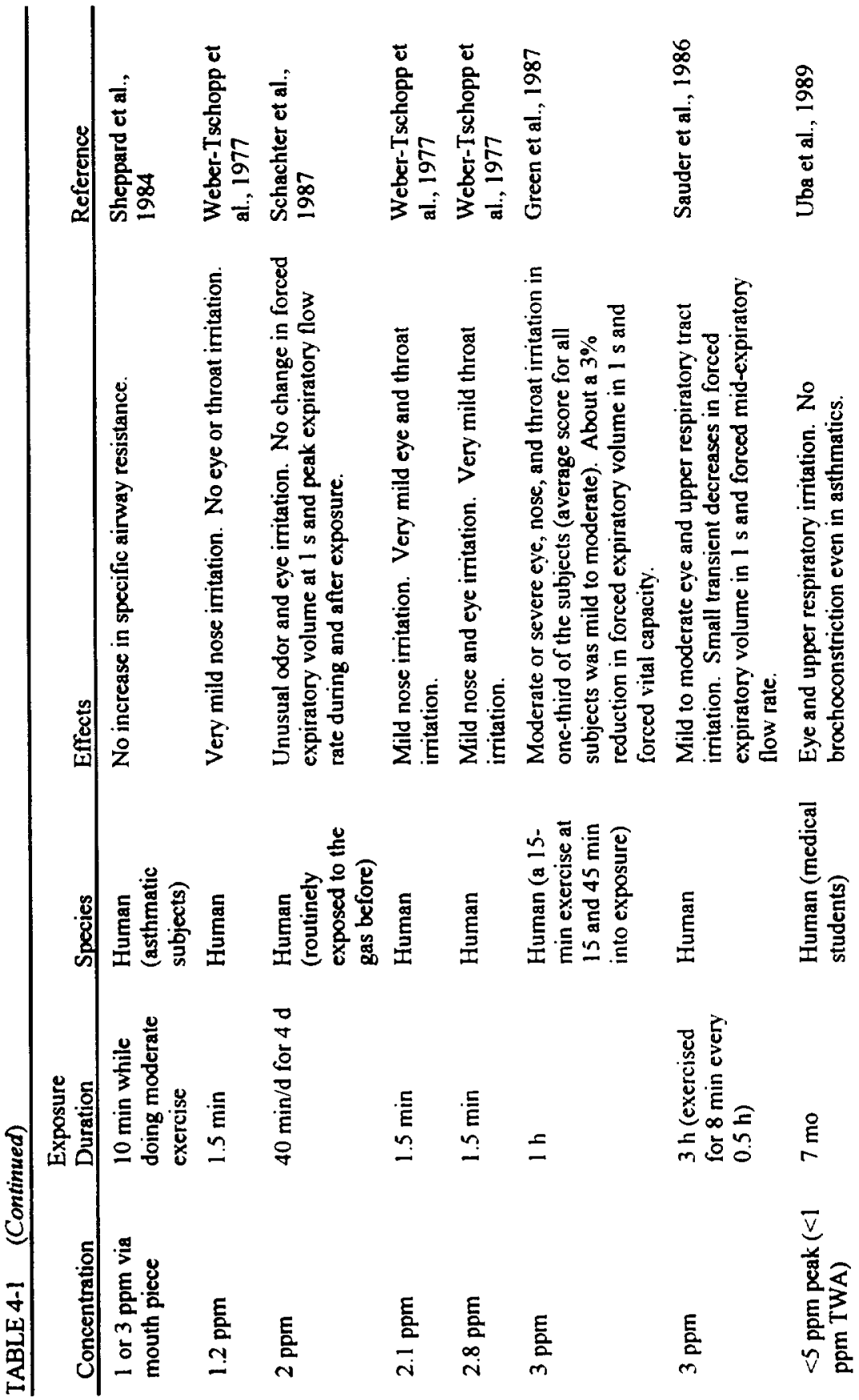




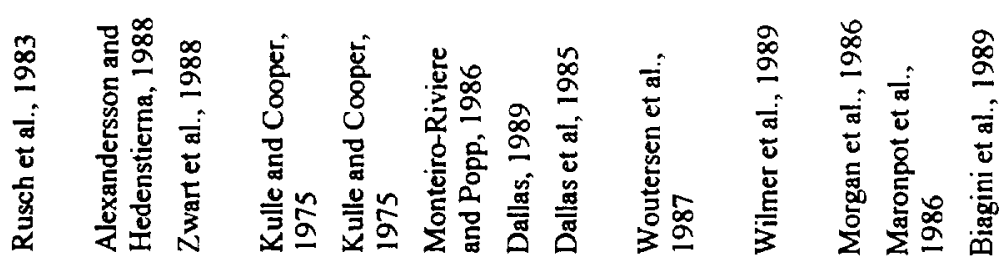

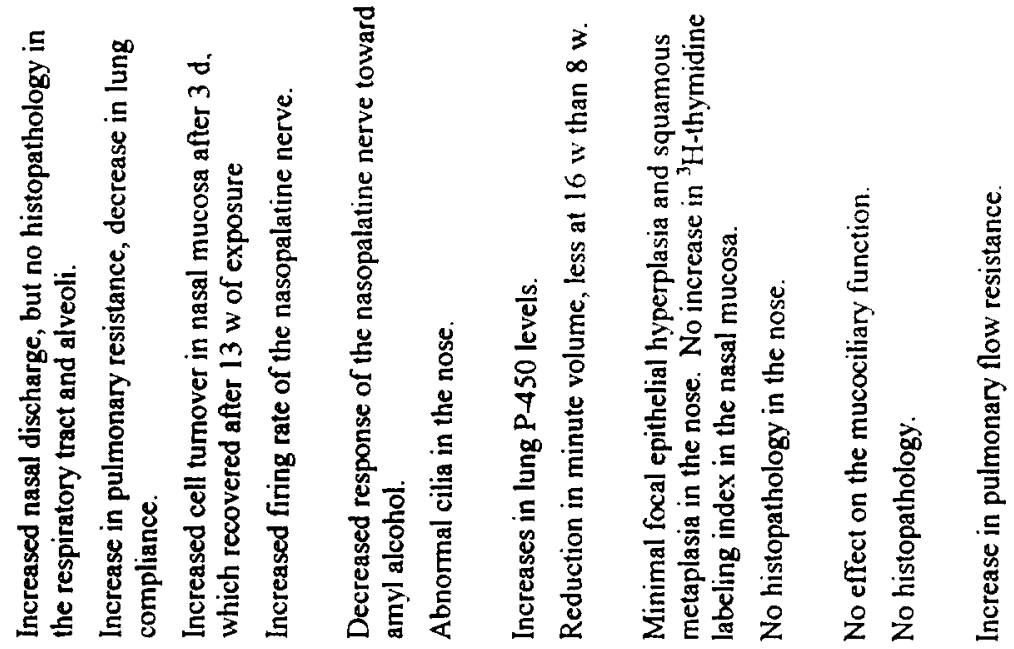

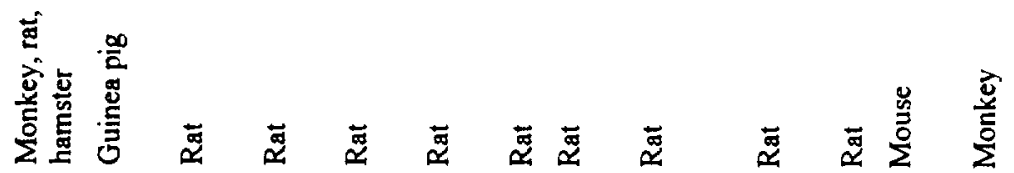

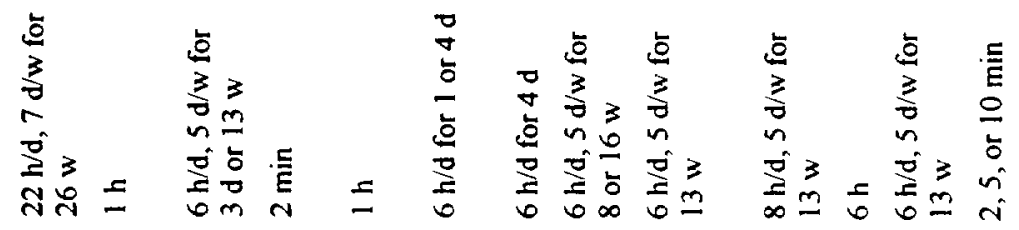

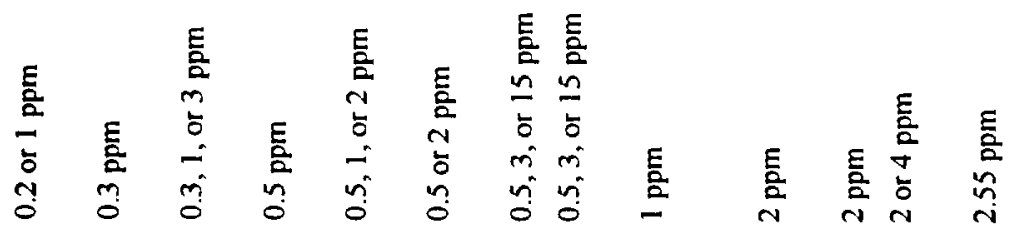




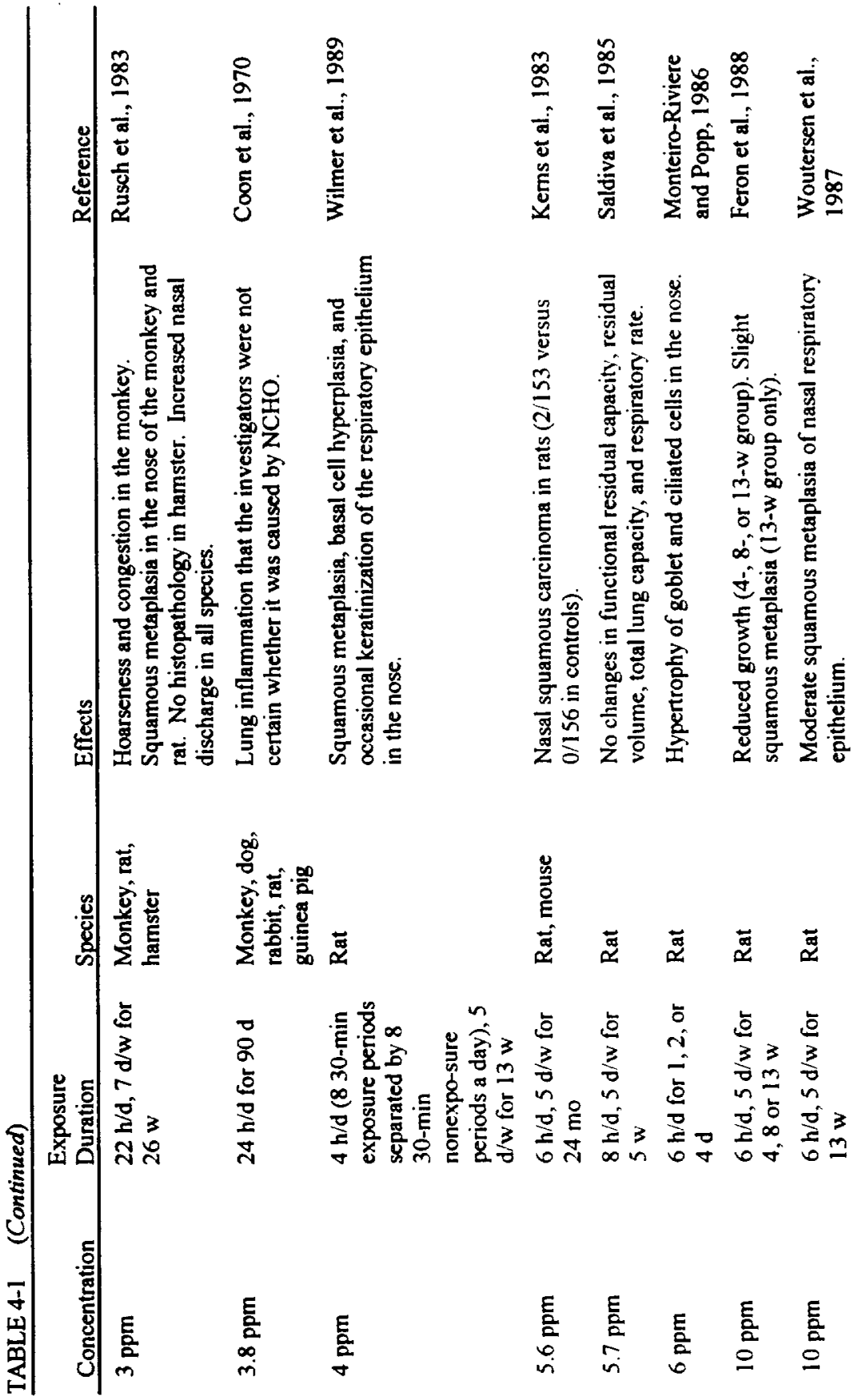



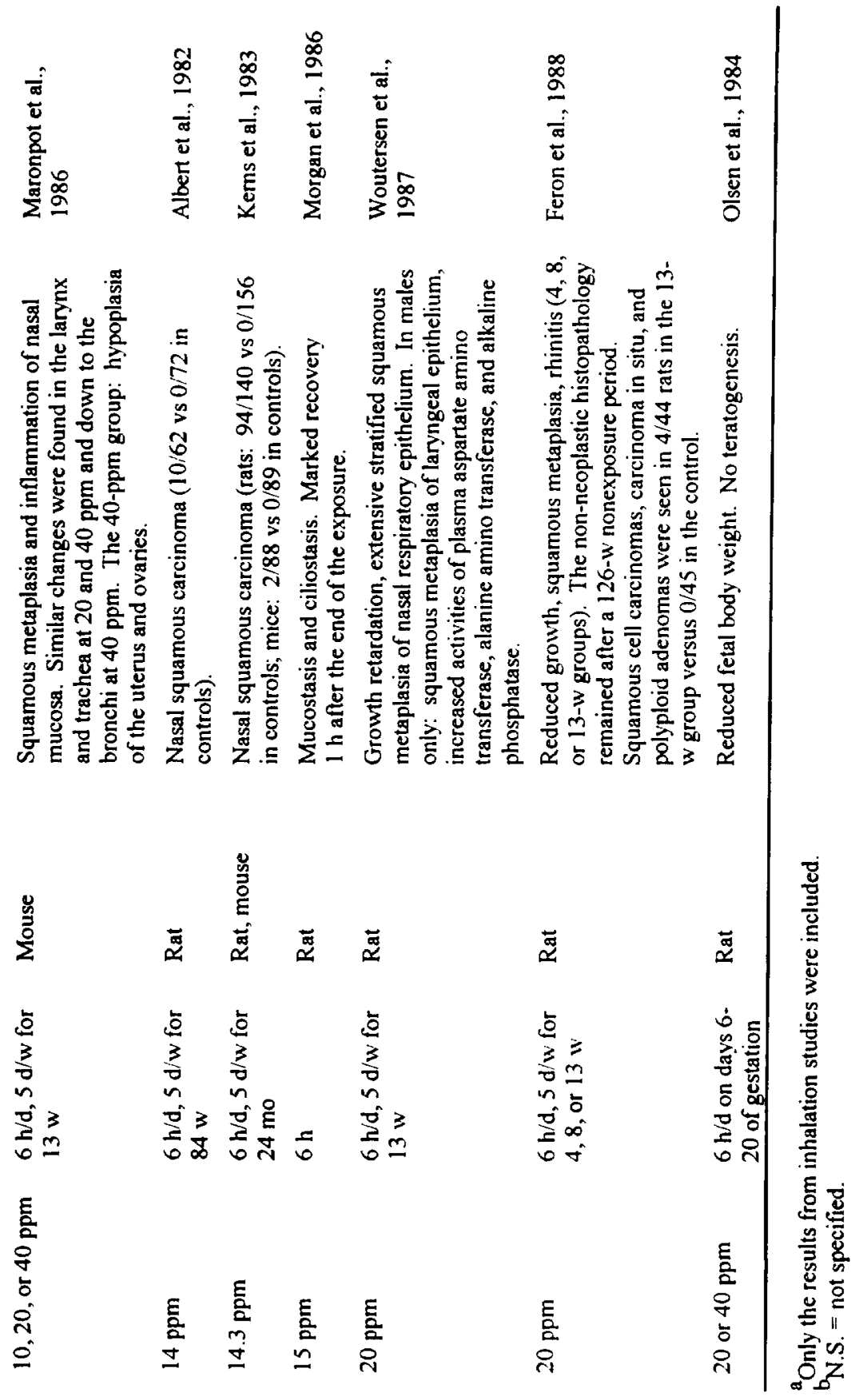
TABLE 4-2 Exposure Limits Set by Other Organizations

\begin{tabular}{ll}
\hline Organization & Concentration, ppm \\
\hline ACGIH's TLV & 1 (0.3 proposed ceiling) \\
OSHA's PEL & 3 (TWA) \\
& 5 (ceiling) \\
NIOSH's REL & Limit exposure to the lowest feasible level \\
NIOSH's IDLH & 100 \\
\hline TLV = threshold limit value. PEL = permissible exposure limit. REL = \\
recommendexl exposure limit. IDLH = immediately dangerous to life and health.
\end{tabular}

TABLE 4-3 Spacecraft Maximum Allowable Concentrations

\begin{tabular}{llll}
\hline Duration $^{\mathrm{a}}$ & $\mathrm{ppm}$ & $\mathrm{mg} / \mathrm{m}^{3}$ & Target Toxicity \\
\hline $1 \mathrm{~h}$ & 0.4 & 0.50 & Mucosal irritation \\
$24 \mathrm{~h}$ & 0.1 & 0.10 & Mucosal irritation \\
$7 \mathrm{~d}^{\mathrm{b}}$ & 0.04 & 0.05 & Mucosal irritation \\
$30 \mathrm{~d}$ & 0.04 & 0.05 & Mucosal irritation \\
$180 \mathrm{~d}$ & 0.04 & 0.05 & Mucosal irritation \\
\hline
\end{tabular}

'Ceiling limits.

${ }^{b}$ Former 7-d SMAC $=0.1 \mathrm{ppm}$

\section{RATIONALE}

In setting the SMACs for formaldehyde, we compared the acceptable concentration (AC) based on noncarcinogenic end points with that based on carcinogenesis for each exposure duration. Among the noncarcinogenic end points, mucosal irritation appears to be the most important. This is because formaldehyde was irritating at as low as $0.1 \mathrm{ppm}$ (Ritchie and Lehnen, 1987; Horvath et al., 1988), but it did not impair lung function until the level reached $3 \mathrm{ppm}$ (Green et al., 1987; Sauder et al., 1986; Kulle et al., 1987; Schachter et al., 1987, Day et al., 1984). Therefore, a formaldehyde level low enough to prevent mucosal irritation will also prevent lung function impairment.

There are no data on the formaldehyde concentrations required to sensitize individuals. In the absence of data, a nonirritating formaldehyde 
level is assumed not to sensitize the astronauts. Therefore, the SMACs set to prevent mucosal irritation would probably also prevent the sensitization of individuals exposed to formaldehyde.

It has been reported that formaldehyde-sensitized nurses developed asthmatic attacks upon re-exposures to formaldehyde (Hendrick and Lane, 1977). If there were astronauts sensitized by prior formaldehyde exposures not related to space flights, the SMACs ideally should be set at levels that would not trigger any reaction in these sensitized astronauts. Unfortunately, in the study with nurses, the formaldehyde concentration required to induce the asthmatic reaction was unknown (Hendrick and Lane, 1977). However, data from two studies have shown that even irritating levels, as high as $3 \mathrm{ppm}$, did not produce any asthmatic attack in asthmatic individuals (Uba et al., 1989; Sheppard et al., 1984). Even though individuals sensitized with formaldehyde cannot be equated with asthmatic individuals, due to the lack of better information, a nonirritating formaldehyde concentration is assumed not to trigger an asthmatic reaction in sensitized astronauts.

\section{Mucosal Irritation}

The short-term SMACs are designed for contingencies, so a minor degree of irritation is acceptable. Based on the Wisconsin mobile-home study, $0.4 \mathrm{ppm}$ would cause eye irritation in about half of the individuals (or $75 \%$ of the individuals based on the upper $95 \%$ confidence limit) (Hanrahan et al., 1984), and based on a human study, $0.35 \mathrm{ppm}$ would cause only slight eye irritation (Bender et al., 1983); therefore, based on mucosal irritation, the $1-\mathrm{h} \mathrm{AC}$ is set at $0.4 \mathrm{ppm}$. To reduce the probability of the crew having to endure mild eye irritation for $24 \mathrm{~h}$, a lower 24-h AC is desirable. The $24-\mathrm{h} \mathrm{AC}$ is, therefore, set at $0.1 \mathrm{ppm}$, which could produce eye irritation in only $4 \%$ of the subjects (or $18 \%$ of the subjects based on the upper $95 \%$ confidence limit) (Hanrahan et al., 1984). Because a little mucosal irritation is acceptable in $1 \mathrm{~h}$ and $24 \mathrm{~h}$, no adjustment is niade for using data generated from a population of only 61 individuals.

Ideally, the long-term SMACs should be set at nonirritating levels, but the threshold concentration for formaldehyde's irritation effect could not be accurately estimated. Lacking a better approach, the "normal" ambient 
level of formaldehyde is taken to be the practical irritation threshold. In the Wisconsin mobile-home study, the outdoor formaldehyde level was $0.04 \pm 0.03 \mathrm{ppm}$ (mean \pm S.D.) (Hanrahan et al., 1984). The indoor formaldehyde level in homes without urea formaldehyde construction materials was $0.03 \pm 0.004 \mathrm{ppm}$ (mean \pm S.D.) (Gupta et al., 1982). From these measurements, the "normal" ambient level appears to be about $0.04 \mathrm{ppm}$. The 180-d, 30-d, and 7-d ACs for irritation are, therefore, set at $0.04 \mathrm{ppm}$. Based on an extrapolation of the concentration-response data of the Wisconsin mobile-home study (Hanraham et al., 1984), the longterm ACs of $0.4 \mathrm{ppm}$ are expected to result in mucosal irritation in less than $1 \%$ of the individuals (or less than $10 \%$ of the individuals based on the upper $95 \%$ confidence limit).

\section{Carcinogenesis}

Some genotoxic carcinogens are known to produce tumors even after a single exposure (Williams and Weisburger, 1985). Formaldehyde is genotoxic and, consequently, its carcinogenicity has to be considered in setting even the 24-h SMAC. Quantitative risk assessments of carcinogens have traditionally been done using the exposure concentration as a measurement of the extent of the carcinogen exposure. However, to quantify the tumor risk of a carcinogen, such as formaldehyde, which shows a tumor response nonlinearly proportional to the exposure concentration in a bioassay, the dose at the target site is preferred over the exposure concentration as a measurement of the extent of exposure (Hoel et al., 1983). The dose at the target site is also preferred if interspecies extrapolation will be done. This is because, for the same exposure concentration, the dose at the target site could differ between the test species and humans owing to species differences in anatomy and physiology.

A group in the Chemical Industry Institute of Toxicology has measured the dose, represented by the amount of formaldehyde bound to DNA, as DNA-protein crosslinks, in the nasal mucosa of rats and monkeys (Starr, 1990; Heck et al., 1990). Their data are shown in the table below together with the tumor data from the 2-y bioassay (Kerns et al., 1983; Starr, 1990). 
TABLE 4-4 Molecular Dosimetry

\begin{tabular}{llll}
\hline $\begin{array}{l}\text { Tumor } \\
\text { Incidence } \\
\text { In Rats }\end{array}$ & $\begin{array}{l}\text { Airborne } \\
\text { Formaldehyde } \\
\text { Conc. (ppm) }\end{array}$ & $\begin{array}{l}\text { DNA Binding } \\
\text { in Rats in 6 h } \\
\text { (pmol/mg DNA) }\end{array}$ & $\begin{array}{l}\text { DNA Binding in } \\
\text { Monkeys in 6 h } \\
\text { (pmol/mg DNA) }\end{array}$ \\
\hline $0 / 160$ & 0 & - & - \\
- & 0.3 & 1.4 & - \\
- & 0.7 & 3.9 & 0.36 \\
$0 / 160$ & 2.0 & 20 & 2.5 \\
$2 / 160$ & 5.6 & $98^{\mathrm{a}}$ & - \\
- & 6.0 & 106 & 18.2 \\
- & 10.0 & 266 & - \\
$87 / 160$ & 14.3 & $439^{\mathrm{a}}$ & - \\
\hline
\end{tabular}

${ }^{a}$ Obtained by interpolation or extrapolation from the data.

They found that the target dose in the nasal mucosa was not linearly proportional to the airborne formaldehyde concentration, so that a linear extrapolation of the target doses at concentrations above $5.6 \mathrm{ppm}$ would overestimate the target doses at low concentrations. That means a quantitative risk assessment using the airborne formaldehyde concentrations would probably overestimate the tumor risk at low exposure concentrations. They also discovered that the doses in the monkey were about 5-10 times lower than that in the rat, indicating that the tumor risk for primates would also be overestimated if the quantitative risk assessment were done using the dosimetry data in the rat.

Starr performed a quantitative risk assessment with the linearized multistage model using the target dose in the nasal mucosa in rats and the tumor incidence data from the bioassay (Starr, 1990). From the DNA binding-data in the monkey, he calculated that inhalation of formaldehyde at $1 \mathrm{ppm}$ for $6 \mathrm{~h}$ is equivalent to a dose of formaldehyde at $0.85 \mathrm{pmol} / \mathrm{mg}$ of DNA in the monkey. He then assumed that a given dose in the nasal mucosa has the same tumor-induction potency in the rat and the monkey (Starr, 1990). Because the quantitative risk assessment with the molecular dosimetry data from the rat shows that a dose of $0.85 \mathrm{pmol} / \mathrm{mg}$ of DNA in the bioassay would yield a tumor risk of 140 cases $/ 10^{6}$ (the upper $95 \%$ confidence limit), a lifetime exposure of monkeys to 1-ppm formaldehyde at $6 \mathrm{~h} / \mathrm{d}, 5 \mathrm{~d} / \mathrm{w}$ would yield the same tumor risk. Assuming that the 
molecular dosimetry of formaldehyde in humans and monkeys is the same, and assuming that the human is as sensitive as the rat toward formaldehyde's carcinogenicity, a formaldehyde exposure at $1 \mathrm{ppm}, 6 \mathrm{~h} / \mathrm{d}$, $5 \mathrm{~d} / \mathrm{w}$ for $70 \mathrm{y}$ would yield 140 cases of tumors $/ 10^{6}$ exposed human beings (the upper $95 \%$ confidence limit) (Starr, 1990).

Assuming a linear dose response in the region of interest to us, a lifetime continuous exposure at $1 \mathrm{ppm}$ would produce in astronauts, based on the molecular dosimetry approach,

$$
\begin{aligned}
& \text { a lifetime tumor risk } \\
& \qquad \begin{array}{l}
=\left(140 / 10^{6}\right) \times(24 \mathrm{~h} / \mathrm{d} \times 7 \mathrm{~d} / \mathrm{w}) /(6 \mathrm{~h} / \mathrm{d} \times 5 \mathrm{~d} / \mathrm{w}) \\
=784 / 10^{6} \\
=7.84 / 10^{4}
\end{array}
\end{aligned}
$$

To get a $10^{-4}$ lifetime tumor risk in astronauts, based on the molecular dosimetry approach,

$$
\begin{aligned}
& \text { formaldehyde concentration } \\
& \quad=1 \mathrm{ppm} / 7.84 \\
& \quad=0.13 \mathrm{ppm}
\end{aligned}
$$

Because NRC's Subcommittee on Guidelines for Developing SMACs felt that the molecular dosimetry approach had not been reviewed by the full Committee on Toxicology (COT) and that it might be more appropriate to express risk on the basis of picomole of formaldehyde bound per cell rather than on per milligram of DNA, the carcinogenic risk was also estimated by the traditional approach.

Based on the EPA's quantitative risk assessment using airborne formaldehyde concentrations as a measure of exposure (EPA, 1990), the lifetime exposure concentration that would yield an upper $95 \%$ confidence limit tumor risk of $10^{-4}$ was calculated to be $0.0063 \mathrm{ppm}$. Therefore, the lifetime exposure concentration yielding a $10^{-4}$ tumor risk from the traditional approach is about 20 times lower than that estimated with the Chemical Industrial Institute of Toxicology's molecular dosimetry approach. According to the NRC subcommittee, the ACs, using carcinogenesis as the basis, are calculated below with the traditional approach.

Based on that approach (NRC, 1990) and setting $k=3, t=25,550 \mathrm{~d}$, 
and $s_{1}=10,950 \mathrm{~d}$, the adjustment factor is calculated to be 26,082 for calculating a near-instantaneous exposure level that would yield the same excess tumor risk as a continuous lifetime exposure.

24-h exposure level that would yield an excess tumor risk of $10^{-4}$ $=0.0063 \mathrm{ppm} \times 26,082$

$=164 \mathrm{ppm}$.

For the 7-d, 30-d, and 180-d ACs, adjustment factors are calculated with the COT approach (NRC, 1990), setting $\mathrm{k}=3, \mathrm{t}=25,550 \mathrm{~d}$, and assuming that the earliest age of exposure is $30 \mathrm{y}$. The adjustment factors are 3728,871 , and 146.7 for a continuous $7-d, 30-d$, and 180-d exposure, respectively, that would yield the same excess tumor risk as a continuous life-time exposure.

7-d exposure level that would yield an excess tumor risk of $10^{-4}$

$=0.0063 \mathrm{ppm} \times 3728$

$=23 \mathrm{ppm}$.

30-d exposure level that would yield an excess tumor risk of $10^{-4}$ $=0.0063 \mathrm{ppm} \times 871$

$=6 \mathrm{ppm}$.

$180-\mathrm{d}$ exposure level that would yield an excess tumor risk of $10^{-4}$ $=0.0063 \mathrm{ppm} \times 146.7$

$=0.9 \mathrm{ppm}$.

\section{Establishment of SMACs}

After the ACs for mucosal irritation and carcinogenesis are tabulated below, it is quite apparent that mucosal irritation is a more sensitive end point. The 1-h, 24-h, 7-d, 30-d, and 180-d SMACs are set at the corresponding ACs based on mucosal irritation and they are $0.4,0.1,0.04$, 0.04 , and $0.04 \mathrm{ppm}$, respectively. Finally, because it is not anticipated that microgravity effects on the body would affect the irritancy or carcinogenicity of formaldehyde, the SMACs are not adjusted for any microgravity-induced physiological effects. 
TABLE 4-5 Acceptable Concentrations

\begin{tabular}{llllll}
\hline & \multicolumn{6}{l}{ Acceptable Concentrations, ppm } \\
\cline { 2 - 6 } Toxic End Points & $1 \mathrm{~h}$ & $24 \mathrm{~h}$ & $\mathbf{7 d}$ & $30 \mathrm{~d}$ & $180 \mathrm{~d}$ \\
\hline Mucosal irritation & 0.4 & 0.1 & 0.04 & 0.04 & 0.04 \\
Carcinogenesis & 3400 & 164 & 23 & 6 & 0.9 \\
\hline SMAC & 0.4 & 0.1 & 0.04 & 0.04 & 0.04 \\
\hline
\end{tabular}

\section{REFERENCES}

Albert, R.E., A.R. Sellakumar, S. Laskin, M. Kruschner, and N. Nelson. 1982. Gaseous formaldehyde and hydrogen chloride induction of nasal cancer in the rat. J. Natl. Cancer Inst. 68:597-603.

Alexandersson, R. 1988. Decreased lung function and exposure to formaldehyde in the wood working industry. A five-year follow-up. Arh. Hig. Rada Toksikol./Arch. Ind. Hyg. Toxicol. 39:421-424.

Alexandersson, R. and G. Hedenstierna. 1988. Respiratory hazards associated with exposure to formaldehyde and solvents in acid-curing paints. Arch. Environ. Health 43:222-227.

Alexandersson, R., B. Kolmodin-Hedman, and G. Hedenstierna. 1982. Exposure to formaldehyde: Effects on pulmonary function. Arch. Environ. Health 37:279-284.

Bach, B., O.F. Pedersen, and L. Molhave. 1990. Human performance during experimental formaldehyde exposure. Environ. Int. 16:105-113.

Bender, J.R., L.S. Mullin, J. Graepel, and W.E. Wilson. 1983. Eye irritation response of humans to formaldehyde. Am. Ind. Hyg. Assoc. J. 44:463-465.

Biagini, R.E., W.J. Moorman, E.A. Knecht, J.C. Clark, and I.L. Bernstein. 1989. Acute airway narrowing in monkeys from challenge with $2.5 \mathrm{ppm}$ formaldehyde generated from formalin. Arch. Environ. Health 44:12-17.

Blair, A., P. Stewart, M. O'Berg, W. Gaffey, J. Walrath, J. Ward, R. Bales, S. Kaplan, and D. Cubit. 1986. Mortality among industrial workers exposed to formaldehyde. J. Natl. Cancer Inst. 76:1071-1084.

Blair, A., P.A. Stewart, R.N. Hoover, J.F. Fraumeni, Jr., J. Walrath, M. O'Berg, and W. Gaffey. 1987. Cancers of the naso/pharynx and 
oropharynx and formaldehyde exposure. J. Natl. Cancer Inst. 78:191193.

Blair, A., P.A. Stewart, and R.N. Hoover. 1990. Mortality from lung cancer among workers employed in formaldehyde industries. Am. J. Ind. Med. 17:683-699.

Boreiko, C.J., D.B. Couch, and J.A. Swenberg. 1982. Mutagenic and carcinogenic effects of formaldehyde. Pp. 353-367 in Genotoxic Effects of Airborne Agents. R.R. Tice et al., eds. Plenum, New York.

Bourne, H.G. and S. Seferian. 1959. Formaldehyde in wrinkle-proof apparel produces tears for milady. Ind. Med. Surg. 28:232.

Casanova, M., H.d'A. Heck, J.I. Everitt, W.W. Harrington, Jr., and J.A. Popp. 1988. Formaldehyde concentrations in the blood of rhesus monkeys after inhalation exposure. Food Chem. Toxicol. 26:715-716.

Casanova-Schmitz, M., R.M. David, and J. d'A. Heck. 1984. Oxidation of formaldehyde and acetaldehyde by $\mathrm{NAD}^{+}$-dependent dehydrogenases in rat nasal mucosal homogenates. Biochem. Pharmacol. 33:1137-1142.

Chang, J.C.F., W.H. Steinhagen, and C.S. Barrow. 1981. Effect of single or repeated formaldehyde exposure to minute volume of $\mathrm{B} 6 \mathrm{C} 3 \mathrm{~F} 1$ mice and F-344 rats. Toxicol. Appl. Pharmacol. 61:451-459.

Coon, R.A., R.A. Jones, L.J. Jenkins, Jr., and J. Siegel. 1970. Animal inhalation studies on ammonia, ethylene chloride, formaldehyde, dimethylamine, and ethanol. Toxicol. Appl. Pharmacol. 16:646-655.

Dalhamn, T. and L. Reid. 1967. Ciliary activity and histologic observations in the trachea after exposure to ammonia and carbon particles. Pp. 299-306 in Inhaled Particles and Vapours II. C.N. Davies, ed. Oxford, U.K.: Pergamon Press.

Dallas, C.E. 1989. The influence of inhaled formaldehyde on rat lung cytochrome P-450. Environ. Res. 49:50-59.

Dallas, C.E., J.C. Theiss, R.B. Harriet, and E.J. Fairchild. 1985. Effect of subchronic formaldehyde inhalation on minute volume and nasal deposition in Sprague-Dawley rats. J. Toxicol. Environ. Health 16:553564.

Day, J.H., R.E.M. Lees, R.H. Clark, and P.L. Pattee. 1984. Respiratory response to formaldehyde and off-gas of urea formaldehyde foam insulation. Can. Med. Assoc. J. 131:1061-1065.

Edling, C., H. Hellquist, and L. Odkvist. 1988. Occupational exposure to formaldehyde and histopathological changes in the nasal mucosa. $\mathrm{Br}$. J. Ind. Med. 45:761-765. 
EPA. 1990. Formaldehyde. In Integrated Risk Information System, a computerized database by the Environmental Criteria and Assessment Office, U.S. Environmental Protection Agency, Cincinnati, Ohio.

Feron, V.J., J.P. Bruynitjes, R.A. Woutersen, H.R. Immel, and L.M. Appelman. 1988. Nasal tumours in rats after short-term exposure to a cytotoxic concentration of formaldehyde. Cancer Lett. 39:101-111.

Green, D.J., L.R. Sauder, T.J. Kulle, and R. Bascom. 1987. Acute response to $3.0 \mathrm{ppm}$ formaldehyde in exercising healthy nonsmokers and asthmatics. Am. Rev. Resp. Dis. 135:1261-1266.

Gupta, K.C., A.G. Ulsamer, and P.W. Preuss. 1982. Formaldehyde in indoor air: Source and toxicity. Environ. Int. 8:349-358.

Hanrahan, L.P., L.P. Hanrahan, K.A. Dally, H.A. Anderson, M.S. Kanarek, and J. Rankin. 1984. Formaldehyde vapor in mobile homes: A cross sectional survey of concentrations and irritant effects. Am. J. Public Health 74:1026-1027.

Harrington, J.M and H.S. Shannon. 1975. Mortality study of pathologists and medical laboratory technicians. Br. Med. J. 4:329-332.

Harving, H., J. Korsgaard, O.F. Pedersen, L. Molhave, and R. Dahl. 1990. Pulmonary function and bronchial reactivity in asthmatics during low-level formaldehyde exposure. Lung 168:15-21.

Hayes, R.B., J.W. Raatgever, and A. de Bruyn. 1986. Cancer of the nasal cavity and paranasal sinuses, and formaldehyde exposure. Int. J. Cancer 37:487-492.

Heck, H. d'A., M. Casanova, and T.B. Starr. 1990. Formaldehyde toxicity - new understanding. Crit. Rev. Toxicol. 20:397-426.

Heck, H., M. Casanova-Schmitz, P.B. Dodd, E.N. Schachter, T.J. Witek, and $\mathrm{T}$. Tosun. 1985. Formaldehyde $\left(\mathrm{CH}_{2} \mathrm{O}\right)$ concentration in the blood of humans and Fischer-344 rats exposed to $\mathrm{CH}_{2} \mathrm{O}$ under controlled conditions. Am. Ind. Hyg. Assoc. J. 46:1-3.

Hendrick, D.J. and D.J. Lane. 1977. Occupational formalin asthma. Br. J.Ind. Med. 34:11-18.

Hoel, D.G., N.L. Kaplan, and M.W. Anderson. 1983. Implication of nonlinear kinetics on risk estimation in carcinogenesis. Science 219: 1032-1037.

Holmstrom, M. and B. Wilhelmsson. 1988. Respiratory symptoms and pathophysiological effects of occupational exposure to formaldehyde and wood dust. Scand. J. Work Environ. Health 14:306-311.

Horvath, E.P., Jr., H. Anderson, W.E. Pierce, L. Hanrahan, and J.D. 
Wendlick. 1988. The effects of formaldehyde on mucus membranes and lungs. J. Am. Med. Assoc. 259:701-707.

Huennekens, F.M. and M.J. Osborne. 1959. Folic acid coenzymes and one-carbon metabolism. Adv. Enzymol. 21:369.

IARC. 1987. Formaldehyde. Pp. 211-215 in IARC Monographs on the Evaluation of Carcinogenic Risks to Humans. Overall Evaluations of Carcinogenicity: An Updating of IARC Monographs. Vols. 1-42, Suppl. 7. International Agency for Research on Cancer, Lyon, France.

James, J.T. 1991. Toxicological Assessment of Noxious Odors Produced by the Orbiter Refrigerator Freezer During the STS-40 Mission. JSC Memorandum, SD4/91-308, Aug. 13, 1991. Johnson Space Center, Houston, Tex.

Kerns, W.D., K.L. Pavkov, D.J. Donofrio, E.J. Galla, and J.A. Swenberg. 1983. Carcinogenicity of formaldehyde in rats and mice after long-term inhalation exposure. Cancer Res. 43:4382-4392.

Koivusalo, M., T. Koivula, and L. Uotila. 1982. Oxidation of formaldehyde by nicotinamide nucleotide dependent dehydrogenases. P. 155 in Enzymology of Carbonyl Metabolism: Aldehyde Dehydrogenase and Aldol Keto Reductase. H. Weiner and B. Wermuth, eds. Alan R. Liss, New York.

Kulle, T.J. and G.P. Cooper. 1975. Effects of formaldehyde and ozone on the trigeminal nasal sensory system. Arch. Environ. Health 30:237243.

Kulle, T.J., L.R. Sauder, J.R. Hebel, D.J. Green, and M.D. Chatham. 1987. Formaldehyde dose-response in healthy non-smokers. J. Am. Pollut. Control Assoc. 37:919-924.

Levine, R.J., D.A. Andjelkovich, and L.K. Shaw. 1984. Mortality of Ontario undertakers and a review of formaldehyde-related mortality studies. J. Occup. Med. 26:740-746.

Maronpot, R.R., R.A. Miller, W.J. Clarke, R.B. Westerberg, J.R. Decker, and O.R. Moss. 1986. Toxicity of formaldehyde vapor in B6C3F1 mice exposed for 13 weeks. Toxicology 41:253-266.

McMartin, K.E., G. Martin-Amat, P.E. Noker, and T.R. Tephly. 1979. Lack of a role for formaldehyde in methanol poisoning in the monkey. Biochem. Pharmacol. 28:645-649.

Monteiro-Riviere, N.A. and J.A. Popp. 1986. Ultrastructural evaluation of acute nasal toxicity in the rat respiratory epithelium in response to formaldehyde gas. Fund. Appl. Toxicol. 6:251-262. 
Morgan, K.T., E.A. Gross, and D.L. Patterson. 1986. Distribution, progression, and recovery of acute formaldehyde-induced inhibition of nasal mucociliary function in F-344 rats. Toxicol. Appl. Pharmacol. 86:448-456.

Morrill, Jr., E.E. 1961. Formaldehyde exposure from paper process solved by air sampling and current studies. Air Cond. Heat. Vent. 58:94-95.

NRC. 1980. Formaldehyde-An Assessment of Its Health Effects. National Academy Press, Washington, D.C.

NRC. 1990. Guidelines for Developing Spacecraft Maximum Allowable Concentrations for Space Station Contaminants. National Academy Press, Washington, D.C.

Olsen, J.H. and M. Dossing. 1982. Formaldehyde induced symptoms in day care centers. Am. Ind. Hyg. Assoc. J. 43:366-370.

Olsen, J.H., S.P. Jensen, H. Morgan, K. Faurbo, N.O. Breum, and O.M. Jensen. 1984. Occupational formaldehyde exposure and increased nasal cancer risk in man. Int. J. Cancer 34:639-644.

Partanen, T., T. Kauppinen, S. Hernberg, J. Nickels, R. Luukkonen, T. Hakulinen, and E. Pukkala. 1990. Formaldehyde exposure and respiratory cancer among woodworkers-An update. Scand. J. Work Environ. Health 16:394-400.

Peto, P.G. 1981. Results of Soviet-Hungarian Space Research. East Europe Report No. 699, April 3, 1981. Pp. 4-12.

Proctor, B.L., M.E. Gaulden, and M.A. Dowd. 1986. Reactivity and fate of benzene and formaldehyde in culture medium with and without fetal calf serum; relevance to in vitro mutagenicity testing. Mutat. Res. 160: 259-266.

Ritchie, I.M and R.G. Lehnen. 1987. Formaldehyde-related complaints of residents living in mobile and conventional homes. Am. J. Public Health 77:323-328.

Rusch, G.M., J.J. Clary, W.E. Rinehart, and H.F. Bolte. 1983. A 26-week inhalation toxicity study with formaldehyde in the monkey, rat, and hamster. Toxicol. Appl. Pharmacol. 68:329-343.

Saillenfait, A.M. 1989. The effects of maternally inhaled formaldehyde on embryonal and foetal development in rats. Food Chem. Toxicol. 27:545-548.

Saldiva, P.H., M.P. do Rio Caldeira, E. Massad, D.F. Calheiros, L.M. Cardoso, G.M. Bohm, and C.D. Saldiva. 1985. Effects of formalde- 
hyde and acetaldehyde inhalation on rat pulmonary mechanics. J. Appl. Toxicol. 5:288-292.

Sauder, L.R., M.D. Chatham, D.J. Green, and T.J. Kulle. 1986. Acute pulmonary response to formaldehyde exposure in healthy nonsmokers. J. Occup. Med. 28:420-424.

Sax, N.I. 1984. P. 1451 in Dangerous Properties of Industrial Materials. Van Nostrand Reinhold, New York.

Schachter, E.N., T.J. Witek, Jr., D.J. Brody, T. Tosun, G.J. Beck, and B.P. Leaderer. 1987. A study of respiratory effects from exposure to $2.0 \mathrm{ppm}$ formaldehyde in occupationally exposed workers. Environ. Res. 44:188-205.

Sheppard, D., W.L. Eschenbacher, and J. Epstein. 1984. Lack of bronchomotor response to up to $3 \mathrm{ppm}$ formaldehyde in subjects with asthma. Environ. Res. 35:133-139.

Starr, T.B. 1990. Workshop on indoor air quality. Quantitative cancer risk estimation for formaldehyde. Risk Anal. 10:85-91.

Stayner, L.T., L. Elliott, L. Blade, R. Keenlyside, and W. Halperin. 1988. A retrospective cohort mortality study of workers exposed to formaldehyde in the garment industry. Am. J. Ind. Med. 13:667-681.

Sterling, T.D. and J.J. Weinkam. 1988. Reanalysis of lung cancer mortality in the National Cancer Institute study on mortality among industrial workers exposed to formaldehyde. J. Occup. Med. 30:895901.

TLV Committee. 1989. Documentation of TLV's and BEI's. American Conference of Governmental Industrial Hygienists, Cincinnati, Ohio.

Tuthill, R.W. 1984. Brief reports. Woodstoves, formaldehyde, and respiratory disease. Am. J. Epidemiol. 120: 952-955.

Uba, G., D. Pachorek, J. Bernstein, D.H. Garabrant, J.R. Balmes, W.E. Wright, and R.B. Amar. 1989. Prospective study of respiratory effects of formaldehyde among healthy and asthmatic medical students. Am. J. Ind. Med. 15:91-101.

Uotila, L. and M. Koivusalo. 1974. Formaldehyde dehydrogenase from human liver: Purification, properties and evidence for the formation of glutathione thiol esters by the enzyme. J. Biol. Chem. 249:7653-7663.

Vaughn, T.L., C. Strader, S. Davis, and J.R. Daling. 1986a. Formaldehyde and cancers of the pharynx, sinus and nasal cavity. I. Occupational exposures. Int. J. Cancer 38:677-683.

Vaughn, T.L., C. Strader, S. Davis, and J.R. Daling. 1986b. Formal- 
dehyde and cancers of the pharynx, sinus and nasal cavity. II. Residential exposures. Int. J. Cancer 38:685-688.

Weber-Tschopp, A., T. Fischer, and E. Grandjean. 1977. [Irritating effects of formaldehyde on man.] Int. Arch. Occup. Environ. Health 39:207-218.

Williams, G.M. and J.H. Weisburger. 1985. P. 104 in Casarett and Doull's Toxicology: The Basic Science of Poisons. C.D. Klaassen, M.O. Amdur, and J. Doull, eds. Macmillan, New York.

Wilmer, J.W.G.M., R.A. Woutersen, L.M. Appelman, W.R. Leeman, and V.J. Feron. 1989. Subchronic (13-week) inhalation toxicity study of formaldehyde in male rats: 8-hour intermittent versus 8-hour continuous exposures. Toxicol. Lett. 47:287-293.

Woutersen, R.A., L.M. Appelman, J.W.G.M. Wilmer, H.E. Falke, and V.J. Feron. 1987. Subchronic (13-week) inhalation toxicity study of formaldehyde in rats. J. Appl. Toxicol. 7:43-49.

Zwart, A., R.A. Woutersen, J.W.G.M. Wilmer, B.J. Spit, and V.J. Feron. 1988. Cytotoxic and adaptive effects in rat nasal epithelium after 3-day and 13-week exposure to low concentrations of formaldehyde vapour. Toxicology 51:87-99. 


\title{
B5 Freon 113
}

Hector D. Garcia, Ph.D., and John T. James, Ph.D.

Johnson Space Center Toxicology Group

Biomedical Operations and Research Branch

Houston, Texas

\section{PHYSICAL AND CHEMICAL PROPERTIES}

Freon 113 is a colorless, odorless, nonflammable liquid at room temperature (Sax, 1984; Imbus and Adkins, 1972).

\author{
Formula: $\mathrm{CCl}_{2} \mathrm{FCClF}_{2}$ \\ CAS number: 76-13-1 \\ Chemical name: 1,1,2-trichloro-1,2,2-trifluoroethane \\ Synonyms: FC113; fluorocarbon 113; Frigen \\ 113; CFC-113; TCTF; Freon TF; \\ Genesolv D; Freon PCA; Isotron \\ 113; Cleaning compound $\mathrm{S}$; Clean- \\ ing compound solvent trichlorotri- \\ fluoroethane (MIL-C-81302). \\ Molecular weight: $\quad 197.5$ \\ Boiling point: $47.6^{\circ} \mathrm{C}$ \\ Melting point: $-35^{\circ} \mathrm{C}$ \\ Specific gravity: $1.5635 \mathrm{~g} / \mathrm{L}\left(25^{\circ} \mathrm{C}\right)$ \\ Vapor pressure: $284 \mathrm{~mm} \mathrm{Hg}$ at $20^{\circ} \mathrm{C}$ \\ Solubility: Insoluble in water; soluble in \\ alcohol, ether, and benzene \\ Conversion factors at $25^{\circ} \mathrm{C}, 1 \mathrm{~atm}: \quad 1 \mathrm{ppm}=8.0 \mathrm{mg} / \mathrm{m}^{3}$ \\ $1 \mathrm{mg} / \mathrm{m}^{3}=0.12 \mathrm{ppm}$
}




\section{OCCURRENCE AND USE}

FC113 does not occur naturally. It is manufactured for use principally as a dry-cleaning solvent, refrigerant, and blowing agent. It is also used as a cleaning solvent for metals and sensitive electronic parts and in the maintenance of hydraulic piping systems in submarines. FC113 has been piped into each of three clean rooms at Kennedy Space Center for use in cleaning, hydrocarbon sampling, particle sampling and general degreasing. FC113 is not used in the spacecraft during flight, but has been used to clean and degrease spacecraft components between missions. It has been detected in the atmosphere in the spacecraft in almost every mission, usually at low levels, the highest to date being $8.7 \mathrm{ppm}$ (Liebich et al., 1975).

\section{PHARMACOKINETICS}

Inhaled FC1 13 distributes in a dose-dependent manner into the perirenal fat and brain of rats; the concentrations were 126,506 , and $1133 \mathrm{nmol} / \mathrm{g}$ of fat after exposure to 200,1000 , and $2000 \mathrm{ppm}$, respectively, for $6 \mathrm{~h} / \mathrm{d}, 5$ $d / w$, for 2 w (Savolainen and Pffäfli, 1980).

Blood concentrations of FC113 in dogs inhaling FC113 at 1000, 5000, or $10,000 \mathrm{ppm}$ increased rapidly during the first $5 \mathrm{~min}$, then more slowly or not at all for the remainder of a 10-min exposure (Trochimowicz et al., 1974). The kinetics of blood-level variations suggest a tissue uptake of FC113 during exposure, followed by a release into the venous blood after the exposure is terminated. FC113 is rapidly eliminated from the bloodstream and expelled through the lungs after cessation of exposure, having a venous half-life of approximately $15 \mathrm{~min}$.

A study (Woolen et al., 1990) in seven male human volunteers of blood and breath levels during, and for several days after, exposure to FC113 for $4 \mathrm{~h}$ at concentrations of 240,490 , or $920 \mathrm{ppm}$ suggested a three compartment model (e.g. blood, tissues, fat) with half-lives for the elimination of FC1 13 in the breath of $0.22,2.3$, and $29 \mathrm{~h}$, respectively. Blood concentrations of FC113 approached a plateau after approximately 30 min exposure and peak concentrations were related to the exposure concentrations. Pulmonary retention of $14 \%$ was measured during exposure but only 2.6$4.3 \%$ of the dose was recovered unchanged in breath after the exposure 
period, suggesting that $\mathrm{FCl} 13$ could be metabolized following inhalation exposure. The data from this study do not permit a firm conclusion to be drawn as to whether FC113 is metabolized by humans (Auton and Woolen, 1991).

In another study (Reinhardt et al., 1971), four human male volunteers were exposed to $\mathrm{FCl} 13$ for $5 \mathrm{~d}$ at $500 \mathrm{ppm}, 3 \mathrm{~h}$ each morning and $3 \mathrm{~h}$ each afternoon, followed $3 \mathrm{~d}$ later by exposure for $5 \mathrm{~d}$ at $1000 \mathrm{ppm}, 3 \mathrm{~h}$ each morning and $3 \mathrm{~h}$ each afternoon. Measurements were taken of FC113 levels in end tidal breaths taken $1 \mathrm{~min}$ after the end of each exposure. The highest measured level was $115 \mathrm{ppm}$ on the afternoon following the first exposure at $1000 \mathrm{ppm}$ in one subject. End tidal breath levels taken on the third day following the last exposure showed FC113 concentrations of 1.5 $\mathrm{ppm}$ in one subject and less than $1 \mathrm{ppm}$ in the other three subjects. Although this result demonstrates that almost all FC113 that might have been retained in the tissues under these exposure conditions was eliminated after two successive exposure-free days, it is not sufficient to establish that a gradual tissue build up of $\mathrm{FCl} 13$ would not occur under continuous exposure conditions.

\section{TOXICITY SUMMARY}

\section{Acute Toxicity ( $<24$ h Exposure)}

\section{Lethality}

Human fatalities have been reported for exposures to $\mathrm{FC} 113$ in Japan and in the United States. One Japanese death involved a worker who was exposed for less than $30 \mathrm{~min}$ to an atmosphere containing $13.7-17.5 \%$ oxygen and FC113 at $118,000-140,000$ ppm (11.8-14\%, v/v) (Yonemitsu et al., 1983). One of two other Japanese workers died after being occupationally exposed for about $1 \mathrm{~h}$ to an undetermined concentration of FCl13 (Hoshika et al., 1989). The dead worker had signs of central-nervoussystem (CNS) toxicity: urination and defecation as well as probable lung injury (discharge from nose and ears). The survivor was exposed for about half an hour before going to the clinic complaining of heart palpitations and heavy-headedness. He was found to be anemic and had colitis. Within a 3-y period, four active-duty Navy and one civilian employee died in three 
separate incidents attributed to FC113 exposure of unstated duration in areas that could permit accumulation of vapors, including confined spaces and low-lying areas aboard ships (Arnitz, 1985). FC113 may be responsible for some fatalities in cases of individuals intentionally inhaling aerosol propellants, although FC113 was not one of the halocarbon propellants identified in the 110 "sudden sniffing deaths" reported by Bass (1970).

The 4-h $\mathrm{LC}_{50}$ for rats is from 52,000 to $68,000 \mathrm{ppm}$ (O.L. Dashiell, J.W. Sarver, and T.K. Bogdanowicz, DuPont, unpublished data, 1971), while lethal concentrations for a 2-h exposure of rats, guinea pigs, mice, and rabbits range from 50,000 to $120,000 \mathrm{ppm}$. The 15 -min $\mathrm{LC}_{50}$ in rats is $130,000 \mathrm{ppm}$ (Clark and Tinston, 1982). The oral $\mathrm{LD}_{50}$ in rats is $43 \mathrm{~g} / \mathrm{kg}$ (Michaelson and Huntsman, 1964).

\section{No-Observed-Adverse-Effect Level (NOAEL)}

Two human males exposed to 1,500 ppm for $2.5 \mathrm{~h}$ showed no adverse psychomotor effects (Stopps and McLaughlin, 1967). Because only two subjects were exposed at a single FC113 concentration and only behavioral effects (manual dexterity, depth perception, card sorting) were examined, limited weight can be given these results. Dogs exposed for $10 \mathrm{~min}$ to $2500 \mathrm{ppm}$ FC113 showed no cardiac sensitization to epinephrine-induced arrhythmias (Reinhardt et al., 1973).

\section{Cardiac Arrhythmia}

Clinical experience indicates that halohydrocarbons might be cardiac arrhythmogens (Back and Van Stee, 1977) at high concentrations. Hine et al. (1968) monitored EKGs during exposure of humans to nominal concentrations of bromotrifluoromethane at 50,000,100,000, and $150,000 \mathrm{ppm}$. Auriculoventricular (AV) dissociation and premature ventricular contractions (maximum 16.9\%) were recorded during exposure to the highest concentrations.

In a study of the cardiac effects of FC113, four dogs were exposed to FC113 for $10 \mathrm{~min}$ via face mask to 1000,5000 , and $10,000 \mathrm{ppm}$ (Reinhardt et al., 1973). At 10,000 ppm, three of four dog exposures resulted in life-threatening cardiac arrhythmias (multiple consecutive ventricular beats or ventricular fibrillation) after a challenge dose of 
epinephrine at $8 \mu \mathrm{g} / \mathrm{kg}$. At $5,000 \mathrm{ppm}$, the incidence was $10 \mathrm{of} 29 \mathrm{dog}$ exposures, and at $2500 \mathrm{ppm}$, the incidence was 0 of 12 dog exposures.

In another study from the same lab, FC113 did not produce cardiac sensitization in dogs at $1000 \mathrm{ppm}$, and arterial blood concentrations (2.6 $\mu \mathrm{g} / \mathrm{mL}$ ) were proportionally lower than arterial blood concentrations associated with cardiac sensitization $(12.5 \mu \mathrm{g} / \mathrm{mL}$ ) (Trochimowicz, 1973). An inspired concentration of $5000 \mathrm{ppm}$ was required to sensitize the dog heart to the arrhythmic action (multiple consecutive ventricular beats or ventricular fibrillation) of exogenous epinephrine (Trochimowicz et al., 1974; Trochimowicz, 1973). The $\mathrm{EC}_{50}$ for cardiac sensitization to epinephrine in dogs for a 5-min exposure to FCl13 was reported to be $7000 \mathrm{ppm}$ (Clark and Tinston, 1982). In mice, inhalation of 5000-ppm FC113 is required to sensitize the heart to epinephrine-induced arrhythmias, and a level of $10,000 \mathrm{ppm}$ will induce arrhythmias without exogenous epinephrine (Aviado and Belej, 1974). Sensitization is only a temporary effect, however, since an epinephrine injection given $10 \mathrm{~min}$ after exposure (at which time much of the FCl13 had probably been eliminated from the blood) did not cause arrhythmia (Clark and Tinston, 1971).

\section{CNS Effects}

The $\mathrm{EC}_{50}$ for CNS stimulation (tremors of the limbs) for a 10-min exposure of rats to FC113 was found to be $28,000 \mathrm{ppm}$ (Clark and Tinston, 1982).

\section{Eye and Skin}

A single application or instillation of FC113 was found to be practically nonirritating to the ocular mucosa and skin of rabbits (Duprat et al., 1976).

\section{Sleepiness}

In a limited study involving six rats exposed to $12,000 \mathrm{ppm}$ for up to 24 mo, a slight sleepiness was observed that disappeared immediately after daily exposure stopped (Desoille et al., 1968). 


\section{Subchronic Toxicity (1-13 w Exposure)}

\section{NOAEL}

Four male volunteers exposed at 500 or $1000 \mathrm{ppm}$ for $6 \mathrm{~h} / \mathrm{d}, 5 \mathrm{~d} / \mathrm{w}$ for 2 $w$ showed no adverse effects on performance of complex mental tasks or changes in clinical status or biochemical tests (Reinhardt et al., 1971). Although the exposure of humans makes this study potentially valuable, the small number of subjects limits its usefulness.

Twenty-one rats exposed to FC113 at $2520 \mathrm{ppm}$ for $7 \mathrm{~h} / \mathrm{d}, 5 \mathrm{~d} / \mathrm{w}$ for $6 \mathrm{w}$ showed no signs of toxicity during the exposure period and no gross or microscopic pathology attributed to FC113 exposure (Limperos, 1954). Similarly, no changes in behavior or external appearance were seen in rats exposed to FC113 at 10,000 ppm or dogs exposed to FC113 at $5000 \mathrm{ppm}$; both species were exposed for $6 \mathrm{~h} / \mathrm{d}, 7$ times a week for $90 \mathrm{~d}$ (Leuschner et al., 1983).

\section{Biochemical Effects on the CNS}

Reported biochemical effects on the CNS of the rat include dose-dependent accumulation in brain tissue and perirenal fat, an increase of NADPH-diaphorase activity at $200 \mathrm{ppm}$ and a decrease in cerebral glutathione at $2000 \mathrm{ppm}$ in the first week of exposure for $2 \mathrm{w}, 5 \mathrm{~d} / \mathrm{w}, 6 \mathrm{~h} / \mathrm{d}$ (Savolainen and Pffäfli, 1980). During the second week, these effects disappeared while RNA tended to increase, and glutathione peroxidase activity tended to decrease at the highest dose. After a withdrawal period of $7 \mathrm{~d}$, no FC113 was detected and the neurochemical effects had disappeared, except that brain RNA at the highest exposure was below the control range. It is not clear whether these biochemical changes are detrimental or merely adaptive. Dose-response or time-response effects were not demonstrated.

\section{Hepatotoxicity}

Male rats exposed to FC113 at 1000 or $2000 \mathrm{ppm}$ for $5 \mathrm{~d} / \mathrm{w}, 6 \mathrm{~h} / \mathrm{d}$ for 1 or 2 w showed subtle changes in liver cells (Vainio et al., 1980). Indica- 
tions of lipid accumulation were seen in the light microscope. In the electron microscope, a slight to moderate increase of the smooth endoplasmic reticulum with vacuolization was seen in the 1000- and 2000-ppm groups after 1 and $2 \mathrm{w}$ of exposure. These same groups also showed an increased number of autophagous vacuoles, reduced glycogen, and condensations in some mitochondria. All these observations were subjective in nature. Biochemical studies on these rats after $1 \mathrm{w}$ of exposure showed dose-related decreases in the levels of NADPH cytochrome-c reductase and microsomal cytochrome P-450 and increases in UDP glucuronosyltransferase activity in liver but not in kidney (Vainio et al., 1980). These reported effects were reduced or absent after $2 \mathrm{w}$ of exposure; hence, the meaning of the effects reported at $1 \mathrm{w}$ is uncertain. It is not clear whether the histological and biochemical changes reported at 1000 and $2000 \mathrm{ppm}$ actually occurred, and if they did, whether they were detrimental or merely adaptive.

\section{Chronic Toxicity ( $>13$ w Exposure)}

\section{NOAEL}

A group of 50 workers, exposed for an average of $2.77 \mathrm{y}$ in an environment that contained $\mathrm{FCl} 13$ at $46-4700 \mathrm{ppm}$, were given clinical and laboratory examinations and compared to 50 workers who were not so exposed. No significant differences were seen between the two groups, other than one individual who complained of dryness of the skin due to FC113 exposure (Imbus and Adkins, 1972).

\section{Carcinogenicity and Genotoxicity}

A 2-y joint study by DuPont and Allied Corporation has concluded that FC113 has no carcinogenic or toxic effects in rats exposed to 0,2000 , 10,000 , or $20,000 \mathrm{ppm}(\mathrm{v} / \mathrm{v})$ by inhalation for $6 \mathrm{~h} / \mathrm{d}, 5 \mathrm{~d} / \mathrm{w}$ for $104 \mathrm{w}$ (Trochimowicz et al., 1988). No significant toxic effects were observed, including histopathology of 43 tissues, hematology, gross appearance, behavior, and mortality (Trochimowicz et al., 1988). A 5-10\% decrease in body-weight gain was seen at the 10,000- and 20,000-ppm exposure levels. 
FC113 was found to have no dominant lethal effects in mice (Epstein et al., 1972) given i.p. doses of $200 \mathrm{mg} / \mathrm{kg}$ or $1000 \mathrm{mg} / \mathrm{kg}$. FCl13 was not mutagenic in Salmonella (Longstaff, 1988).

A 1988 study has shown that preparation of microsomal enzymes from livers of mice exposed to FC113 at $20,000 \mathrm{ppm}$ for a total of $8 \mathrm{~h}$ greatly enhanced the metabolic activation of procarcinogenic polyaromatic hydrocarbons (aminofluorene, acetylaminofluorene) (Mahurin and Bernstein, 1988) as compared with microsomal enzymes prepared from the livers of sham-exposed mice, although FC113 itself was not mutagenic as measured by a microbial assay.

\section{Kidney Effects}

A study of Danish metal workers occupationally exposed to trichloroethylene or FC113 concluded that chlorinated organic solvents can induce subclinical nephropathy after long-term exposure. Concentrations were not estimated, however (Rasmussen et al., 1988).

\section{Memory and Psychomotor Effects}

A study of 99 workers engaged in degreasing with halogenated hydrocarbons found the following signs and symptoms of psychoorganic syndrome in the three workers who had heavy exposure to only FC113 for 2.5-4.5 y: impaired psychomotor speed, impaired learning, and impaired long-term memory (Rasmussen et al., 1988).

\section{Mechanistic Studies}

Comparison of the relative potencies of a wide range of halogenated and unsubstituted hydrocarbons that can produce rapidly reversible effects on the CNS and the heart suggests that these effects are probably structurally nonspecific, i.e. these chemicals may be regarded as physical toxicants whose effects are predictable from their physicochemical properties (Clark and Tinston, 1982). These chemicals probably exert their toxic effects not by combining with some specific target or receptor but by simply being 
present in some part of the cell in a concentration sufficient to disorganize its function temporarily. Such a model would predict that there should be a threshold tissue concentration below which this class of chemicals would have no effect on a given tissue. Some effects, nevertheless, might be subtle and might require long-term continuous exposure before becoming significant.

\section{Spaceflight Effects}

There have been several reports of cardiac arrhythmias in U.S. astronauts (Bungo, 1980) and Soviet cosmonauts (Gazenko et al., 1990) during spaceflights. During the third month of a flight aboard the Soviet Mir Space Station, the flight engineer of the second prime crew showed cardiac rhythm irregularities in response to emotional and physical stress. During an extravehicular activity (EVA) (April 11, 1987), he registered a series of atrial extrasystoles with episodes of trigeminy. While performing graded physical exercise on a treadmill soon after the EVA, he displayed marked tachycardia incommensurate with the exercise level and a significant number of isolated supraventricular extrasystoles. Utilization of a number of medical measures, adjustment of the prophylactic program, and stringent organization of the work-rest schedule led to gradual normalization of cardiac rhythm during exercise. No further cardiac arrhythmias were seen on two subsequent EVAs (June 12 and 16, 1987), but at the end of June, supraventricular extrasystoles were again noted during exercise, although the cosmonaut himself did not experience any associated sensations. Postflight cardiological examination of this cosmonaut revealed no organic changes in his myocardium, nor was any further disruption of cardiac rhythm noted.

During the first four flights of the space shuttle, one crew member exhibited uniform PVCs (premature ventricular contractions) during nearly every minute of re-entry after the onset of gravitational loading. Although preflight examinations had revealed occasional PVCs in this crew member, the rate of ectopics per minute during re-entry was perhaps eight-fold higher than preflight. A second crew member, who had no significant prior history of ventricular ectopia, exhibited rare PVC during the entry phase. Serum electrolytes were not abnormal in either crew member (Bungo and Johnson, 1983). 
Unfortunately, there have been insufficient data collected on the baseline incidence of cardiac arrhythmias of individuals on earth to assess the health risk associated with these putative anomalies. Even in the shuttle program, EKG measurements are routinely taken only during EVAs.

\section{Synergism}

FC113 has been widely used domestically and industrially as a propellant for pesticide mixtures containing piperonyl butoxide (PB) as a synergist to inhibit detoxifying enzymes. FC113 and PB, both relatively low-toxicity compounds, were found to be highly toxic and carcinogenic when a $10 \%-F C 113,5 \%$-PB mixture dissolved in tricaprylin was injected subcutaneously into neonatal mice, although neither compound alone was toxic or carcinogenic under the same conditions (Epstein et al., 1967). There is no basis to expect PB to be present in spacecraft air. 


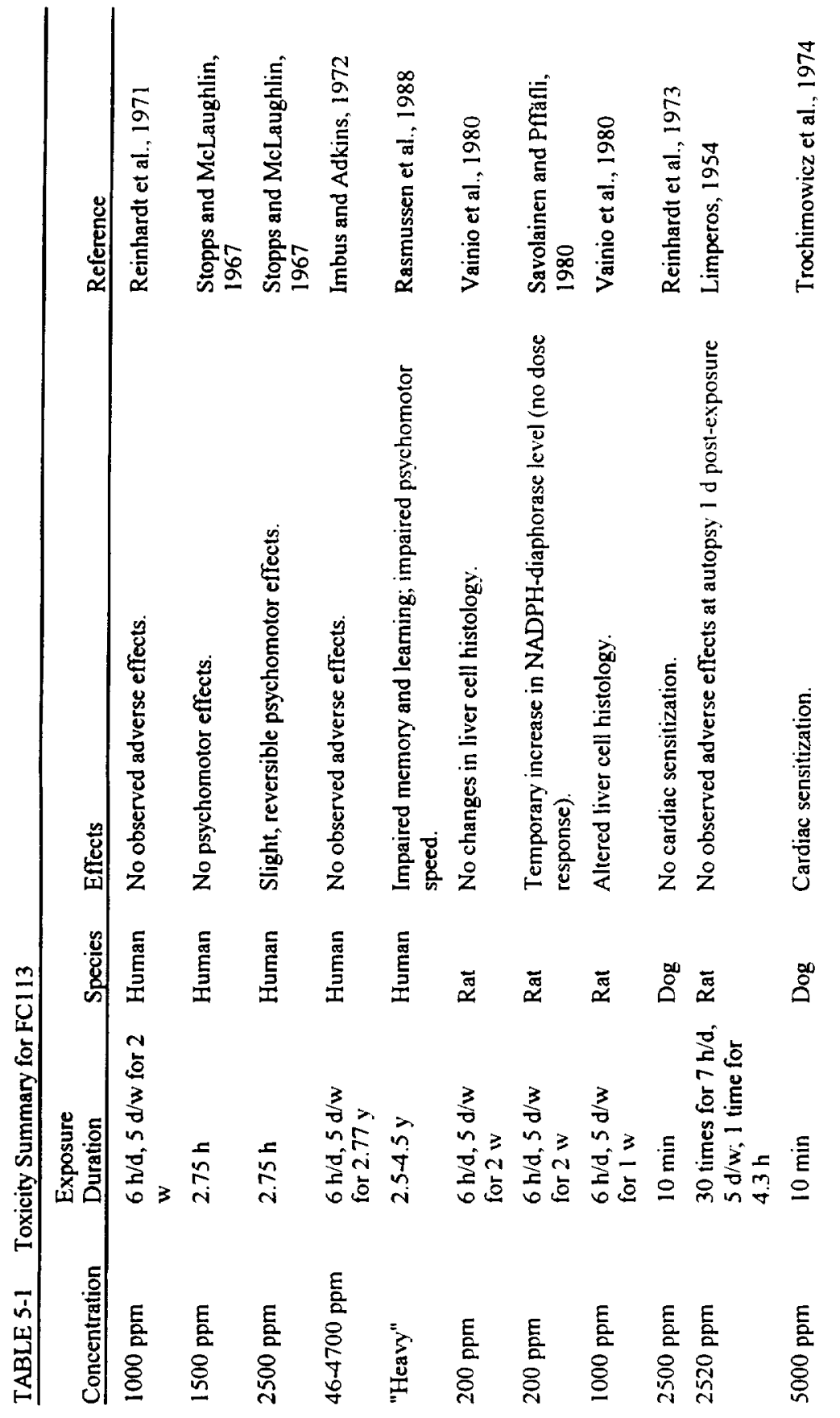




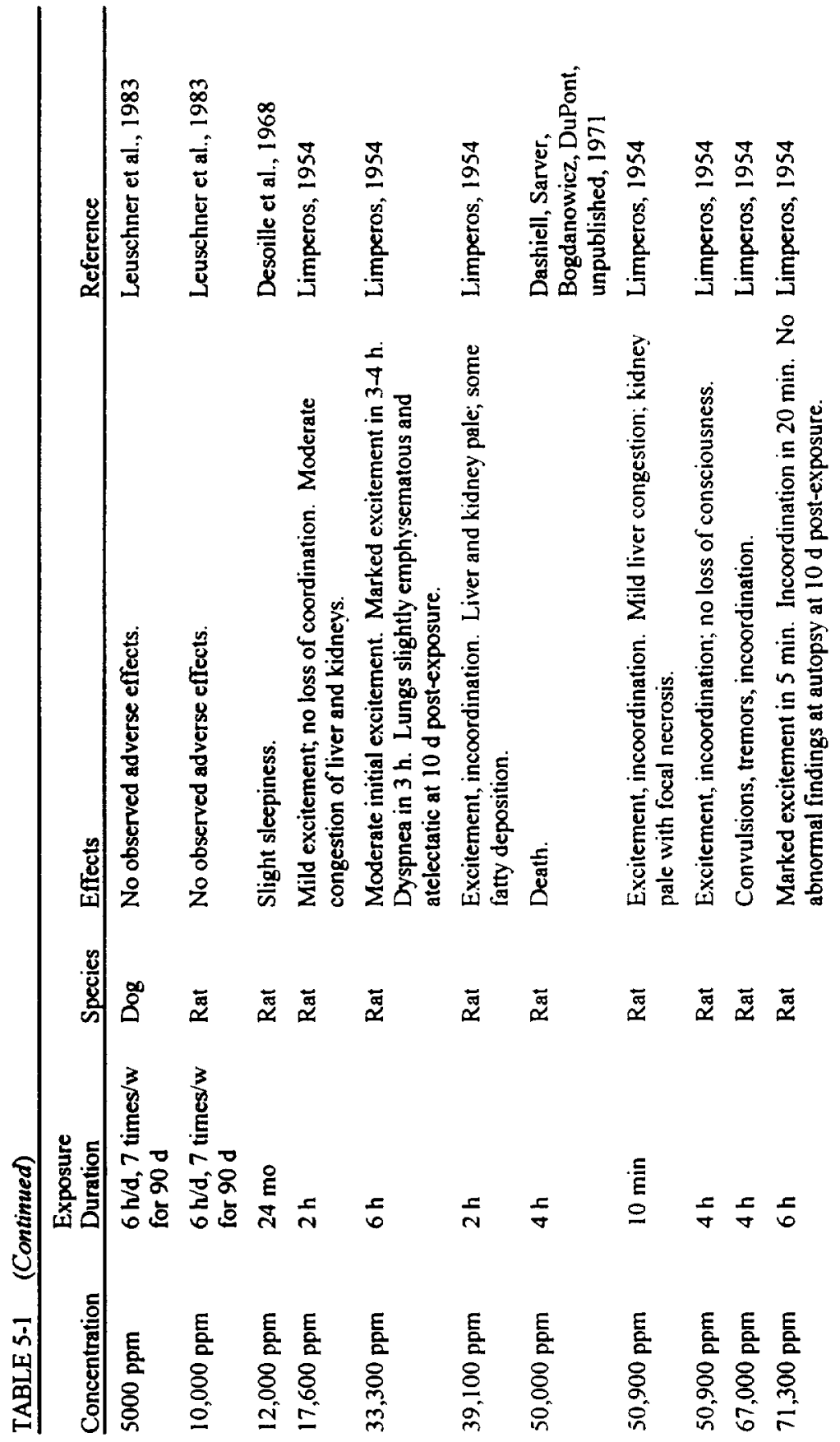




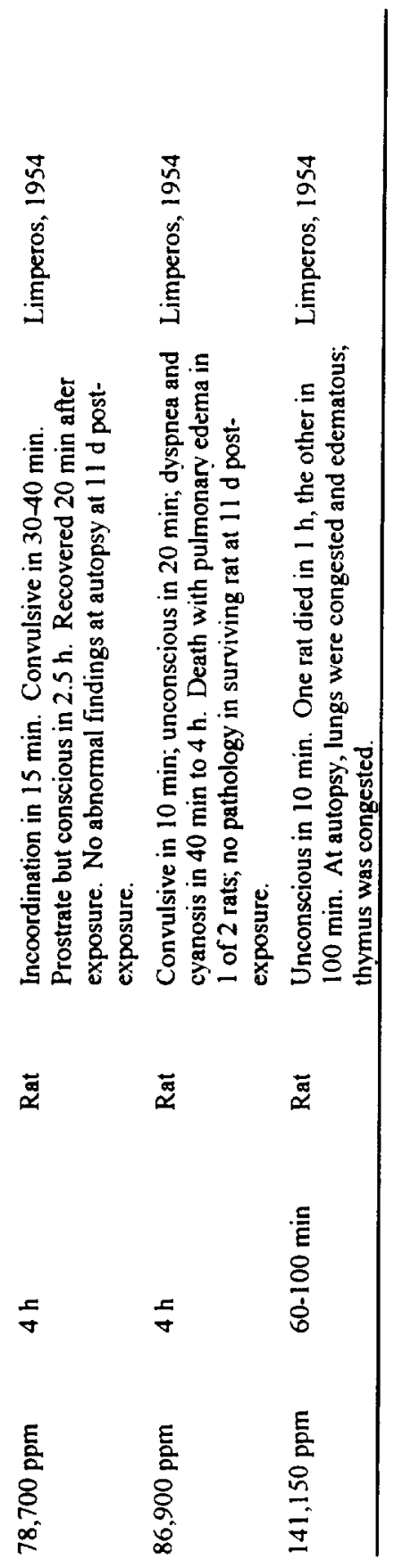


TABLE 5-2 Exposure Limits Set by Other Organizations

\begin{tabular}{ll}
\hline Organization & Concentration, ppm \\
\hline ACGIH's TLV (TWA) & 1000 \\
ACGIH's TLV (STEL) & 1250 (ceiling) \\
OSHA's PEL & 1000 \\
OSHA's STEL & 1250 (ceiling) \\
NIOSH's REL & 1000 \\
NIOSH's STEL & 1250 (ceiling) \\
NRC's 1-h EEGL & $1500\left(12.1 \mathrm{~g}^{3} \mathrm{~m}^{3}\right)$ \\
NRC's 24-h EEGL & $500\left(4.0 \mathrm{~g} / \mathrm{m}^{3}\right)$ \\
NRC's 90-d CEGL & $100\left(0.8 \mathrm{~g} / \mathrm{m}^{3}\right)$ \\
\hline TLV = threshold limit value. TWA $=$ time-weighted average. PEL $=$ \\
permissible exposure limit. STEL $=$ short-term exposure limit. REL = \\
recommended exposure limit. EEGL =emergency exposure guidance level. \\
CEGL = continuous exposure guidance level.
\end{tabular}

TABLE 5-3 Spacecraft Maximum Allowable Concentrations

\begin{tabular}{llll}
\hline Duration & ppm & $\mathrm{mg} / \mathrm{m}^{3}$ & Target Toxicity \\
\hline $1 \mathrm{~h}$ & 50 & 400 & Cardiac Sensitization \\
$24 \mathrm{~h}$ & 50 & 400 & Cardiac Sensitization \\
$7 \mathrm{~d}^{\mathrm{a}}$ & 50 & 400 & Cardiac Sensitization \\
$30 \mathrm{~d}$ & 50 & 400 & Cardiac Sensitization \\
$180 \mathrm{~d}$ & 50 & 400 & Cardiac Sensitization \\
\hline
\end{tabular}

${ }^{\mathrm{a}}$ Previous 7-d SMAC $=50 \mathrm{ppm}\left(383 \mathrm{mg} / \mathrm{m}^{3}\right)$

\section{RATIONALE}

FC113 can produce effects on the liver, heart, and the CNS. Subtle ultrastructural changes in liver cells have been reported at concentrations of $1000 \mathrm{ppm}$. Heart arrhythmias (usually multiple consecutive ventricular beats or ventricular fibrillation) have been induced at concentrations of at least $5000 \mathrm{ppm}$ if the heart has been challenged with exogenous epinephrine. Subtle changes in the levels of enzymes and RNA in nerve tissue have been reported. 
Of these end points, the only definitely adverse effect is cardiac sensitization. Mild, subclinical, "adaptive" effects on the liver, such as the equivocal changes in enzyme activities and smooth endoplasmic reticulum in liver cells reported after exposure of rats to $1000 \mathrm{ppm}$ for $6 \mathrm{~h} / \mathrm{d}, 5 \mathrm{~d} / \mathrm{w}$ for $1 \mathrm{w}$, are not considered to be significant changes.

Cardiac arrhythmias are unacceptable because, although they might not be incapacitating by themselves, some types might signal a substantially increased risk of incapacitating or fatal cardiac injury. The SMAC for a 1$\mathrm{h}$ exposure to $\mathrm{FC} 113$ was set at $50 \mathrm{ppm}$ on the basis of the findings that a 10 -min exposure to $2500 \mathrm{ppm}$ did not sensitize dog hearts to the arrhythmogenic action of epinephrine and then applying a species extrapolation factor of 10 and an additional factor of 5 for possible spaceflight-enhanced sensitivity to arrhythmias. No time extrapolation should be applied to the 50-ppm 1-h SMAC because this effect is dependent on blood concentration, which reaches a plateau in about $30 \mathrm{~min}$ in humans $(10 \mathrm{~min}$ in dogs).

The SMACs for $24 \mathrm{~h}, 7 \mathrm{~d}, 30 \mathrm{~d}$, and $180 \mathrm{~d}$ exposures to FCl13 were also set at $50 \mathrm{ppm}$ on the basis that arrhythmogenicity is dependent on blood concentration, which reaches a plateau in about $30 \mathrm{~min}$, and is apparently independent of time (Trochimowicz et al., 1974).

This 50 -ppm value is well below the concentration of $1000 \mathrm{ppm}$ which, based on only two test subjects, appears to have no effect on manual dexterity in humans exposed $6 \mathrm{~h} / \mathrm{d}, 5 \mathrm{~d} / \mathrm{w}$ for $1 \mathrm{w}$ immediately after exposure to $500 \mathrm{ppm}$ for $1 \mathrm{w}$ on the same schedule (Reinhardt et al., 1971).

\section{REFERENCES}

Arnitz, W.E. 1985. Discontinued use of trichlorotrifluoroethane. Office of Chief of Naval Operations. Document No. X1-F-85-05.

Auton, T.R. and B.H. Woolen. 1991. A physiologically based mathematical model for the human inhalation pharmacokinetics of 1,1,2-trichloro-1,2,2-trifluoroethane. Int. Arch. Occup. Environ. Health 63: 133-138.

Aviado, D.M. and M.A. Belej. 1974. Toxicity of aerosol propellants in the respiratory and circulatory systems. 1. Cardiac arrhythmia in the mouse. Toxicology 2:31-42.

Back, K.C. and E.W. Van Stee. 1977. Toxicology of haloalkane propel- 
lants and fire extinguishants. Annu. Rev. Pharmacol. Toxicol. 17: 83-95.

Bass, M. 1970. Sudden sniffing death. J. Am. Med. Assoc. 12:20752079.

Brogren, C.-H., J.M. Christensen, and K. Rasmussen. 1986. Occupational exposure to chlorinated organic solvents and its effect on the renal excretion of $N$-acetyl- $\beta$-D-glucosaminidase. Arch. Toxicol. Suppl. 9:460-464.

Bungo, M. 1989. The cardiopulmonary system. Pp. 197-199 in Space Physiology and Medicine. Nicogossian, A.E., C.L. Huntoon, and S.L. Pool, eds. Lea \& Febiger, Philadelphia.

Bungo, M.W. and P.C. Johnson. 1983. Cardiovascular examinations and observations of deconditioning during the space shuttle orbital flight test program. Aviat. Space Environ. Med. 1001-1004.

Clark, D.G. and D.J. Tinston. 1971. The Influence of Fluorocarbon Propellants on the Arrhythmogenic Activities of Adrenaline and Isoprenaline. Pp. 212-217 in Proceedings of the 12th Meeting of the European Society for the Study of Drug Toxicity. European Society of Toxicology, Basel, Switzerland.

Clark, D.G. and D.J. Tinston. 1982. Acute inhalation toxicity of some halogenated and non-halogenated hydrocarbons. Hum. Toxicol. 1:239247.

Desoille, H., L. Truffert, A. Bourguignon, P. Delavierre, M. Philbert, and C. Girard-Wallon. 1968. Étude experimentale de la toxicité du trichlorotrifluoroethane (Freon 113). Arch. Mal. Prof. Med. Trav. Secur. Soc. 29:381-388.

Duprat, P., L. Delsaut, and D. Gradiski. 1976. Pouvoir irritant des principaux solvants chlorés aliphatiques sur la peau et les muqueuses oculaires du lapin. Eur. J. Toxicol. 9:171-177.

Epstein, S.S., E. Arnold, J. Andrea, W. Bass, and Y. Bishop. 1972. Detection of chemical mutagens by the dominant lethal assay in the mouse. Toxicol. Appl. Pharmacol. 23:288-325.

Epstein, S.S., S. Joshi, J. Andrea, P. Clapp, H. Falk, and N. Mantel. 1967. Synergistic toxicity and carcinogenicity of "Freons" and piperonyl butoxide. Nature 214:526-528.

Gazenko, O.G., A.I. Grigor'yev, S.A. Bugrov, V.V. Yegorov, V.V. Bogomolov, I.B. Kozlovskaya, and I.K. Tarasov. 1990. Review of the major results of medical research during the flight of the second prime 
crew of the Mir Space Station. Kosmicheskaya Biologiya i Aviakosmicheskaya Meditsina 23(4):3-11; translated and abstracted in USSR Space Life Sciences Digest. NASA Contractor Rep. 3922(34): 119-120.

Hine, C.H., H.W. Elliott, J.W. Kaufman, S. Leung, and M.D. Harrah. 1968. Clinical toxicologic studies on freon FE1301. Presented at the 4th Annual Conference on Atmospheric Contaminants in Confined Spaces. AMRL-TR-68-175. Wright-Patterson Air Force Base, Dayton, Ohio.

Hoshika, Y., T. Tsuchiya, and N. Murayama. 1989. Two cases of acute poisoning of 1,1,2-trichloro-1,2,2-trifluoroethane (Freon 113). J. Ind. Health 31:248-249.

Imbus, H. R. and C. Adkins. 1972. Physical examinations of workers exposed to trichlorotrifluoroethane. Arch. Environ. Health 24:257-261.

Leuschner, F., B.-W. Neumann, and F. Hübscher. 1983. Report on subacute toxicological studies with several fluorocarbons in rats and dogs by inhalation. Arzneimittel-Forschung./Drug Res. 33(II):14751476.

Liebich, H. M., W. Bertsch, A. Zlatkis, and H.J. Schneider. 1975. Volatile organic components in the Skylab 4 spacecraft atmosphere. Aviat. Space Environ. Med. 46:1002-1007.

Limperos, G. 1954. Inhalation toxicity of "Freon-113" (1,1,2-trichloro-1,2,2-trifluoroethane). Rep. 3-54. E.I. DuPont de Nemours \& Company, Haskell Laboratories for Toxicology and Industrial Medicine.

Longstaff, E. 1988. Carcinogenic and mutagenic potential of several fluorocarbons. Ann. N.Y. Acad. Sci. 534:283-298.

Mahurin, R.G. and R.L. Bernstein. 1988. Fluorocarbon-enhanced mutagenesis of polyaromatic hydrocarbons. Environ. Res. 45:101-107.

Michaelson, J.B. and D.J. Huntsman. 1964. Oral toxicity study of 1,2,2-trichloro-1,1,2-trifluoroethane. J. Med. Pharmacol. Chem. 7:378-379.

Rasmussen, K., H.J. Jeppesen, and P. Arlien-Søborg. 1988. Psychoorganic syndrome from exposure to fluorocarbon 113-An occupational disease? Eur. Neurol. 28:205-207.

Reinhardt, C.F., M. McLaughlin, M.E. Maxfield, L.S. Mullin, and P.E. Smith, Jr. 1971. Human exposures to fluorocarbon 113. Am. Ind. Hyg. Assoc. J. 32:143-151.

Reinhardt, C.F., L.S. Mullin, and M.E. Maxfield. 1973. Epinephrine- 
induced cardiac arrhythmia potential of some common industrial solvents. J. Occup. Med. 15:953-955.

Savolainen, H. and P. Pffäfli. 1980. Dose-dependent neurochemical effects of 1,1,2-trichloro-1,2,2-trifluoroethane inhalation exposure in rats. Toxicol. Lett. 6:43-49.

Sax, N.I., ed. 1984. Pp. 1762-1763 in Dangerous Properties of Industrial Materials. Sixth edition. Van Nostrand Reinhold, New York.

Stopps, F.J. and M. McLaughlin. 1967. Psychophysiological testing of human subjects exposed to solvent vapors. Am. Ind. Hyg. Assoc. J. 28:43-50.

Trochimowicz, H.J. 1973. Blood levels of fluorocarbon during and after acute inhalation. AMRL Tech. Rep. TR-73 125:137-147. U.S. Air Force Armstrong Medical Research Laboratory, Dayton, Ohio.

Trochimowicz, H.J., A. Azar, J.B. Terrill, and L.S. Mullin. 1974. Blood levels of fluorocarbon related to cardiac sensitization: Part II. Am. Ind. Hyg. Assoc. J. 35:632-639.

Trochimowicz, H.J., G.M. Rusch, T. Chiu, and C.K.Wood. 1988. Chronic inhalation toxicity/carcinogenicity study in rats exposed to fluorocarbon 113 (FC-113). Fundam. Appl. Toxicol. 11:68-75.

Vainio, H., J. Nickels, and T. Heinonen. 1980. Dose-related hepatotoxicity of 1,1,2-trichloro-1,2,2-trifluoroethane in short-term intermittent inhalation exposure in rats. Toxicology 18:17-25.

Woolen, B.H., E.A. Guest, W. Howe, J.R. Marsh, H.K. Wilson, T.R. Auton, and P.G. Blain. 1990. Human inhalation phamacokinetics of 1,1,2-trichloro-1,2,2-trifluoroethane (FC113). Int. Arch. Occup. Environ. Health 62:73-78.

Yonemitsu, K., S. Tsunenari, and M. Kanda. 1983. An industrial accidental death due to Freon 113 poisoning-Toxicological analysis of its cause of death. Nippon Hoigaku Zasshi 37:428-433. 


\section{B6 Hydrogen}

King Lit Wong, Ph.D.

Johnson Space Center Toxicology Group

Biomedical Operations and Research Branch

Houston, Texas

\section{PHYSICAL AND CHEMICAL PROPERTIES}

Hydrogen is a colorless, odorless, and tasteless gas (Sax, 1984).

$$
\begin{aligned}
\text { Formula: } & \mathrm{H}_{2} \\
\text { CAS number: } & 1333-74-0 \\
\text { Molecular weight: } & 2.0 \\
\text { Boiling point: } & -252.8^{\circ} \mathrm{C} \\
\text { Melting point: } & -259.2^{\circ} \mathrm{C} \\
\text { Gas density: } & 0.069 \text { that of air } \\
\text { Conversion factors at } 25^{\circ} \mathrm{C}, 1 \mathrm{~atm}: & 1 \mathrm{ppm}=0.082 \mathrm{mg} / \mathrm{m}^{3} \\
& 1 \mathrm{mg} / \mathrm{m}^{3}=12.2 \mathrm{ppm}
\end{aligned}
$$

\section{OCCURRENCE AND USE}

Hydrogen is present in fuel cells as a by-product of oxygen generation from water. Flatulence is a biological source of hydrogen, which is formed by bacterial degradation of oligosaccharides in the lower intestine (Hopfer, 1982). The production rate in humans is approximately $50 \mathrm{mg} / \mathrm{d}$ per person (Olcott, 1972). Preliminary date from space-shuttle flights indicate that hydrogen might be present in the cabin atmosphere at about $100 \mathrm{ppm}$. 


\section{PHARMACOKINETICS AND METABOLISM}

No pharmacokinetics and metabolism information on hydrogen was found.

\section{TOXICITY SUMMARY}

Hydrogen is a biological inert gas with no known direct toxic effect (Sax, 1984; NIOSH, 1987). Hydrogen, however, might cause hypoxia via displacement of oxygen in the air. Hypoxic signs and symptoms include tachypnea, cyanosis, sweating, euphoria, impaired judgment, loss of short-term memory, cardiac dysrhythmias, and unconsciousness (Ellenhorn and Barceloux, 1988).

\section{EXPOSURE LIMITS}

No exposure limit was found. The American Conference of Governmental Industrial Hygienists classifies hydrogen as a simple asphyxiant with no exposure limit set (TLV Committee, 1990).

TABLE 6-1 Spacecraft Maximum Allowable Concentrations

\begin{tabular}{llll}
\hline Duration $^{\text {a }}$ & $\mathrm{ppm}$ & $\mathrm{mg} / \mathrm{m}^{3}$ & Target Toxicity \\
\hline $1 \mathrm{~h}$ & 4100 & 336 & None (explosivity) \\
$24 \mathrm{~h}$ & 4100 & 336 & None (explosivity) \\
$7 \mathrm{~d}^{\mathrm{b}}$ & 4100 & 336 & None (explosivity) \\
$30 \mathrm{~d}$ & 4100 & 336 & None (explosivity) \\
$180 \mathrm{~d}$ & 4100 & 336 & None (explosivity) \\
\hline
\end{tabular}

These SMACs are ceiling values.

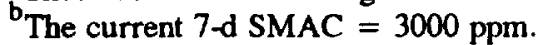

\section{RATIONALE}

Simple asphyxiants should be kept at a level that does not lower the oxygen concentration below $18 \%$ (TLV Committee, 1990). It takes $14.3 \%$ of hydrogen to lower the oxygen concentration from $21 \%$ to $18 \%$. 


$$
\begin{aligned}
\mathrm{H}_{2} \text { concentration } & =(21 \%-18 \%) \times 100 / 21 \\
& =14.3 \% .
\end{aligned}
$$

However, simple asphyxiants are usually not a problem because oxygen concentration in the spacecraft is continuously maintained at acceptable levels. Because hydrogen's lower explosive limit is less than $14.3 \%$ (Sax, 1984), its SMACs are established based on explosivity rather than asphyxiating action. With explosion being a very serious matter, a wide margin of safety is called for. Therefore, all the SMACs of hydrogen are set at one-tenth of its lower explosive limit, i.e., at $4100 \mathrm{ppm}$. A safety factor of 10 agrees with the recommendation of the U.S. Environmental Protection Agency that personnel doing environmental monitoring should evacuate when the concentration of an explosive gas reaches $10 \%$ of the lower explosive limit (EPA, 1988).

\section{REFERENCES}

Ellenhorn, M.J. and D.G. Barceloux. 1988. Pp. 11-12 in Introduction and Initial Evaluation in Medical Toxicology, Diagnosis and Treatment of Human Poisoning. Elsevier, New York.

Hopfer, U. 1982. Digestion and absorption of basic nutritional constituents. P. 1160 in Textbook of Biochemistry with Clinical Correlations. T.M. Devlin, ed. John Wiley \& Sons, New York.

NIOSH. 1987. P. 2726 in Registry of Toxic Effects of Chemical Substances 1985-86. DHHS (NIOSH) Publ. No. 87-114. National Institute for Occupational Safety and Health, Cincinnati, Ohio.

Olcott, T.M. 1972. Development of a Sorbent Trace Contaminant Control System, Including Pre- and Postsorbers for a Catalytic Oxidizer. NASA CR-2027. Johnson Space Center, Houston, Tex.

Sax, I., ed. 1984. P. 1549 in Dangerous Properties of Industrial Materials, 6th Edition. Van Nostrand Reinhold, New York.

TLV Committee. 1990. Pp. 8 and 26 in Threshold Limit Values and Biological Exposure Indices. American Conference of Governmental Industrial Hygienists, Cincinnati, Ohio.

EPA. 1988. Air Surveillance for Hazardous Materials. Environmental Response Team, Office of Emergency and Remedial Response, U.S. Environmental Protection Agency, Washington, D.C. 

Hector D. Garcia, Ph.D., and John T. James, Ph.D. Johnson Space Center Toxicology Group Biomedical Operations and Research Branch Houston, Texas

\title{
PHYSICAL AND CHEMICAL PROPERTIES
}

Methane is a colorless, odorless, nonpoisonous, flammable gas that burns with a pale, faintly luminous flame. Methane is soluble in alcohol, ether, and other organic solvents and is slightly soluble in water (Sax, 1984; Budavari, 1976). It forms explosive mixtures with air and reacts violently with halogens, interhalogens, and oxidizers when exposed to heat or flame (Sax, 1984).

\author{
Formula: $\mathrm{CH}_{4}$ \\ CAS number: $74-82-8$ \\ Synonyms: Natural gas, marsh gas, firedamp, methyl \\ hydride \\ Molecular weight: 16.04 \\ Boiling point: $-161.4^{\circ} \mathrm{C}$ \\ Melting point: $\quad-182.6^{\circ} \mathrm{C}$ \\ Density: $\quad 0.554$ (air $=1$ ) or $0.7168 \mathrm{~g} / \mathrm{L}$ \\ Vapor pressure: $40 \mathrm{~mm} \mathrm{Hg}$ at $-86.3^{\circ} \mathrm{C}$ \\ Explosion limits: $5.3-14 \%$ in air (Sax, 1984) \\ Atmospheric concentration: $0.00022 \%$ by volume (Budavari, 1976) \\ Autoignition temperature: $650^{\circ} \mathrm{C}$
}




\section{OCCURRENCE AND USE}

Methane occurs naturally as a product of decaying vegetable matter. In population studies, $35-61 \%$ of healthy human subjects have detectable methane in their breath (Segal et al., 1988). It is used as a fuel for illuminating and cooking; in organic syntheses; and in the manufacture of hydrogen, hydrogen cyanide, ammonia, acetylene, and formaldehyde.

\section{PHARMACOKINETICS}

Methane installed into the human colon is exhaled (Bjorneklett and Jenssen, 1982). Inhalation of commercial natural gas scented with 16.8 $\mathrm{mg} / \mathrm{m}^{3}$ tert-butylmercaptan and $7.2 \mathrm{mg} / \mathrm{m}^{3}$ of methyl acrylate by mice in a gas chamber for $2 \mathrm{~h}$ produced isopropanol, acetone, sec-butyl alcohol, and methyl ethyl ketone in the blood and liver (Tsukamoto et al., 1985). Even though the authors considered these substances to be metabolites of the natural gas, the study did not distinguish between metabolism of the methane and metabolism of the added fragrance compounds. The authors also stated that methane (and propane) "can exert an anesthetic effect on animals even when sufficient oxygen exists, the results sometimes proving lethal" (Tsukamoto et al., 1985); however, they gave no citation for that report. No studies supporting this assertion were found.

\section{TOXICITY SUMMARY}

Methane is a simple asphyxiant and does not produce general systemic effects (Klaassen et al., 1986). Studies of the morphology of lung tissues of rats exposed to $8 \%$ methane, $20 \%$ oxygen for $1 \mathrm{~h}$, followed by $100 \%$ methane found no effects attributable to the chemical specificity of methane but only to the decrease of oxygen (Morita and Tabata, 1988). Although patients with large bowel cancer have been found to have high levels of methane in their breath, no relationship has been found between in vivo production of methane and the risk of developing large bowel cancer (Segal et al., 1988; Flick et al., 1990). No studies on the effects of chronic inhalation of methane were found in the literature. The bowel cancer studies, however, found that outwardly healthy subjects had breath methane 
levels of up to $56 \mathrm{ppm}$, and in some people, methane (presumably generated by fecal microorganisms) is present in colonic gases but is not excreted in the breath (McKay et al., 1985).

TABLE 7-1 Exposure Limits Set by Other Organizations

\begin{tabular}{ll}
\hline Organization & Concentration \\
\hline ACGIH's TLV & None set for simple asphyxiants \\
OSHA's PEL & None set \\
NIOSH's REL & None set \\
NIOSH's IDLH & None set \\
\hline
\end{tabular}

TLV $=$ threshold limit value. PEL $=$ permissible exposure limit. REL = recommended exposure limit. IDLH $=$ immediately dangerous to life and health.

TABLE 7-2 Spacecraft Maximum Allowable Concentrations

\begin{tabular}{llll}
\hline Duration & $\mathrm{ppm}$ & $\mathrm{mg} / \mathrm{m}^{3}$ & Target Toxicity \\
\hline $1 \mathrm{~h}$ & 5300 & 3800 & $0.1 \times$ lower explosive limit \\
$24 \mathrm{~h}$ & 5300 & 3800 & $0.1 \times$ lower explosive limit \\
$7 \mathrm{~d}$ & 5300 & 3800 & $0.1 \times$ lower explosive limit \\
$30 \mathrm{~d}$ & 5300 & 3800 & $0.1 \times$ lower explosive limit \\
$180 \mathrm{~d}$ & 5300 & 3800 & $0.1 \times$ lower explosive limit \\
\hline
\end{tabular}

\section{RATIONALE}

SMACs were set on the basis of methane's explosive properties rather than its toxicity with the following considerations. First, methane has no demonstrable toxicity and does not produce general systemic effects other than being a simple asphyxiant. Air at sea level contains about $21 \%$ oxygen. Humans at rest are not significantly affected until the oxygen concentration falls to $14 \%$, but with exercise, anoxia develops quickly owing to the limited rate of diffusion of oxygen through the lung's alveolar walls (Rogan, 1972). Table 7-3 shows the relationship between exercise, oxygen saturation of the blood, and oxygen concentration in the atmosphere (Rogan, 1972). 
TABLE 7-3 The Relationship Between Exercise and Oxygen Concentrations

\begin{tabular}{lccccccccc}
\hline \multicolumn{1}{l}{ Oxygen in Air at $760 \mathrm{~mm} \mathrm{Hg}, \%$} \\
\cline { 2 - 9 } Amount of Exercise & 21 & 20 & 19 & 18 & 17 & 16 & 15 & 14 \\
\hline Resting & $\circ$ & $\circ$ & $\circ$ & $\circ$ & $\circ$ & $\circ$ & $\circ$ & $\circ$ \\
Walking & $\circ$ & $\circ$ & $\circ$ & $\circ$ & $\circ$ & $\circ$ & $\circ$ & $\bullet$ \\
Hurrying, moderate & $\circ$ & $\circ$ & $\circ$ & $\circ$ & $\circ$ & $\bullet$ & $\bullet$ & $\bullet$ \\
work & & & & & & & & \\
Heavy work & $\circ$ & $\circ$ & $\circ$ & $\circ$ & $\bullet$ & $\bullet$ & $\bullet$ & $\bullet$ \\
\hline
\end{tabular}

$0=$ adequate oxygen saturation.

- = desaturation likely (danger of rapid loss of consciousness).

Even if an astronaut performed heavy work in an atmosphere containing a simple asphyxiant, Table $7-3$ shows that a level of oxygen of about $18 \%$ would be adequate to prevent loss of consciousness. For methane to dilute the oxygen in the atmosphere to $18 \%$ would require the methane concentration to reach $14.3 \%$ :

$$
\frac{(0.21-0.18)}{0.21}=0.143=143,000 \mathrm{ppm} .
$$

Second, as shown in Figure $7-1,14 \%$ methane and $18 \%$ oxygen is capable of forming explosive mixtures if diluted slightly with air. If the atmosphere contains an appreciable amount of hydrogen, the Coward's triangle will have a different shape, and explosions can occur with a lower percentage of oxygen. The shape of the triangle can also be varied by high concentrations of carbon monoxide (Rogan, 1972).

Thus, before increasing methane concentrations could reach asphyxiating levels, methane would form explosive mixtures with air. Also, if provision is made for maintaining $21 \%$ oxygen in the spacecraft by injection of pure oxygen, the assumption, based on Coward's triangle, is made that the lower-explosive-limit concentration of methane would not change appreciably. Therefore, SMACs were set at one-tenth the lower explosive limit of $5.3 \%$ methane. A safety factor of 10 -fold below the explosive limit was used to allow for some inhomogeneities in the local distribution of methane near the site of leakage or generation of the methane, assuming that air circulation within the spacecraft produces moderately effective mixing. 


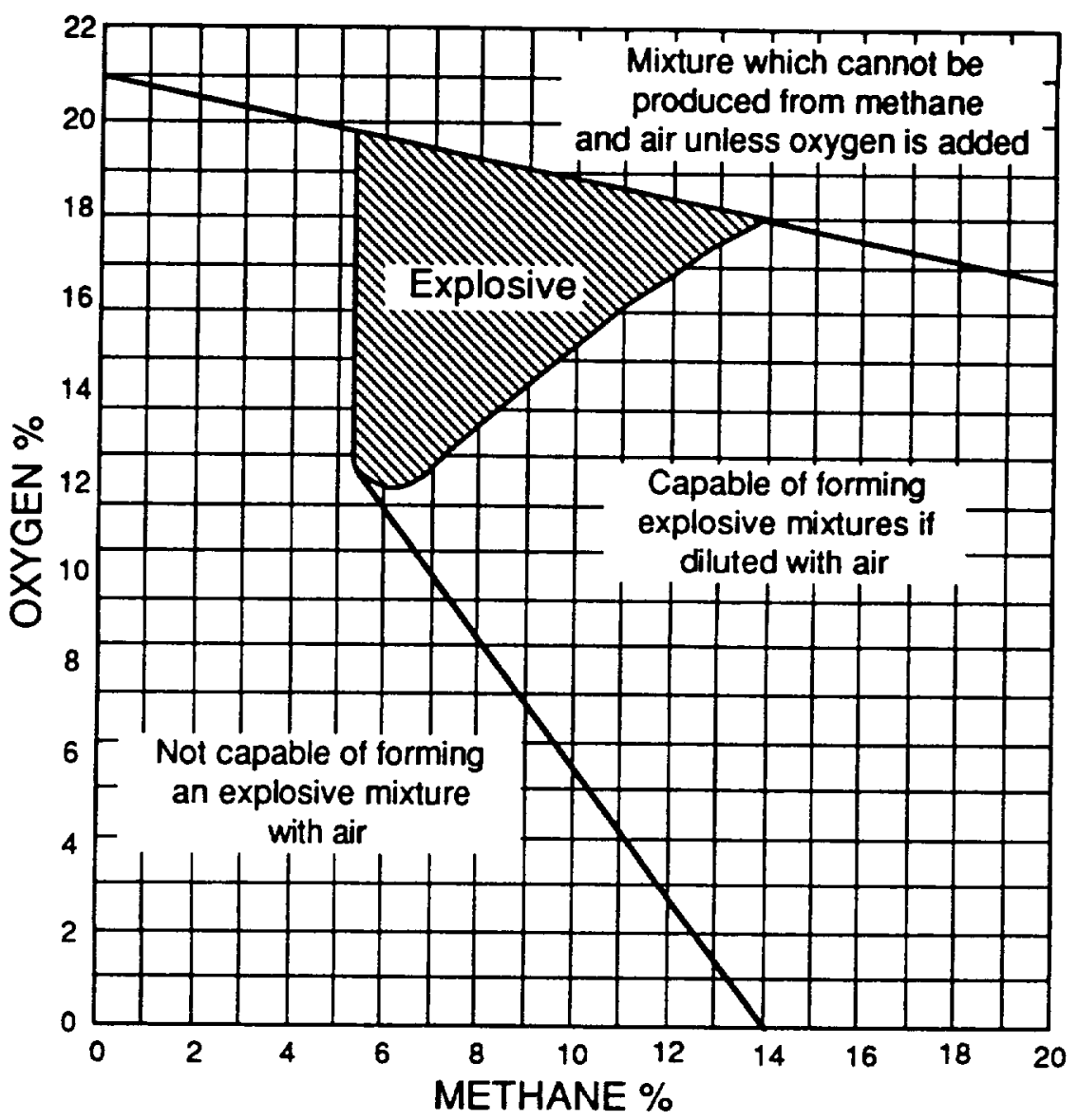

FIGURE 7-1 The explosive limits of methane-Coward's Triangle.

\section{REFERENCES}

Bjorneklett, A. and E. Jenssen. 1982. Relationships between hydrogen $\left(\mathrm{H}_{2}\right)$ and methane $\left(\mathrm{CH}_{4}\right)$ production in man. Scand. J. Gastroenterol. 17:985-992.

Budavari, S., ed. 1976. P. 938 in The Merck Index, 11 th Edition. Merck \& Co., Rahway, N.J.

Flick, J.A., S.R. Hamilton, F.J. Rosales, and J.A. Perman. 1990. 
Methane excretion and experimental colonic carcinogenesis. Digestive Dis. Sci. 35:221-224.

Klaassen, C.D., M.O. Amdur, and J. Doull, eds. 1986. P. 658 in Casarett and Doull's Toxicology, 3rd Edition. Macmillan, New York.

McKay, L.F., M.A. Eastwood, and W.G. Brydon. 1985. Methane excretion in man-A study of breath, flatus, and faeces. Gut 26:69-74.

Morita, M. and N. Tabata. 1988. Studies on asphyxia: On the changes of the alveolar walls of rats in the hypoxic state. II. The hypoxic state produced by carbon dioxide and methane gases. Forensic Sci. Int. 39:257-262.

Sax, N.I., ed. 1984. Pp. 1762-1763 in Dangerous Properties of Industrial Materials, 6th Edition. Van Nostrand Reinhold, New York.

Segal, I., A.R.P. Walker, S. Lord, and J.H. Cummings. 1988. Breath methane and large bowel cancer risk in contrasting African populations. Gut 29:608-613.

Tsukamoto, S., S. Chiba, T. Ishikawa, and M. Shimamura. 1985. Experimental study on the metabolism of volatile hydrocarbons by inhalation of natural gas (13 A-Tokyo Gas). Nihon Univ. J. Med. 27:33-38.

Rogan, J.M., ed. 1972. Pp. 224-227 in Medicine in the Mining Industries. William Heinemann Medical Books, London. 


\title{
B8 Methanol
}

King Lit Wong, Ph.D.

Johnson Space Center Toxicology Group

Biomedical Operations and Research Branch

Houston, Texas

\section{PHYSICAL AND CHEMICAL PROPERTIES}

Methanol is a colorless liquid (ACGIH, 1986).

\author{
Synonyms: Methyl alcohol, wood alcohol \\ Formula: $\quad \mathrm{CH}_{3} \mathrm{OH}$ \\ CAS number: $67-56-1$ \\ Molecular weight: 32.0 \\ Boiling point: $64.5^{\circ} \mathrm{C}$ \\ Melting point: $\quad-97.8^{\circ} \mathrm{C}$ \\ Vapor pressure: 92 torr at $20^{\circ} \mathrm{C}$ \\ Saturated vapor concentration: $121,053 \mathrm{ppm}$ at $20^{\circ} \mathrm{C}, 1 \mathrm{~atm}$ \\ Conversion factors at $25^{\circ} \mathrm{C}, 1 \mathrm{~atm}: 1 \mathrm{ppm}=1.31 \mathrm{mg} / \mathrm{m}^{3}$ \\ $1 \mathrm{mg} / \mathrm{m}^{3}=0.76 \mathrm{ppm}$.
}

\section{OCCURENCE AND USE}

We are not aware of any use of methyl alcohol in the operation of spacecraft. Methyl alcohol, however, has been used in payload experiments in the space shuttle (Wong and Lam, 1990) and detected in off-gas tests of flight hardware (H. Leano, Johnson Space Center, personal commun., 1990). One potential source of methanol exposure is via the diet. Fruit juices contain an average of $140 \mathrm{mg}$ of methanol per liter (Francot and 
Geoffroy, 1956). Diet soda containing aspartame could release methanol, equivalent to $10 \%$ of its weight, when aspartame is hydrolyzed in the intestine (Stegink et al., 1981). A typical diet soda contains aspartame equivalent to $56 \mathrm{mg}$ of methanol per liter, so drinking a 12-oz. can (355 $\mathrm{mL}$ ) of such beverages could lead to the absorption of $20 \mathrm{mg}$ of methanol. However, adult humans who ingested an amount of aspartame equivalent to that in 12 12-oz. cans of diet soda failed to increase the methanol concentration in blood during the $24 \mathrm{~h}$ after ingestion (Stegink et al., 1981). It took an amount of aspartame in 36 12-oz cans of diet soft drink to significantly elevate the blood methanol concentration. Therefore, oral intake of diet soda will not significantly contribute to methanol exposure in the astronauts.

\section{PHARMACOKINETICS AND METABOLISM}

The dog's respiratory system retains $81-88 \%$ of inhaled methanol in the first few minutes of an exposure at $300-550 \mathrm{ppm}$ (Egle and Gochberg, 1975). In a human study, except for the first few minutes of exposure, the respiratory system consistently retained $58 \%$ of inhaled methanol throughout an 8-h exposure (Sedivec et al., 1981). The degree of retention also remained constant as the methanol concentration varied from 78 to 216 $\mathrm{ppm}$ or as the minute volume was increased 2.5 times when the individual exercised (Sedivec et al., 1981). After absorption, methanol is distributed rapidly throughout the dog's body in body water (Yant and Schrenk, 1937). Methanol is first metabolized to formaldehyde, which is very rapidly metabolized into formic acid, so that very little formaldehyde is detected in tissues (Tephly et al., 1979). Formic acid is then metabolized to $\mathrm{CO}_{2}$ (McMartin et al., 1977). The conversion rate of formic acid to $\mathrm{CO}_{2}$ in primates is less than half of that in nonprimates (McMartin et al., 1977). Formic acid is, therefore, methanol's major metabolite in primates, but not in nonprimates (Clay et al., 1975). Formic acid is believed to be methanol's toxic metabolite (Clay et al., 1975), so toxicity data on nonprimates should not be relied on in setting methanol's SMACs. The species difference in methanol metabolism explains why Gilger and Pott (1955) found that methanol toxicity in monkeys differed from that in nonprimates.

In addition to metabolism, methanol is also eliminated unchanged via the lung and in the urine (Jacobsen et al., 1983; Leaf and Zatman, 1952). The 
pulmonary clearance of methanol was determined to be $5.6 \mathrm{~mL}$ of blood per minute in a man poisoned with methanol (Jacobsen et al., 1983). Humans excreted $0.76 \%$ of an oral dose of methanol unchanged in the urine in $12 \mathrm{~h}$ (Leaf and Zatman, 1952). The major route of methanol elimination is via metabolism, which was estimated to account for $97 \%$ of the elimination in humans (Kavet and Nauss, 1990). In workers occupationally exposed to methanol at about $93 \mathrm{ppm}$ for several months to 30 years, the venous methanol concentration reached $9 \mathrm{mg} / \mathrm{L}$ at the end of the working week, and the urinary methanol and formic acid concentrations were 22 and $30 \mathrm{mg} / \mathrm{L}$, respectively (Heinrich and Angerer, 1982).

Methanol elimination depends on the dose. In monkeys, at a high intraperitoneal dose of $1 \mathrm{~g} / \mathrm{kg}$, methanol elimination from the blood followed zero-order kinetics, with a hourly elimination rate of $0.44 \mathrm{mg} / \mathrm{L}$ (Eells et al., 1983). In $24 \mathrm{~h}, 60 \%$ of the administered methanol was eliminated (Eells et al., 1983). At lower doses, the elimination of methanol and its metabolites follows first-order kinetics. Methanol's half-life in blood is about 1.5-2.0 h in humans exposed to methanol vapor at 100-300 ppm (Sedivec et al., 1981). In monkeys, the half-lives of formaldehyde and formic acid in blood are about 1-1.5 $\mathrm{min}$ and 31-51 min, respectively (McMartin et al., 1977; Clay et al., 1975; McMartin et al., 1979).

\title{
TOXICITY SUMMARY
}

\author{
Acute Toxicity \\ Metabolic Acidosis, Headaches, and Ocular Toxicity \\ Methanol intoxication produces metabolic acidosis and ocular injuries in \\ humans (Klaassen, 1990). With single oral exposure to methanol at a \\ sufficient dose, headache, dizziness, nausea, abdominal pain, and blurred \\ vision develop after a latent period of 8-36 h (Klaassen, 1990). An inges- \\ tion of as little as $15 \mathrm{~mL}$ of methanol is sufficient to cause blindness in \\ humans (Klaassen, 1990). The latent period is thought to be due partly to \\ the time for transformation of methanol to an active metabolite (Gosselin et \\ al., 1984). Formic acid has been proposed to be the active metabolite \\ because formic acid has been shown to produce both metabolic acidosis and \\ ocular injuries (McMartin et al., 1977; Clay et al., 1975; Gilger and Potts, \\ 1955).
}




\section{CNS Effects Other Than Headaches}

Ingestion of high doses of methanol causes inebriation, but methanol is less potent than ethanol in causing inebriation (Klaassen, 1990). In addition to causing inebriation, methanol intoxication has been shown to cause a prolonged parkinsonian syndrome with lesions in the putamen in three human cases (Bourrat and Riboullard, 1986; Verslegers et al., 1988; LeWitt and Martin, 1988). In one of the cases, the intoxication was so severe that the individual developed permanent parkinsonism with visual impairment, increased dopamine beta-hydroxylase activity and decreased met-enkephalin levels in the cerebrospinal fluid (Verslegers et al., 1988). Brain hemorrhage was also documented in at least $13.5 \%$ of the cases of accidental methanol poisoning (Phang et al., 1988). Other than being toxic to the brain and eyes, methanol might also affect the heart. There has been one report of acute methanol intoxication causing severe reversible cardiac failure in a 55-year-old man (Cavalli et al., 1987). Because methanol's morphological effects on the brain and cardiac toxicity have been reported to occur after acute poisoning at high doses and they have not been reported to occur after inhalation exposures, the SMACs are not established according to the morphological effects on the brain and the cardiac toxicity.

\section{Subchronic Toxicity}

\section{Headaches and Ocular Toxicity}

Kingsley and Hirsch (1955) reported that a number of workers complained of frequent, recurrent headaches in the offices of a plant where certain duplicating machines were operated for the major part of an 8-h working day. These machines used a duplicating fluid containing methanol and the airborne methanol concentration was $210-375 \mathrm{ppm}$ in the winter, when most of the windows were shut. The methanol concentration reached $300 \mathrm{ppm}$ at $1 \mathrm{~h}$ into the operation of a machine. These concentrations persisted for as long as $4 \mathrm{~h}$ following a machine operation. The headaches were more severe in the workers located close to the machine than those more remotely situated. The most severe symptom was detected in the machine operators. Because Kingsley and Hirsch did not report the number of employees involved in the study in that one plant, their results are not used in setting SMACs. 
Other than recurrent headaches, inhaled methanol could also cause visual disturbances (Frederick et al, 1984). However, Kingsley and Hirsch (1955) failed to report whether the workers, exposed to methanol at 210 $375 \mathrm{ppm}$ in that study, complained of any visual problems. In their paper, Kingsley and Hirsch did recognize that optic injury is a feature of methanol poisoning.

An analysis of the data of a National Institute for Occupational Safety and Health (NIOSH) study provides evidence that $391 \mathrm{ppm}$ is probably the lowest-observed-effect level (LOEL) for methanol to cause visual toxicity and headaches (Frederick et al., 1984). In this epidemiology study performed by NIOSH, the prevalence of symptoms in 66 female teacher aides and 66 female teachers of similar age were compared (Frederick et al., 1984). The percentage of work hours spent at spirit duplicating machines that used methanol in poorly ventilated areas ranged from 0 to $90 \%$ for the teacher aides and 0 to $20 \%$ for the teachers, so the teacher aides presumably were exposed to methanol more often than the teachers. During the month before the investigation, $22 \%$ more teacher aides complained of blurred vision than teachers and $17 \%$ more teacher aides complained of headaches than teachers (Frederick et al., 1984). Although the difference between the teacher aides and teachers in the prevalence of blurred vision was significant, there was no statistically significant difference in the prevalence of "trouble with or changes in vision" between the teacher aides and teachers (Frederick et al., 1984). The higher percentage of teacher aides with headaches than teachers was statistically significant.

The higher prevalence of blurred vision in the teacher aides did not appear to be due to eye irritation because the increased prevalence of eye burning, itching, and tearing in the teacher aides was not statistically significant compared with that in the teachers (Frederick et al., 1984). These teacher aides worked from $1 \mathrm{~h} / \mathrm{w}$ to $40 \mathrm{~h} / \mathrm{w}$. Measurements made in the breathing zone of the teacher aides at the duplicating machines showed that the methanol concentrations varied from 365 to $3080 \mathrm{ppm}$. The attack rates of methanol-related symptoms in the teacher aides and teachers were correlated with the percentage of time spent at the duplicating machines per week.

Using the Chauvenet's criterion (Gad and Weil, 1988), the highest methanol concentration of $3080 \mathrm{ppm}$ in table 1 of the NIOSH paper (Frederick et al., 1984) was found to be an outlier (the next two highest concentrations were 1440 and $1365 \mathrm{ppm}$ ). With the highest methanol concentration discarded, the mean and standard deviation were calculated to be 960 
and $346 \mathrm{ppm}$, respectively, and the median is $1020 \mathrm{ppm}$. The scattergram of the methanol concentration data points shows that the concentration is monomodal and is relatively evenly distributed around the mean. The methanol concentration can be assumed to follow a normal distribution.

One way to interpret the NIOSH study (Frederick et al., 1984) is that working in an environment with methanol at about $1000 \mathrm{ppm}$ could result in blurred vision and headaches. Unfortunately, the NIOSH investigators did not present the methanol concentrations that the teacher aides afflicted with blurred vision or headaches were exposed to versus that of the nonresponding teacher aides. However, with three assumptions, the lowestobserved-adverse-effect level (LOAEL) based on visual disturbances and headaches can be estimated. First, assume that about equal number of the 66 teacher aides worked with each of the 21 duplicating machines that measured for methanol concentration (so that the percentage of teacher aides exposed to methanol at a concentration greater than or equal to a certain value can be estimated by the percentage of methanol-concentration measurements at or above that value). Second, assume that these teacher aides worked for equal amount of time with each of the duplicating machines (so that the amount of exposure, $\mathrm{C} \times \mathrm{T}$, could be approximated by $\mathrm{C}$ alone). Finally, a normal distribution is assumed for the exposure concentration. The lower $90 \%$ confidence limit of the teacher aides' exposure concentration is calculated to be $391 \mathrm{ppm}$ (mean - $1.645 \times$ S.D. $=960 \mathrm{ppm}-1.645 \times 346 \mathrm{ppm}=391 \mathrm{ppm})($ Steel and Torrie, 1980). The National Research Council's subcommittee on SMACs agreed that the lower $90 \%$ confidence limit, i.e. $391 \mathrm{ppm}$, can be treated as the LOAEL on the basis of blurred vision and headaches. That way of estimating the LOAEL should be valid because only $23 \%$ of the teacher aides complained of blurred vision and $17 \%$ complained of headaches (Frederick et al., 1984), and if methanol-induced toxicity follows a concentration response, the $23 \%$ and $17 \%$ responders (for blurred vision and headaches, respectively) were probably exposed to methanol concentrations at the upper half of the bell-shaped, concentration distribution curve.

In a German study, it was reported that a 4-y occupational exposure to 1200 to $8000 \mathrm{ppm}$ of methanol impaired the vision in one worker (Humperdinck, 1941). It appeared that the vision of other workers in the same plant was not affected. The vision of this apparently sensitive worker improved after exposures were stopped for $6 \mathrm{w}$. 


\section{Chronic and Genetic Toxicity}

It should be noted that no carcinogenic data on methanol has been found. Methanol is not genotoxic as evidenced by negative findings in the Ames test, the methanol's inability to cause sister chromatid exchange in Chinese hamster ovary cells, and micronuclei in mice (Florin et al., 1980; Obe and Ristow, 1977; Gocke et al., 1981).

\section{Developmental Toxicity}

Unlike inhaled ethanol, which affects pregnant rats and is not teratogenic in fetuses at high concentrations, inhaled methanol affects both the fetuses and dams at high concentrations (Nelson et al., 1985). Inhalation exposure to methanol at $5000 \mathrm{ppm}$ for $7 \mathrm{~h} / \mathrm{d}$ on days $1-19$ of gestation of pregnant rats had no effects on the fetuses and dams (Nelson et al., 1985). Exposure at 10,000 ppm, however, depressed fetal weight, but it did not affect maternal body weight, behavior, and water and feed consumption. Exposure at 20,000 ppm caused fetal malformation and slightly unsteady gait in the dams. 


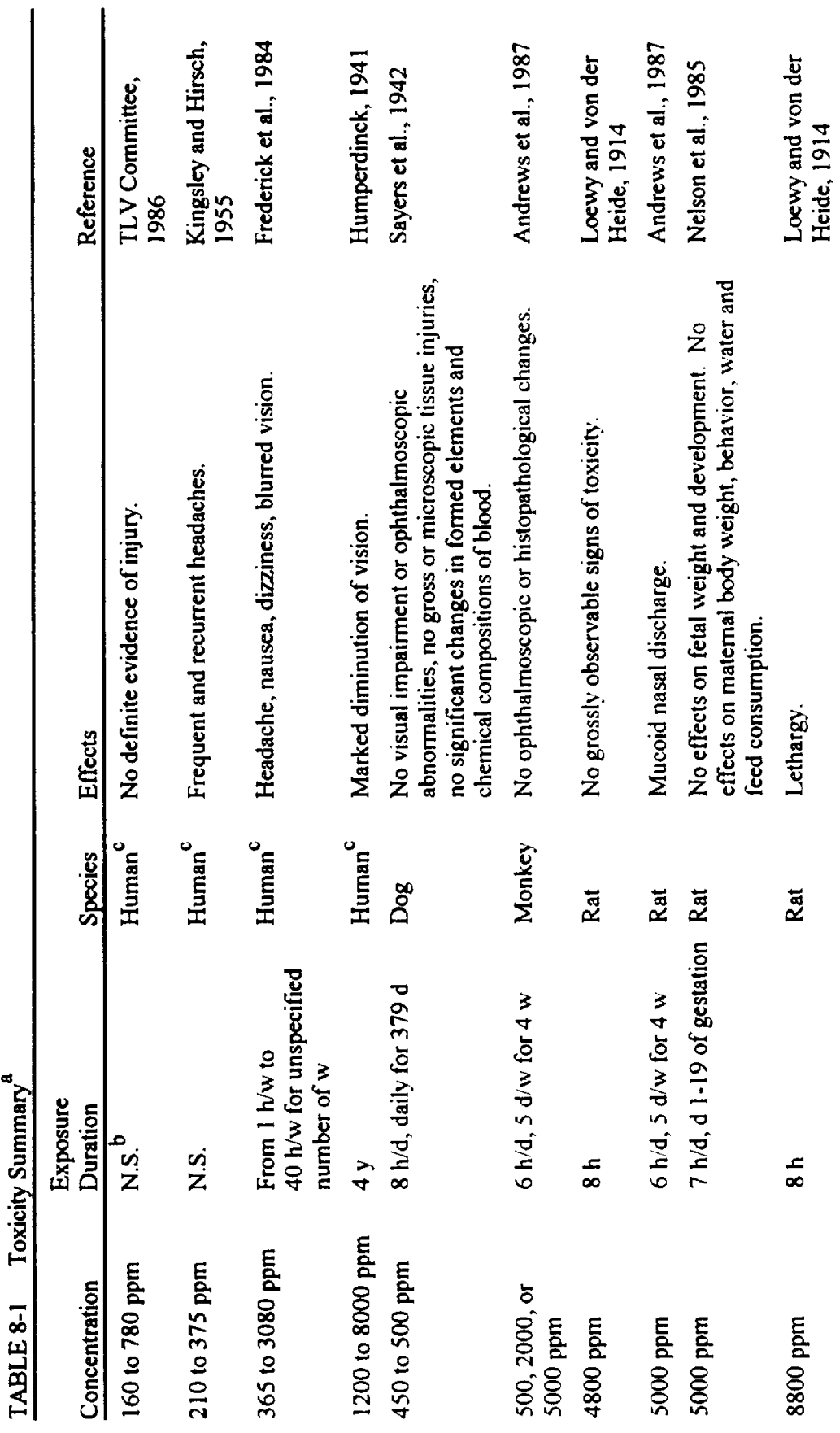



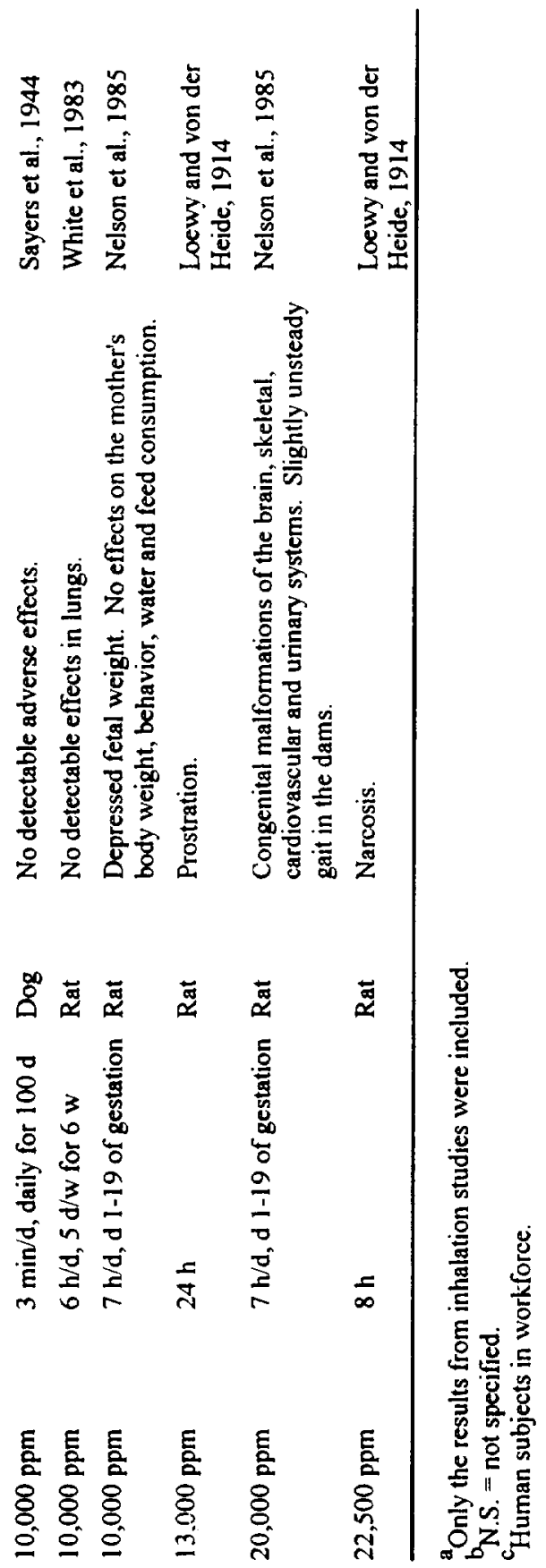
TABLE 8-2 Exposure Limits Set by Other Organizations

\begin{tabular}{ll}
\hline Organization & Concentration, ppm \\
\hline ACGIH's TLV & 200 (TWA) \\
ACGIH's STEL & 250 \\
OSHA's PEL & 200 (TWA) \\
NIOSH's REL & 200 (TWA), 800 (15-min ceiling) \\
NIOSH's IDLH & 25,000 \\
NRC's 1-h EEGL & 200 \\
NRC's 24-h EEGL & 10 \\
\hline
\end{tabular}

TLV $=$ threshold limit value. TWA $=$ time-weighted average. $P E L=$ permissible exposure limit. STEL $=$ short-term exposure limit. REL $=$ recommended exposure limit. IDLH $=$ immediately dangerous to life and health. EEGL = emergency exposure guidance level.

TABLE 8-3 Spacecraft Maximum Allowable Concentrations

\begin{tabular}{llll}
\hline Duration & $\mathrm{ppm}$ & $\mathbf{m g} / \mathrm{m}^{3}$ & Target Toxicity \\
\hline $1 \mathrm{~h}$ & 30 & 40 & Visual disturbances \\
$24 \mathrm{~h}$ & 10 & 13 & Visual disturbances \\
$7 \mathrm{~d}^{\mathrm{a}}$ & 7 & 9 & Visual disturbances \\
$30 \mathrm{~d}$ & 7 & 9 & Visual disturbances \\
$180 \mathrm{~d}$ & 7 & 9 & Visual disturbances \\
\hline
\end{tabular}

${ }^{\mathrm{a}}$ Current 7-d SMAC $=40 \mathrm{ppm}$.

\section{RATIONALE}

Methanol's SMACs are set to protect the astronauts against headaches and ocular injury, the two major toxic end points of methanol poisoning. For each desired exposure duration, an acceptable concentration (AC) for each of the toxic end point is derived from the toxicity data. At the end, the lowest $A C$ is chosen as the SMAC for that exposure duration. 
Headache

\section{1-h AC}

In a study by Kingsley and Hirsch (1955) and in a NIOSH study (Frederick et al., 1984), workers complained of headaches when they worked in the vicinity of duplicating machines in which methanol was used. As described in "Toxicity Summary," the LOAEL for headaches is estimated to be $391 \mathrm{ppm}$ according to the data in the NIOSH study. Since some degree of headache is acceptable during emergencies, the LOAEL in an occupational setting is chosen to be the $1-\mathrm{h}$ AC based on headaches.

1-h AC based on headaches

= occupational LOAEL

$=391 \mathrm{ppm}$.

\section{4-h AC}

In an emergency that lasts up to $24 \mathrm{~h}$, it is not acceptable for the crew to have to endure recurrent headaches for $24 \mathrm{~h}$. So the 24-h SMAC should be set lower than the 1-h SMAC. Unfortunately, there are no data on the level of methanol that does not cause headaches. The American Conference of Governmental Industrial Hygienists (ACGIH) cited a study performed by the Massachusetts Division of Occupational Hygiene in 1937 that detected no definite evidence of injury at $160-780$ ppm (TLV Committee, 1986). Because two more recent reports showed that methanol could produce headaches at less than 780 ppm (Kingsley and Hirsch, 1955; Frederick et al., 1984), the apparently negative finding in the Massachusetts study was disregarded. Instead, to estimate a concentration that might not cause headaches, an extrapolation factor of 5 is applied to the LOAEL, $391 \mathrm{ppm}$, based on headaches in an occupational study (Kingsley and Hirsch, 1955). The factor of 5 is chosen because minor headaches are acceptable in a 24-h contingency, as a factor half the size of the traditional factor of 10 is used to estimate a no-observed-adverse-effect level (NOAEL) from a LOAEL.

Time adjustment is needed to account for the potential difference be- 
tween an 8-h workday exposure and a 24-h continuous exposure. The time adjustment for headaches is performed with the assumptions that headaches are dependent on the blood concentration of methanol's active metabolite, formic acid, and that there is a threshold blood concentration below which no headaches would occur. According to classical pharmacokinetics, during a continuous exposure at a constant dose rate of a chemical that follows a one- or two-compartment model, the blood concentration will reach $99 \%$ of the steady state seven elimination half-lives into the exposure (Gibaldi and Perrier, 1975). Since methanol distributes rapidly throughout the body in body water (Yant and Schrenk, 1937), one can assume that methanol follows a one-compartment model. However, the findings of Leaf and Zatman (1952) tend to indicate that methanol follows either a oneor a two-compartment model. They showed that the urinary methanol concentration declined monoexponentially from 1 to $14 \mathrm{~h}$ after an ingestion of up to $7 \mathrm{~mL}$ of methanol in adult males and the urinary methanol concentrations closely reflected the changes in blood concentration. That means the methanol concentration in blood declined monoexponentially from 1 to $14 \mathrm{~h}$ following an ingestion. Because Leaf and Zatman did not collect any data in the first hour after methanol ingestion, they might have missed an early exponential phase, so it is possible that methanol follows a two-compartment model. Regardless of whether a one- or two-compartment model is used, with a half-life of 1.5-2 $\mathrm{h}$ in humans (Sedivec et al., 1981), it only takes $14 \mathrm{~h}$ for the methanol blood level to essentially reach equilibrium.

We need to estimate the time the blood level of methanol's active metabolite, i.e., formic acid, takes to reach equilibrium. As summarized above, methanol is metabolized first to formaldehyde, which is further metabolized to formic acid. Because formaldehyde is very rapidly metabolized to formic acid (Tephly et al., 1979) and because the elimination half-life of formaldehyde is only about 1/30th of that of formic acid (McMartin et al., 1977, 1979; Clay et al., 1975), kinetically we can assume that the metabolism of methanol to formic acid consists of only one step. It has been shown that, for a metabolite with a elimination half-life less than the elimination half-life of the parent compound, the blood level of the metabolite follows that of the parent compound after an initial period (Gibaldi and Perrier, 1975). Formic acid's elimination half-life is $31 \mathrm{~min}$ in monkeys (McMartin et al, 1977) and that of methanol is 1.5-2 $\mathrm{h}$ in humans (Sedivec et al., 1981). Assuming that formic acid's half-life in humans resembles that in monkeys, the blood level of formic acid should, therefore, follow the blood level of methanol after an initial period. Formic acid started to 
appear in blood as soon as $2 \mathrm{~h}$ after monkeys ingested methanol (Tephly et al., 1979). It follows that formic acid's blood level probably lags behind that of methanol by no more than $2 \mathrm{~h}$ during an inhalation exposure of methanol. So formic acid's blood level should reach steady state at $14 \mathrm{~h}+$ $2 \mathrm{~h}$, i.e. $16 \mathrm{~h}$, in a continuous methanol inhalation exposure. That means the time adjustment for any exposure longer than $16 \mathrm{~h}$, e.g. $24 \mathrm{~h}, 7 \mathrm{~d}, 30$ $\mathrm{d}$, and $180 \mathrm{~d}$, could be done using $16 \mathrm{~h}$ in place of the actual exposure duration. So the time-adjustment factor becomes $8 \mathrm{~h} / 16 \mathrm{~h}$. Such a timeadjustment factor is conservative because it implies that the blood concentration of formic acid increases linearly with exposure time for $16 \mathrm{~h}$ into a methanol exposure. Actually, the blood concentration of formic acid will probably increase in some exponential function to $16 \mathrm{~h}$, but because the data available do not allow for an accurate estimation of the exponential function, a linear function is used instead.

24-h AC based on headaches

$=$ occupational LOAEL $\times 1 /$ extrapolation factor $\times$ time adjustment

$=391 \mathrm{ppm} \times 1 / 5 \times 8 \mathrm{~h} / 16 \mathrm{~h}$

$=39 \mathrm{ppm}$.

\section{7-d, 30-d, and 180-d ACs}

Since formic acid reaches steady state in $16 \mathrm{~h}$, the time adjustment for a 7-d, 30-d, or 180-d continuous exposure is all done using $16 \mathrm{~h}$. To estimate the NOAEL, a safety factor of 10 is applied onto the LOAEL. Because the LOAEL is derived from a NIOSH study based on only 66 teacher aides, an adjustment for "small $n$ " is used to derive the 7-d, 30-d, and 180-d ACs. The adjustment for small $n$ is not needed for the 1-h and 24-h ACs based on headaches because a small degree of headache is acceptable for $1 \mathrm{~h}$ or $24 \mathrm{~h}$, so a wide safety margin is not needed.

7-d, 30-d, and 180-d AC based on headaches

$=$ occupational LOAEL $\times 1 /$ NOAEL factor $\times$ time adjustment $\times 1 /$ small- $n$ factor

$=391 \mathrm{ppm} \times 1 / 10 \times 8 \mathrm{~h} / 16 \mathrm{~h} \times($ square root of $n) / 10$

$=391 \mathrm{ppm} \times 1 / 10 \times 8 \mathrm{~h} / 16 \mathrm{~h} \times($ square root of 66$) / 10$

$=16 \mathrm{ppm}$, 
where the NOAEL factor is the uncertainty factor used to estimate a NOAEL from a LOAEL.

\author{
Visual Disturbances
}

\title{
1-h AC
}

As discussed in "Toxicity Summary," the LOAEL for visual disturbances is estimated to be $391 \mathrm{ppm}$ in an occupational exposure setting on the basis of data from the NIOSH study of 66 teacher aides (Frederick et al., 1984).

1-h AC based on visual disturbances

$=$ occupational LOAEL $\times 1 /$ NOAEL factor $\times 1 /$ small $-n$ factor

$=391 \mathrm{ppm} \times 1 / 10 \times($ square root of $n) / 10$

$=391 \mathrm{ppm} \times 1 / 10 \times($ square root of 66$) / 10$

$=32 \mathrm{ppm}$.

\section{4-h AC}

Unlike headaches, methanol's occular toxicity might not be entirely dependent on the blood concentration of formic acid and might not have a threshold. Methanol's occular toxicity is prudently assumed to be dependent on the product of exposure concentration and exposure duration. Because it is difficult to find a representative workday for the teacher aides in the NIOSH study, the time adjustment used to derive the $24-\mathrm{h} \mathrm{AC}$ is based on an occupational exposure of $8 \mathrm{~h}$, so the time-adjustment factor is $8 \mathrm{~h} / 24 \mathrm{~h}$. Considering the fact that some of the teacher aides were exposed for $1 \mathrm{~h} / \mathrm{w}$ and others were exposed for years at $40 \mathrm{~h} / \mathrm{w}$, a time-adjustment factor of $8 \mathrm{~h} / 24 \mathrm{~h}$ seems to be an appropriate compromise.

24-h AC based on visual disturbances

$=$ occupational LOAEL $\times 1 /$ NOAEL factor $\times$ time adjustment $\times 1 /$ small $-n$ factor

$=391 \mathrm{ppm} \times 1 / 10 \times 8 \mathrm{~h} / 24 \mathrm{~h} \times($ square root of $n) / 10$

$=391 \mathrm{ppm} \times 1 / 10 \times 8 \mathrm{~h} / 24 \mathrm{~h} \times($ square root of 66$) / 10$

$=11 \mathrm{ppm}$. 


\section{7-d, 30-d, and 180-d ACs}

A similar rationale is used in deriving the longer-term ACs. As a compromise for the facts that some workers were exposed to less than 40 $\mathrm{h} / \mathrm{w}$ for less than a year, while others were exposed for years at $40 \mathrm{~h} / \mathrm{w}$, all time adjustments are done on a per-week basis regardless of whether the $\mathrm{AC}$ is for 7,30 , or $180 \mathrm{~d}$.

$$
\begin{aligned}
& \text { 7-d, } 30-\mathrm{d}, \text { and } 180-\mathrm{d} \text { ACs based on visual disturbances } \\
&= \text { occupational LOAEL } \times 1 / \text { NOAEL factor } \times \text { time adjustment } \\
& \times 1 / \text { small- } n \text { factor } \\
&= 69 \mathrm{ppm} \times 1 / 10 \times(40 \mathrm{~h} / \mathrm{w}) /(24 \mathrm{~h} / \mathrm{d} \times 7 \mathrm{~d} / \mathrm{w}) \\
& \times(\text { square root of } n) / 10 \\
&= 69 \mathrm{ppm} \times 1 / 10 \times(40 \mathrm{~h} / \mathrm{w}) /(24 \mathrm{~h} / \mathrm{d} \times 7 \mathrm{~d} / \mathrm{w}) \\
& \times(\mathrm{square} \text { root of } 66) / 10 \\
&= 7 \mathrm{ppm}
\end{aligned}
$$

The data of a subchronic exposure of monkeys to methanol can be used to check if the 180-d AC of $7 \mathrm{ppm}$ can prevent ocular damage in a 180-d exposure. Andrews et al. (1987) showed that an exposure of monkeys to methanol at 500,2000 , or $5000 \mathrm{ppm}, 6 \mathrm{~h} / \mathrm{d}, 5 \mathrm{~d} / \mathrm{w}$ for $4 \mathrm{w}$ failed to produce any eye injury on the basis of microscopic and ophthalmoscopic examinations (Andrews et al., 1987). Therefore, $5000 \mathrm{ppm}$ is considered the NOAEL in this 4-w study. Haber's rule is used in adjusting for the differences in exposure durations.

180-d acceptable concentration derived from data in monkeys

$=4$-w NOAEL $\times$ species extrapolation factor $\times$ time adjustment

$=5000 \mathrm{ppm} \times 1 / 10 \times(6 \mathrm{~h} / \mathrm{d} \times 5 \mathrm{~d} / \mathrm{w} \times 4 \mathrm{w}) /(24 \mathrm{~h} / \mathrm{d}$ $\times 180 \mathrm{~d})$

$=5000 \mathrm{ppm} \times 1 / 10 \times 0.03$

$=14 \mathrm{ppm}$.

Since the 180-d AC derived from the human data of NIOSH is lower than the acceptable methanol exposure concentration based on the data in monkeys, the 180-d AC appears to be appropriate. With a preference of human data over animal data, the 180-d acceptable concentration derived from data in monkeys is not adopted in setting the 180-d SMAC.

Because methanol's toxicity in primates differs from that in nonprimates 
(Gilger and Potts, 1955), the data from the long-term study in dogs (Andrews et al., 1987) are not used to set the long-term SMACs.

\section{Establishment of SMACs}

The ACs based on headaches and visual disturbances for each of the exposure durations are listed in Table 10-4. The lowest ACs for each exposure duration are chosen to be the corresponding SMACs. The 1-h, 24-h, 7-d, 30-d, and 180-d SMACs are set at 30, 10, 7, 7, and $7 \mathrm{ppm}$, respectively.

Finally, these SMACs are not adjusted for microgravity effects, because microgravity-induced changes are not expected to affect methanol's ocular toxicity and its propensity to produce acidosis.

TABLE 8-4 Acceptable Concentrations

\begin{tabular}{|c|c|c|c|c|c|}
\hline \multirow[b]{2}{*}{ Toxic End Points } & \multicolumn{5}{|c|}{ Acceptable Concentrations, ppm } \\
\hline & $1 \mathbf{h}$ & $24 \mathrm{~h}$ & $7 \mathrm{~d}$ & $30 \mathrm{~d}$ & $180 \mathrm{~d}$ \\
\hline Headaches & 391 & 39 & 16 & 16 & 16 \\
\hline Visual Disturbances & 32 & 11 & 7 & 7 & 7 \\
\hline SMAC & 30 & 10 & 7 & 7 & 7 \\
\hline
\end{tabular}

\section{REFERENCES}

ACGIH. 1986. Methanol. In Documentation of TLVs and BEIs. American Conference of Governmental Industrial Hygienists, Cincinnati, Ohio.

Andrews, L.S., J.J. Clary, J.B. Terrill, and H.F. Bolte. 1987. Subchronic inhalation toxicity of methanol. J. Toxicol. Environ. Health 20:117-124.

Bourrat, C. and L. Riboullard. 1986. Voluntary methanol poisoning. Severe regressive encephalopathy with anomalies on $\mathrm{x}$-ray computed tomography. Rev. Neurol. (Paris) 142:530-534. 
Cavalli, A., A. Volpi, A.P. Maggioni, M. Tusa, and G. De Pieri. 1987. Severe reversible cardiac failure associated with methanol intoxication. Postgrad. Med. J. 63:867-868.

Clay, K.L., R.C. Murphy, and W.D. Watkins. 1975. Experimental methanol toxicity in the primate: Analysis of metabolic acidosis. Toxicol. Appl. Pharmacol. 34:49-61.

Eells, J.T., K.A. Black, C.E. Tedford, and T.R. Tephly. 1983. Methanol toxicity in the monkey: Effects of nitrous oxide and methionine. J. Pharmacol. Exp. Ther. 227:349-353.

Egle, J.L. and B.J. Gochberg. 1975. Retention of inhaled isoprene and methanol in the dog. Am. Ind. Hyg. Assoc. J. 36:369-373.

Florin, I., L. Rutberg, M. Curvall, and C.R. Enzell. 1980. Screening of tobacco smoke constituents for mutagenicity using the Ames test. Toxicology 15:219-232.

Francot, P. and P. Geoffroy. 1956. Le methanol dans les jus de fruits, les boissons, fermentees, les alcools et spiriteux. Rev. Ferment. Ind. Aliment. 11:279.

Frederick, L.J., P.A. Schulte, and A. Apol. 1984. Investigation and control of occupational hazards associated with the use of spirit duplicators. Am. Ind. Hyg. Assoc. J. 45:51-55.

Gad, S. and C.S. Weil. 1988. P. 13 in Statistics and Experimental Design for Toxicologists. Telford Press, Caldwell, N.J.

Gibaldi, M. and D. Perrier. 1975. Pharmacokinetics. Marcel Dekker, New York.

Gilger, A.P. and A.M. Potts. 1955. Studies of the visual toxicity of methanol. Am. J. Ophthalmol. 39:63-86.

Gocke, E., M.T. King, K. Eckhardt, and D. Wild. 1981. Mutagenicity of cosmetics ingredients licensed by the European communities. Mutat. Res. 90:91-109.

Gosselin, R.E., R.P. Smith, and H.C. Hodge. 1984. Pp. III-275 in Clinical Toxicology of Commercial Products. Williams and Wilkins, Baltimore, Md.

Heinrich, R. and J. Angerer. 1982. Occupational chronic exposure to organic solvents. X. Biological monitoring parameters for methanol exposure. Int. Arch. Occup. Environ. Health 50:341-349.

Humperdinck, K. 1941. [On the problem of chronic intoxication with methanol vapors.] Arch. Gewerbepathol. U. Gewerbehyg. 10:569-574.

Jacobsen, D., S. Ovreb:, E. Arnesen, and P.N. Paus. 1983. Pulmonary 
excretion of methanol in man. Scand. J. Clin. Lab. Invest. 43:377-379.

Kavet, R. and K.M. Nauss. 1990. The toxicity of inhaled methanol vapors. Crit. Rev. Toxicol. 21:21-50.

Kingsley, W.H. and F.C. Hirsch. 1955. Toxicologic considerations in direct process spirit duplicating machines. Compen. Med. 40:7-8.

Klaassen, C.D. 1990. Solvents and vapors. P. 1624 in Goodman and Gilman's The Pharmacological Basis of Therapeutics. A.G. Gilman, et al., eds. Macmillan, New York.

Leaf, G. and L.J. Zatman. 1952. A study of the condition under which methanol may exert a toxic hazard in industry. Br. J. Ind. Med. 9:1931.

LeWitt, P.A. and S.D. Martin. 1988. Dystonia and hypokinesis with putaminal necrosis after methanol intoxication. Clin. Neuropharmacol. 11:161-167.

Loewy, A. and R. von der Heide. 1914. Uber die aufnahme des methylalkohls durch die atmung. Biochem. Z. 65:230-252.

Mahieu, P., A. Hassoun, and R. Lauwerys. 1989. Predictors of methanol intoxication with unfavourable outcome. Hum. Toxicol. 8:135-137.

McMartin, K.E., G. Martin-Amat, A.B. Makar, and T.R. Tephly. 1977. Methanol poisoning. V. Role of formate metabolism in the monkey. J. Pharmacol. Exp. Ther. 201:564-572.

McMartin, K.E., G. Martin-Amat, P.E. Noker, and T.R. Tephly. 1979. Lack of a role of formaldehyde in methanol poisoning in the monkey. Biochem. Pharmacol. 28:645-649.

Nelson, B.K., W.S. Brithwell, D.R. Mackenzie, A. Khan, J.R. Burg, W.W. Weigel, and P.T. Goad. 1985. Teratological assessment of methanol and ethanol at high inhalation levels in rats. Fundam. Appl. Toxicol. 5:727-736.

Obe, G. and H. Ristow. 1977. Acetaldehyde, but not ethanol, induces sister chromatid exchanges in Chinese hamster cells in vitro. Mutat. Res. 56:211-213.

Phang, P.T., L. Passerini, B. Mielke, R. Berendt, and E.G. King. 1988. Brain hemotrhage associated with methanol poisoning. Crit. Care Med. 16:137-140.

Sayers, R.R., W.P. Yant, H.H. Schrenk, J. Chornyak, S.J. Pearce, F.A. Patty, and J.G. Linn. 1942. P. 1 in Methanol poisoning-I. Exposure of dogs to $450-500 \mathrm{ppm}$ methanol vapor in air. Rep. Invest. No. 3617. U.S. Department of the Interior, Bureau of Mines, Washington, D.C.

Sayers, R.R., W.P. Yant, H.H. Schrenk, J. Chornyak, S.J. Pearce, F.A. 
Patty, and J.G. Linn. 1944. Methanol poisoning II. Exposure of dogs for brief periods eight times daily to high concentrations of methanol vapor in air. J. Ind. Hyg. Toxicol. 26:255-259.

Sedivec, V., M. Mräz, and J. Flek. 1981. Biological monitoring of persons exposed to methanol vapors. Int. Arch. Occup. Environ. Health 48:257-271.

Steel, R.G.D. and J.H. Torrie. 1980. Pp. 55-56 in Principles and Procedures of Statistics. A Biomedical Approach. McGraw-Hill, New York.

Stegink, L.D., M.C. Brummel, K. McMartin, G. Matin-Amat, L.J. Filer, G.L. Baker, and T.R. Tephly. 1981. Blood methanol concentrations in normal adult subjects administered abuse doses of aspartame. J. Toxicol. Environ. Health 7:281-290.

Tephly, T.R., A.B. Makar, K.E. McMartin, S.S. Hayreh, and G. MartinAmat. 1979. Methanol: Its metabolism and toxicity. Pp. 145-164 in Biochemistry and Pharmacology of Ethanol. Vol. I. E. Majchrowicz and E.P. Noble, eds. Plenum, New York.

Verslegers, W., M. Van den Kerchove, R. Crols, W. De Potter, B. Appel, and A. Lowenthal. 1988. Methanol intoxication. Parkinsonism and decreased met-enkephalin levels due to putaminal necrosis. Acta Neurol. Belg. 88:163-171.

White, L.R., A.B. Marthinsen, R.J. Richards, K.B. Eik-Nes, and O.G. Nilsen. 1983. Biochemical and cytological studies of rat lung after inhalation of methanol vapour. Toxicol. Lett. 17:1-5.

Wong, K.L. and C.-W. Lam. 1990. STS-31 Orbiter Payload, DSO and Utility Chemicals. Toxicologic Information and Risk Assessments. JSC 24227. Toxicology Group, Biomedical Operations and Research Branch, Medical Sciences Division, Johnson Space Center, NASA, Houston, Tex.

Yant, W.P. and H.H. Schrenk. 1937. Distribution of methanol in dogs after inhalation and administration by stomach tube and subcutaneously. J. Ind. Hyg. Toxicol. 19:337-345. 



\section{B9 Octamethyltrisiloxane}

Rogene F. Henderson, Ph.D.

Lovelace Biomedical and Environmental Research Institute Albuquerque, New Mexico

John T. James, Ph.D.

Johnson Space Center Toxicology Group

Biomedical Operations and Research Branch

Houston, Texas

\section{PHYSICAL AND CHEMICAL PROPERTIES}

Organosiloxane polymers (silicones) have high thermal and chemical stability and unusual release from sticking and surface properties (Rochow, 1951). The compounds are useful for waterprooting because the polar $\mathrm{Si}-\mathrm{O}$ bonds orient themselves near the surface and the organic groups present a water-repelling exterior. The compounds are more thermostable and less viscous than hydrocarbons of comparable molecular weight and are therefore valuable as lubricants and hydraulic fluids. Octamethyltrisiloxane (MDM), one of the lower molecular weight silicones, is a flammable liquid that might decompose on exposure to water. The compound is described as stable and inert to most chemicals (Merck Index, 1989).

Formula: $\mathrm{C}_{8} \mathrm{H}_{24} \mathrm{O}_{2} \mathrm{Si}_{3}$ Structure:

Synonym: MDM

CAS number: $107-51-7$

Molecular weight: 236.54

Boiling point: $153^{\circ} \mathrm{C}$

Melting point: $\quad-82^{\circ} \mathrm{C}$

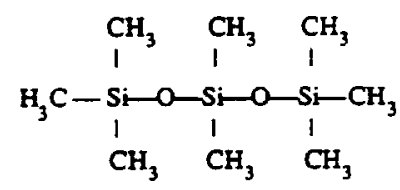

Flash point: $29^{\circ} \mathrm{C}$

Vapor pressure: $50 \mathrm{~mm} \mathrm{Hg}$ at $73^{\circ} \mathrm{C}$ (measured)

$2.6 \mathrm{~mm} \mathrm{Hg}$ at $20^{\circ} \mathrm{C}$ (calculated)

Conversion factor: $1 \mathrm{ppm}=10.56 \mathrm{mg} / \mathrm{m}^{3}$ at $25^{\circ} \mathrm{C}, 1 \mathrm{~atm}$

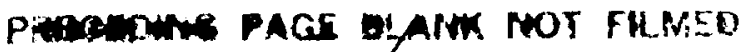

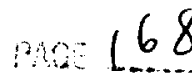




\section{OCCURRENCE AND USE}

MDM is one of a series of compounds known as silicones. They are used as lubricants, hydraulic oils, heat transfer media, and dielectric oils; in rubber for electrical coatings, for molding, and as release agents for the food industry, metal-working applications, and rubbers, plastics, and ceramics; as water repellents for textiles, paper, masonry, and concrete; and in cosmetic and pharmaceutical formulations. A specialty product known as "silly putty" has unusual rheological properties that have made it popular as a toy for children. Medicinally, silicones have been used as antifrothing agents (antiflatulent; bronchial antifoam) and as dermal implants for soft tissue augmentation.

MDM is used in making silicone oils or fluids designed to withstand extremes of temperature and as a foam suppressant in petroleum lubricating oil. It was detected in the Skylab 4 spacecraft atmosphere at concentrations of 105 to $138 \mathrm{ppb}$ (Liebich et al., 1975).

\section{PHARMACOKINETICS AND METABOLISM}

No pharmacokinetic and metabolism papers were found in the literature for MDM specifically. However, some studies have been done on medical-grade polydimethylsiloxane fluids. Bruggeman et al. (1984) reported on the absorption and retention of high-molecular-weight polydimethylsiloxanes in fish. In contrast to polychlorinated biphenyls, only very small amounts of the silicones were retained by fish after $6 \mathrm{w}$ of feeding. The authors had not expected such low retention based on octanol:water partitioning coefficients. Apparently, rapid evaporation of the lower molecular weight components (including MDM) from the test food prevented a measurement of the "magnification factor" (concentration in fish/concentration in food). Because hexamethyldisiloxane (HMDS) is toxic and irritating (Rowe et al., 1948), it is clearly absorbed to some extent. It is not clear whether MDM would be absorbed during an inhalation exposure.

Ingestion of massive amounts of silicone fluids in the rat appears to cause no local or systemic effects (Ashley et al., 1967), suggesting that the material was not absorbed. Tissue histiocytes can phagocytize silicone and migrate to other organs with it (Rees et al., 1970; Travis et al., 1985; Achauer, 1983). 


\section{TOXICITY SUMMARY}

A summary of the early toxicity studies performed with silicone oils can be found in a review by McGregor (1954). Rowe et al. (1948) state that "the silicones (methyl and mixed methyl and phenyl polysiloxanes) as a class are very low in toxicity and present no significant handling problems." Massive feeding of animals resulted only in a laxative action similar to mineral oil (Barondes et al., 1950). There was no irritation to the skin and only mild transitory irritation to the eyes. Injections of animals intramuscularly produced no reaction and led to the suggestion of the oils as nonaqueous vehicles for administration of drugs (McNamara et al., 1950).

The vapor pressures of most siloxane polymers are too low to present a problem as an airborne vapor (Flaningam, 1986). If one looks at the lower boiling HMDS (boiling point, $99.5^{\circ} \mathrm{C}$ ), guinea pigs and rats exposed repeatedly for 7-h periods to $4400 \mathrm{ppm}$ showed no signs of discomfort, but the concentration was disagreeable to humans (Rowe et al. 1948). Exposure of the animals to HMDS at $40,000 \mathrm{ppm}$ caused death in 15-20 min due to respiratory failure.

Feeding studies with methylsiloxanes have been reported in rats (Rowe et al., 1950) and dogs (Child et al., 1951). The rats were fed a diet containing $0.3 \%$ methylpolysiloxane oils (DC Antifoam A) for $2 y$. No adverse effects were observed based on growth, mortality, gross appearance and behavior, hematology, blood urea nitrogen, organ weights, hepatic lipid, and histopathology of tissues. The dogs were fed the same material at $3 \mathrm{~g} / \mathrm{d} / \mathrm{kg}$ body weight for $6 \mathrm{mo}$ and also showed no ill effects.

A more recent review of the toxicity of silicone oils (Clark et al., 1989) indicates that medical-grade silicones are near-inert compounds. Animal studies (mice, rats, guinea pigs, rabbits, dogs, and monkeys), including ingestion studies up to $20 \mathrm{~g} / \mathrm{kg}$, showed no ill effects (Ashley et al., 1967; Hawthorne et al., 1970; Rees et al., 1970). In humans, cosmetic injections of silicone oils were reported to cause no tissue reaction when small amounts of medical-grade silicone were used.

The oral toxicity studies cited above were performed with a mixture of methyl and phenyl siloxanes. No data on the toxicity of pure MDM were found. However, the National Toxicology Program has selected this compound as a candidate for a $2-y$ carcinogenesis assay, reflecting a growing interest in the potential toxicity of polymers. 


\section{EXPOSURE LIMITS}

No limits were found to have been set by other organizations.

\section{RATIONALE}

The most pertinent toxicity data are reported by Rowe et al. (1948) for HMDS and dodecamethylpentasiloxane (DMPS). Structurally, these two compounds bracket MDM and provide the basis for setting SMACs from structure-activity relationships (SARs). Both HMDS and DMPS were tested by single doses given by intraperitoneal injection, intradermal injection, subcutaneous injection, and oral gavage. The findings are shown in Table 9-1.

\section{TABLE 9-1 HMDS and DMPS Data}

\begin{tabular}{|c|c|c|c|}
\hline $\begin{array}{l}\text { Route } \\
\text { (Species) }\end{array}$ & Dosage & $\begin{array}{l}\text { Response } \\
\text { to HMDS } \\
\end{array}$ & $\begin{array}{l}\text { Response } \\
\text { to DMPS }\end{array}$ \\
\hline Oral (rat) & $10 \mathrm{~mL} / \mathrm{kg}$ & 0 of 7 died & 0 of 3 diexl, slight laxative \\
\hline Oral (rat) & $30 \mathrm{~mL} / \mathrm{kg}$ & 0 of 7 died & $\begin{array}{l}0 \text { of } 6 \text { died, moderate } \\
\text { laxative }\end{array}$ \\
\hline Oral (rat) & $50 \mathrm{~mL} / \mathrm{kg}$ & $\begin{array}{l}1 \text { of } 10 \text { died (CNS } \\
\text { depression) }\end{array}$ & 3 of 3 died \\
\hline $\begin{array}{l}\text { Intraperitoneal } \\
\text { (rat) }\end{array}$ & $\begin{array}{l}0.1-10 \\
\mathrm{~mL} / \mathrm{kg}\end{array}$ & $\begin{array}{l}\text { Some deaths, local } \\
\text { irritation, adhesion }\end{array}$ & No effect \\
\hline $\begin{array}{l}\text { Intradermal } \\
\text { (rabbit) }\end{array}$ & $0.1 \mathrm{~mL}$ & $\begin{array}{l}\text { Inflammation, edema, } \\
\text { necrosis }\end{array}$ & Blebs, no local reaction \\
\hline $\begin{array}{l}\text { Subcutaneous } \\
\text { (rabbit) }\end{array}$ & $0.1 \mathrm{~mL}$ & Irritation, necrosis & No effect \\
\hline
\end{tabular}

It is clear from this table that except for the laxative effect of DMPS by oral administration, HMDS is more toxic. This effect is not relevant to the inhalation route of administration because the effect is induced by local "lubrication" of the gastrointestinal tract. More rats died after oral administration of DMPS than HMDS; however, that occurred only at the extreme dosage of $50 \mathrm{~mL} / \mathrm{kg}$ and is not pertinent to the inhalation route.

Inhalation data are available for repeated exposures of rats and guinea 
pigs to HMDS; however, no inhalation data are available on DMPS. For HMDS it was reported that 157 -h exposures of rats to $4400 \mathrm{ppm}$ only caused $10 \%$ decreases in the weights of liver and kidney (Rowe et al., 1948). Histological changes were not found in these organs or any of the others examined in this limited study. It was also reported that $207-\mathrm{h}$ exposures of guinea pigs to $4400 \mathrm{ppm}$ caused only a $10 \%$ decrease in body weight without effect on organ weights or histopathology. Changes in body weight or organ weight of this magnitude, in the absence of other changes, are not considered adverse effects. Hence, to avoid possible liver or kidney effects, $4400 \mathrm{ppm}$ is considered to be a no-observed-adverse-effect level (NOAEL) for repeated exposures of guinea pigs or rats to HMDS.

Unfortunately, no inhalation data are available on DMPS, so it is not possible to form a complete picture of SARs. Based on the other routes of administration, it can be concluded that DMPS is very unlikely to be as toxic by inhalation as HMDS. However, because the SAR is not complete for the inhalation route, the inhalation NOAEL estimate for HMDS (4400 ppm) is reduced by a factor of 3 to estimate a NOAEL for MDM, the compound of interest. The 7-d SMAC for MDM is calculated using that factor and others as shown below:

$$
\begin{aligned}
& \text { 7-d SMAC } \\
& =4400 \mathrm{ppm} \times 1 / 3 \times 1 / 10 \times(15 \times 7 \mathrm{~h}) /(7 \times 24 \mathrm{~h})=92 \mathrm{ppm} . \\
& \text { (SAR) (species) (time factors) }
\end{aligned}
$$

Since a clear target organ or mechanism of toxic action is not known for these compounds, it is not apparent how to extrapolate to longer exposures. The conservative approach is to use Haber's rule to give 30- and 180-d SMACs of 21 and $3.6 \mathrm{ppm}$, respectively.

The short-term SMACs may be estimated from the acute inhalation data on HMDS. For that compound, a 30-min exposure to $25,000 \mathrm{ppm}$ caused no clinical effects or deaths. A NOAEL for a 1-h exposure can be estimated as follows:

$$
\begin{aligned}
& \text { 1-h SMAC } \\
& =25,000 \mathrm{ppm} \times 1 / 3 \times 1 / 10 \times 30 / 60=420 \mathrm{ppm} . \\
& (\text { SAR) }(\text { species) } \\
& (\text { (time) }
\end{aligned}
$$

The 24-h SMAC should be between that value and the 7-d SMAC 
calculated above. A reasonable choice seems to be $200 \mathrm{ppm}$. Rounding off the values calculated above, the SMACs are set as shown below:

TABLE 9-2 Spacecraft Maximum Allowable Concentrations

\begin{tabular}{llll}
\hline Duration & ppm & $\mathbf{m g} / \mathbf{m}^{3}$ & Effect \\
\hline $1 \mathrm{~b}$ & 400 & 4000 & Lethality \\
$24 \mathrm{~h}$ & 200 & 2000 & $\begin{array}{l}\text { Lethality, kidney, } \\
\text { liver }\end{array}$ \\
$7 \mathrm{~d}$ & 100 & 1000 & Kidney, liver \\
$30 \mathrm{~d}$ & 20 & 200 & Kidney, liver \\
$180 \mathrm{~d}$ & 4 & 40 & Kidney, liver \\
\hline
\end{tabular}

\section{REFERENCES}

Achauer, B.M. 1983. A serious complication following medical-grade silicone injection of the face. Plast. Reconstr. Surg. 71:251-253.

Ashley, F.L., S. Braley, T.D. Rees, et al. 1967. The present status of silicone fluid in soft tissue augmentation. Plast. Reconstr. Surg. 39: 411-420.

Barondes, R. de R., W.D. Judge, C.G. Towne, and J.L. Baxter. 1950. The silicones in medicine: New organic derivatives and some of their unique properties. Military Surgeon 106:379-387.

Bruggeman, W.A., D. Weber-Fund, A. Opperhuizen, J. Van der Steen, A. Wijbenga, and O. Hutzinger. 1984. Absorption and retention of polydimethylsiloxanes (silicones) in fish: Preliminary experiments. Toxicol. Environ. Chem. 7:287-296.

Child, G.P., H.O. Paquin, and W.B. Deichmann. 1951. Chronic toxicity of the methylpolysiloxane "DC Antifoam A" in dogs. Arch. Ind. Hyg. Occup. Med. 3:479-482.

Clark, D.P., C.W. Hanke, and N.A. Swanson. 1989. Dermal implants: Safety of products injected for soft tissue augmentation. J. Am. Acad. Dermatol. 21:992-998.

Flaningam, O.L. 1986. Vapor pressures of poly(dimethylsiloxane) oligomers. J. Chem. Eng. Data 31:266-272. 
Hawthorne, G.A., D.L. Ballantyne, Jr., T.D. Rees, and I. Seidman. 1970. Hematological effects of dimethylpolysiloxane fluid in rats. J. Reticuloendothel. Soc. 7:587-593.

Liebich, H.M., W. Bertsch, A. Zaltkis, and H.J. Schneider. 1975. Volatile organic components in the Skylab 4 spacecraft atmosphere. Aviat. Space Environ. Med. 46:1002-1007.

McGregor, R.R. 1954. Silicones and Their Uses. McGraw-Hill, New York.

McNamara, B.P., E.A. McKay, and M.M. Quille. 1950. Silicon fluids as vehicles for the intramuscular administration of drugs. Fed. Proc. Fed. Am. Soc. Exp. Biol. 9:301.

Merck Index. 1989. P. 6674 in Merck Index. 11 th Edition. S. Budavari, ed. Merck \& Co., Rahway, N.J.

Rees, T.D., D.L. Ballantyne, and G.A. Hawthorne. 1970. Silcone fluid research: A follow-up summary. Plast. Reconst. Surg. 46:56-56.

Rochow, E.G. 1951. An Introduction to the Chemistry of the Silicones. 2nd Edition. Wiley, New York.

Rowe, V.K., H.C. Spencer, and S.L. Bass. 1948. Toxicological studies on certain commercial silicones and hydrolyzable silane intermediates. J. Ind. Hyg. Toxicol. 30:332-352.

Rowe, V.K., H.C. Spencer, and S.L. Bass. 1950. Toxicological studies on certain commercial silicones. Arch. Ind. Hyg. Occup. Med. 1:539544.

Travis, W.D., K. Balogh, and J. Abraham. 1985. Silicone granulomas: Report of three cases and review of the literature. Hum. Pathol. 16:1927. 



\section{B10 Trimethylsilanol}

Harold L. Kaplan, Ph.D., Martin E. Coleman, Ph.D., and John T. James, Ph.D.

Johnson Space Center Toxicology Group

Biomedical Operations and Research Branch

Houston, Texas

\section{PHYSICAL AND CHEMICAL PROPERTIES}

Trimethylsilanol (TMS) is a volatile liquid with the following properties (Rouviere, 1973):

$$
\begin{aligned}
\text { Synonym: } & \text { Trimethylhydroxysilane } \\
\text { Formula: } & \left(\mathrm{CH}_{3}\right)_{3} \mathrm{Si}-\mathrm{OH} \\
\text { CAS number: } & 1066-40-6 \\
\text { Molecular weight: } & 90.2 \\
\text { Liquid density: } & 0.81 \\
\text { Boiling point: } & 98.6-99^{\circ} \mathrm{C} \\
\text { Conversion factors at } 25^{\circ} \mathrm{C}, 1 \mathrm{~atm}: & 1 \mathrm{ppm}=3.69 \mathrm{mg} / \mathrm{m}^{3} \\
& 1 \mathrm{mg} / \mathrm{m}^{3}=0.27 \mathrm{ppm} .
\end{aligned}
$$

\section{OCCURRENCE AND USE}

TMS is commonly seen as an off-gassed product in spacecraft atmospheres and from individual flight articles (Coleman, 1991). Concentrations measured during a number of shuttle missions ranged from 0.004 to $0.018 \mathrm{mg} / \mathrm{m}^{3}$ (Coleman, 1991). TMS is released largely from the breakdown of silicone polymers in various types of lubricants, fluids, adhesives, and plastics.

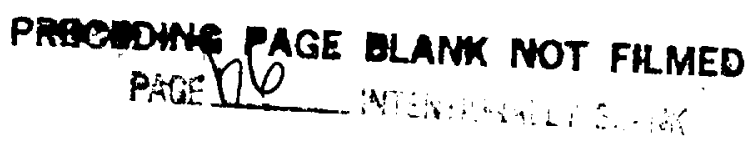




\section{PHARMACOKINETICS AND METABOLISM}

There is no information on the pharmacokinetics of TMS vapor because, to our knowledge, inhalation studies with this compound have not been conducted in animals or humans. However, analyses of urine, blood, and tissues indicate that TMS administered orally to the rat is absorbed from the gastrointestinal tract into the systemic circulation and is eliminated within $48 \mathrm{~h}$ from the body (Dow Corning Corp., 1972). In a study in which TMS was administered orally to rats at doses of 33 and $100 \mathrm{mg} / \mathrm{kg} / \mathrm{d}$ for $31 \mathrm{~d}$, there was no evidence of TMS or organosoluble silicon metabolites in blood, liver, or kidneys or of silicon in urine beyond $48 \mathrm{~h}$ following the last dosing (Dow Corning Corp., 1972).

\section{TOXICITY SUMMARY}

\section{Acute and Short-Term Studies}

Inhalation studies of the toxicity of TMS have not been conducted in animals or humans (Dow Corning Corp., 1991), and published animal studies of TMS by other routes of administration are rare. The available studies do not provide much relevant information. The most useful information for establishing SMAC values for TMS are in internal research reports, abstracts of which were provided by Dow Corning Corp. of Midland, Michigan. On the basis of these reports, TMS is a central nervous system (CNS) depressant, producing states of sedation, hypnosis, or general anesthesia in the rat, guinea pig, and rabbit, depending on the dose and route of administration (Dow Corning Corp., 1991). Depression of the CNS was the only effect observed grossly in studies in which TMS (in a $2 \%$ solution in saline) was administered by oral, subcutaneous (sc), intramuscular (im), intraperitoneal (ip), or intravenous (iv) routes. This effect was reversible. Qualitatively, it was the same as that of a carbon analog, tert-butyl alcohol, but TMS appeared to be more potent.

In a Russian study of the tranquilizing activity of several silicon compounds, the silating agent, TMS, at doses of $6.25-25 \mathrm{mg} / \mathrm{kg}$ (route not specified in English abstract) did not produce a tranquilizing effect in mice nor did it alter neuromediator (GABA, dopamine) turnover in the brain (Tsareva et al., 1982). 
Intraperitoneal or intravenous administration of TMS to the rat, guinea pig, and rabbit in doses of $100-200 \mathrm{mg} / \mathrm{kg}$ produced light-to-moderate anesthesia, persisting for 10 to $60 \mathrm{~min}$ (Dow Corning Corp., 1991). The lowest reported lethal ip dose of a lithium derivative of TMS in the mouse is $125 \mathrm{mg} / \mathrm{kg}$ (DHHS, 1988). However, this report is not relevant to SMAC values for TMS because of possible interactive effects of lithium with CNS depressants. A Dow Corning Corp. internal report stated that the initial data suggest that rapid attainment of a blood level of $1 \mathrm{mg} / \mathrm{mL}$ of TMS is necessary to produce a state of light anesthesia (Dow Corning Corp., 1991). The statement most likely was intended to indicate that ip or iv administration of $100-200 \mathrm{mg} / \mathrm{kg}$ of TMS results in rapid absorption of TMS and blood levels of $1 \mathrm{mg} / \mathrm{mL}$ necessary for light anesthesia.

\section{Subchronic and Chronic Studies}

In a study in which TMS was administered by gavage once daily for 5 $d / w$ for $2 w$ to four groups of male Sprague-Dawley rats (number unspecified) at doses of $0,250,500$, or $750 \mathrm{mg} / \mathrm{kg} / \mathrm{d}$, no significant toxic or adverse effects, including behavioral changes, gross pathological changes, or effects on food consumption or body or organ weights, were observed at the lowest TMS dose of $250 \mathrm{mg} / \mathrm{kg} / \mathrm{d}$ (Dow Corning Corp., 1983). At doses of 500 and $750 \mathrm{mg} / \mathrm{kg} / \mathrm{d}$, CNS depressant effects were observed, consisting of ataxia, decreased locomotor activity, dyspnea, irregular respiration, weakness of hind-leg muscles, and loss of consciousness. At both doses there were significant reductions in total body-weight gains, but there were no significant dose-related pathological changes or effects on food consumption or organ weights. There was one death at the 750$\mathrm{mg} / \mathrm{kg} / \mathrm{d}$ dose (Dow Corning Corp., 1983).

In a 31-d study in which TMS was administered to rats in single daily oral doses of 33 and $100 \mathrm{mg} / \mathrm{kg}$, there were no deaths or significant alterations in hematology or body and organ weight ratios of the liver, kidneys, adrenals, heart, or gonads (Dow Corning Corp, 1972). There also were no histopathological changes or significant alterations in clinical blood chemistry parameters (uric acid, cholesterol, triglycerides, total lipid, creatinine, bilirubin, LDH, SGOT, AP, albumin, total protein). Analyses for total silicon in urine and for organosoluble silicon in blood, liver, and kidneys indicated the absence of TMS in blood, tissues, and urine at $48 \mathrm{~h}$ following the last dose. 


\section{Genotoxicity}

Results of in vivo bone marrow cytogenic assays indicate that TMS is not genotoxic at doses of $100-500 \mathrm{mg} / \mathrm{kg}$ administered ip to rats (Isquith et al., 1988). The lack of significant clastogenic potential of TMS also was evident in a rodent dominant lethal test in which oral doses of 20-200 $\mathrm{mg} / \mathrm{kg} / \mathrm{d}, 5 \mathrm{~d} / \mathrm{w}$ for $8 \mathrm{w}$ had no effect on fertility index, pre-implantation loss, or fetal resorptions in the rat (Isquith et al., 1988). No data are available on the carcinogenicity of TMS by any route of administration. 


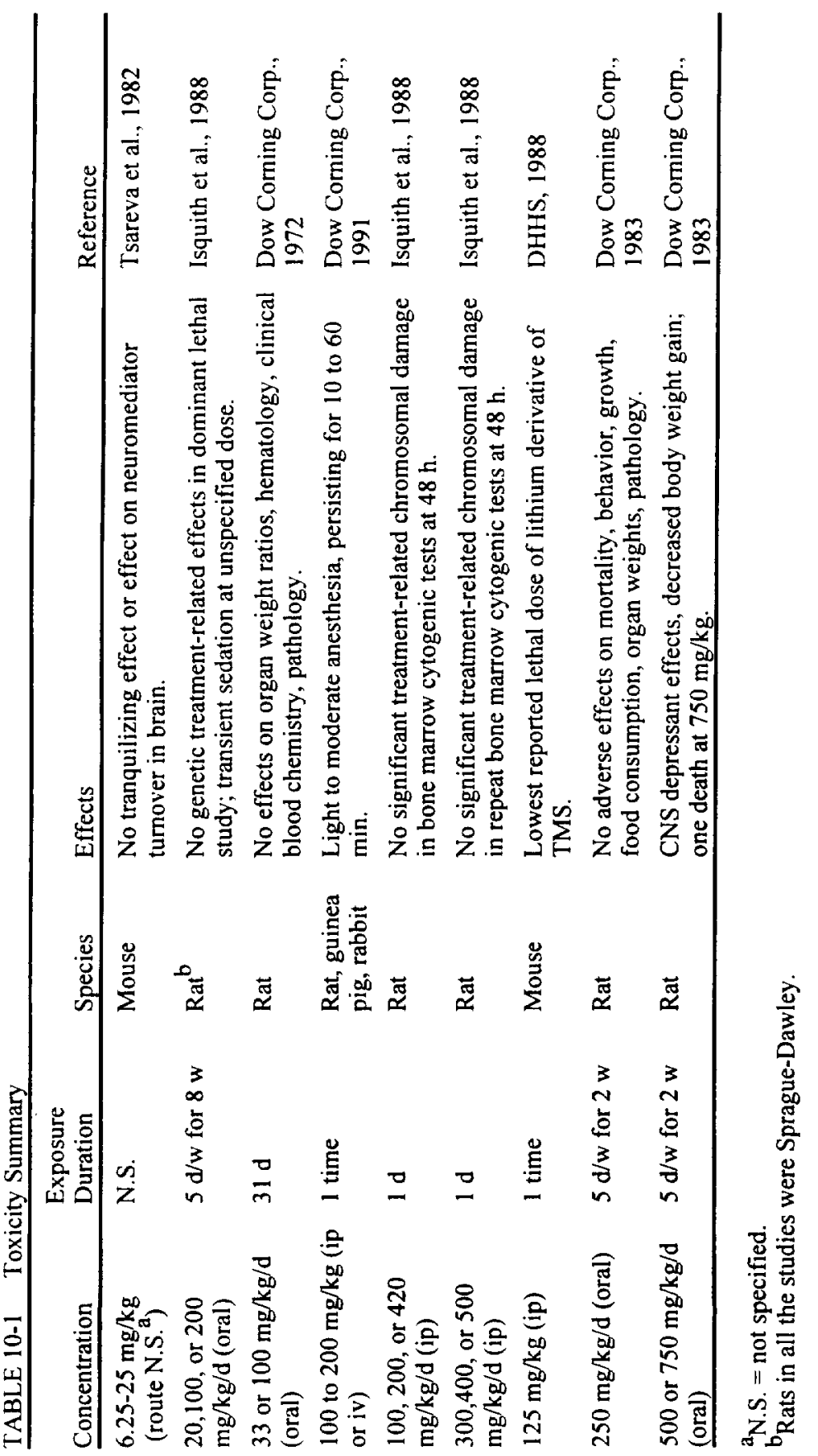




\section{EXPOSURE LIMITS}

No exposure limits have been set for TMS by any other organizations.

TABLE 10-2 Spacecraft Maximum Allowable Concentrations

\begin{tabular}{llll}
\hline Duration & ppm & $\mathrm{mg} / \mathrm{m}^{3}$ & Target Toxicity \\
\hline $1 \mathrm{~h}$ & 150 & 555 & CNS \\
$24 \mathrm{~h}$ & 20 & 0.74 & CNS \\
$7 \mathrm{~d}$ & 10 & 37 & $\mathrm{CNS}$ \\
$30 \mathrm{~d}$ & 10 & 37 & CNS \\
$180 \mathrm{~d}$ & 10 & 37 & CNS \\
\hline
\end{tabular}

\section{RATIONALE}

Inhalation toxicity data are not available on TMS; however, it is clear from studies using other routes of administration that the primary acute effect is on the CNS. The information available to the authors was in abstract form from private communications; hence, the details of the experiments could not be reviewed. From oral dosing studies at 250, 500, and $750 \mathrm{mg} / \mathrm{kg} / \mathrm{d}, 5 \mathrm{~d} / \mathrm{w}$ for $2 \mathrm{w}$, a no-observed-adverse-effect level (NOAEL) for CNS effects, and all other measured effects, was 250 $\mathrm{mg} / \mathrm{kg} / \mathrm{d}$ (Dow Corning Corp., 1983). A more sensitive NOAEL comes from ip and iv studies in which single injections of 100 or $200 \mathrm{mg} / \mathrm{kg}$ induced light or moderate anesthesia (Dow Corning Corp, 1991). Light anesthesia was associated with blood concentrations of $1 \mathrm{mg} / \mathrm{mL}$, and the effects disappeared in 10 to $60 \mathrm{~min}$. The dose of $100 \mathrm{mg} / \mathrm{kg}$ was a lowestobserved-adverse-effect level (LOAEL), and the NOAEL was calculated by using the proportion (100/200) that caused a change from moderate-tolight anesthesia as the proportion that would convert light anesthesia to no anesthesia. The NOAEL for anesthesia was calculated to be $50 \mathrm{mg} / \mathrm{kg}$ by injection in rats.

This injection dosage might be converted to an equivalent dosage in humans by using the species extrapolation factor of 10 . The equivalent inhalation dosage was calculated assuming a moderate breathing volume of 
$20 \mathrm{~L} / \mathrm{min}$ and a body weight of $70 \mathrm{~kg}$. Additional assumptions were that the uptake was $50 \%$ from the inspired air and that there was no clearance of TMS from blood during a 1-h exposure. A $50 \%$ uptake is typical of many organic vapors (Dahl et al., 1991). The computation was as follows:

$$
\begin{aligned}
\mathrm{C}= & 50 \mathrm{mg} / \mathrm{kg} \times 1 / 10 \times 70 \mathrm{~kg} \div(50 \% \times 20 \mathrm{~L} / \mathrm{min} \times 60 \mathrm{~min}) \\
& =580 \mathrm{mg} / \mathrm{m}^{3} \\
& =157 \mathrm{ppm} .
\end{aligned}
$$

The 1-h SMAC was set at $150 \mathrm{ppm}$ to protect against CNS effects.

The 24-h SMAC was set using the same starting point except the average breathing volume was $15 \mathrm{~L} / \mathrm{min}$ and it was assumed that at least $50 \%$ of inhaled TMS was cleared from the blood in a $24-\mathrm{h}$ period. This latter assumption was based on the fact that no trace of TMS could be found $48 \mathrm{~h}$ after administration (Dow Corning Corp, 1972) and clinical anesthesia disappeared quickly after rats were injected with TMS (Dow Corning Corp., 1991). The computation was as follows:

$$
\begin{aligned}
\mathrm{C}= & 50 \mathrm{mg} / \mathrm{kg} \times 1 / 10 \times 70 \mathrm{~kg} \div \\
& (50 \% \times 50 \% \times 15 \mathrm{~L} / \mathrm{min} \times 1440 \mathrm{~min})=18 \mathrm{ppm} .
\end{aligned}
$$

The 24-h SMAC was rounded to $20 \mathrm{ppm}$.

The long-term SMACs were based on the NOAEL from $31 \mathrm{~d}$ of oral dosing of rats with $100 \mathrm{mg} / \mathrm{kg} / \mathrm{d}$ (Dow Corning Corp., 1972). Since the CNS appears to be the target of TMS, there should be a threshold below which no effects occur even in prolonged exposure. That threshold was determined from the rat oral data, assuming a species factor of 10 , a body weight of $70 \mathrm{~kg}$, and a breathing volume of $15 \mathrm{~L} / \mathrm{min}$. The concentration was

$$
\begin{aligned}
\mathrm{C}= & 100 \mathrm{mg} / \mathrm{kg} / \mathrm{d} \times 1 / 10 \times 70 \mathrm{~kg} \div(15 \mathrm{~L} / \mathrm{min} \times 1440 \mathrm{~min} / \mathrm{d}) \\
& =32 \mathrm{mg} / \mathrm{m}^{3} \\
& =9 \mathrm{ppm} .
\end{aligned}
$$

Therefore, the 7-d, 30-d, and 180-d SMACs were set at 10 ppm by rounding of the value above. It should be noted that factors for uptake from the respiratory system and elimination were not used because the comparative uptake and elimination using the oral and inhalation routes are unknown. 
Since there is no evidence that spaceflight-induced physiological changes would sensitize astronauts to anesthetics, no factor was applied to the values derived above.

\section{REFERENCES}

Coleman, M. 1991. Summary Report of Posttlight Atmospheric Analysis for STS-26 to STS-36, SD4-91-430. National Aeronautics and Space Administration, Washington, D.C.

Dahl, A.R., M.B. Snipes, and P. Gerde. 1991. Sites for uptake of inhaled vapors in Beagle dogs. Toxicol. Appl. Pharmacol. 109:263275.

Dow Corning Corp. 1972. A toxicological evaluation of trimethylsilanol and dimethylsilanediol in the rat. Dow Corning Internal Research Report Abstract. Dow Corning Corp., Midland, Mich.

Dow Corning Corp. 1983. A two-week maximum tolerated dose study of trimethylsilanol in the rat. Dow Corning Internal Research Report Abstract. Dow Corning Corp., Midland, Mich.

Dow Corning Corp. 1991. Trimethylsilanol. Dow Corning Internal Research Report Summary. Dow Corning Corp., Midland, Mich.

Isquith, A., R. Slesinski, and D. Matheson. 1988. Genotoxicity studies on selected organosilicon compounds: In vivo assays. Fd. Chem. Toxic. 26:263-266.

Rouviere, J., V. Tabacik, and G. Fleury. 1973. Vibrational spectra of trimethylsilanol. Part A. Spectrochim. Acta 29:229-242.

Tsareva, T.A., E.P. Kramarova, and A.M. Zharkovskii. 1982. Pharmacological characteristics of the silyl derivatives of alpha-pyrrolidine [English abstract]. Farmakol. Toksikol. 45:20-23.

DHHS. 1988. No. 77713, Silanol, trimethyl-, lithium derivative. In Registry of Toxic Effects of Chemical Substances. 1985-86 Edition. U.S. Department of Health and Human Services, Washington, D.C. 


\title{
B11 Vinyl Chloride
}

King Lit Wong, Ph.D.

Johnson Space Center Toxicology Group

Biomedical Operations and Research Branch

Houston, Texas

\section{PHYSICAL AND CHEMICAL PROPERTIES}

Vinyl chloride is a colorless gas with a high flammability and an odor like that of ether (ACGIH, 1986).

\author{
Synonyms: Chloroethene, chloroethylene \\ Formula: $\quad \mathrm{CH}_{2} \mathrm{CHCl}$ \\ CAS number: $75-01-4$ \\ Molecular weight: 62.5 \\ Boiling point: $-13.9^{\circ} \mathrm{C}$ \\ Melting point: Not applicable \\ Vapor pressure: $2530 \mathrm{~mm} \mathrm{Hg}$ at $20^{\circ} \mathrm{C}$ \\ Conversion factors at $25^{\circ} \mathrm{C}, 1 \mathrm{~atm}: \quad 1 \mathrm{ppm}=2.55 \mathrm{mg} / \mathrm{m}^{3}$ \\ $1 \mathrm{mg} / \mathrm{m}^{3}=0.39 \mathrm{ppm}$
}

\section{OCCURRENCE AND USE}

Vinyl chloride is used primarily in the manufacture of polyvinyl chloride resins (ACGIH, 1986). It is also used in organic syntheses. There is no known use of vinyl chloride in spacecraft, and it has never been found in air samples taken during space-shuttle missions. However, vinyl chloride has been predicted to be off-gassed in the space station (Leban and Wagner, 1989). 


\section{PHARMACOKINETICS AND METABOLISM}

When inhaled, vinyl chloride is absorbed quite well by human subjects. In male human volunteers exposed to $7.5-60 \mathrm{mg} / \mathrm{m}^{3}$ (3-24 ppm) for $6 \mathrm{~h}$, about $42 \%$ of the inhaled vinyl chloride was retained by the respiratory system; i.e., the exhaled concentration was $42 \%$ less than the inhaled concentration (Krajewski et al., 1980). The degree of respiratory retention achieved a relatively stable level $30 \mathrm{~min}$ into the 6-h exposure and appeared not to vary significantly with the exposure concentration, which ranged from 3 to $24 \mathrm{ppm}$.

Rats tend to readily absorb vinyl chloride in inhalation exposure. In rats exposed to ${ }^{14} \mathrm{C}$-labeled vinyl chloride at $20,000 \mathrm{ppm}$ for $5 \mathrm{~min}$, radioactivity was detected in the liver, bile duct, kidney, and gastrointestinal tract within 10 min (Duprat et al., 1977). Similarly, in rats exposed to ${ }^{14} \mathrm{C}$ labeled vinyl chloride at 50 or $100 \mathrm{ppm}$ for 5 or $6 \mathrm{~h}$, liver and kidney had the highest concentration of radioactivity among all the tissues after the exposure (Bolt et al., 1976; Watanabe et al., 1976).

In rats exposed to vinyl chloride at $1000 \mathrm{ppm}$ for $1-6 \mathrm{~h}$, it has been postulated that vinyl chloride was oxidized to 2-chloroacetaldehyde via three pathways, listed as follows (Hefner et al., 1975). (1) At low concentrations, vinyl chloride is oxidized first to 2-chloroethanol, which is further oxidized by alcohol dehydrogenase to 2-chloroacetaldehyde. (2) When the first pathway is saturated, vinyl chloride is oxidized by mixed function oxidase to an epoxide, 2-chloroethylene oxide, which arranges to 2-chloroacetaldehyde. (3) Alternatively, when the first pathway is saturated, vinyl chloride is oxidized by catalase to 2-chloroethyl hydroperoxide, which in turn is converted to 2 -chloroacetaldehyde.

Because pretreatment of rats with 6-nitro-1,2,3-benzothiadiazole, which inhibits some microsomal cytochrome $\mathrm{P}-450$ pathways, completely blocked vinyl chloride metabolism in rats exposed to vinyl chloride, Bolt et al. (1977) postulated that microsomal mixed function oxidase is the major enzyme for vinyl chloride metabolism.

Most of the 2-chloroacetaldehyde formed from vinyl chloride reacts with sulfhydryl groups in the cells, but some of it is oxidized by aldehyde dehydrogenase to 2-chloroacetic acid (Hefner et al., 1975). The reaction of 2-chloroacetaldehyde with sulfhydryl groups explains the formation of $n$-acetyl-S-(2-hydroxyethyl) cysteine, $S$-(2-hydroxyethyl) cysteine, and mercaptoacetic acid in the urine of rats exposed to vinyl chloride (Wata- 
nabe et al., 1976, 1978a). Urinary mercaptoacetic acid has also been found in workers exposed to vinyl chloride (Shu, 1986).

Bolt et al. (1977) exposed rats to vinyl chloride at 50-1200 ppm in a closed inhalation system and they found that vinyl chloride metabolism was saturated at about $250 \mathrm{ppm}$. Similarly, Buchter et al. (1980) discovered that vinyl-chloride metabolism in rhesus monkeys was saturated at 200 ppm. In rats exposed to vinyl chloride at 10,1000 , or $5000 \mathrm{ppm}$ for $6 \mathrm{~h}$, Watanabe's group presented evidence that vinyl chloride metabolism appeared to be saturated at $1000 \mathrm{ppm}$ (Watanabe et al., 1976, 1978a; Watanabe and Gehring, 1976). At $10 \mathrm{ppm}, 68 \%$ of the body burden was excreted in the urine, $12 \%$ was expired as $\mathrm{CO}_{2}, 4 \%$ was excreted in the feces, and about 2\% was expired unchanged (Watanabe et al., 1976; Watanabe and Gehring, 1976). When the exposure level was increased to $1000 \mathrm{ppm}$, however, the fraction of the body burden eliminated in the urine was reduced to $56 \%$ and that expired as vinyl chloride increased to $12 \%$.

There is evidence that vinyl chloride's epoxide metabolite, 2-chloroethylene oxide, and its rearrangement product, 2-chloroacetaldehyde, could bind to macromolecules in rats. Watanabe and his colleagues showed that, in rats exposed to vinyl chloride, the amount of macromolecular binding directly increased with the exposure concentration or phenobarbital pretreatment (Watanabe et al., 1978a,b; Guengerich and Watanabe, 1979). It has been postulated that the epoxide metabolite is the active metabolite of vinyl chloride and the macromolecular binding is responsible for vinyl chloride's carcinogenicity.

There are few data on vinyl chloride metabolism in humans. However, it has been shown that incubation of Salmonella typhimurium with S-9 fraction isolated from human liver increased the mutational frequency in a similar magnitude as incubation with rat S-9 fraction (Sabadie et al., 1980). This indicates that electrophilic metabolites could be formed by the action of human mixed function oxidase on vinyl chloride.

\section{TOXICITY SUMMARY}

\section{Acute and Short-Term Toxicity}

\section{Mucosal Irritation}

Vinyl chloride is known to cause mucosal irritation at over $500 \mathrm{ppm}$ in 
humans (Lefaux, 1968). Baretta et al. (1969) reported that two of seven human subjects complained of dryness of nose and eyes in an exposure to $500-\mathrm{ppm}$ vinyl chloride lasting for $3.5 \mathrm{~h}$. The dryness of nose and eyes was probably an indication of very slight mucosal irritation. It appears that $500 \mathrm{ppm}$ is probably the threshold for vinyl chloride's mucosal irritation. Since none of the four subjects exposed to $250 \mathrm{ppm}$ for $7.5 \mathrm{~h}$ complained of dryness of nose or eyes (Baretta et al., 1969), the no-observed-adverseeffect level (NOAEL) for mucosal irritation is $250 \mathrm{ppm}$.

\section{Miscellaneous Symptoms}

In a study by Lester et al. (1963) nausea was reported in five of six human subjects exposed to vinyl chloride at $16,000 \mathrm{ppm}$ for $5 \mathrm{~min}$. In that study, one of six human subjects exposed to vinyl chloride at $20,000 \mathrm{ppm}$ for $5 \mathrm{~min}$ experienced headache, which lasted for $30 \mathrm{~min}$. Baretta et al. (1969) reported that two of seven men exposed to $500 \mathrm{ppm}$ for $3.5 \mathrm{~h}$ complained of mild headache, but they did not complain of nausea. Therefore, the concentration of vinyl chloride causing headache is lower than that causing nausea. Because nausea was detected only at such a high exposure concentration (it was absent in a 5 -min exposure at $12,000 \mathrm{ppm}$ or less), nausea will not be relied on in setting the SMACs. None of the four men in the study of Baretta et al. (1969) complained of headache in a 7.5-h exposure to 250-ppm vinyl chloride. The NOAEL for headache is $250 \mathrm{ppm}$ in acute vinyl chloride exposures.

\section{Liver Toxicity}

As will be discussed later, liver is the major target organ of vinyl chloride in subchronic and long-term exposures. Whether vinyl chloride could cause non-neoplastic liver toxicity in humans in acute exposures is debatable. A group of Hungarian scientists exposed mice, rats, and rabbits to vinyl chloride at $1500 \mathrm{ppm}$ for $24 \mathrm{~h}$ (Tatrai and Ungvary, 1981). No liver pathology was found in rats and rabbits. However, in mice, vasomotor paralysis and shock developed during the exposure, followed by hepatic histopathology, which included coagulation necrosis and confluent hemorrhages in the centrilobular zone, and ultrastructural changes, such as dilation of the cisterns of rough endoplasmic reticulum and Golgi apparatus

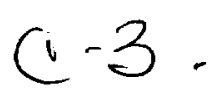


and atrophy of some mitochondria. All the mice died as a result of the 24 $\mathrm{h}$ exposure at $1500 \mathrm{ppm}$, whereas a 12-h exposure killed 16 of 20 mice. In contrast, no rats or rabbits were killed by the 24-h exposure (Tatrai and Ungvary, 1981). In a human study, Baretta et al. (1969) failed to detect any changes in the serum levels of glutamyl pyruvate transaminase, alkaline phosphatase, lactic dehydrogenase, bilirubin, blood urea nitrogen, and creatinine in four men $24 \mathrm{~h}$ after a 7.5 -h exposure to vinyl chloride at 500 or $250 \mathrm{ppm}$. Therefore, if vinyl chloride is indeed acutely toxic to the liver in humans, $500 \mathrm{ppm}$ appears to be the NOAEL.

\section{Central Nervous System Toxicity}

Vinyl chloride could impair the central nervous system (CNS). Lester et al. (1963) reported that light-headedness, dizziness, and dulling of vision and hearing were detected in five of six human subjects exposed at 16,000 ppm for $5 \mathrm{~min}$. When these six subjects were exposed at 12,000 ppm for 5 min, two subjects felt slight dizziness. At $8000 \mathrm{ppm}$, only one of six subjects felt light-headed. No CNS symptoms were detected in a 5-min exposure at $4000 \mathrm{ppm}$ (Lester et al., 1963). According to Lefaux (1968), vinyl chloride at $1000 \mathrm{ppm}$ produces drowsiness, slight visual disturbances, tingling sensation on the limbs, numbness, and faltering gait. Vinyl chloride has no perceptible action on the CNS below 1000 ppm (Lefaux, 1968). Baretta et al. (1969) reported no CNS impairment in seven subjects exposed to vinyl cluloride at $500 \mathrm{ppm}$ for $3.5 \mathrm{~h}$ or in four subjects exposed for $7.5 \mathrm{~h}$. The NOAEL for acute CNS impairment is, therefore, $500 \mathrm{ppm}$.

\section{Mortality}

A person was reported killed by a massive exposure to vinyl chloride at an unknown concentration (Damziger, 1966). Although the lethal concentration of vinyl chloride in humans is not known for certain, it is probably over 10,000 ppm based on the animal data of Mastromatteo et al. (1960). This group of scientists exposed five mice, five rats, and five guinea pigs to various concentrations of vinyl chloride for $30 \mathrm{~min}$. No deaths occurred at $10,000 \mathrm{ppm}$. One of five mice died but no rats or guinea pigs died at $20,000 \mathrm{ppm}$. At 30,000 ppm, all five mice and all five rats died, and one of the five guinea pigs died. Because the lethal concentration of vinyl 
chloride is estimated to be much higher than the concentrations required to cause other toxic effects, mortality is not used as a toxic end point in deriving the SMACs.

\section{Subchronic and Chronic Toxicity}

\section{Liver Toxicity}

Liver is the major target organ of vinyl chloride. Liver function impairment and hepatic histological changes have been reported in workers employed in places where vinyl chloride was manufactured or used (Lillis et al., 1975; Popper and Thomas, 1975; Tamburro et al., 1984). Clinically, occupational exposure to vinyl chloride might cause abdominal pain in the upper right-hand quadrant, hepatomegaly, portal hypertension, esophageal varices, and liver cirrhosis (Lillis et al., 1975; Popper and Thomas, 1975; Lee et al., 1977). No exposure-concentration data were given in these reports. In a study conducted with 168 workers in two Romanian factories where they were exposed to vinyl chloride from 1962 to 1972 , the investigators compared, among other things, the rates of nervous symptoms and gastroenterological symptoms in the workers in 1962 with those in 1966 (Suciu et al., 1975).

Without specifying the analytical method, the investigators reported that the average vinyl chloride concentrations in 1962 and 1966 were 2298 and $98 \mathrm{mg} / \mathrm{m}^{3}$ (896 and $38 \mathrm{ppm}$ ), respectively (Suciu et al., 1975). They detected a higher rate of euphoria, dizziness, somnolence, nervousness, headache, complete narcosis, weight loss, anorexia, epigastric pains, and hepatomegaly in the year the workers were exposed to $896 \mathrm{ppm}$ than in the year they were exposed to $38 \mathrm{ppm}$ (Suciu et al., 1975). The rate of pains in the right hypochondrium was lower, however, at $896 \mathrm{ppm}$ than at 38 ppm. Because no control group was used and because of a lack of information on how the exposure concentrations were determined, the Romanian data are not used in setting SMACs. Nevertheless, the data illustrate the potential toxicity of vinyl chloride in the CNS and liver in human workers.

Kramer and Mutchler (1972) did a medical study with 98 workers employed over two decades in two vinyl chloride polymerization facilities. These workers were exposed mainly to vinyl chloride, but there were co-exposures to vinylidene chloride, which was at lower concentrations. 
The exposures to vinylidene chloride in the second decade of the occupational exposure were probably negligible because vinylidene chloride was frequently detected only at trace levels. During the two decades of employment, there were environmental monitoring and medical surveillance. The investigators did not report all the results of the environmental monitoring during the two decades, but they stated that "in more recent measurements, infrared and gas chromatographic techniques have established that the vinyl chloride concentrations average $10 \mathrm{ppm}$." When compared with a control group, the vinyl-chloride workers had no significant disease. There were no differences in chest $\mathrm{x}$-rays and electrocardiograms between the two groups. No acroosteolysis was detected. Based on the medical history taken periodically in the medical surveillance program, the exposed workers reported a higher history of asthma and kidney stone and blood urine but a lower history of gastrointestinal and hepatic trouble and nervous symptoms. By physical examinations, the investigators found a higher rate of anal and rectal abnormalities in the exposed workers than in the controls. From a regression analysis of the data collected, the investigators estimated that, in $60-y$-old workers who had been on the job for $20 \mathrm{y}$, vinyl chloride at $300 \mathrm{ppm}$ time-weighted average (TWA) would increase the bromsulphalein clearance time by five-fold, $150 \mathrm{ppm}$ would raise it by twofold, and $50 \mathrm{ppm}$ would increase it by $80 \%$. They concluded that repeated exposure to vinyl chloride at $300 \mathrm{ppm}$ or higher for a working lifetime could cause some impairment in liver function.

In a study by Ho et al. (1991) 12 of over 100 workers in a polyvinyl chloride plant in Singapore were found to have elevated serum glutamic pyruvic transaminase and gamma glutamyl transpeptidase levels, when they worked in an environment with the vinyl chloride concentrations ranging between 1 and $21 \mathrm{ppm}$, with a geometric mean of $6 \mathrm{ppm}$ for 1-13 y. Nine of the 12 workers had mild-to-moderate nonspecific fatty changes on liver biopsies. None of them had a history of jaundice, Raynaud's disease, or blood transfusion. No liver function impairment attributable to vinyl chloride was detected in the workers after the vinyl chloride was lowered to $0.6-2.9 \mathrm{ppm}$, with a geometric mean of $1.5 \mathrm{ppm}$, in 1983 . In workers afflicted by vinyl-chloride-induced liver disease, their liver function improved within 0.5-2 y after they were removed from further exposure (Ho et al., 1991). Based on the human data of Ho et al., the NOAEL for non-neoplastic liver toxicity is about $1.5 \mathrm{ppm}$.

Lee et al. (1977) showed that increased cell turnover and DNA synthesis were detected in the livers of rats exposed to vinyl chloride at 50 or 250 
$\mathrm{ppm}, 6 \mathrm{~h} / \mathrm{d}, 5 \mathrm{~d} / \mathrm{w}$ for $12 \mathrm{mo}$. Because increased cell turnover and DNA synthesis, by themselves, are not considered adverse clinically, the SMACs are not set to prevent them. Similarly, increased liver weight by itself is not considered a significant toxic end point. So the SMACs are not derived from the discovery made by Bi et al. (1985) that the liver weight increased in rats exposed to vinyl chloride at 10,100 , or $3000 \mathrm{ppm}, 6 \mathrm{~h} / \mathrm{d}, 6 \mathrm{~d} / \mathrm{w}$ for $6 \mathrm{mo}$.

Torkelson et al. (1961) found that there were species differences in the sensitivity to vinyl chloride's liver toxicity. In a 6-mo exposure, at $7 \mathrm{~h} / \mathrm{d}$, $5 \mathrm{~d} / \mathrm{w}$, of guinea pigs, rats, and rabbits to 200-ppm vinyl chloride, no changes were seen in guinea pigs, but increased liver weight was detected in rats and the liver in rabbits developed centrilobular degeneration and necrosis (Torkelson et al., 1961). Therefore, the rat is more sensitive than the guinea pig. However, it is not clear whether the rabbit is more sensitive than the rat because only three male and three female rabbits were used in the experiment, making it difficult to draw a conclusion.

In the study of Torkelson et al. (1961) a 4.5-mo exposure of rats at 500 ppm resulted in centrilobular degeneration in liver. A similar exposure of rats at 100 or $200 \mathrm{ppm}$ led to increased liver weight, but an exposure at 50 ppm failed to cause any significant changes.

There are reports of liver toxicity in animals subchronically exposed to very high concentrations of vinyl chloride. The group of Feron showed that an exposure of rats to $5000 \mathrm{ppm}, 7 \mathrm{~h} / \mathrm{d}, 5 \mathrm{~d} / \mathrm{w}$ for $52 \mathrm{w}$ produced degeneration, hyperplasia, hepatocellular carcinoma, and angiosarcoma in the liver (Feron and Kroes, 1979). Viola (1970) discovered hepatomegaly, hepatitis, and liver necrosis in male rats exposed to vinyl chloride at 30,000 ppm for $4 \mathrm{~h} / \mathrm{d}, 5 \mathrm{~d} / \mathrm{w}$ for $1 \mathrm{y}$.

\section{Kidney Toxicity}

Kidney is the second major organ affected by vinyl chloride. At a very high concentration of $30,000 \mathrm{ppm}$, Viola (1970) found that vinyl chloride produced tubular nephrosis and chronic interstitial nephritis in rats exposed $4 \mathrm{~h} / \mathrm{d}, 5 \mathrm{~d} / \mathrm{w}$ for $1 \mathrm{y}$. Tubular nephrosis was also produced in rats exposed to vinyl chloride at $5000 \mathrm{ppm}$ for $7 \mathrm{~h} / \mathrm{d}, 5 \mathrm{~d} / \mathrm{w}$ for $1 \mathrm{y}$ (Feron and Kroes, 1979). Torkelson et al. (1961) discovered that 500-ppm vinyl chloride could cause histopathology in the interstitial and tubular areas of the kidney 
in rats exposed $7 \mathrm{~h} / \mathrm{d}, 5 \mathrm{~d} / \mathrm{w}$ for $4.5 \mathrm{mo}$. Because a similar exposure of rats at $200 \mathrm{ppm}$ failed to produce any histological changes (Torkelson et al., 1961), the NOAEL for kidney toxicity is $200 \mathrm{ppm}$.

\section{Neurological Toxicity}

Psychiatric disease and mild distal axonal neuropathy have been reported in workers exposed to vinyl chloride repetitively at unknown concentrations (Halama et al., 1985; Perticonti et al., 1986). Since the exposure concentrations were not measured, these human data cannot be used to set the SMACs. In the experiment conducted by Viola (1970) an exposure to vinyl chloride at $30,000 \mathrm{ppm}$ for $4 \mathrm{~h} / \mathrm{d}, 5 \mathrm{~d} / \mathrm{w}$ for $1 \mathrm{y}$ led to diffuse degeneration of the white and gray matter in the brain and atrophy of granular cells in the cerebellum in rats. Because Feron and Kroes (1979) showed that $5000 \mathrm{ppm}$ failed to cause any nonneoplastic injuries in the brain of rats exposed $7 \mathrm{~h} / \mathrm{d}, 5 \mathrm{~d} / \mathrm{w}$ for $1 \mathrm{y}$, the NOAEL for brain toxicity is $5000 \mathrm{ppm}$.

\section{Effects on the Extremities}

Occupational exposures to vinyl chloride are known to cause circulatory disturbance in the extremities, Raynaud's disease (Lillis et al., 1975; Preston et al., 1976), acroosteolysis, and scleroderma (Dinman et al., 1971; Wilson et al., 1967; Sakabe, 1975). Unfortunately, the exposure concentrations at which these effects were seen in workers are not known. Because Raynaud's disease was usually detected before acroosteolysis in vinyl-chloride workers, vascular lesion is believed to precede the bone changes (Dodson and Dinman, 1971). Viola (1970) reported that an exposure of rats at $30,000 \mathrm{ppm}$ for $4 \mathrm{~h} / \mathrm{d}, 5 \mathrm{~d} / \mathrm{w}$ for $1 \mathrm{y}$ resulted in pathology in the paws, such as metaplasia of metatarsal bones, chondroid metaplasia, epidermal edema, epidermal hyperkeratosis, and degeneration of basal cells. These pathological changes in rats somewhat resemble the acroosteolysis and scleroderma seen in vinyl-chloride workers. Because there are no concentration-response data and $30,000 \mathrm{ppm}$ is a very high concentration, Viola's data on the paws of rats are not suitable for setting the SMACs. 


\section{Effects on the Respiratory System}

In an epidemiology study performed by Wong et al. (1991), a significant mortality excess from emphysema and chronic obstructive pulmonary disease was found in vinyl-chloride workers. Since emphysema and chronic obstructive pulmonary disease have not been found to be associated with occupational vinyl chloride exposures in other epidemiology studies, it is uncertain whether vinyl chloride causes emphysema or chronic obstructive pulmonary disease in humans. However, there is some evidence of the pulmonary toxicity of vinyl chloride in animals. Suzuki $(1978,1980)$ exposed male mice to vinyl chloride at 2500 or $6000 \mathrm{ppm}$ for $5 \mathrm{~h} / \mathrm{d}, 5 \mathrm{~d} / \mathrm{w}$ for 5 or $6 \mathrm{mo}$. In the exposed mice, he found hyperplasia of the alveolar epithelium, degeneration of the alveolar septal cells, hypertrophy and hyperplasia of Clara cells and ciliated epithelial cells in the terminal bronchioles, and bronchiolitis. It appears that the lowest-observed-effect level (LOEL) for lung toxicity is $2500 \mathrm{ppm}$. Taken together, the epidemiology data of Wong et al. and Suzuki's data in mice show that vinyl chloride might produce lung injuries in humans, so the SMACs are prudently set to prevent this toxic end point.

\section{Effects on the Reproductive System}

There were two Soviet reports on the reproductive effects of vinyl chloride in workers (Makarov, 1984; Makarov et al., 1984). A decline in sexual function, which was evaluated by questionnaire, was found in men and women exposed to vinyl chloride occupationally. In the exposed women workers, gynecological examinations revealed increased incidences of ovarian dysfunction, benign uterine growths, and prolapsed genital organs. The Agency for Toxic Substances and Disease Registry characterized the two reports as "not adequately reported for proper evaluation; therefore, such data cannot be used to identify thresholds" (ATSDR, 1989). So the SMACs are not set relying on the Soviet data. Instead the animal data of Bi et al. (1985) are used.

In the study of $\mathrm{Bi}$ et al., 74 or 75 male rats were exposed to vinyl chloride at $0,10,100$, or $3000 \mathrm{ppm}, 6 \mathrm{~h} / \mathrm{d}, 6 \mathrm{~d} / \mathrm{w}$ for $1 \mathrm{y}$. Sacrifices were made of $8,30,6$, and 10 rats at the $3 \mathrm{rd}, 6 \mathrm{th}, 9 \mathrm{th}$, and 12 th mo, respectively, and the surviving rats were killed 6 mo after the 12-mo exposure. Testicular histology was evaluated in the rats sacrificed and also in rats that 
died before the interim and final sacrifices. A reduction in the testicularto-body-weight ratio was found in the 100- and 3000-ppm groups after 6 mo of exposure. With the rats killed at different time points taken together, Bi et al. (1985) reported a statistically higher rate of testicular injuries in the 100- and 3000-ppm groups, but not in the 10-ppm group. There was fusion of spermatids or spermatocytes into giant cells. Spermatids disappeared first, followed by sloughing of secondary and primary spermatocytes into the lumen of seminiferous tubules, leaving behind spermatogonia and Sertoli cells. The degeneration and necrosis distributed randomly in the testis without any relationship to the vascular system.

\section{Carcinogenicity}

Vinyl chloride was found to cause liver cancers, especially angiosarcoma, in vinyl-chloride workers in the 1970s (Health et al., 1975; Tabershaw and Gaffey, 1974; Nicholson et al., 1975; Fox and Collier, 1977). An epidemiology study showed that the mortality excess from liver cancers increased with duration of employment (Health et al., 1975). Other than liver cancers, there have been epidemiological reports that vinyl-chloride exposures may produce cancer in other tissues. For instance, Heldaas et al. (1987) observed 6 cases of malignant melanoma in 454 vinyl-chloride and polyvinyl-chloride workers in Norway, where only 1.1 cases were expected. Nevertheless, Heldaas et al. admitted that it was difficult to make a solid conclusion on the causality between vinyl chloride and malignant melanoma.

More recently, there have been reports of a multiplant cohort study in the United States by Wong et al. (1991) and one in Europe by Simonato et al. (1991). Both the U.S. and European studies confirmed the findings of earlier epidemiology studies on the excesses of liver cancers in general and angiosarcoma in particular caused by occupational exposures to vinyl chloride (Wong et al., 1991; Simonato et al., 1991). Both studies also found an increase in brain tumors in vinyl-chloride workers. In addition, an increase in biliary-tract cancers was discovered in the U.S. study and an increase in lymphoma was found in the European study. In the European study, the mortality excess from liver cancers was found to be related to time since initial exposure to vinyl chloride, duration of employment, and estimated exposure levels (Simonato et al., 1991). 
The mortality excesses from lymphoma and brain tumor, however, were not correlated with these exposure variables in the European study (Simonato et al., 1991). That makes it doubtful whether vinyl chloride could cause lymphoma and brain tumor. Similarly, a case-control study by Wu et al. (1989) found mortality excesses due to liver, lung, and brain cancers in 3635 workers exposed to vinyl chloride. Wu et al. also demonstrated that, among tumors in those three sites, only the excess mortality for liver cancer was significantly associated with the cummulative dose of vinyl chloride. It can be concluded from these recent epidemiology studies that vinyl chloride could cause liver cancers in humans, but the evidence that vinyl chloride also causes tumors in other sites in humans is rather weak.

Viola et al. (1971) were the first group to demonstrate vinyl chloride's carcinogenicity in laboratory animals. They exposed rats to vinyl chloride at $30,000 \mathrm{ppm}$ for $4 \mathrm{~h} / \mathrm{d}, 5 \mathrm{~d} / \mathrm{w}$ for $1 \mathrm{y}$ and found that vinyl chloride caused lung carcinoma, osteochondroma, and epidermoid carcinoma in the skin. In a study conducted by Lee et al. (1978), an exposure of rats or mice to vinyl chloride at 50,250 , or $1000 \mathrm{ppm}$ for $6 \mathrm{~h} / \mathrm{d}, 5 \mathrm{~d} / \mathrm{w}$ for $1 \mathrm{y}$ resulted in liver hemangiosarcoma in rats at $250 \mathrm{ppm}$ or greater and liver hemangiosarcoma and bronchoalveolar adenoma in the lung in mice at $50 \mathrm{ppm}$ or greater. The most extensive animal bioassay was done by Maltoni and coworkers (Maltoni, 1977; Maltoni et al., 1981). They also exposed rats to vinyl chloride for 1 y $(4 \mathrm{~h} / \mathrm{d}, 5 \mathrm{~d} / \mathrm{w})$ but held the rats for $83-103 \mathrm{w}$ after exposure before sacrificing them. Maltoni et al. found that, in SpragueDawley rats, vinyl chloride produced liver angiosarcoma at as low as 100 $\mathrm{ppm}$ and nephroblastoma in the kidney at $25 \mathrm{ppm}$ or greater. The incidences of these tumors in male and female rats combined are shown in Table 11-1.

Maltoni and co-workers also tested with mice and hamsters in the bioassays. In mice exposed to vinyl chloride $4 \mathrm{~h} / \mathrm{d}, 5 \mathrm{~d} / \mathrm{w}$ for $30 \mathrm{w}$ and held for observation for $51 \mathrm{w}$, increased incidences of liver angiosarcoma and lung tumor were detected at $250 \mathrm{ppm}$ or greater. They found that $79 \mathrm{w}$ after hamsters were exposed to vinyl chloride at 2500 ppm or greater for $30 \mathrm{w}$, papillomas and acanthomas of the forestomach were increased.

The data gathered in the literature indicate that vinyl chloride is a potent carcinogen in rodents because many studies showed that vinyl chloride was carcinogenic after an exposure for less than half of the normal lifespan of the test species (Viola et al., 1971; Lee et al., 1978; Maltoni, 1977; 
TABLE 11-1 Incidence of Liver Angiosarcoma and Nephroblastoma in Rats

\begin{tabular}{lll}
\hline $\begin{array}{l}\text { Concentration, } \\
\text { ppm }\end{array}$ & $\begin{array}{l}\text { Liver } \\
\text { Angiosarcoma }\end{array}$ & $\begin{array}{l}\text { Kidney } \\
\text { Nephroblastoma }\end{array}$ \\
\hline 10,000 & $18 / 60$ & $5 / 60$ \\
6000 & $13 / 59$ & $5 / 59$ \\
2500 & $13 / 60$ & $6 / 60$ \\
500 & $6 / 60$ & $6 / 60$ \\
250 & $3 / 59$ & $5 / 59$ \\
200 & $12 / 120$ & $7 / 120$ \\
150 & $6 / 119$ & $11 / 119$ \\
100 & $1 / 120$ & $10 / 120$ \\
50 & $1 / 60$ & $1 / 60$ \\
25 & $5 / 120$ & $1 / 120$ \\
10 & $1 / 119$ & $0 / 119$ \\
5 & $0 / 119$ & $0 / 110$ \\
1 & $0 / 118$ & $0 / 118$ \\
0 & $0 / 363$ & $0 / 363$ \\
\hline
\end{tabular}

Maltoni et al., 1981). Hong et al. (1981) showed that vinyl chloride was carcinogenic in mice for an exposure lasting as little as $1 \mathrm{mo}$. It took a vinyl chloride exposure of only $1 \mathrm{mo}$ at $6 \mathrm{~h} / \mathrm{d}, 5 \mathrm{~d} / \mathrm{w}$ to cause bronchoalveolar tumors in mice at $250 \mathrm{ppm}$ or greater (Hong et al., 1981).

Age also plays a role in the carcinogenicity of vinyl chloride in rats. Drew et al. (1983) found that the earlier in life a rat is exposed to vinyl chloride, the higher the tumor risk. In a 2-y study, Drew et al. exposed three groups of rats to vinyl chloride at $50 \mathrm{ppm}$ and three groups to 200 ppm for $6 \mathrm{~h} / \mathrm{d}, 5 \mathrm{~d} / \mathrm{w}$ for $12 \mathrm{mo}$ and then held the rats without exposure for the remaining $12 \mathrm{mo}$. For two groups of rats, they started the exposures ( 50 or $200 \mathrm{ppm}$ ) at the beginning of the $2-y$ study. For four other groups, the exposures (two groups at $50 \mathrm{ppm}$ and two at $200 \mathrm{ppm}$ ) were started 6 or 12 mo into the $2-y$ study. For each of the exposure concentrations, Drew et al. then compared the tumor incidences in the three groups exposed to the same concentration at three different ages. The rats that were exposed for $12 \mathrm{mo}$ at the beginning of the $2-\mathrm{y}$ study had the highest inci- 
dences of hepatocellular carcinomas, hemangiosarcomas, and mammary gland carcinomas. The rats that were held for 6 mo before being exposed also developed tumors, albeit at lower incidences. However, there were no statistically significant increases in tumor incidences in the rats exposed in the last 12 mo of the 2-y study.

Based on the data available, the International Agency for Research on Cancer concluded that there is sufficient evidence to support vinyl chloride's carcinogenicity to both humans and animals (IARC, 1987). The U.S. Environmental Protection Agency also classified vinyl chloride as a known human carcinogen (EPA, 1984).

\section{Genotoxicity}

There are in vivo data showing that vinyl chloride is genotoxic in humans. Hansteen et al. (1978) found an increase in the percent of peripheral lymphocytes with chromosomal aberrations in workers exposed to 25 -ppm vinyl chloride but not in workers exposed to 1-ppm. In another study, an increase in peripheral lymphocytes with chromosomal aberrations was noted in workers exposed to about 50-ppm vinyl chloride (Anderson et al., 1980). No significant increase in chromosomal aberrations was seen in the workers after the vinyl chloride concentration had been lowered to a level estimated to be less than $5 \mathrm{ppm}$ (Anderson et al., 1980). There is also in vivo evidence of the genotoxicity of vinyl chloride in animals. Vinyl chloride was tested negative in the dominant lethal test and positive in the micronucleus test in mice (Jenssen and Ramel, 1980; Purchase et al., 1975).

Vinyl chloride has been shown to be genotoxic in various in vitro assays in numerous reports. Only some of them will be summarized here. Vinyl chloride was shown to be mutagenic in the Ames test, with or without activation by S-9 fraction, by Bartsch et al. (1975) and Andrews et al. (1976). Even without S-9 activation, vinyl chloride produced forward mutation in Chinese hamster cell V79 and cell transformation of neonatal hamster kidney cells (Drevon and Kuroki, 1979; Styles, 1977).

\section{Developmental Toxicity}

There is conflicting evidence on whether vinyl chloride causes devel- 
opmental toxicity in humans. In an Ohio city, Edmonds et al. (1975) found no differences between how far parents of malformed infants lived from a local polyvinyl chloride plant and how far parents of normal infants lived from it. They concluded that malformations were not associated with parental exposures to vinyl chloride. Theriault et al. (1983) conducted a similar study in a Canadian town with a polyvinyl chloride plant and arrived at the same conclusion as Edmonds et al. In contrast, Infante et al. (1976) reported a higher rate of fetal loss, based on questionnaires, in pregnant wives of vinyl-chloride workers than in rubber workers not exposed to vinyl chloride. Infante (1976) also found a higher incidence of malformations in three Ohio cities that have a polyvinyl chloride production plant than in other parts of the counties where the three cities are situated. These two studies of Infante have been criticized as being deficient in the way the studies were conducted and in the data analyses, so the "positive" findings are highly questionable (Hatch et al., 1981; Stallones, 1987).

Animal data showed that vinyl chloride caused some malformations in rats at concentrations that also caused maternal toxicity (John et al., 1977). Vinyl chloride did not produce any malformations in mice and rabbits (John et al., 1977). Therefore, it can be concluded that vinyl chloride does not appear to be a serious teratogenic threat. John et al. (1977) showed that vinyl chloride, at 500 or $2500 \mathrm{ppm}$, failed to produce developmental toxicity and maternal toxicity in rabbits exposed $7 \mathrm{~h} / \mathrm{d}$ on gestation days 618. In the same study, a similar exposure of rats to vinyl chloride at 2500 ppm on gestation days 6-15 increased the incidence of dilated ureters in the fetuses and reduced the body-weight gain and food consumption in the mothers. An exposure of rats to $500 \mathrm{ppm}$ increased the incidence of lumbar spurs in the fetuses and reduced the body-weight gain in the mothers. In mice, an exposure of $500 \mathrm{ppm}$ for $7 \mathrm{~h} / \mathrm{d}$ on gestation days 6-15 failed to produce any malformations, but vinyl chloride caused increased fetal resorption, decreased fetal weight, reduced litter size, retarded ossification of the cranium and sternum in the fetuses. Vinyl chloride exposure at $500 \mathrm{ppm}$ was also toxic to the mothers, causing mortality, reduced bodyweight gain, and decreased liver weight (John et al., 1977). It should be noted that the measurement of maternal body weight for days 6-18 of gestation might not be adequate. Nevertheless, these data indicate that vinyl chloride does not have selective developmental toxicity because it produced developmental effects only in the exposure range that also affected the mothers. 


\section{Synergistic Effects}

Pretreatments of rats with chemicals, such as phenobarbital and polychlorinated biphenyls, which induce microsomal enzymes, are known to potentiate vinyl chloride's acute hepatotoxicity (Jaeger et al., 1974; Reynolds et al., 1975). These findings support the theory that vinyl chloride acts through its epoxide metabolite formed via microsomal oxidation. Therefore, in the event that an astronaut is exposed to vinyl chloride and a known microsomal inducer, one should be aware of the potential toxicity of vinyl chloride. 


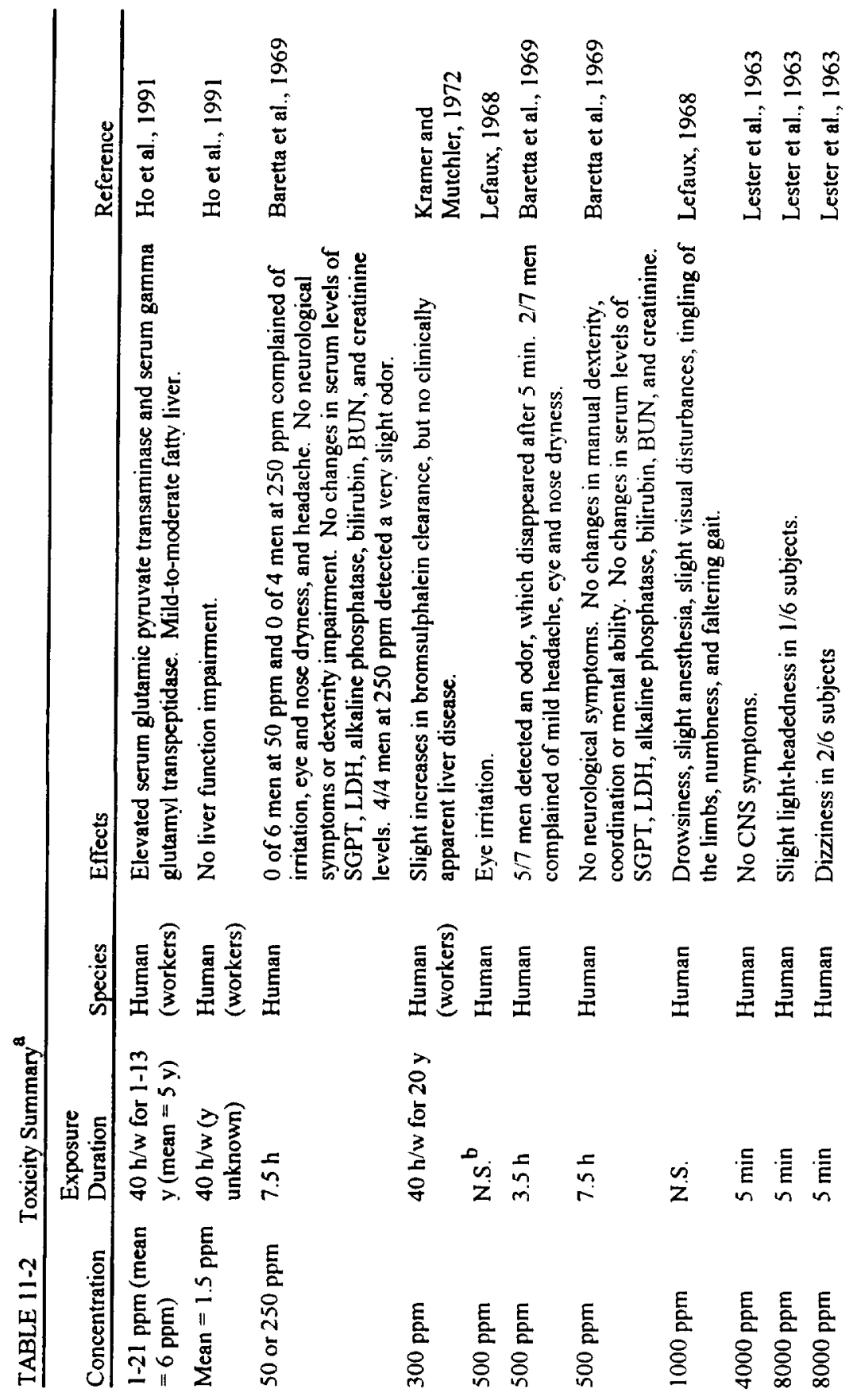




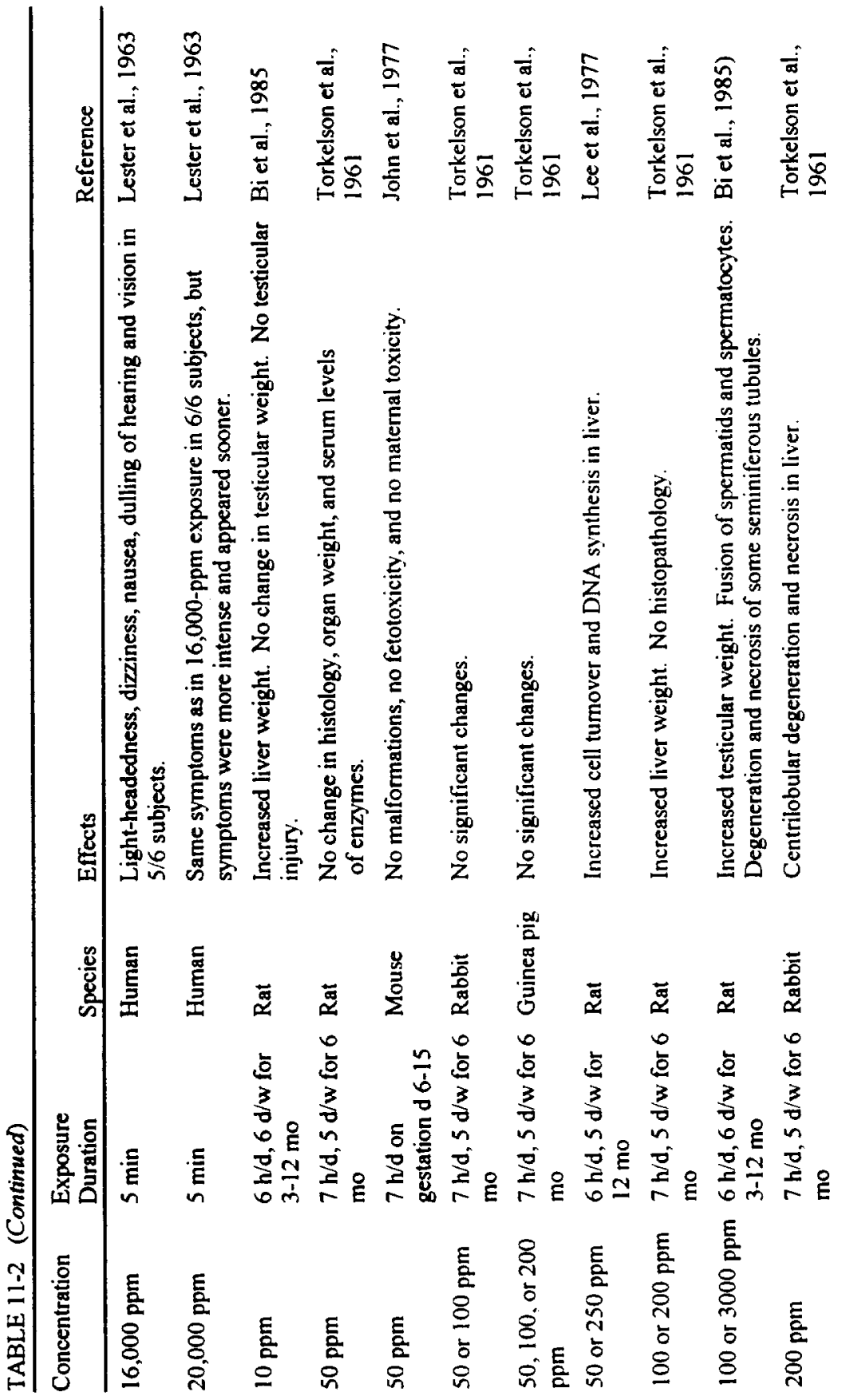




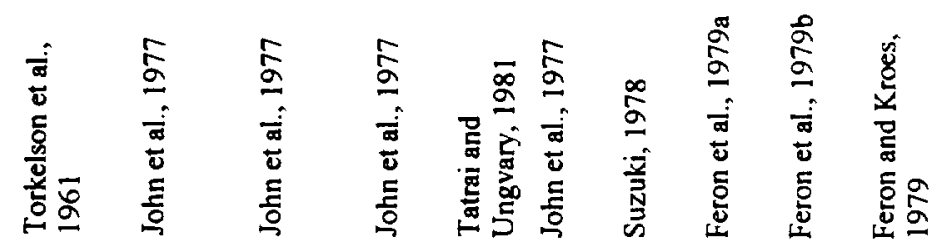

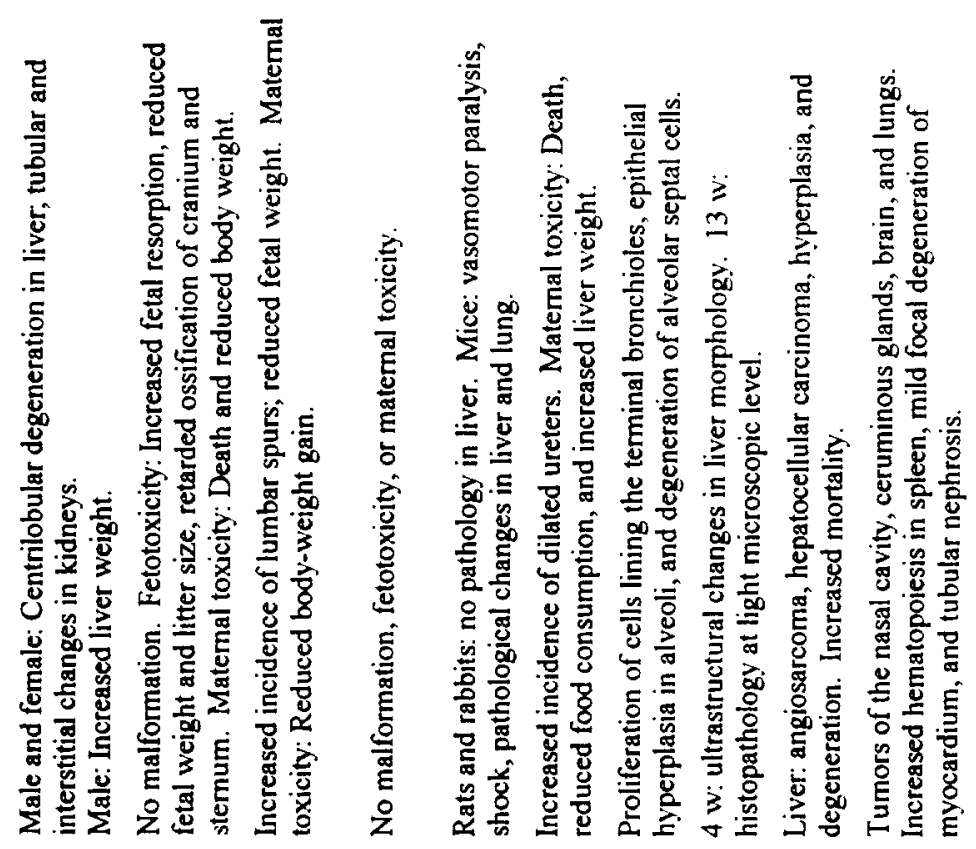

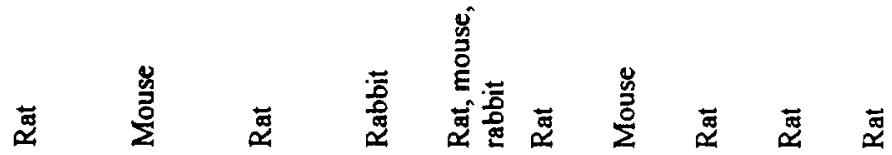

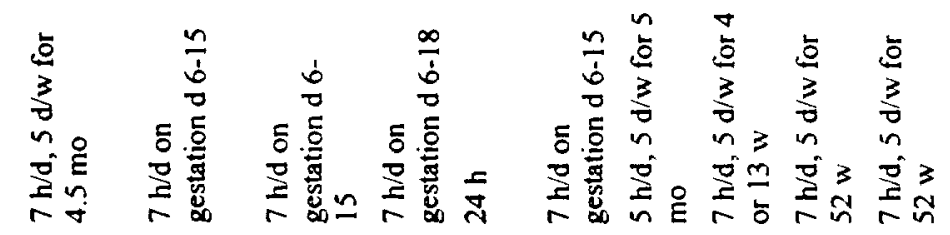

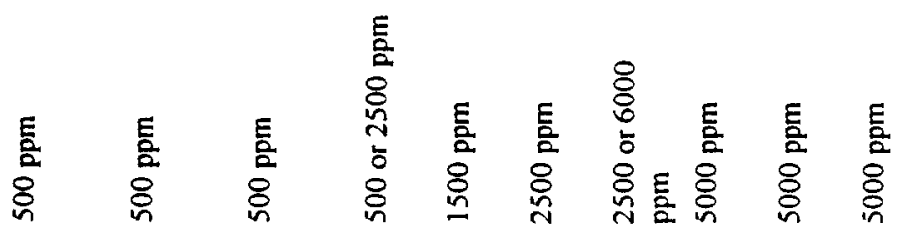




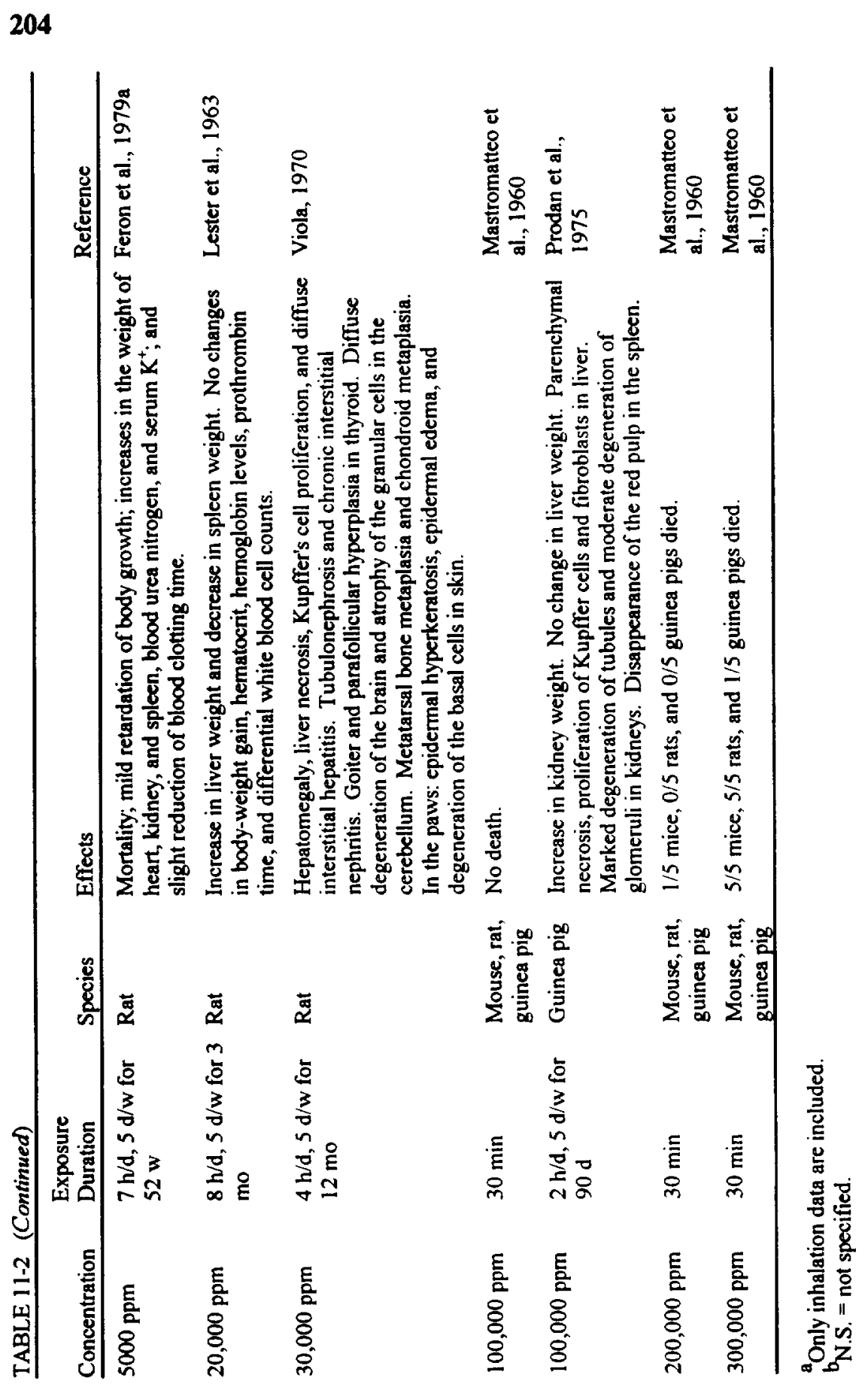


TABLE 11-3 Exposure Limits Set by Other Organizations

\begin{tabular}{ll}
\hline Organization & Concentration, ppm \\
\hline ACGIH's TLV & 5 (TWA) \\
OSHA's PEL & 1 (TWA) \\
& 5 (ceiling) \\
NIOSH's REL & Lowest reliably detectable concentration \\
\hline
\end{tabular}

TLV $=$ threshold limit value. $\quad$ TWA $=$ time-weighted average. $\quad$ PEL $=$ permissible exposure limit. REL $=$ recommended exposure limit.

TABLE 11-4 Spacecraft Maximum Allowable Concentrations

\begin{tabular}{llll}
\hline Duration & $\mathrm{ppm}$ & $\mathrm{mg} / \mathrm{m}^{3}$ & Target Toxicity \\
\hline $1 \mathrm{~h}$ & 130 & 330 & $\begin{array}{l}\text { Liver dysfunction, } \\
\text { CNS impairment, } \\
\text { headache } \\
24 \mathrm{~h}\end{array}$ \\
& 30 & 80 & $\begin{array}{l}\text { Liver dysfunction, } \\
\text { CNS impairment }\end{array}$ \\
$7 \mathrm{~d}^{\mathrm{a}}$ & 1 & 2.6 & Testicular toxicity \\
$30 \mathrm{~d}$ & 1 & 2.6 & Testicular toxicity \\
$180 \mathrm{~d}$ & 1 & 2.6 & Testicular toxicity \\
\hline
\end{tabular}

${ }^{a}$ Former 7-d SMAC $=0.1 \mathrm{ppm}$.

\section{RATIONALE}

For each toxic end point worth considering, an acceptable concentration (AC) is derived for each of the exposure durations, namely $1 \mathrm{~h}, 24 \mathrm{~h}, 7 \mathrm{~d}$, $30 \mathrm{~d}$, and $180 \mathrm{~d}$. The lowest $A C$ among all the toxic end points is then chosen to be the SMAC for that exposure duration.

\section{Mucosal Irritation}

Lefaux (1968) reported that vinyl chloride irritates human eyes at a concentration over $500 \mathrm{ppm}$. According to the data of Baretta et al. 
(1969), $500 \mathrm{ppm}$ appears to be the threshold for mucosal irritation in acute exposures of human subjects, and $250 \mathrm{ppm}$ is the NOAEL in a $7.5-\mathrm{h}$ exposure. Two of seven human subjects experienced dryness of the nose and eyes at $500 \mathrm{ppm}$ (Baretta et al., 1969). Since slight mucosal irritation is acceptable in contingency situations, the 1-h and 24-h ACs are derived from the LOAEL of $500 \mathrm{ppm}$.

$$
\begin{aligned}
& \text { 1-h and 24-h ACs based on mucosal irritation } \\
& \quad=3.5-\mathrm{h} \text { LOAEL } \\
& =500 \mathrm{ppm} \\
& =500 \mathrm{ppm} .
\end{aligned}
$$

The 7-d, 30-d, and 180-d ACs, however, should be established at a no-effect level. The 7.5-h NOAEL of $250 \mathrm{ppm}$ is based on the data of only four men (Baretta et al., 1969), so a safety margin is needed by applying a factor for "small $n$."

7-d, 30-d, and 180-d ACs based on mucosal irritation

$=7.5-\mathrm{h}$ NOAEL $\times 1 /$ safety factor for small $n$

$=250 \mathrm{ppm} \times($ square root of $n) / 10$

$=250 \mathrm{ppm} \times($ square root of 4$) / 10$

$=50 \mathrm{ppm}$.

The same value is chosen for the 7-d, 30-d, and 180-d ACs because mucosal irritation is not expected to get worse when the exposure is extended beyond $7.5 \mathrm{~h}$.

\section{Headache}

Vinyl chloride produced mild headache in two of seven men at $500 \mathrm{ppm}$ in $3.5 \mathrm{~h}$, but all of the four men exposed to $250 \mathrm{ppm}$ for $7.5 \mathrm{~h}$ were free of any headache (Baretta et al., 1969). Since mild headache is acceptable in contingency situations, the 1-h AC based on headache is set at the LOAEL of $500 \mathrm{ppm}$. Unlike mucosal irritation, headache tends not to diminish in severity as the exposure continues, so the 24-h AC for headache should be set lower than the 1-h AC. The 7.5-h NOAEL of $250 \mathrm{ppm}$ is chosen to be the starting point for the 24-h AC based on headache. 
24-h AC based on headache

$=7.5-\mathrm{h}$ NOAEL $\times($ square root of $n) / 10 \times$ time adjustment

$=250 \mathrm{ppm} \times($ square root of 4$) / 10 \times 7.5 \mathrm{~h} / 24 \mathrm{~h}$

$=50 \mathrm{ppm}$.

Because the use of Haber's rule to extrapolate from the 7.5-h NOAEL to an $\mathrm{AC}$ for an exposure lasting $7-\mathrm{d}, 30-\mathrm{d}$, or $180-\mathrm{d}$ is probably not valid, the setting of 7-d, 30-d, and 180-d ACs for headache is not attempted.

\section{CNS Impairment}

The NOAEL for CNS impairment was $500 \mathrm{ppm}$ for $3.5 \mathrm{~h}$ based on the data of seven men; it was $500 \mathrm{ppm}$ for $7.5 \mathrm{~h}$ based on the data from four men (Baretta et al., 1969).

1-h AC based on CNS effects

$=3.5-\mathrm{h}$ NOAEL $\times 1 /$ safety factor for small $n$

$=500 \mathrm{ppm} \times($ square root of $n) / 10$

$=500 \mathrm{ppm} \times($ square root of 7$) / 10$

$=130 \mathrm{ppm}$.

\section{4-h AC based on CNS effects}

$=7.5$-h NOAEL $\times 1 /$ safety factor for small $n \times$ time adjustment

$=500 \mathrm{ppm} \times($ square root of $n) / 10 \times 7.5 \mathrm{~h} / 24 \mathrm{~h}$

$=500 \mathrm{ppm} \times($ square root of 4$) / 10 \times 7.5 \mathrm{~h} / 24 \mathrm{~h}$

$=30 \mathrm{ppm}$.

Due to a lack of data on the time response of vinyl chloride's CNS impairment, no acceptable concentrations are estimated beyond $24 \mathrm{~h}$.

\section{Non-neoplastic CNS Injury}

In long-term exposures, vinyl chloride has been shown to cause degeneration of the white and gray matter of the brain and atrophy of the granular cells in the cerebellum of rats (Viola, 1970). The NOAEL for CNS injury, based on a 1-y exposure of rats, is $5000 \mathrm{ppm}$. 
7-d and 30-d ACs based on CNS injury

$=1-y$ NOAEL $\times 1 /$ species factor

$=5000 \mathrm{ppm} \times 1 / 10$

$=500 \mathrm{ppm}$.

The time adjustment for $180 \mathrm{~d}$

$=1820 \mathrm{~h} /(24 \mathrm{~h} / \mathrm{d} \times 180 \mathrm{~d})$

$=1820 \mathrm{~h} / 4320 \mathrm{~h}$.

180-d AC based on CNS injury

$=1-\mathrm{y}$ NOAEL $\times$ time adjustment $\times 1 /$ species factor

$=5000 \mathrm{ppm} \times(7 \mathrm{~h} / \mathrm{d} \times 5 \mathrm{~d} / \mathrm{w} \times 52 \mathrm{w}) /(24 \mathrm{~h} / \mathrm{d} \times 180 \mathrm{~d}) \times 1 / 10$

$=5000 \mathrm{ppm} \times 0.42 \times 1 / 10$

$=210 \mathrm{ppm}$.

Because vinyl chloride is not known to cause CNS injuries acutely, no 1-h and 24-h ACs are needed for this end point.

\section{Liver Toxicity}

Tatrai and Ungvary (1981) discovered liver histopathology in mice exposed to vinyl chloride at $1500 \mathrm{ppm}$ for $24 \mathrm{~h}$. In contrast, Baretta et al. (1969) did not detect any changes in the serum levels of SGPT, alkaline phosphatase, lactic dehydrogenase, and bilirubin in seven workers exposed to vinyl chloride at $500 \mathrm{ppm}$ for $3.5 \mathrm{~h}$ or in four workers exposed for $7.5 \mathrm{~h}$ (Baretta et al., 1969). Therefore, the NOAEL for acute vinyl chloride exposures appears to be $500 \mathrm{ppm}$.

1-h AC based on non-neoplastic liver toxicity

$=3.5-\mathrm{h}$ NOAEL $\times 1 /$ safety factor for small $n$

$=500 \mathrm{ppm} \times($ square root of $n) / 10$

$=500 \mathrm{ppm} \times($ square root of 7$) / 10$

$=130 \mathrm{ppm}$.

24-h AC based on non-neoplastic liver toxicity

$=7.5$-h NOAEL $\times 1$ safety factor for small $n \times$ time adjustment $=500 \mathrm{ppm} \times($ square root of $n) / 10 \times 7.5 \mathrm{~h} / 24 \mathrm{~h}$ 


$$
\begin{aligned}
& =500 \mathrm{ppm} \times(\text { square root of } 4) / 10 \times 7.5 \mathrm{~h} / 24 \mathrm{~h} \\
& =30 \mathrm{ppm} .
\end{aligned}
$$

Based on the occupational data of Ho et al. (1991), liver dysfunction is possible when the vinyl chloride concentration in the workplace averages 6 $\mathrm{ppm}$ and no liver dysfunction would be found at about $1.5 \mathrm{ppm}$. It appears that the NOAEL for non-neoplastic liver toxicity is about $1.5 \mathrm{ppm}$ in occupational exposure. The NOAEL of $1.5 \mathrm{ppm}$ is based on data from over 100 workers exposed to vinyl chloride for at least 1 y since 1983 (Ho et al., 1991). For simplicity sake, the NOAEL is assumed to be based on a 1-y occupational exposure. Because this type of liver dysfunction is believed to be reparable, a NOAEL for a 1-y occupational exposure ought to be devoid of liver toxicity for 7,30 , or $180 \mathrm{~d}$.

$$
\begin{aligned}
& \text { 7-d, 30-d, and 180-d ACs based on non-neoplastic liver toxicity } \\
& =1-\mathrm{y} \text { NOAEL } \\
& =1.5 \mathrm{ppm} .
\end{aligned}
$$

\section{Kidney Toxicity}

As discussed in "Toxicity Summary," the NOAEL for non-neoplastic kidney toxicity is $200 \mathrm{ppm}$, based on data from a 6-mo exposure of rats (Torkelson et al., 1961).

$$
\begin{aligned}
& \text { 7-d and 30-d ACs based on kidney toxicity } \\
& \quad=6-\mathrm{mo} \text { NOAEL } \times 1 / \text { species factor } \\
& =200 \mathrm{ppm} \times 1 / 10 \\
& =20 \mathrm{ppm} .
\end{aligned}
$$

Because vinyl chloride's kidney injuries are believed to be reparable, the 180-d AC is set to equal the $30-\mathrm{d} \mathrm{AC}$ of $20 \mathrm{ppm}$. Since kidney injuries have never been reported in acute vinyl chloride studies, no 1-h and 24-h ACs are needed for this end point.

\section{Lung Toxicity}

Vinyl chloride has been shown to produce non-neoplastic lung injuries in 
mice (Suzuki, 1978, 1980). The LOAEL based on a 6-mo exposure of mice is $2500 \mathrm{ppm}$ (Suzuki, 1978, 1980), so the NOAEL is estimated to be $250 \mathrm{ppm}$.

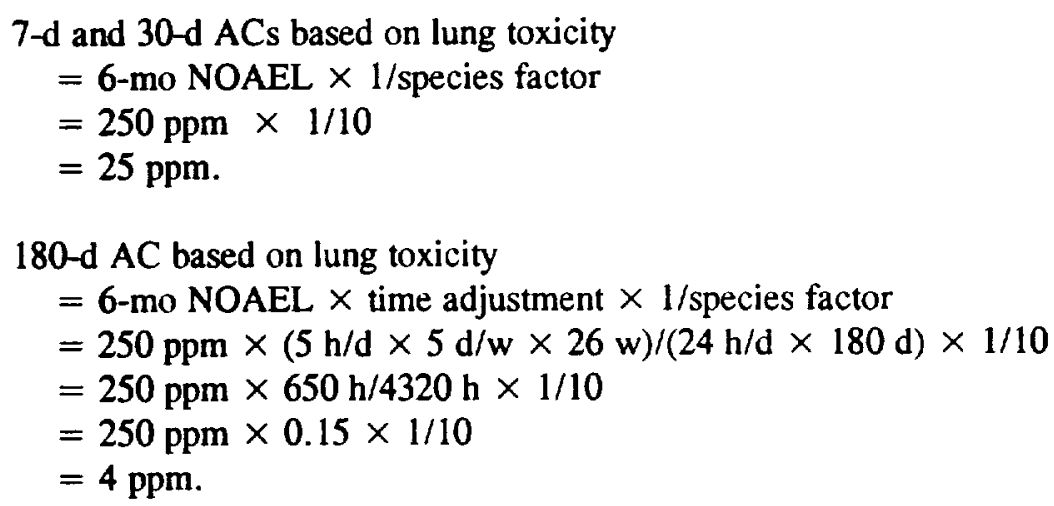

No 1-h and 24-h ACs are needed because vinyl chloride is not known to cause lung toxicity acutely.

\section{Testicular Toxicity}

According to the data of Bi et al. (1985), vinyl chloride is known to cause testicular injuries in rats in long-term exposures. A reduction in testicular weight was noted in rats exposed to vinyl chloride at 100 or 3000 ppm for $6 \mathrm{~h} / \mathrm{d}, 6 \mathrm{~d} / \mathrm{w}$ for $6 \mathrm{mo}$. Bi et al. expressed the pathology data by combining the histopathological data of rats sacrificed after a 3-, 6-, 9-, or 12-mo exposure to vinyl chloride at $0,10,100$, or $3000 \mathrm{ppm}$. They found that exposures to 100 or $3000 \mathrm{ppm}$ produced a higher percent of rats with fusion of cells and degeneration of seminiferous tubules in the testis than the control. The NOAEL was $10 \mathrm{ppm}$. Since the number of rats sacrificed after $6 \mathrm{mo}$ of exposure approximately equaled the combined number of rats sacrificed immediately after a 3-, 9-, or 12-mo exposure, the NOAEL of $10 \mathrm{ppm}$ is assumed to represent a NOAEL based on a 6-mo exposure.

7-d and 30-d ACs based on testicular toxicity

$$
\begin{aligned}
& =6-\mathrm{mo} \text { NOAEL } \times 1 / \text { species factor } \\
& =10 \mathrm{ppm} \times 1 / 10 \\
& =1 \mathrm{ppm} .
\end{aligned}
$$


Because the cell types that could be injured by vinyl chloride are spermatids and spermatocytes, vinyl chloride's testicular injuries are believed to be reversible. As a result, the $180-\mathrm{d} \mathrm{AC}$ is set to equal the 30- $\mathrm{d}$ AC.

180- $\mathrm{d}$ AC based on testicular toxicity

$$
\begin{aligned}
& =30-\mathrm{d} \mathrm{AC} \\
& =1 \mathrm{ppm} .
\end{aligned}
$$

Because there is no evidence that acute vinyl chloride exposures are toxic to the testis, the 1-h and 24-h ACs are not derived.

\section{Carcinogenicity}

Vinyl chloride exposures could lead to the production of tumors in several organs, especially in the liver. Based on the rat data from Maltoni and his colleagues (Maltoni, 1977), the U.S. Environmental Protection Agency, using the linearized multistage model, estimated that a life-time exposure of humans at $1 \mathrm{ppm}$ has a tumor risk of $6.80 \times 10^{-3}$ (EPA, 1984). The life-time exposure concentration that would yield a $10^{-4}$ tumor risk, which is the tumor risk accepted by NASA, is calculated as follows:

Life-time exposure concentration that would generate a $10^{-4}$ tumor risk $=\left(1 \mathrm{ppm} / 6.80 \times 10^{-3}\right) \times 10^{-4}$

$=0.0147 \mathrm{ppm}$.

This life-time exposure concentration is converted to the ACs using the Crump and Howe approach as suggested by the NRC's Committee on Toxicology (NRC, 1992; Crump and Howe, 1984). Setting $k=3, t=$ $25,550 \mathrm{~d}$, and $s_{1}=10,950 \mathrm{~d}$, the adjustment factor is calculated to be 26,082 for estimating a near-instantaneous exposure level that would yield the same excess tumor risk as a continuous life-time exposure.

$$
\begin{aligned}
& \text { 24-h AC based on carcinogenicity } \\
& =0.0147 \mathrm{ppm} \times 26,082 \\
& =380 \mathrm{ppm} .
\end{aligned}
$$

For the 7-d, 30-d, and 180-d ACs based on carcinogenicity, the adjustment 
factors are 3728, 871, and 146.7 , respectively, assuming $\mathrm{k}=3, \mathrm{t}=$ $25,550 \mathrm{~d}$, and the earliest age of exposure to be $30 \mathrm{y}$.

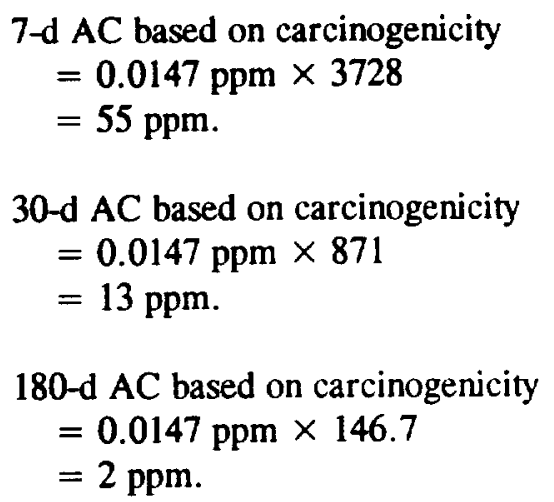

\section{Establishment of SMACs}

By selecting the lowest ACs among the various toxic end points for an exposure duration, the 1-h, 24-h, 7-d, 30-d, and 180-d SMACs are set at $130,30,1,1$, and $1 \mathrm{ppm}$, respectively. Because these toxic end points are not expected to be affected by any microgravity-induced physiological changes, the SMACs are not adjusted any further.

TABLE 11-5 Acceptable Concentrations

\begin{tabular}{llllll}
\hline & \multicolumn{7}{l}{ Acceptable Concentration, ppm } \\
\cline { 2 - 6 } Toxic End Point & $1 \mathrm{~h}$ & $24 \mathrm{~h}$ & $7 \mathrm{~d}$ & $30 \mathrm{~d}$ & $180 \mathrm{~d}$ \\
\hline Mucosal irritation & 500 & 500 & 50 & 50 & 50 \\
Headache & 130 & 50 & - & - & - \\
CNS impairment & 130 & 30 & - & - & - \\
Liver toxicity & 130 & 30 & 1.5 & 1.5 & 1.5 \\
Kidney toxicity & - & - & 20 & 20 & 20 \\
Lung toxicity & - & - & 25 & 25 & 4 \\
Testicular toxicity & - & - & 1 & 1 & 1 \\
Carcinogenicity & - & 380 & 55 & 130 & 2 \\
\hline SMAC & $\mathbf{1 3 0}$ & $\mathbf{3 0}$ & $\mathbf{1}$ & 1 & 1 \\
\hline
\end{tabular}




\section{REFERENCES}

ACGIH. 1986. Vinyl chloride. Pp. 623-626 in Threshold Limit Values and Biological Exposure Indices. American Conference of Governmental Industrial Hygienists, Cincinnati, Ohio.

Anderson, D., C.R. Richardson, T.M. Weight, and W.G. Adams. 1980. Chromosomal analyses in vinyl chloride exposed workers. Results from analysis 18 and 42 months after an initial sampling. Mutat. Res. 79:151-162.

Andrews, A.W., E.S. Zawistowski, and C.R. Valentine. 1976. A comparison of the mutagenic properties of vinyl chloride and methyl chloride. Mutat. Res. 40:273-275.

ATSDR. 1989. P. 51 in Toxicology Profile for Vinyl Chloride. ATSDR/TP-88/25. Agency for Toxic Substances and Disease Registry, U.S. Public Health Service, and U.S. Environmental Protection Agency, Washington, D.C.

Baretta, E.D., R.D. Stewart, and J.E. Mutchler. 1969. Monitoring exposures to vinyl chloride vapor breath analysis and continuous air sampling. Am. Ind. Hyg. Assoc. J. 30:537-544.

Bartsch, H., C. Malaveille, and R. Montesano. 1975. Human, rat and mouse liver-mediated mutagenicity of vinyl chloride in $S$. typhimurium strains. Int. J. Cancer 15:429-437.

Bi, W., Y. Wang, M. Huang, and D. Meng. 1985. Effect of vinyl chloride on testis in rats. Ecotoxicol. Environ. Safety 10:281-289.

Bolt, H.M., H. Kappus, A. Buchter, and W. Bolt. 1976. Disposition of $\left(1,2-{ }^{14} \mathrm{C}\right)$ vinyl chloride in the rat. Arch. Toxicol. 35:153-162.

Bolt, H.M., R.J. Laib, H. Kappus, and A. Buchter. 1977. Pharmacokinetics of vinyl chloride in the rat. Toxicology 7:179-188.

Buchter, A., J.G. Filser, H. Peter, and H.M. Bolt. 1980. Pharmacokinetics of vinyl chloride in the rhesus monkey. Toxicol. Lett. 6:33-36.

Crump, K.S. and R.B. Howe. 1984. The multistage model with a timedependent dose pattern: Applications to carcinogenic risk assessment. Risk Anal. 4:163-176.

Damziger, H. 1966. Accidental poisoning by vinyl chloride: Report of two cases. Can. Med. Assoc. J. 82:828.

Dinman, B.D., W.A. Cook, W.M. Whitehouse, H.J. Magnuson, and T. Ditcheck. 1971. Occupational acroosteolysis. I. An epidemiological study. Arch. Environ. Health 22:61-73.

Dodson, V.N. and B.D. Dinman. 1971. Occupational acroosteolysis. III. 
A clinical study. Arch. Environ. Health 22:83-91.

Drevon, C. and T. Kuroki. 1979. Mutagenicity of vinyl chloride, vinylidene chloride and chloroprene in V79 Chinese hamster cells. Mutat. Res. 67:173-182.

Drew, R.T., G.A. Boorman, J.K. Haseman, E.E. McConnell, W.M. Busey, and J.A. Moore. 1983. The effect of age and exposure duration on cancer induction by a known carcinogen in rats, mice, and hamsters. Toxicol. Appl. Pharmacol. 68:120-130.

Duprat, P., J.P. Fabry, D. Gradiski, and J.L. Magadur. 1977. Metabolic approach to industrial poisoning: Blood kinetics and distribution of ${ }^{14} \mathrm{C}$ vinyl chloride (VCM). Acta Pharmacol. Toxicol. Suppl. (Kbh). 41:142143.

Edmonds, L.D., H. Falk, and J.E. Nissim. 1975. Congenital malformations and vinyl chloride. Lancet 2(7944): 1098.

EPA. 1984. Health Effects Assessment for Vinyl Chloride. EPA/540/186-036. U.S. Environmental Protection Agency, Washington, D.C.

Feron, V.J. and R. Kroes. 1979. One-year time-sequence inhalation toxicity study of vinyl chloride in rats. II. Morphological changes in the respiratory tract, ceruminous glands, brain, kidneys, heart, and spleen. Toxicology 13:131-141.

Feron, V.J., B.J. Spit, H.R. Immel, and R. Kroes. 1979a. One-year time-sequence inhalation toxicity study of vinyl chloride in rats. III. Morphological changes in the liver. Toxicology 13:143-154.

Feron, V.J., A. Kruysse, and H.P. Til. 1979b. One-year time-sequence inhalation toxicity study of vinyl chloride in rats. 1. Growth, mortality, haematology, clinical chemistry, and organ weights. Toxicology 13:2535.

Fox, A.J. and P.F. Collier. 1977. Mortality experience of workers exposed to vinyl chloride monomer in the manufacture of polyvinyl chloride. Br. J. Ind. Med. 34:1-10.

Guengerich, F.P. and P.G. Watanabe. 1979. Metabolism of $\left({ }^{14} \mathrm{C}\right)-$ and $\left({ }^{36} \mathrm{Cl}\right)$-labeled vinyl chloride in vivo and in vitro. Biochem. Pharmacol. 28:589-596.

Halama, J., S. Becker-Stone, and J.M. Halama. 1985. Das haemangiosarkom der bei arbeitern in der PVC-inductrie and andere VCbedingte erkrankungen mit angiologish-dermatologischer, heptalogischer, radiologischer and neurologischer symptomatik. Der Radiolog. 25:22-29. 
Hansteen, I.L., L. Hillestad, E. Thiis-Evensten, and S.S. Heldaas. 1978. Effects of vinyl chloride in man: A cytogenetic follow-up study. Mutat. Res. 51:271-278.

Hatch, M., J. Kline, and Z. Stein. 1981. Power considerations in studies of reproductive effects of vinyl chloride and some structural analogs. Environ. Health Perspect. 41:195-201.

Health, C.W., Jr., H. Fable, and J.L. Creech, Jr. 1975. Characteristics of cases of angiosarcoma of the livers among vinyl chloride workers in the United States. Ann. N.Y. Acad. Sci. 246:231-236.

Hefner, R.E., Jr., P.G. Watanabe, and P.J. Gehring. 1975. Preliminary studies of the fate of inhaled vinyl chloride monomer in rats. Ann. N.Y. Acad. Sci. 246: 135-148.

Heldaas, S.S., A.A. Andersen, and S. Langard. 1987. Incidence of cancer among vinyl chloride and polyvinyl chloride workers: Further evidence for an association with malignant melanoma. $\mathrm{Br}$. J. Ind. Med. 44:278-280.

Ho, S.F., W.H. Phoon, S.L. Gan, and Y.K. Chan. 1991. Persistent liver dysfunction among workers at a vinyl chloride monomer polymerization plant. J. Soc. Occup. Med. 41:10-16.

Hong, C.B., J.M. Winston, L.P. Thornburg, and C.C. Lee. 1981. Follow-up study on the carcinogenicity of vinyl chloride and vinylidene chloride in rats and mice: Tumor incidence and mortality subsequent to exposure. J. Toxicol. Environ. Health 7:909-924.

IARC. 1987. Pp. 373-376 in IARC Monographs on the Evaluation of Carcinogenic Risks to Humans, Suppl. 7. International Agency for Research on Cancer, Lyon, France.

Infante, P.F. 1976. Oncogenic and mutagenic risks in communities with polyvinyl chloride production facilities. Ann. N.Y. Acad. Sci. 271:4957.

Infante, P.F., J.K. Wagoner, A.J. McMichael, R.J. Waxweiler, and H. Falk. 1976. Genetic risks of vinyl chloride. Lancet. 1:734-735.

Jaeger, R.J., E.S. Reynolds, R.B. Conolly, M.T. Moslen, S. Szabo, and S.D. Murphy. 1974. Acute hepatic injury by vinyl chloride in rats pretreated with phenobarbital. Nature 252:724-726.

Jenssen, D. and C. Ramel. 1980. The micronucleus test as part of a short-term mutagenicity test program for the prediction of carcinogenicity evaluated by 143 agents tested. Mutat. Res. 75:191-202.

John, J.A., F.A. Smith, B.K.J. Leong, and B.A. Schwetz. 1977. The 
effects of maternally inhaled vinyl chloride on embryonal and fetal development in mice, rats, and rabbits. Toxicol. Appl. Pharmacol. 39:497-513.

Krajewski, J., M. Dobecki, and J. Gromiec. 1980. Retention of vinyl chloride in the human lung. Br. J. Ind. Med. 37:373-374.

Kramer, C.G. and J.E. Mutchler. 1972. The correlation of clinical and environmental measurements for workers exposed to vinyl chloride. Am. Ind. Hyg. Assoc. J. 33:19-30.

Leban, M.I. and P.A. Wagner. 1989. Space Station Freedom Gaseous Trace Contaminant Load Model Development. SAE Technical Paper Series 891513. Society of Automotive Engineers, Warrendale, Pa.

Lee, C.C., J.C. Bhandari, and J.M. Winston. 1977. Inhalation toxicity of vinyl chloride and vinylidene chloride. Environ. Health Perspect. 21:25-32.

Lee, C.C., J.C. Bhandari, J.M. Winston, W.B. House, R.L. Dixon, and J.S. Woods. 1978. Carcinogenicity of vinyl chloride and vinylidene chloride. J. Toxicol. Environ. Health 4:15-30.

Lefaux, R. 1968. Industrial toxicology. Pp. 63-83 in Practical Toxicology of Plastics, P.P. Hopf, ed. CRC Press, Boca Raton, Fla.

Lester, D., L.A. Greenberg, and W.R. Adams. 1963. Effects of single and repeated exposures of humans and rats to vinyl chloride. Am. Ind. Hyg. Assoc. J. 24:265-275.

Lillis, R., H. Anderson, W.J. Nicholson, S. Daum, A.S. Fischbein, and I.J. Selikoff. 1975. Prevalence of disease among vinyl chloride and polyvinyl chloride workers. Ann. N.Y. Acad. Sci. 246:22-41.

Makarov, I.A. 1984. Sexual disorders in male workers occupationally exposed to methyl-methacrylate vinyl chloride. Gig. Tr. Prof. Zabol. 6:19-23.

Makarov, I.A., M.S. Solovyeva, and G.I. Vnelitsky. 1984. On sexual disorders in women chronically exposed to methylmethacrylate and vinyl chloride. Gig. Tr. Prof. Zabol. 3:22-27.

Maltoni, C. 1977. Recent findings on the carcinogenicity of chlorinated olefins. Environ. Health Perspect. 21:1-5.

Maltoni, C., G. Lefemine, A. Ciliberti, G. Cotti, and D. Carretti. 1981. Carcinogenicity bioassay of vinyl chloride monomer: A model of risk assessment on an experimental basis. Environ. Health Perspect. 41:329.

Mastromatteo, E., A.M. Fischer, H. Christie, and H. Danziger. 1960. 
Acute inhalation toxicity of vinyl chloride to laboratory animals. Am. Ind. Hyg. Assoc. J. 21:394-398.

Nicholson, W.J., E.C. Hammond, H. Seidman, and I.J. Selikoff. 1975. Mortality experience of a cohort of vinyl chloride-polyvinyl chloride workers. Ann. N.Y. Acad. Sci. 246:225-230.

NRC. 1992. Guidelines for Developing Spacecraft Maximum Allowable Concentrations for Space Station Contaminants. National Academy Press, Washington, D.C.

Perticonti, G.F., G. Abbritti, T.A. Cantisani, L. Bond, and L. Mauro. 1986. Polineuropathy in workers with long exposure to vinyl chloride. Electro-physiological study. Electromyogr. Clin. Neurophysiol. 26:4147.

Popper, H. and L.B. Thomas. 1975. Alterations of liver and spleen among workers exposed to vinyl chloride. Ann. N.Y. Acad. Sci. 246:172-194.

Preston, B.J., K.L. Jones, and R.G. Grainger. 1976. Clinical aspects of vinyl chloride disease. Proc. Soc. Med. 69:284-306.

Prodan, L., I. Suciu, V. Pilaru, E. Ilea, and L. Pascu. 1975. Experimental chronic poisoning with vinyl chloride (monochloroethane). Ann. N.Y. Acad. Sci. 246:159-163.

Purchase, I.F.H., C.R. Richardson, and D. Anderson. 1975. Chromosomal and dominant lethal effects of vinyl chloride. Lancet. 2:410411.

Reynolds, E.S., M.T. Moslen, and S. Szabo. 1975. Hepatotoxicity of vinyl chloride and 1,1-dichloroethylene. Am. J. Pathol. 81:219-231.

Sabadie, N., C. Malaveille, A.M. Camus, and H. Bartsch. 1980. Comparison of the hydroxylation of benzo(a)pyrene with the metabolism of vinyl chloride, $n$-nitrosomorpholine, and $n$-nitroso-n-methylpiperazine to mutagens by human and rat liver microsomal fractions. Cancer Res. 409:119-126.

Sakabe, H. 1975. Bone lesions among polyvinyl chloride production workers in Japan. Ann. N.Y. Acad. Sci. 246:78-79.

Shu, P. 1986. Study of excretion regularity of thiodiglycolic acid in urine of vinyl chloride-exposed workers. Clin. J. Prev. Med. 20:8789.

Simonato, L., K.A. L'Abbe, A. Andersen, S. Belli, P. Comba, G. Engholm, G. Ferro, L. Hagmar, and S. Langard. 1991. A collaborative study of cancer incidence and mortality among vinyl chloride 
workers. Scand. J. Work Environ. Health. 17:159-169.

Stallones, R.A. 1987. The use and abuse of subgroup analysis in epidemiological research. Prev. Med. 16:183-194.

Styles, J.A. 1977. A method for detecting carcinogenic organic chemicals using mammalian cells in culture. Br. J. Cancer 36:558-563.

Suciu, I., L. Prodan, E. Ilea, A. Paduraru, and L. Pascu. 1975. Clinical manifestations in vinyl chloride poisoning. Ann. N.Y. Acad. Sci. 246:53-69.

Suzuki, Y. 1978. Pulmonary tumors induced in mice by vinyl chloride monomer. Environ. Res. 16:285-301.

Suzuki, Y. 1980. Nonneoplastic effects of vinyl chloride in mouse lung. Environ. Res. 21:235-253.

Tabershaw, I.R. and W.R. Gaffey. 1974. Mortality study of workers in the manufacture of vinyl chloride and its polymers. J. Occup. Med. 16:509-518.

Tamburro, C.H., L. Makk, and H. Popper. 1984. Early hepatic histologic alterations among chemical (vinyl monomer) workers. Hepatology 4:413-418.

Tatrai, E. and G. Ungvary. 1981. On the acute hepatotoxicity of inhaled vinyl chloride. Acta Morphol. Acad. Sci. Hung. 29:221-226.

Theriault, G., H. Iturra, and S. Gingras. 1983. Evaluation of the association between birth defects and exposure to ambient vinyl chloride. Teratology 27:359-370.

Torkelson, T.R., F. Oygen, and V.K. Rowe. 1961. The toxicity of vinyl chlroide as determined by repeated exposure of laboratory animals. Am. Ind. Hyg. Assoc. J. 22:354-361.

Viola, P.L. 1970. Pathology of vinyl chloride. Med. Lav. 61:174-180.

Viola, P.L., A. Bigotti, and A. Caputo. 1971. Oncogenic response of rat skin, lungs, and bones to vinyl chloride. Cancer Res. 31:516-522.

Watanabe, P.G. and P.J. Gehring. 1976. Dose-dependent fate of vinyl chloride and its possible relationship to oncogenicity in rats. Environ. Health Perspect. 17:145-152.

Watanabe, P.G., G.R. McGowan, E.O. Madrid, and P.J. Gehring. 1976. Fate of $\left({ }^{14} \mathrm{C}\right)$ vinyl chloride following inhalation exposure in rats. Toxicol. Appl. Pharmacol. 37:49-59.

Watanabe, P.G., J.A. Zempel, and P.J. Gehring. 1978a. Comparison of the fate of vinyl chloride following single and repeated exposure in rats. Toxicol. Appl. Pharmacol. 44:391-399. 
Watanabe, P.G., J.A. Zempel, D.G. Pegg, and P.J. Gehring. 1978 b. Hepatic macromolecular binding following exposure to vinyl chloride. Toxicol. Appl. Pharmacol. 44:571-579.

Wilson, R.H., W.E. McCormick, C.F. Tatum, and J.L. Creech. 1967. Occupational acroosteolysis report of 31 cases. J. Am. Med. Assoc. 201:577-580.

Wong, O., M.D. Whorton, D.E. Foliart, and D. Ragland. 1991. An industry-wide epidemiology study of vinyl chloride workers, 19421982. Am. J. Ind. Med. 20:317-334.

Wu, W., K. Steenland, D. Brown, V. Wells, J. Jones, P. Schulte, and W. Halperin. 1989. Cohort and case-control analyses of workers exposed to vinyl chloride: An update. J. Occup. Med. 31:518-523. 




\section{NATIONAI ACADEMY PRESS}

The Natiomal Acaleme l'rens was areded be the National Acodemy of Seiencento publish the reports issued be the Acatemy and by the National Acatemy of forgineering, the bertitute of Medicine, and the National Researdh Cenmeit, all operating under the charter granted to the Vational Acondemy of Siciences by the Congress of the United States. 